\title{
Molecular assessment of the cellular origin of Merkel cell carcinoma
}

Citation for published version (APA):

Chteinberg, E. (2020). Molecular assessment of the cellular origin of Merkel cell carcinoma. [Doctoral Thesis, Maastricht University, RWTH Aachen University]. Maastricht University. https://doi.org/10.26481/dis.20201120ec

Document status and date:

Published: 01/01/2020

DOI:

10.26481/dis.20201120ec

Document Version:

Publisher's PDF, also known as Version of record

\section{Please check the document version of this publication:}

- A submitted manuscript is the version of the article upon submission and before peer-review. There can be important differences between the submitted version and the official published version of record.

People interested in the research are advised to contact the author for the final version of the publication, or visit the DOI to the publisher's website.

- The final author version and the galley proof are versions of the publication after peer review.

- The final published version features the final layout of the paper including the volume, issue and page numbers.

Link to publication

\footnotetext{
General rights rights.

- You may freely distribute the URL identifying the publication in the public portal. please follow below link for the End User Agreement:

www.umlib.nl/taverne-license

Take down policy

If you believe that this document breaches copyright please contact us at:

repository@maastrichtuniversity.nl

providing details and we will investigate your claim.
}

Copyright and moral rights for the publications made accessible in the public portal are retained by the authors and/or other copyright owners and it is a condition of accessing publications that users recognise and abide by the legal requirements associated with these

- Users may download and print one copy of any publication from the public portal for the purpose of private study or research.

- You may not further distribute the material or use it for any profit-making activity or commercial gain

If the publication is distributed under the terms of Article $25 \mathrm{fa}$ of the Dutch Copyright Act, indicated by the "Taverne" license above, 


\section{Molecular assessment of the cellular origin of Merkel cell carcinoma}
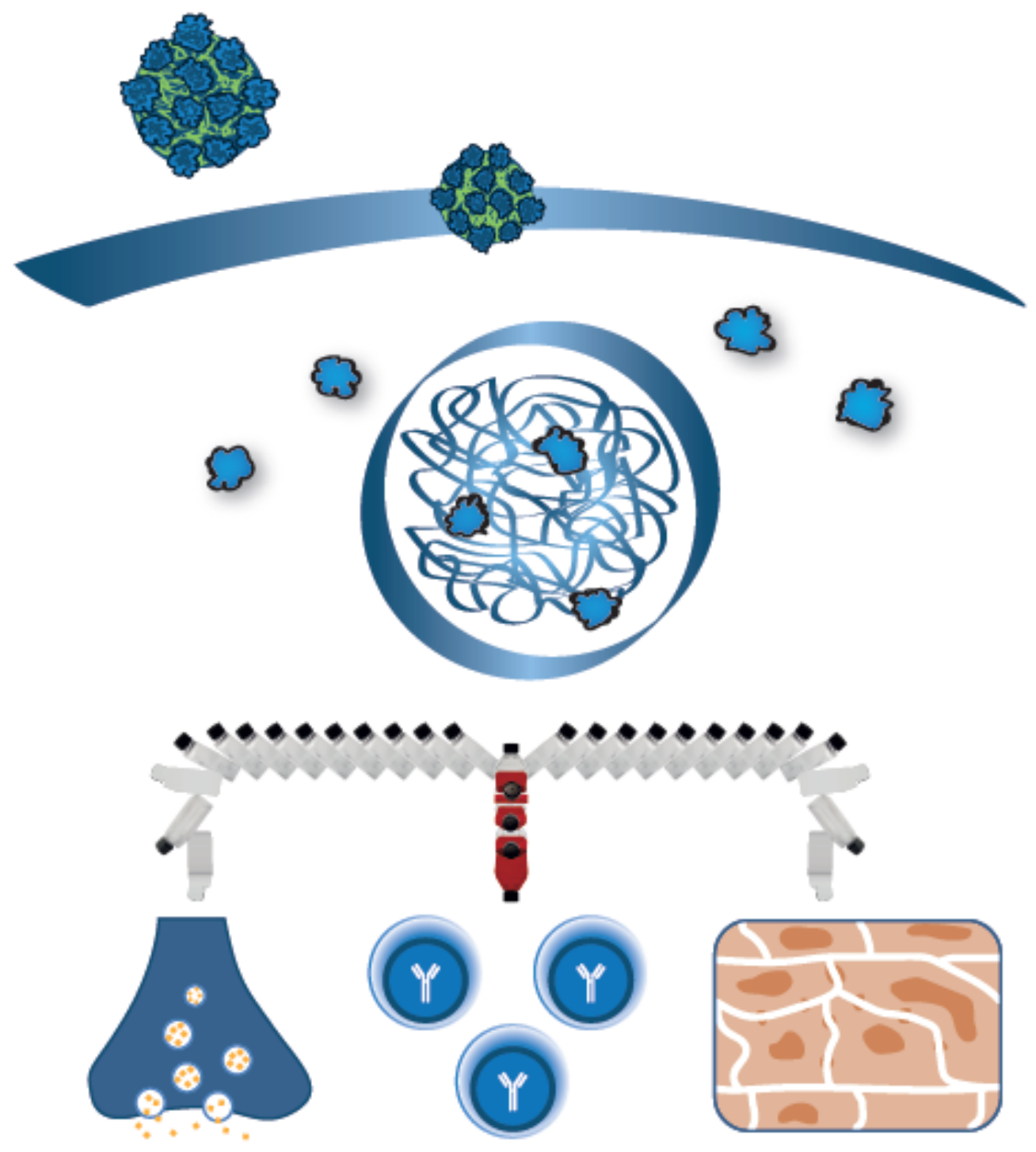



\section{MOLECULAR ASSESSMENT OF THE CELLULAR ORIGIN OF MERKEL CELL CARCINOMA}

\section{Emil Chteinberg}

Cover design

and layout

Printing
Werbetechnik Prummern and Emil Chteinberg

Werbetechnik Prummern 
CEmil Chteinberg, 2020

All rights reserved. No part of this publication may be reproduced, stored in a retrieval system, or transmitted in any form or by any means, electronic, mechanical, photocopying, recording or otherwise, without prior written permission from the author, or when applicable, from the copyright-owning journals for previous published chapters.

Molecular Assessment of the Cellular Origin of Merkel Cell Carcinoma

Emil Chteinberg

\section{Supervisors:}

Prof. Dr. A. zur Hausen, M.D., Ph.D. (Maastricht University Medical Centre+)

Prof. Dr. rer. nat. M. Zenke (RWTH Aachen University)

\section{Co-Supervisor:}

Prof. Dr. E. Speel, Ph.D. (Maastricht University Medical Centre+)

Dr. V. Winnepenninckx, Ph.D. (Maastricht University Medical Centre+)

\section{Assessment Committee (Maastricht):}

Prof. Dr. F. Ramaekers (Chairman)

Prof. Dr. E. Stickeler (RWTH Aachen University)

Prof. Dr. P. Steijlen

Dr. A.J.C. van den Brule (Jeroen Bosch Medical Centre, Hertogenbosch, The Netherlands)

\section{Promotion Committee (Aachen):}

Univ.-Prof. Dr. rer. nat. M. Zenke

Univ.-Prof. Dr. rer. nat. R. Panstruga

Univ.-Prof. A. zur Hausen, M.D., Ph.D. (Maastricht University)

Univ.-Prof. Dr. rer. nat. G. Zimmer-Bensch

The described studies were mostly conducted in the Department of Pathology in the Maastricht University Medical Centre+, Maastricht, the Netherlands, as part of GROW-School for Oncology and Developmental Biology and within the Department of Cell Biology in the RWTH Aachen University Hospital, Aachen, Germany.

Emil Chteinberg was financially supported (11.2015-10.2018) by RWTH University Aachen (Graduiertenförderung nach Richtlinien zur Förderung des wissenschaftlichen Nachwuchses der RWTH Aachen (RFwN)). 


\title{
MOLECULAR ASSESSMENT OF THE CELLULAR ORIGIN OF MERKEL CELL CARCINOMA
}

\section{DISSERTATION}

\author{
to obtain the Doctoral Degree at \\ Maastricht University and RWTH Aachen University \\ on the authority of the Rector Magnifici, Prof. Dr. Rianne Letschert \\ and Univ.-Prof. Dr. rer. nat. Dr. h.c. mult. Ulrich Rüdiger, \\ in accordance with the decision of the \\ Board of Deans of Maastricht University, \\ in accordance with the Faculty of Mathematics, \\ Computer Sciences and Natural Sciences of \\ RWTH Aachen University. \\ to be defended in public in Maastricht \\ on Friday 20th November, 2020 at 12 o'clock
}

by

Emil Chteinberg, M. Sc.

born $1^{\text {st }}$ of May 1990 in Taschkent, Uzbekistan 



\title{
MOLECULAR ASSESSMENT OF THE CELLULAR ORIGIN OF MERKEL CELL CARCINOMA
}

Der Fakultät für Mathematik, Informatik und Naturwissenschaften der RWTH Aachen Universität vorgelegte Dissertation zur Erlangung des akademischen Grades eines Doktors der Naturwissenschaften

vorgelegt von

\author{
Emil Chteinberg, \\ Master of Science \\ aus Taschkent, Usbekistan
}

Berichter:

Univ.-Prof. Dr. rer. nat. Martin Zenke

Univ.-Prof. Dr. Axel zur Hausen, M.D., Ph.D.

Univ.-Prof. Dr. rer. nat. Ralph Panstruga

Univ.-Prof. Dr. rer. nat. Geraldine Zimmer-Bensch

Tag der mündlichen Prüfung: 14.12.2020 



\section{TABLE OF CONTENT}

Chapter 1 General introduction

Chapter 2 The curious case of Merkel cell carcinoma: epigenetic youth and lack of pluripotency

Chapter 3 Neuroendocrine key regulator gene expression in

Merkel cell carcinoma

Chapter 4 Reviewing the current evidence supporting early B-cells as the cellular origin of Merkel cell carcinoma

Chapter 5 Decoding of PAX5 expression and its transcriptional network program in Merkel cell carcinoma

Chapter 6 Phosphatidylinositol 3-kinase p110ס expression in

Merkel cell carcinoma

Chapter 7A Navitoclax combined with Alpelisib effectively inhibits

Merkel cell carcinoma cell growth in vitro

Chapter 7B Navitoclax combined with chemotherapeutics is less effective in Merkel cell carcinoma cell growth inhibition in vitro

Chapter 8 General discussion

Addendum Summary/ Samenvatting/ Zusammenfassung

Valorization

List of abbreviations

Curriculum vitae \& list of publications 

CHAPTER 1 GENERAL INTRODUCTION 



\subsection{MERKEL CELL CARCINOMA}

\subsection{THE RARE AND AGGRESSIVE KIND}

In 1972 Toker described a rare and highly aggressive "trabecular carcinoma of the skin" 1.1980 this nonmelanoma skin cancer was thought to arise from Merkel cells and thus called Merkel cell neoplasm or later Merkel cell carcinoma (MCC) $)^{2-}$ 4. MCC is could be distinguishable in three types: intermediate, small cell and trabecular. The latter is only found in approximal $10 \%$ of MCCs. Also, approximal $10 \%$ are characterized as small cell. With approximal $80 \%$ the intermediate type is the most common MCC (Figure 1$)^{5}$.
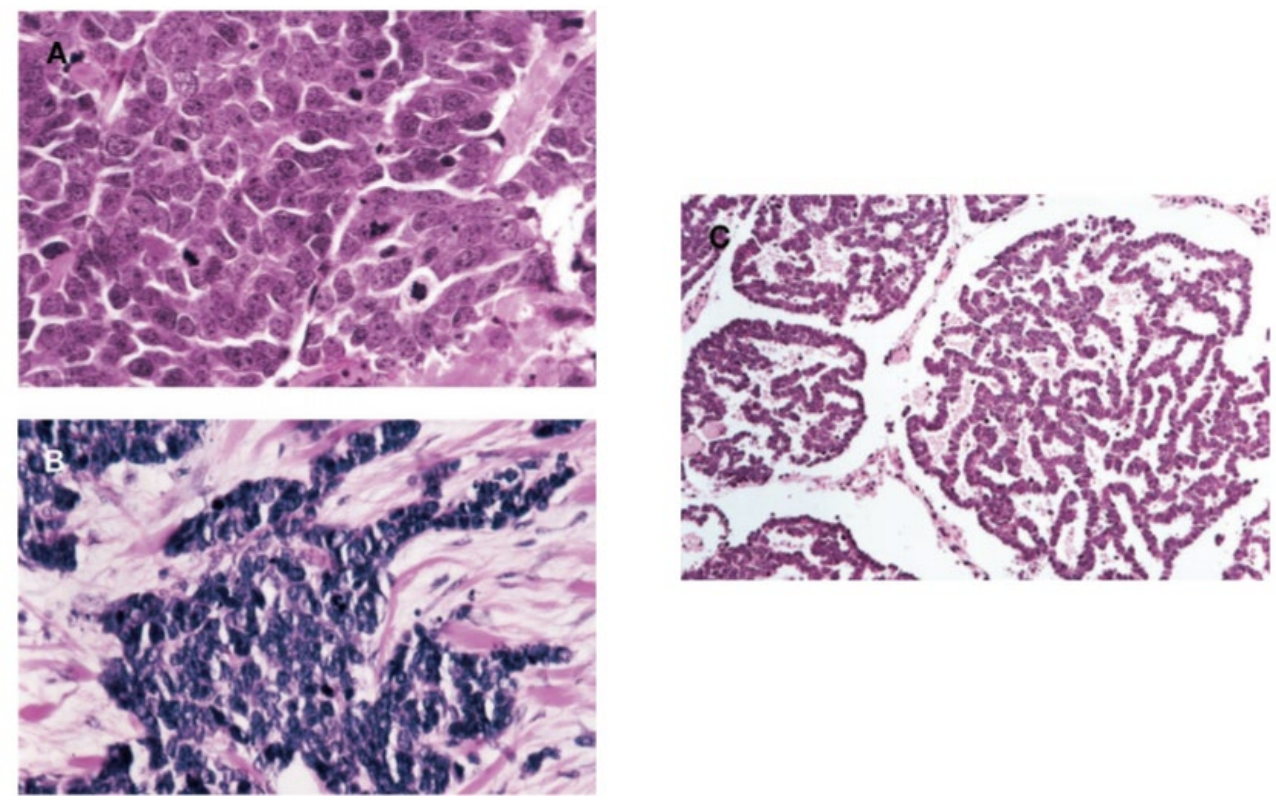

Figure 1: Merkel cell carcinoma different subtypes (published by Goessling et al., 2002) ${ }^{6}$

In $\mathbf{A}$ the intermediat, in $\mathbf{B}$ the small cell variant and in $\mathbf{C}$ the trabecular MCC is shown.

MCC occurs mainly in elderly patients above 65 years of age ${ }^{7}$. MCC is most often detected in the sun-exposed areas of the body e.g. the head and neck area ${ }^{8,9}$. Therefore, UV-exposure was considered as an important pathogenic factor ${ }^{10}$. Interestingly, only $20 \%$ of MCCs reveal a UV induced somatic mutational pattern. The majority of MCCs (80\%) are Merkel cell Polyomavirus (MCPyV)-positive and are characterized by an exceptional low mutational burden. In addition to UV damage, the risk to develop MCC is increased under immunosuppression. Organ 
transplantation related immunosuppression significantly increases the risk for MCC up to 23.8-fold ${ }^{11}$.

The incidence of MCC has increased in Western countries in the last decades ${ }^{12}$. In the Netherlands the incidence increased from 0.17 in 1993 to 0.59 per 100,000 in 2016. The relative 5-year overall survival for distant metastasis is very poor ${ }^{13,14}$. Based on the continuously world-wide aging of the human population and increased sun exposure, it is expected that the incidence of MCC will further increase $^{10}$.

\subsection{THE CLINICO-PATHOLOGICAL VIEW ON MERKEL CELL CARCINOMA}

MCC usually presents as a rapidly growing, dome-shaped red or bluish nodule ${ }^{15}$. It might appear as a plaque with small satellite lesions ${ }^{16}$ in the head and neck region (41 to $50 \%$ ), at the extremities (32 to $38 \%$ ) or trunk (12 to $14 \%)^{17-19}$. Clinically, these small cancerogenic nodular lesions appear to be benign, thus only a biopsy can determine $\mathrm{MCC}^{20}$. The haematoxylin and eosin staining reveal small round blue cells which are located in the dermis of the $\mathrm{skin}^{21}$. Enlarged dysmorphic nuclei are stained blue and surrounded by a tight faint eosinophilic cytoplasm ${ }^{21}$. MCC frequently contain tumour-infiltrating lymphocytes, and mitoses apoptosis are easily identified (Figure 1).

When MCC is diagnosed first the primary tumour diameter $(T)$ and the infiltration depth are determined. Further, the MCC patient is examined for regional lymph node $(N)$ metastases as well as for distant metastases $(M)$. Dependent on growth and metastasizing of MCC, the overall survival of MCC patients can be also divided in four stages ${ }^{20}$. The overall 5-year survival ranges from $62.8 \%$ (stage I), $54,6 \%$ (stage II) $34.8 \%$ (stage II), 40.3\% (stage IIIA) $26.8 \%$ (stage IIIB) and $13.5 \%$ (stage IV) ${ }^{22}$. The latter stage is characterized by distant metastasis. The most frequent sites of MCC metastases are liver (13\%), bone (10-15\%), lung (10-23\%), brain (18\%), distant skin (9-30\%) and distant lymph nodes $(9 \%)^{23}$. 
Despite the aggressiveness of $\mathrm{MCC}$, up to date no curative therapeutic regimens for MCC are available for advanced stages (stage III and IV) which in part might be owed to its rare incidence 27 . MCC stage I and II are primarily excised with a margin of $1-2 \mathrm{~cm}^{28}$. Although, subsequent adjuvant radiotherapy to the surgical excision of the primary tumour is yet not considered in the German MCC treatment guidelines, adjuvant radiotherapy is advised by the guidelines ${ }^{2829}$. For the treatment of the metastatic stages III and IV MCC chemotherapy was earlier the only alternative ${ }^{30}$. Although, MCC was shown to be a chemotherapy-sensitive tumour, no unique chemotherapeutic therapeutic regimen is established ${ }^{27}$. Since MCC and small cell lung cancer (SCLC) were both regarded as undifferentiated small cell neuroendocrine carcinomas the treatment regime of MCC was adapted to SCLC ${ }^{31}$. The chemotherapeutic treatment contained the topoisomerase II

\begin{abstract}
INFO BOX
Doxorubicin is an anthracycline which induces a cell cycle arrest by activation of the transcription factor p53 ${ }^{24}$. Thereafter, p53 promotes apoptosis by mitochondrial cytochrome c release and subsequently caspase activation through cleavage. This leads finally to the death of the cell ${ }^{25}$.

Vincristine belongs to the vinca alkaloids which induce cell death in tumours by inhibiting the assembly of microtubule to the metaphase mitotic spindles and therefore apoptosis via mitochondrial cytochrome c release is activated ${ }^{26}$.
\end{abstract}

inhibitor Doxorubicin, the mitotic spindle inhibitor Vincristine and the DNA crosslink inducer Cyclophosphamide ${ }^{32}$. Although chemotherapy showed an $55 \%$ overall effect in locoregional or distant metastases of MCC, in the majority of cases the lesions recurred after only 4 to 15 months $^{33-35}$. In addition, it was observed that chemotherapy treated patients had with $28 \%$ a low 5 years survival rate. Therefore, chemotherapy in MCC was controversial discussed and used rarely in comparison to radiotherapy and excision ${ }^{36}$.

Recently immune check point inhibitors (CPIs) were successfully applied to treat MCCs $^{30,37-39}$. Treating in a phase 2 trial 88 stage IIIB and IV patients who previously failed first-line chemotherapy with the anti-programmed cell death protein 1 ligand (PD-L1) antibody avelumab (Merck KGaA and Pfizer) showed an objective response rate of $31.8 \%(n=28)^{40}$. In a first line clinical phase 2 trial avelumab had a better objective response rate of $62.1 \%(n=18)$ after minimum of three months follow up. Avelumab has already been approved by the United States Food and Drug Administration (FDA) for the treatment of several other cancers and for metastatic MCC in first as well as second line ${ }^{41,42}$. Although, immunotherapy is successful and very promising in treating MCCs, there are still 
40 to $50 \%$ of non-responders. Therefore, the objective response could be improved by far.

\subsection{MERKEL CELL CARCINOMA VIRUS ASSOCIATION}

In 2008 Feng et al. detected the Merkel cell polyomavirus (MCPyV) to be clonally integrated in approx. $80 \%$ of the MCC DNA. ${ }^{47}$. Very soon after this discovery the presence of MCPyV in approx. 80\% of MCC was confirmed in a large MCC cohort by Kassem et al. ${ }^{48}$. Back then MCPyV was the fifth known human polyomavirus. Ten years later 14 human polyomaviruses belonging to the Polyomaviridae family are detected ${ }^{49}$. Human polyomaviruses contain a non-enveloped circular doublestranded DNA. The MCPyV genome consists of 5400 bp which is organized in two opposite transcriptional regions: early as well as late and a non-coding region ${ }^{50,51}$. The non-coding region contains the origin of replication and a bidirectional promoter for the early and late genes ${ }^{50}$. The early region encodes for the T-antigen and its different splicing variants: small T-antigen (sT), large Tantigen (LT), 57kT and alternate $\mathrm{LT}$ open reading frame (ALTO). The late region

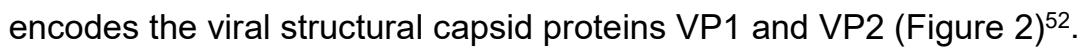

MCPyV requires the capsid proteins which are first attached to glycosaminoglycans, e.g. heparin sulfate and second facilitate the entry the cells with a sialylated glycans in order to enter target cells ${ }^{53,54}$. A recent study described an alternative entry by endocytosis of vesicles containing infectious MCPyV particles ${ }^{55}$. Inside the cells MCPyV LT-antigen recruits the replication machinery for the virusproduction ${ }^{56}$. MCPyV is the first known human polyomavirus which was shown to be integrated in the genome of cancer cells ${ }^{47}$. All integrated MCPyV DNA LT-antigen C-terminal sequences are randomly mutated which potentially lead to a stop-codon ${ }^{57}$. This stop codon induces a non-functional helicase-domain leading to replication deficiency. Schrama and colleagues proposed that this loss of replication might lead to evolutional pressure causing the integration into the host genome. Consequently, MCPyV-DNA can still be replicated via cell division ${ }^{57,58}$. The precise mechanism of random integration is still unknown. Furthermore, the truncated LT- and the sT-antigens have been shown to interact with cell cycle regulatory proteins which lead to a cancerogenic cell growth and replication of the host and virus DNA ${ }^{59}$. 

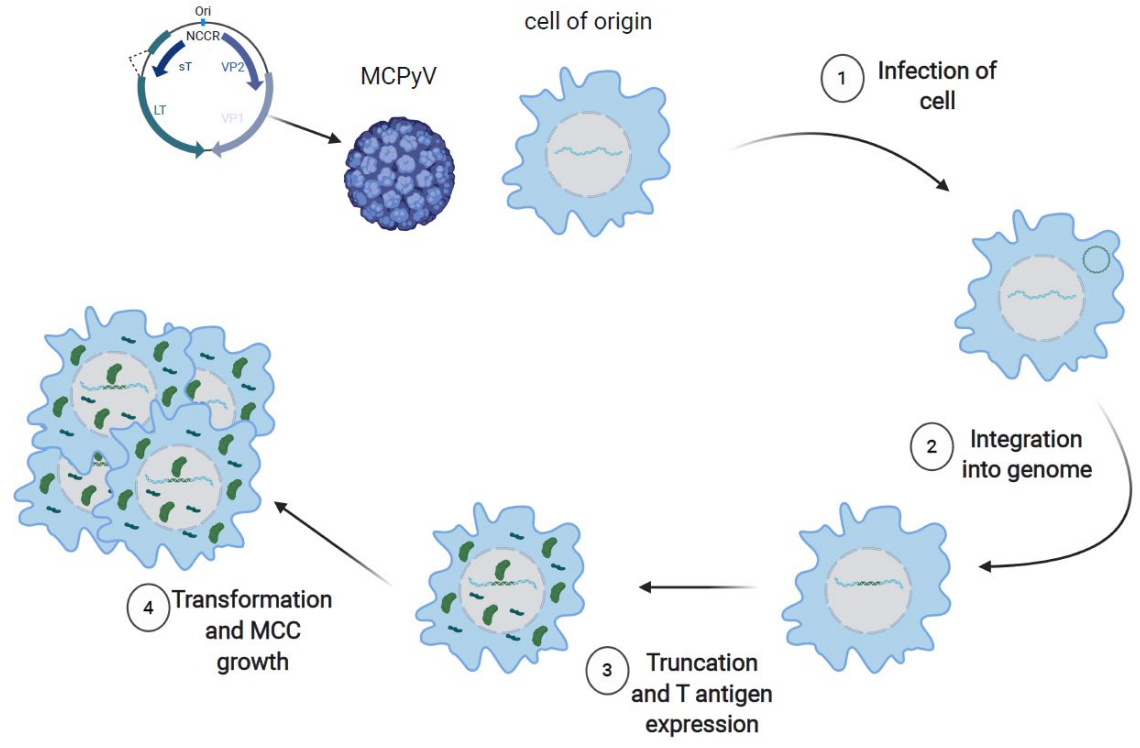

Figure 2: MCPyV-DNA construct, its entry and transformation of cells

MCPyV enters cells through a two-process which include attachment to heparin sulfate and the entry via a sialylated cofactor. Next MCPyV can integrate into the host genome and the LT is truncated. Afterwards sT- and truncated LT-antigen are transforming benign cells into neoplastic cells. (Generated with BioRender)

LT-antigen has been shown to contain a retinoblastoma binding site (RB1) ${ }^{52}$. Members of the RB family control cell proliferation and in cells devoid of replication ability the hyperphosphorylated $\mathrm{RB}$ is binding to the transcription factor $\mathrm{E} 2 \mathrm{~F}$ leading to its inhibition and cell arrest ${ }^{60}$. Dephosphorylated RB does not bind to transcription factor E2F and consequently induces cell growth. LT-antigen in turn forces the cells to enter the $S$ phase of the cell cycle by binding and inactivation of $\mathrm{RB}^{60}$. In addition, it has been described that RB1 binding to $\mathrm{LT}$ induces the overexpression of survivin which has been shown to prevent apoptosis and to activate cell cycle entry ${ }^{61}$. Interestingly, it was demonstrated that MCC cells with truncated LT had a higher growth activity in comparison with the full length LTantigen ${ }^{62}$. This might be since shorten LT have a better binding capacity to RB1 and thus induce higher cell proliferation ${ }^{63}$. However, MCPyV LT-antigen differs from other polyomaviruses LTs which were described to bind and inhibit directly the cell cycle regulator gene p53. P53 function was shown to be indirectly inhibited by the MCPyV-LT as p53 regulated genes were downregulated ${ }^{62,63}$. Thus, 
MCPyV-LT has the ability to induce proliferation and cell growth through direct RB1 and indirect p53 inhibition.

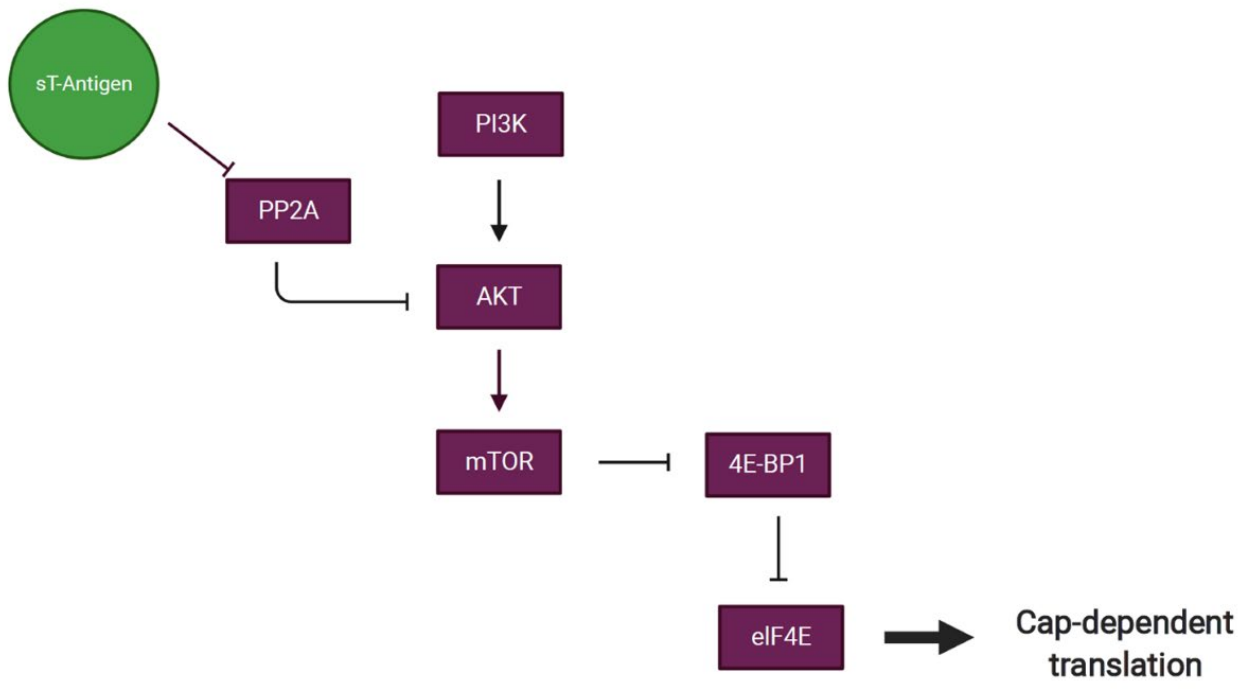

Figure 3: sT-antigen induces Cap-dependent translation through PP2A inhibition (Generated with BioRender)

The other MCPyV T-antigen splice variant sT-antigen has also a transforming capability as it was shown to induce proliferation and tumour growth in transgenic mice $^{64}$. ST-antigen is also inhibiting the LT-antigen turn over through its LT stabilization domain (LSD) ${ }^{65}$ which might in consequence reinforce the LT function. MCPyV ST-antigen contains in addition to the LSD domain the protein phosphatase 2A (PP2A)-binding motif which can lead to inhibition of PP2A function $^{56}$ (Figure 3). PP2A is involved in the dephosphorylation of AKT which is a part of the tumour cell survival PI3K-mTOR pathway66. The PI3K-mTOR pathway was described to be activated in MCC ${ }^{43,44}$. When PP2A is inhibited, the mammalian target of rapamycin (mTOR) kinase subsequently inhibits eukaryotic translation initiation factor 4E-binding protein 1 (4E-BP1) by hyperphosphorylation ${ }^{67}$. Interestingly, sT-antigen has been shown to induce also hyperphosphorylation of 4E-BP167. Hyperphosphorylated 4E-BP1 releases the bound eukaryotic translation initiation factor 4E (elF4E), which initiates the cap assembly and the cap-dependent translation ${ }^{68}$. It has been shown that overexpression of elF4E leads to transformation of rodent cells to tumour cells ${ }^{69}$. In consequence the MCPyV sT-antigen is active downstream of the Akt-mTOR 
pathway which is in contrast to other tumour viruses which target upstream components ${ }^{67,70}$. In addition, MCPyV sT-antigen is capable to induce together with atonal bHLH transcription factor 1 (ATOH1) the expression of the MCC diagnostic markers cytokeratin 20 (CK20) in keratinocytes ${ }^{71}$. In conclusion, both MCPyV Tantigens have transforming activity, are necessary for the MCPyV maintenance and at least ST-antigen can induce one of the MCC characteristic markers.

\subsection{THE TRILINEAR EXPRESSION PATTERN OF MERKEL CELL CARCINOMA}

\section{EPITHELIAL}

MCC as skin cancer is located mostly in the dermis. MCC express Cytokeratins e.g. Cytokeratin 20 (CK20), CK8, CK18 and CK1930. CK20 is detected in approximal $95 \%$ of $\mathrm{MCC}^{72}$. Thereby, CK20 reveal different patterns: a perinuclear dot-like, a diffuse, a mixed membranous, or cytoplasmic (Figure 4). In general, cytokeratins are better known as keratins, and more than $50 \%$ of total approximal 70 different keratins are expressed in epithelial cells ${ }^{73,74}$. Keratins are intermediate filaments which intermediate with actin microfilament and microtubules ${ }^{74}$. Keratins preserve cell stability, establish the cell resilience and the polarity, cell signalling such as apoptosis and vesicle transport ${ }^{75}$. Keratins are divided into types I and II, whereas CK18-CK20 belong to type I and CK8 to type $\mathrm{II}^{74}$. Interestingly, CK8, CK18, CK19 and CK20 are expressed in Merkel cells (MC). This characteristic expression pattern was one of the reasons why MCs were considered to constitute the cellular origin of MCC. 

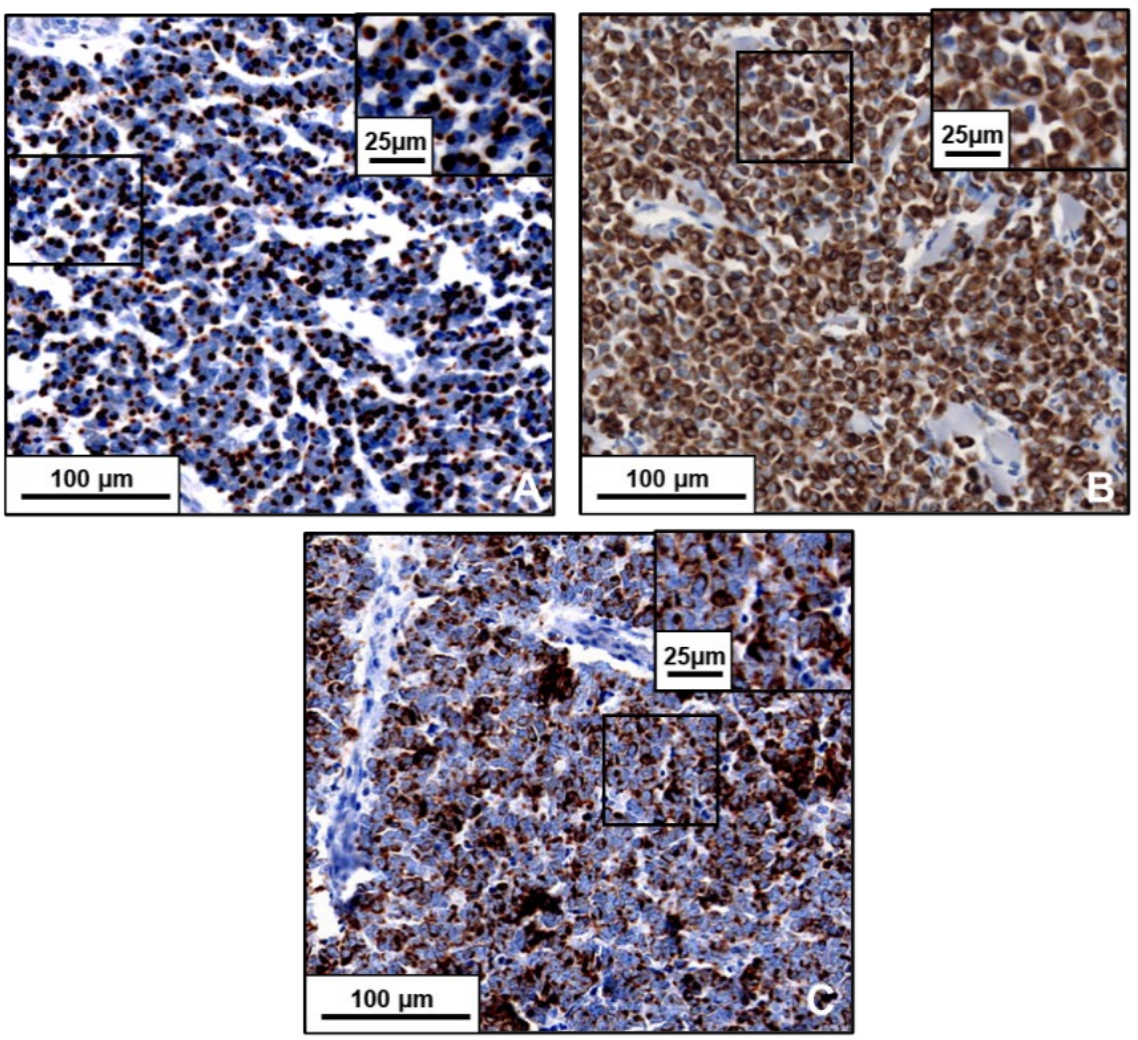

Figure 4: Cytokeratin 20 expression in Merkel cell carcinoma

A perinuclear dot-like (A), a membranous (B) and a mixed (C) detection of CK20 is illustrated

\section{NEUROENDOCRINE}

Neuroendocrine cells are defined as cells which function between the nervous system and the endocrine system ${ }^{76}$. The neuroendocrine skin cells -Merkel cellsare directly involved in the mechanoreception by the release of neurotransmitters such as catecholamines dopamine or norepinephrine which interact with the nervous system ${ }^{77,78}$. The release of neurotransmitter in neuroendocrine cells is achieved e.g. through vesicular structures: secretory granules and synaptic vesicles $^{78}$. The main factor for the formation of secretory granules is the acidic protein chromogranin $A^{79}$. Chromogranin $A$ is also involved in the granule exocytosis by controlling the fusion pore expansion which allows the release of neurotransmitters ${ }^{80,81}$. Synaptophysin is the second most abundant synaptic vesicle protein -32 copies per vesicle- which is located as integral protein in the membrane of synaptic vesicles ${ }^{82}$. After increase of the intracellular 
$\mathrm{Ca}^{2+}$ concentration the synaptic vesicles fuse with the cell membrane. Although, the exact function of synaptophysin is still not clear synaptophysin was described as one of the major core proteins for the binding of synaptic vesicles and for the subsequent release of the neurotransmitters ${ }^{83}$. Thus, chromogranin $A$ and synaptophysin are both important for the release of neurotransmitters, and according to that both are characteristic neuroendocrine proteins.
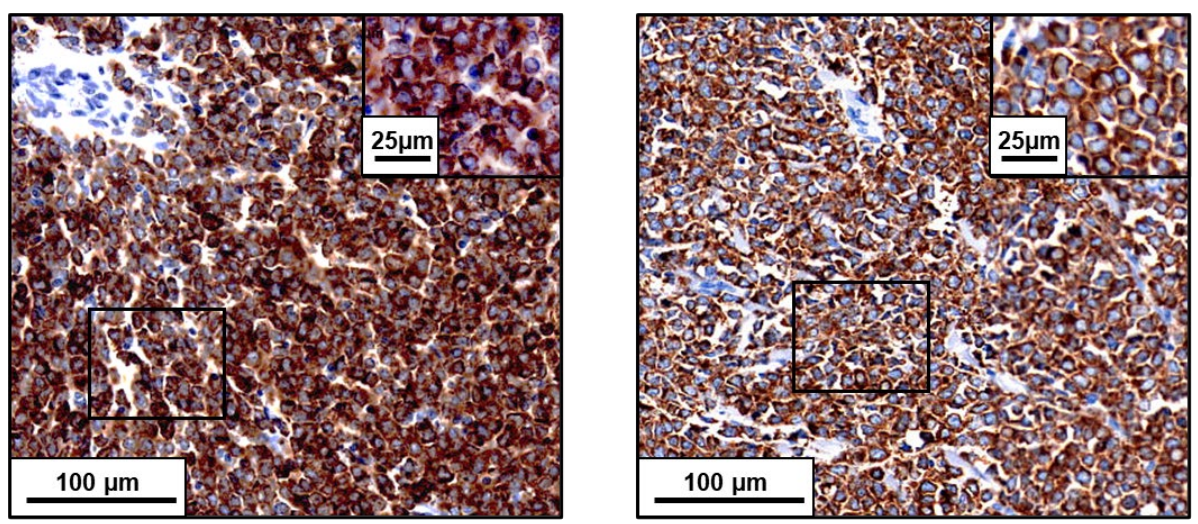

Figure 5: Chromogranin A and synaptophysin expression in Merkel cell carcinoma

The cytoplasmic expression of chromogranin A (A) and synaptophysin (B) are illustrated

Both characteristic neuroendocrine proteins chromogranin $A$ and synaptophysin has been detected in cytoplasm of MCCs (Figure 5). Chromogranin A and synaptophysin are both not present in every MCC as recently reviewed by Tetzlaff and Harms: chromogranin A $84.1 \%(111 / 132)$ and synaptophysin $92 \%$ $(115 / 125)^{84}$. The neuroendocrine differentiation of MCC is also characterized by the expression of the neuron specific enolase (NSE; 97.5\% (39/40)) and the presence of neurofilament (NF; 79.7\% (400/502) ${ }^{84}$. Together with CK20 coexpression this encouraged the hypothesis that MCC is originating from Merkel cells which gave MCC its name $e^{2-4,85}$.

In addition to chromogranin $\mathrm{A}$ as well as synaptophysin the neural cell adhesion molecule (NCAM or CD56) which is important for the neural cell migration, synaptogenesis and synaptic plasticity 86 has been detected in $88.2 \%(30 / 34)$ $\mathrm{MCCs}^{84}$. Interestingly, the basic helix-loop-helix (bHLH) factor neurogenic differentiation 1 (NeuroD1) was shown to regulate the expression of CD56 in neuroendocrine lung carcinomas e.g. SCLC ${ }^{87}$. Moreover, the expression of 
NeuroD1 together with the bHLH master regulator of neuroendocrine differentiation Achaete-scute homolog 1 (ASCL1) in SCLC is characteristic for two groups: neuroendocrine high with chromogranin $A$ expression and neuroendocrine low without chromogranin $A^{88}$. In the latter ASCL1 or NeuroD1 is not expressed. Moreover, both NeuroD1 as well as ASCL1 regulate two distinct neuroendocrine gensets ${ }^{89}$. In the neuroendocrine SCLC the RE-1 silencing transcription factor (REST) which is known to silence neuroendocrine gene expression such as chromogranin $A$ and synaptophysin is expressed ${ }^{90}$. Due to the expression of the chromogranin A, synaptophysin, NSE and NF MCC has been characterized as neuroendocrine cancer.

\section{PRO-/PRE- B-CELL}

The bone marrow pro-/pre-B-cells originate from the hematopoietic lineage which can self-renew or differentiate into mature B-cells ${ }^{91,92}$. The stemness function of Hematopoietic stem cells (HSCs) is linked to the expression of the surface receptor tyrosine kinase CD117 (c-KIT). With high c-KIT expression the HSC selfrenewal is affected ${ }^{93}$. During the maturation of HSCs C-KIT is lost ${ }^{94,95}$. HSCs differentiate into lymphoid-primed multi-potential progenitors (LMPPs) (Figure 6). The multipotent progenitors are first primed for the myeloid and lymphoid lineage through the expression of the purine box transcription factor 1 (Pu.1) which is forming a "permissive epigenetic landscape" to induce both lineages ${ }^{96-99}$. The differentiation into the lymphoid lineage and the subsequent inhibition of the myeloid lineage is achieved by slowly downregulation of the PU.1 expression ${ }^{100,101}$. The downregulation of Pu.1 is caused by Ikaros (IKZF1) ${ }^{102}$. Thus, Ikaros can induce the differentiation of the LMPPs into the common lymphoid progenitors (CLPs) ${ }^{103,104}$. This transition is initiated together with the bHLH transcription factor $3(E 2 A)$ is promoting the lymphoid gene expression ${ }^{105}$. E2A activates the gene expression of the Forehead Box 01 (FoxO1) gene and of the early B-cell factor 1 (Ebf1 $)^{106,107}$. The protein EBF1 consists of a dimer of two $65 \mathrm{kDa}$ subunits which have a palindromic DNA-binding motif (HLHLH) with which it can activate and repress genes by remodelling epigenetically regulated chromatin ${ }^{108-110}$. Together EBF1 and FOXO1 are inducing the expression of specific B-cell lineage genes in a feed-forward loop ${ }^{111,112}$. Furthermore, in pro-Bcells EBF1 activates in concert with E2A the expression of the paired box gene 5 
(PAX5; syn.: BSAP: B cell specific activating protein) which ensures itself a reciprocal positive feed-back loop by the binding to the EBF1 promoter ${ }^{113}$. Consequently, E2A activates the expression of EBF1 and PAX5. PAX5 is responsible for the commitment to the B-cell lineage by PAX5 114,115. PAX5 inhibits non-B-cell genes like macrophage colony-stimulation factor receptor (M-CSFR) and Notch-1 which would cause differentiation into macrophages or $\mathrm{T}$ lymphocytes ${ }^{116-118}$.

The transition of pro- to pre-B-cells is initiating through the expression of the recombination activating 1 (Rag1) and Rag2 genes ${ }^{119}$. The recombinases are part of a complex which is responsible of the rearrangements of variable $(\mathrm{V})$, diversity (D) and joining (J) DNA segments of the immunoglobulin (Ig) heavy chain $(H)^{120,121}$. The recombination starts with the joining of $D$ and $J$ segments which is initiating by the synergy of EBF1, E2A with the RAG1/RAG2 recombinase complex ${ }^{122}$. Thereby, RAG recombinase complex is binding randomly to the specific recombination segment sequences (RSS) of one $\mathrm{J}$ and D DNA-segment and introducing site-specific DNA double-strand breaks (DSBs) ${ }^{123}$. The $\mathrm{J}$ and D cut segments were brought into neighbourhood in so called synaptic complex ${ }^{124}$. The $\mathrm{J}$ and $\mathrm{D}$ cut segments were subsequently fused together through nonhomologous end joining (NHEJ) ${ }^{125}$. Thereby, the terminal desoxynucleotidyl transferase (TdT) add nucleotides to generate biological diversity ${ }^{126}$. Next, in the late pro B-cells PAX5 recruits the DNA polymerases RAG-1 and RAG-2 to the variable region of the heavy chain to fuse a random $V_{H}$ to the $D J_{H}$ gene segments ${ }^{127,128}$. 


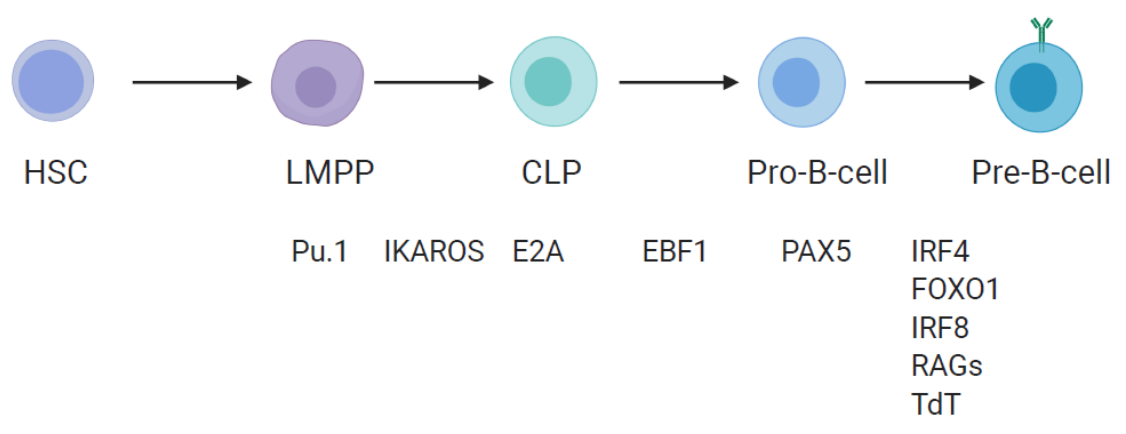

Figure 6: Differentation of haematopoietic stem cell (HSC) into pre-B-cell Different transcription factors such as E2A and EBF1 are necessary for the formation of the pro-B-cells. PAX5 as a guardian for the B-cell differentiation is essential for the differentation to pre-B-cells and generation of the B-cell identity. LMPP= lymphoid-primed multi-potential progenitors; $\mathrm{CLP}=$ common lymphoid progenitors, (Generated with BioRender)

At the pre-B-cell stage, the Ig light chain $(\mathrm{L})$ is recombined from two distinct loci: $K$ and $\lambda$ which contain each a $V_{L}$ and $J L D N A$ segment ${ }^{129}$. This recombination is regulated by the binding of interferon regulatory factor 8 (IRF8) and IRF4 3' $\mathrm{k}$ and $\lambda$ enhancer ${ }^{130,131}$. In addition, the octamer transcription factor-2 (Oct-2) is activating the expression of the $\mathrm{Ig}$ genes by binding to their promoter ${ }^{132}$. The transcribed IgH and IgL pair and form the pre-B-cell receptor (pre-BCR). The Cterminus consists of a constant region of the $\mathrm{lgH}$ which defines the antibody class: $\lg M(\mu), \lg D(\delta), \lg G(\gamma), \lg E(\varepsilon)$ and $\lg A(\alpha)^{133}$. On the pre-B-cell the antibody classes $\lg M$ and $\lg D$ are represented ${ }^{134}$. The $B C R$ signalling is induced by the binding of an antigen to the BCR. Thereafter, the heterodimer transmembrane Iga (CD79a) and Ig $\beta$ (CD79b) cytoplasmic domain immunoreceptor tyrosine-based activation motifs (ITAMs) are phosphorylated ${ }^{135,136}$. Other tyrosine kinases are binding to the phosphorylated sites and are phosphorylating the cytoplasmic site of the B-cell co-receptor CD19 and the B-cell PI3K adaptor (BCAP) ${ }^{137}$. Thereafter, BCAP activates $\mathrm{PI} 3 \mathrm{~K}^{138}$. From the known four catalytic PI3K p110 subunits $\alpha$ and $\delta$ are the most important for the B-cell development and differentiation ${ }^{139}$. The activated p110 subunits phosphorylate PIP2 to PIP3, which recruits the Bruton Agammaglobulinemia tyrosine kinase (BTK) to the plasma membrane ${ }^{140}$. There, BTK positively influences the phosphorylation of AKT ${ }^{141}$. Phosphorylated AKT is 
inhibiting the RAG1/2 expression phosphorylation of FOXO1142. B-cells which show no FOXO1 inhibition were arrested in the pre-B-cell stage ${ }^{143}$. The arrest in the pre-B-cell stage was also observed for the simultaneous loss of PI3K p110 and $\mathrm{p} 110 \delta$. Thus, the PI3K p110 $\alpha$ and $\mathrm{p} 110 \delta$ subunits are crucial for the B-cell development and differentiation ${ }^{139}$.

In MCCs the expression of PI3K p110ס as well as the heavy and light chain rearrangements as and the subsequent expression of Ig heavy and light chains were detected ${ }^{45,145}$. The expression of Igs was only detected in MCPyV-positive MCCs ${ }^{146}$. Irrespective of the MCPyV status Oct-2 and C-KIT were expressed in MCCs ${ }^{146}$. Moreover, the specific nuclear expression of PAX5 and the expression of TdT has been repeatedly reported in the majority of MCC by diverse groups during the past years 147-152. As described above under physiological circumstances co-expression of TdT and PAX5 is mainly restricted to pro- and pre-B cells. Based on that and the Ig rearrangement as well as the Ig expression it was postulated that pro-/pre- B cells might be the cellular origin of MCCs ${ }^{145}$.

\section{CANCER CELLULAR ORIGIN}

Cancer is known since the ancient time as the first documented chirurgical treatment was performed $1600 \mathrm{BC}$ in Egypt ${ }^{153}$. The name cancer itself comes from Latin and mean crab because of its common crab-like properties in insist griping the invaded tissue. Nowadays cancer is characterized by a large group of different diseases ${ }^{154}$. According to the world health organization (WHO) 9.6 million people died in 2018 from cancer ${ }^{155}$. The number of people suffering from cancer was predicted to rise to 14 million in $2035^{156}$. The treatment options which were used in the past are based on the tissue origin and some markers rarely on the cancerspecific molecular pathways itself. For example, MCC was treated in a comparable regime to SCLC because both share neuroendocrine features ${ }^{157,158}$. Precision medicine and preventing cancer e.g. MCC is becoming more applicable, since the knowledge about the carcinogenesis can alter the prognosis and treatment regimens as it was observed for diffuse large B-cell lymphoma ${ }^{159}$. This cancer-initiating cell are also known as cellular origin of a specific type of cancer. To determine the cellular origin of cancers there were different assays used: transplantation assay and lineage tracing assay. The transplantation assay uses 
a tumour xenograft in immunocompromised mice. It is becoming more evident that the cancer cell population is heterogenic and that some cells show stemness which is defined by self-renew and capability to differentiate into different cell types. These cancer stem cells (CSCs) are thus present in the xenograft and could be isolated and rise again into the tumour xenografts ${ }^{160}$. Although, CSCs have tumour-initiating ability it is rather a tumour-regeneration. Thus, CSCs show already the changed, altered cancer phenotype. In comparison the cancer cell of origin is defined as a normal cell which has not underwent the process of cancerogenesis $^{161}$. Therefore, the cell of origin e.g. of MCC cannot generate the cancer without the cancer specific driving events like UV-induced mutations, Merkel cell polyomavirus T-antigen expression, etc. Thus, the transplantation assay is not applicable to determine the cellular origin.

In contrast lineage tracing which is also using mice model oncogenic events like mutations of tumour suppressor genes. Depending on the lineage specific promoter the reporter genes (green fluorescent (GFP) or red fluorescent proteins (RFP) are expressed in the neoplasia. The GFP-positive the cells were sorted and further analysed ${ }^{160}$. Although, for colorectal cancer three different possible candidates for the cellular origin has been described (intestinal stem cells, transit amplifying cells and differentiated villus cells), this kind of experiments are limited to determine the precise cell of origin of most cancers ${ }^{162-164}$. In addition, the precise oncogenic events which lead to the particular cancer have to be known and applied. Regarding to MCC the MCPyV T-antigen expression and UVsignature in MCPyV-negative MCCs as events are known. However, which events or microenvironment are additional needed are unknown. Therefore, lineage tracing to identify the cellular origin of MCC is possible but more knowledge about the MCC oncogenesis is needed. 
Another promising approach to determine the cell of origin is to use methylome of cancer and healthy tissues. Bormann and colleagues could show that during carcinogenesis of colorectal cancer the DNA methylation signatures stayed unchanged $^{165}$. Thus, methylation analysis could hint to the cellular origin. For this approach however the methylome of the subjected cellular origin must be available. If the cellular origin is in a differentation stage the changes in methylation have to be considered. Thus, the determination of the cell of origin of a particular cancer is not trivial and need considerations which approach is the most applicable. 


\subsection{AIMS AND OUTLINES OF THIS THESIS}

In this thesis we aimed to understand the cellular origin of MCC. An overview of the outline is visualized in Figure 7.

For the analysis of the cellular origin we focused on methylome and pathway analysis. In Chapter 2 we analyse the epigenetic age and the pluripotency of MCCs. This should help to investigate if cells which are at the end of their differentiation could be the cells of origin of MCC. In Chapter 3 neuroendocrine key regulator expression and the influence of methylation is assessed in MCC. Chapter 4- 7 focus on the hypothesis that pro-/pre-B-cells are the cellular origin of MCC. In Chapter 4 the B-cell gene expression and the other theories regarding the MCC cell of origin are reviewed. Chapter 5 describes the B-cell like expression of PAX5 and the accessibility of the PAX5 binding sites. In addition, the expression of some B-cell transcription factors which interacting with PAX5 by inducing the B-cell gene expression and some PAX5 regulated B-cell genes are assessed. In Chapter 6 the expression of the B-cell specific PI3K subunit $\mathrm{p} 110 \delta$ and the efficacy of its inhibitor idelalisib is evaluated. Chapter 7 focuses on the expression of BCL2 and the efficacy of the PI3K-BCL2 combinatorial inhibition which is used among others to treat leukaemia.

In the end, in the general discussion the cellular origin, especially the expression of the new B-cell genes in MCC and the efficacy of the leukaemia-like treatment are discussed (Chapter 8). Finally, a summary of the dissertation is provided. 

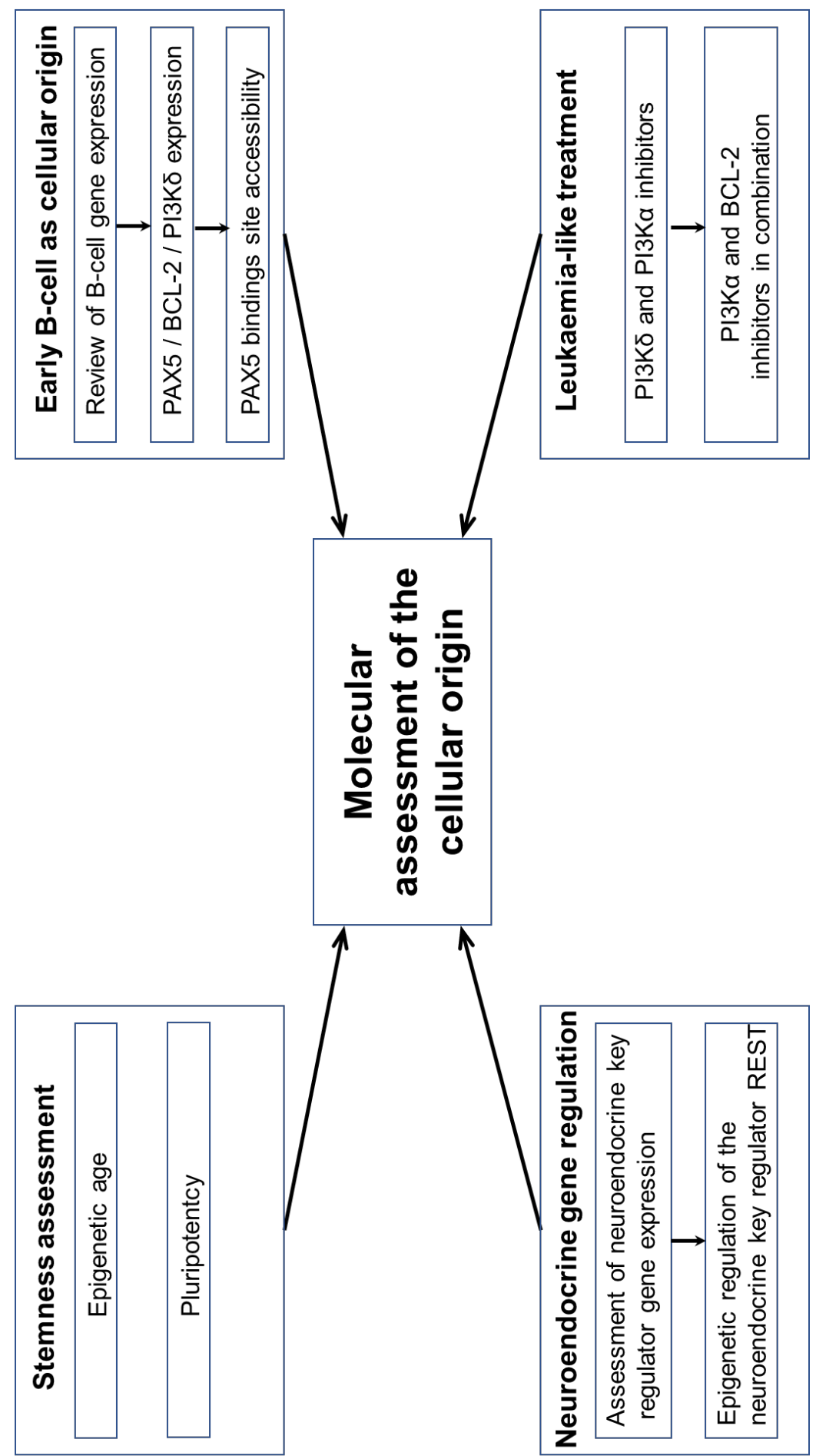

Figure 7: Outline of the thesis "Molecular assessment of the cellular origin of Merkel cell carcinoma" 


\section{REFERENCES}

1. Toker C. TRabecular carcinoma of the skin. Archives of Dermatology. 1972;105(1):107-110.

2. Sidhu GS, Feiner H, Flotte TJ, Mullins JD, Schaefler K, Schultenover SJ. Merkel cell neoplasms. Histology, electron microscopy, biology, and histogenesis. The American Journal of dermatopathology. 1980;2(2):101-119.

3. Johannessen JV, Gould VE. Neuroendocrine skin carcinoma associated with calcitonin production: a Merkel cell carcinoma? Hum Pathol. 1980;11(5 Suppl):586-588.

4. Sibley RK, Rosai J, Foucar E, Dehner LP, Bosl G. Neuroendocrine (Merkel cell) carcinoma of the skin. A histologic and ultrastructural study of two cases. The American journal of surgical pathology. 1980;4(3):211-221.

5. Becker JC. Merkel cell carcinoma. Ann Oncol. 2010;21 Suppl 7:vii81-85.

6. Goessling W, McKee PH, Mayer RJ. Merkel cell carcinoma. J Clin Oncol. 2002;20(2):588598.

7. Tello TL, Coggshall K, Yom SS, Yu SS. Merkel cell carcinoma: An update and review: Current and future therapy. Journal of the American Academy of Dermatology. 2018;78(3):445-454.

8. Allen PJ, Bowne WB, Jaques DP, Brennan MF, Busam K, Coit DG. Merkel Cell Carcinoma: Prognosis and Treatment of Patients From a Single Institution. Journal of Clinical Oncology. 2005;23(10):2300-2309.

9. Medina-Franco H, Urist M, Fiveash J, Heslin M, Bland K, Beenken S. Multimodality Treatment of Merkel Cell Carcinoma: Case Series and Literature Review of 1024 Cases. Ann Surg Oncol. 2001;8(3):204-208.

10. Bichakjian CK, Lowe L, Lao CD, et al. Merkel cell carcinoma: Critical review with guidelines for multidisciplinary management. Cancer. 2007;110(1):1-12.

11. Clarke CA, Robbins HA, Tatalovich Z, et al. Risk of Merkel Cell Carcinoma After Solid Organ Transplantation. Journal of the National Cancer Institute. 2015;107(2).

12. Albores-Saavedra J, Batich K, Chable-Montero F, Sagy N, Schwartz AM, Henson DE. Merkel cell carcinoma demographics, morphology, and survival based on 3870 cases: a population based study. Journal of Cutaneous Pathology. 2010;37(1):20-27.

13. Reichgelt BA, Visser O. Epidemiology and survival of Merkel cell carcinoma in the Netherlands. A population-based study of 808 cases in 1993-2007. European Journal of Cancer. 2011;47(4):579-585.

14. Uitentuis SE, Louwman MWJ, van Akkooi ACJ, Bekkenk MW. Treatment and survival of Merkel cell carcinoma since 1993: A population-based cohort study in The Netherlands. Journal of the American Academy of Dermatology. 2019;81(4):977-983.

15. Nasseri E. Merkel cell carcinoma. Can Fam Physician. 2012;58(9):967-969.

16. Eng TY, Boersma MG, Fuller CD, et al. A Comprehensive Review of the Treatment of Merkel Cell Carcinoma. American Journal of Clinical Oncology. 2007;30(6):624-636.

17. Eng TY, Boersma MGK, Fuller CD, Cavanaugh SX, Valenzuela F, Herman TS. Treatment of Merkel Cell Carcinoma. American Journal of Clinical Oncology. 2004;27(5):510-515.

18. Pectasides D, Pectasides M, Economopoulos T. Merkel cell cancer of the skin. Annals of Oncology. 2006;17(10):1489-1495.

19. Lemos BD, Storer BE, Iyer JG, et al. Pathologic nodal evaluation improves prognostic accuracy in Merkel cell carcinoma: Analysis of 5,823 cases as the basis of the first consensus staging system for this cancer. Journal of the American Academy of Dermatology. 2010;63(5):751-761.

20. Cornejo C, Miller CJ. Merkel Cell Carcinoma: Updates on Staging and Management. Dermatol Clin. 2019;37(3):269-277.

21. Tetzlaff MT, Nagarajan P. Update on Merkel Cell Carcinoma. Head and Neck Pathology. 2018;12(1):31-43.

22. Harms KL, Healy MA, Nghiem P, et al. Analysis of Prognostic Factors from 9387 Merkel Cell Carcinoma Cases Forms the Basis for the New 8th Edition AJCC Staging System. Ann Surg Oncol. 2016;23(11):3564-3571.

23. Duprat JP, Landman G, Salvajoli JV, Brechtbühl ER. A review of the epidemiology and treatment of Merkel cell carcinoma. Clinics. 2011;66(10):1817-1823.

24. Suzuki K, Matsubara H. Recent Advances in p53 Research and Cancer Treatment. Journal of Biomedicine and Biotechnology. 2011;2011:978312.

25. Benchimol S. p53-dependent pathways of apoptosis. Cell death and differentiation. 2001;8(11):1049-1051.

26. Ehrhardt H, Pannert L, Pfeiffer S, Wachter F, Amtmann E, Jeremias I. Enhanced anti-tumour effects of Vinca alkaloids given separately from cytostatic therapies. British Journal of Pharmacology. 2013;168(7):1558-1569. 
27. Schadendorf D, Lebbé C, zur Hausen A, et al. Merkel cell carcinoma: Epidemiology, prognosis, therapy and unmet medical needs. European Journal of Cancer. 2017;71:53-69.

28. Becker JC, Eigentler T, Frerich B, et al. S2k guidelines for Merkel cell carcinoma (MCC neuroendocrine carcinoma of the skin) - update 2018. JDDG: Journal der Deutschen Dermatologischen Gesellschaft. 2019;17(5):562-576.

29. Bhatia S, Storer BE, lyer JG, et al. Adjuvant Radiation Therapy and Chemotherapy in Merkel Cell Carcinoma: Survival Analyses of 6908 Cases From the National Cancer Data Base. JNCl: Journal of the National Cancer Institute. 2016;108(9).

30. Becker JC, Stang A, DeCaprio JA, et al. Merkel cell carcinoma. Nat Rev Dis Primers. 2017;3:17077-17077.

31. Desch L, Kunstfeld R. Merkel Cell Carcinoma: Chemotherapy and Emerging New Therapeutic Options. Journal of Skin Cancer. 2013;2013:9.

32. Ehrhardt $\mathrm{H}$, Schrembs D, Moritz C, et al. Optimized anti-tumor effects of anthracyclines plus Vinca alkaloids using a novel, mechanism-based application schedule. In. Vol 1182011:6123-6131.

33. Cachaza JA, Garcia del Moral R, Lopez Caballero J, Caracuel Ruiz M, Caballero Morales T. Primary small cell carcinoma of skin. Histogenetical study. Acta pathologica japonica. 1986;36(6):905-912.

34. Redmond J, 3rd, Perry J, Sowray P, Vukelja SJ, Dawson N. Chemotherapy of disseminated Merkel-cell carcinoma. Am J Clin Oncol. 1991;14(4):305-307.

35. Iyer JG, Blom A, Doumani R, et al. Response rates and durability of chemotherapy among 62 patients with metastatic Merkel cell carcinoma. Cancer Med. 2016;5(9):2294-2301.

36. Henness S, Vereecken P. Management of Merkel tumours: an evidence-based review. Current Opinion in Oncology. 2008;20(3):280-286.

37. Lyngaa R, Pedersen NW, Schrama D, et al. T-cell responses to oncogenic merkel cell polyomavirus proteins distinguish patients with merkel cell carcinoma from healthy donors. Clin Cancer Res. 2014;20(7):1768-1778.

38. Harms PW, Vats P, Verhaegen ME, et al. The Distinctive Mutational Spectra of Polyomavirus-Negative Merkel Cell Carcinoma. Cancer research. 2015;75(18):3720-3727.

39. Afanasiev OK, Yelistratova L, Miller N, et al. Merkel Polyomavirus-Specific T Cells Fluctuate with Merkel Cell Carcinoma Burden and Express Therapeutically Targetable PD-1 and Tim3 Exhaustion Markers. Clinical Cancer Research. 2013;19(19):5351-5360.

40. Kaufman HL, Russell J, Hamid O, et al. Avelumab in patients with chemotherapy-refractory metastatic Merkel cell carcinoma: a multicentre, single-group, open-label, phase 2 trial. The Lancet Oncology. 2016;17(10):1374-1385.

41. Postow MA, Callahan MK, Wolchok JD. Immune Checkpoint Blockade in Cancer Therapy. J Clin Oncol. 2015;33(17):1974-1982.

42. Garcia GA, Kossler AL. Avelumab as an Emerging Therapy for Eyelid and Periocular Merkel Cell Carcinoma. International Ophthalmology Clinics. 2020;60(2):91-102.

43. Nardi V, Song Y, Santamaria-Barria JA, et al. Activation of PI3K signaling in Merkel cell carcinoma. Clin Cancer Res. 2012;18(5):1227-1236.

44. Hafner C, Houben R, Baeurle A, et al. Activation of the PI3K/AKT Pathway in Merkel Cell Carcinoma. PLOS ONE. 2012;7(2):e31255.

45. Shiver MB, Mahmoud F, Gao L. Response to Idelalisib in a Patient with Stage IV MerkelCell Carcinoma. New England Journal of Medicine. 2015;373(16):1580-1582.

46. Sahi H, Koljonen V, Kavola H, et al. Bcl-2 expression indicates better prognosis of Merkel cell carcinoma regardless of the presence of Merkel cell polyomavirus. Virchows Arch. 2012;461(5):553-559.

47. Feng $\mathrm{H}$, Shuda $\mathrm{M}$, Chang $\mathrm{Y}$, Moore PS. Clonal Integration of a Polyomavirus in Human Merkel Cell Carcinoma. Science. 2008;319(5866):1096-1100.

48. Kassem A, Schopflin A, Diaz C, et al. Frequent detection of Merkel cell polyomavirus in human Merkel cell carcinomas and identification of a unique deletion in the VP1 gene. Cancer Res. 2008;68(13):5009-5013.

49. Prado JCM, Monezi TA, Amorim AT, Lino V, Paladino A, Boccardo E. Human polyomaviruses and cancer: an overview. Clinics (Sao Paulo, Brazil). 2018;73(suppl 1):e558s-e558s.

50. DeCaprio JA, Garcea RL. A cornucopia of human polyomaviruses. Nature reviews Microbiology. 2013;11(4):264-276.

51. Carter JJ, Daugherty MD, Qi X, et al. Identification of an overprinting gene in Merkel cell polyomavirus provides evolutionary insight into the birth of viral genes. Proceedings of the National Academy of Sciences of the United States of America. 2013;110(31):12744-12749. 
52.

53.

54.

55.

56.

57.

58.

59.

60.

61.

64.

65.

66.

67.

68.

69.

70.

71.

72.

73.

74.

75.

76.

Feltkamp MCW, Kazem S, van der Meijden E, Lauber C, Gorbalenya AE. From Stockholm to Malawi: recent developments in studying human polyomaviruses. Journal of General Virology. 2013;94(Pt 3):482-496.

Schowalter RM, Pastrana DV, Buck CB. Glycosaminoglycans and Sialylated Glycans Sequentially Facilitate Merkel Cell Polyomavirus Infectious Entry. PLoS Pathogens. 2011;7(7):e1002161.

Neu U, Hengel H, Blaum BS, et al. Structures of Merkel cell polyomavirus VP1 complexes define a sialic acid binding site required for infection. PLoS pathogens. 2012;8(7):e1002738e1002738.

Becker M, Dominguez M, Greune L, et al. Infectious Entry of Merkel Cell Polyomavirus. Journal of virology. 2019;93(6):e02004-02018.

Kwun HJ, Guastafierro A, Shuda M, et al. The Minimum Replication Origin of Merkel Cell Polyomavirus Has a Unique Large T-Antigen Loading Architecture and Requires Small TAntigen Expression for Optimal Replication. Journal of Virology. 2009;83(23):12118-12128. Shuda $\mathrm{M}$, Feng $\mathrm{H}$, Kwun $\mathrm{HJ}$, et al. T antigen mutations are a human tumor-specific signature for Merkel cell polyomavirus. Proceedings of the National Academy of Sciences. 2008;105(42):16272-16277.

Schrama D, Becker JC. Merkel cell carcinoma - pathogenesis, clinical aspects and treatment. Journal of the European Academy of Dermatology and Venereology. 2011;25(10):1121-1129.

Arora R, Chang Y, Moore PS. MCV and Merkel Cell Carcinoma: A Molecular Success Story. Current opinion in virology. 2012;2(4):489-498.

An P, Sáenz Robles MT, Pipas JM. Large T Antigens of Polyomaviruses: Amazing Molecular Machines. Annual Review of Microbiology. 2012;66(1):213-236.

Arora R, Shuda M, Guastafierro A, et al. Survivin Is a Therapeutic Target in Merkel Cell Carcinoma. Science translational medicine. 2012;4(133):133ra156-133ra156.

Cheng J, Rozenblatt-Rosen O, Paulson KG, Nghiem P, DeCaprio JA. Merkel Cell Polyomavirus Large T Antigen Has Growth-Promoting and Inhibitory Activities. Journal of Virology. 2013;87(11):6118-6126.

Borchert S, Czech-Sioli M, Neumann F, et al. High-Affinity Rb Binding, p53 Inhibition, Subcellular Localization, and Transformation by Wild-Type or Tumor-Derived Shortened Merkel Cell Polyomavirus Large T Antigens. Journal of Virology. 2014;88(6):3144-3160.

Verhaegen ME, Mangelberger D, Harms PW, et al. Merkel cell polyomavirus small T antigen is oncogenic in transgenic mice. J Invest Dermatol. 2015;135(5):1415-1424.

Kwun HJ, Shuda M, Feng H, Camacho CJ, Moore PS, Chang Y. Merkel cell polyomavirus small $\mathrm{T}$ antigen controls viral replication and oncoprotein expression by targeting the cellular ubiquitin ligase SCFFbw7. Cell host \& microbe. 2013;14(2):125-135.

Hemmings BA, Restuccia DF. PI3K-PKB/Akt pathway. Cold Spring Harb Perspect Biol. 2012;4(9):a011189-a011189.

Shuda M, Kwun HJ, Feng H, Chang Y, Moore PS. Human Merkel cell polyomavirus small T antigen is an oncoprotein targeting the 4E-BP1 translation regulator. The Journal of Clinical

Investigation. 2011;121(9):3623-3634.

Josse L, Xie J, Proud CG, Smales CM. mTORC1 signalling and elF4E/4E-BP1 translation initiation factor stoichiometry influence recombinant protein productivity from GS-CHOK1 cells. Biochem J. 2016;473(24):4651-4664.

Hsieh AC, Ruggero D. Targeting Eukaryotic Translation Initiation Factor 4E (elF4E) in Cancer. Clinical Cancer Research. 2010;16(20):4914-4920.

Moore PS, Chang Y. Why do viruses cause cancer? Highlights of the first century of human tumour virology. Nature reviews Cancer. 2010;10(12):878-889.

Verhaegen ME, Mangelberger D, Harms PW, et al. Merkel Cell Polyomavirus Small T Antigen Initiates Merkel Cell Carcinoma-like Tumor Development in Mice. Cancer research. 2017;77(12):3151-3157.

2. Miner AG, Patel RM, Wilson DA, et al. Cytokeratin 20-negative Merkel cell carcinoma is infrequently associated with the Merkel cell polyomavirus. Modern Pathology. 2015;28(4):498-504.

3. Wang F, Zieman A, Coulombe PA. Skin Keratins. Methods Enzymol. 2016;568:303-350. Jacob JT, Coulombe PA, Kwan R, Omary MB. Types I and II Keratin Intermediate Filaments. Cold Spring Harb Perspect Biol. 2018;10(4).

Bragulla $\mathrm{HH}$, Homberger DG. Structure and functions of keratin proteins in simple, stratified, keratinized and cornified epithelia. J Anat. 2009;214(4):516-559.

Oronsky B, Ma PC, Morgensztern D, Carter CA. Nothing But NET: A Review of Neuroendocrine Tumors and Carcinomas. Neoplasia. 2017;19(12):991-1002. 
77. Woo SH, Lumpkin EA, Patapoutian A. Merkel cells and neurons keep in touch. Trends Cell Biol. 2015;25(2):74-81.

78. Hoffman BU, Baba Y, Griffith TN, et al. Merkel Cells Activate Sensory Neural Pathways through Adrenergic Synapses. Neuron. 2018;100(6):1401-1413.e1406.

79. D'Amico MA, Ghinassi B, Izzicupo P, Manzoli L, Di Baldassarre A. Biological function and clinical relevance of chromogranin A and derived peptides. Endocr Connect. 2014;3(2):R45R54.

80. Marotta V, Zatelli MC, Sciammarella C, et al. Chromogranin A as circulating marker for diagnosis and management of neuroendocrine neoplasms: more flaws than fame. Endocr Relat Cancer. 2018;25(1):R11-r29.

81. Abbineni PS, Bittner MA, Axelrod D, Holz RW. Chromogranin A, the major lumenal protein in chromaffin granules, controls fusion pore expansion. Journal of General Physiology. 2018;151(2):118-130.

82. Gordon SL, Cousin MA. The Sybtraps: control of synaptobrevin traffic by synaptophysin, $\alpha-$ synuclein and AP-180. Traffic. 2014;15(3):245-254.

83. Raja MK, Preobraschenski J, Del Olmo-Cabrera S, et al. Elevated synaptic vesicle release probability in synaptophysin/gyrin family quadruple knockouts. Elife. 2019;8.

84. Tetzlaff MT, Harms PW. Danger is only skin deep: aggressive epidermal carcinomas. An overview of the diagnosis, demographics, molecular-genetics, staging, prognostic biomarkers, and therapeutic advances in Merkel cell carcinoma. Modern Pathology. 2020;33(1):42-55.

85. Kervarrec T, Samimi M, Guyétant S, et al. Histogenesis of Merkel Cell Carcinoma: A Comprehensive Review. Front Oncol. 2019;9:451-451.

86. Westphal N, Theis T, Loers G, Schachner M, Kleene R. Nuclear fragments of the neural cell adhesion molecule NCAM with or without polysialic acid differentially regulate gene expression. Scientific Reports. 2017;7(1):13631.

87. Osborne JK, Larsen JE, Shields MD, et al. NeuroD1 regulates survival and migration of neuroendocrine lung carcinomas via signaling molecules TrkB and NCAM. Proceedings of the National Academy of Sciences of the United States of America. 2013;110(16):65246529.

88. Zhang W, Girard L, Zhang Y-A, et al. Small cell lung cancer tumors and preclinical models display heterogeneity of neuroendocrine phenotypes. Transl Lung Cancer Res. 2018;7(1):32-49.

89. Borromeo Mark D, Savage Trisha K, Kollipara Rahul K, et al. ASCL1 and NEUROD1 Reveal Heterogeneity in Pulmonary Neuroendocrine Tumors and Regulate Distinct Genetic Programs. Cell Reports. 2016;16(5):1259-1272.

90. Kashiwagi K, Ishii J, Sakaeda M, et al. Differences of molecular expression mechanisms among neural cell adhesion molecule 1, synaptophysin, and chromogranin A in lung cancer cells. Pathology International. 2012;62(4):232-245.

91. Papathanasiou P, Attema JL, Karsunky H, et al. Self-renewal of the long-term reconstituting subset of hematopoietic stem cells is regulated by Ikaros. Stem Cells. 2009;27(12):30823092.

92. Clarke AJ, Riffelmacher T, Braas D, Cornall RJ, Simon AK. B1a B cells require autophagy for metabolic homeostasis and self-renewal. bioRxiv. 2017:240523.

93. Shin JY, Hu W, Naramura M, Park CY. High c-Kit expression identifies hematopoietic stem cells with impaired self-renewal and megakaryocytic bias. J Exp Med. 2014;211(2):217-231.

94. Abbaspour Babaei M, Kamalidehghan B, Saleem M, Huri HZ, Ahmadipour F. Receptor tyrosine kinase (c-Kit) inhibitors: a potential therapeutic target in cancer cells. Drug Des Devel Ther. 2016;10:2443-2459.

95. Jensen CT, Lang S, Somasundaram R, Soneji S, Sigvardsson M. Identification of StageSpecific Surface Markers in Early B Cell Development Provides Novel Tools for Identification of Progenitor Populations. The Journal of Immunology. 2016;197(5):1937-1944.

96. Imperato MR, Cauchy P, Obier N, Bonifer C. The RUNX1-PU.1 axis in the control of hematopoiesis. International Journal of Hematology. 2015;101(4):319-329.

97. Somasundaram R, Prasad MAJ, Ungerbäck J, Sigvardsson M. Transcription factor networks in B-cell differentiation link development to acute lymphoid leukemia. Blood. 2015;126(2):144-152.

98. Arinobu Y, Mizuno S-i, Chong Y, et al. Reciprocal Activation of GATA-1 and PU.1 Marks Initial Specification of Hematopoietic Stem Cells into Myeloerythroid and Myelolymphoid Lineages. Cell Stem Cell. 2007;1(4):416-427.

99. Heinz S, Benner C, Spann N, et al. Simple combinations of lineage-determining transcription factors prime cis-regulatory elements required for macrophage and B cell identities. Mol Cell. 2010;38(4):576-589. 
100. Pang SHM, de Graaf CA, Hilton DJ, et al. PU.1 Is Required for the Developmental Progression of Multipotent Progenitors to Common Lymphoid Progenitors. Frontiers in Immunology. 2018;9(1264).

101. DeKoter RP, Singh H. Regulation of B lymphocyte and macrophage development by graded expression of PU.1. Science. 2000;288(5470):1439-1441.

102. Zarnegar MA, Rothenberg EV. Ikaros represses and activates PU.1 cell-type-specifically through the multifunctional Sfpi 1 URE and a myeloid specific enhancer. Oncogene. 2012;31(43):4647-4654.

103. Collombet S, van Oevelen C, Sardina Ortega JL, et al. Logical modeling of lymphoid and myeloid cell specification and transdifferentiation. Proceedings of the National Academy of Sciences. 2017;114(23):5792-5799.

104. Yoshida T, Ng SY, Zuniga-Pflucker JC, Georgopoulos K. Early hematopoietic lineage restrictions directed by Ikaros. Nat Immunol. 2006;7(4):382-391.

105. Dias S, Månsson R, Gurbuxani S, Sigvardsson M, Kee BL. E2A proteins promote development of lymphoid-primed multipotent progenitors. Immunity. 2008;29(2):217-227.

106. Welinder E, Mansson R, Mercer EM, Bryder D, Sigvardsson M, Murre C. The transcription factors E2A and HEB act in concert to induce the expression of FOXO1 in the common lymphoid progenitor. Proc Natl Acad Sci U S A. 2011;108(42):17402-17407.

107. Kee BL, Murre C. Induction of early B cell factor (EBF) and multiple $B$ lineage genes by the basic helix-loop-helix transcription factor E12. J Exp Med. 1998;188(4):699-713.

108. Hagman J, Ramírez J, Lukin K. B lymphocyte lineage specification, commitment and epigenetic control of transcription by early B cell factor 1. Curr Top Microbiol Immunol. 2012;356:17-38.

109. Siponen MI, Wisniewska M, Lehtiö L, et al. Structural determination of functional domains in early B-cell factor (EBF) family of transcription factors reveals similarities to Rel DNA-binding proteins and a novel dimerization motif. The Journal of biological chemistry. 2010;285(34):25875-25879.

110. Li R, Cauchy P, Ramamoorthy S, Boller S, Chavez L, Grosschedl R. Dynamic EBF1 occupancy directs sequential epigenetic and transcriptional events in B-cell programming. Genes Dev. 2018;32(2):96-111.

111. Sigvardsson M. Molecular Regulation of Differentiation in Early B-Lymphocyte Development. Int J Mol Sci. 2018;19(7).

112. Mansson R, Welinder E, Åhsberg J, et al. Positive intergenic feedback circuitry, involving EBF1 and FOXO1, orchestrates B-cell fate. Proceedings of the National Academy of Sciences of the United States of America. 2012;109(51):21028-21033.

113. Decker T, Pasca di Magliano M, McManus S, et al. Stepwise activation of enhancer and promoter regions of the B cell commitment gene Pax5 in early lymphopoiesis. Immunity. 2009;30(4):508-520.

114. Nutt SL, Kee BL. The Transcriptional Regulation of B Cell Lineage Commitment. Immunity. 2007;26(6):715-725.

115. Medvedovic J, Ebert A, Tagoh H, Busslinger M. Pax5: A Master Regulator of B Cell Development and Leukemogenesis. Advances in Immunology. 2011;111:179-206.

116. Nutt SL, Heavey B, Rolink AG, Busslinger M. Commitment to the B-lymphoid lineage depends on the transcription factor Pax5. Nature. 1999;401(6753):556-562.

117. Souabni A, Cobaleda C, Schebesta M, Busslinger M. Pax5 Promotes B Lymphopoiesis and Blocks T Cell Development by Repressing Notch1. Immunity. 2002;17(6):781-793.

118. Höflinger S, Kesavan K, Fuxa M, et al. Analysis of Notch1 Function by In Vitro T Cell Differentiation of <em>Pax5</em> Mutant Lymphoid Progenitors. The Journal of Immunology. 2004;173(6):3935-3944.

119. Palacios R, Samaridis J. Fetal liver pro-B and pre-B lymphocyte clones: expression of lymphoid-specific genes, surface markers, growth requirements, colonization of the bone marrow, and generation of B lymphocytes in vivo and in vitro. Mol Cell Biol. 1992;12(2):518530.

120. Oettinger MA, Schatz DG, Gorka C, Baltimore D. RAG-1 and RAG-2, adjacent genes that synergistically activate V(D)J recombination. Science. 1990;248(4962):1517-1523.

121. $\mathrm{Ru} \mathrm{H}$, Zhang $\mathrm{P}, \mathrm{Wu} \mathrm{H}$. Structural gymnastics of RAG-mediated DNA cleavage in $\mathrm{V}(\mathrm{D}) \mathrm{J}$ recombination. Curr Opin Struct Biol. 2018;53:178-186.

122. Romanow WJ, Langerak AW, Goebel P, et al. E2A and EBF act in synergy with the V(D)J recombinase to generate a diverse immunoglobulin repertoire in nonlymphoid cells. Mol Cell. 2000;5(2):343-353.

123. Schatz DG, Swanson PC. V(D)J Recombination: Mechanisms of Initiation. Annual Review of Genetics. 2011;45(1):167-202. 
124. Jones JM, Gellert M. Ordered assembly of the V(D)J synaptic complex ensures accurate recombination. Embo j. 2002;21(15):4162-4171.

125. Corneo B, Wendland RL, Deriano L, et al. Rag mutations reveal robust alternative end joining. Nature. 2007;449(7161):483-486.

126. Gauss GH, Lieber MR. Mechanistic constraints on diversity in human V(D)J recombination. Molecular and cellular biology. 1996;16(1):258-269.

127. Zhang Z, Espinoza CR, Yu Z, et al. Transcription factor Pax5 (BSAP) transactivates the RAG-mediated $\mathrm{V}(\mathrm{H})$-to-DJ(H) rearrangement of immunoglobulin genes. Nat Immunol. 2006;7(6):616-624.

128. Fuxa M, Skok J, Souabni A, Salvagiotto G, Roldan E, Busslinger M. Pax5 induces V-to-DJ rearrangements and locus contraction of the immunoglobulin heavy-chain gene. Genes Dev. 2004;18(4):411-422.

129. Shukla V, Lu R. IRF4 and IRF8: Governing the virtues of B Lymphocytes. Front Biol (Beijing). 2014;9(4):269-282.

130. Brass AL, Kehrli E, Eisenbeis CF, Storb U, Singh H. Pip, a lymphoid-restricted IRF, contains a regulatory domain that is important for autoinhibition and ternary complex formation with the Ets factor PU.1. Genes Dev. 1996;10(18):2335-2347.

131. Brass $A L$, Zhu $A Q$, Singh H. Assembly requirements of PU.1-Pip (IRF-4) activator complexes: inhibiting function in vivo using fused dimers. Embo j. 1999;18(4):977-991.

132. Kemler I, Bucher E, Seipel K, Müller-Immerglück MM, Schaffner W. Promoters with the octamer DNA motif (ATGCAAAT) can be ubiquitous or cell type-specific depending on binding affinity of the octamer site and Oct-factor concentration. Nucleic acids research. 1991;19(2):237-242.

133. Maity PC, Datta M, Nicolò A, Jumaa H. Isotype Specific Assembly of B Cell Antigen Receptors and Synergism With Chemokine Receptor CXCR4. Frontiers in Immunology. 2018;9(2988)

134. Parkhouse RM, Preece G, Sutton R, Cordell JL, Mason DY. Relative expression of surface $\lg \mathrm{M}, \lg \mathrm{D}$ and the Ig-associating alpha(mb-1) and beta(B-29) polypeptide chains. Immunology. 1992;76(4):535-540.

135. Fuentes-Pananá EM, Bannish G, Karnell FG, Treml JF, Monroe JG. Analysis of the Individual Contributions of Iga (CD79a)- and Ig $\beta$ (CD79b)-Mediated Tonic Signaling for Bone Marrow B Cell Development and Peripheral B Cell Maturation. The Journal of Immunology. 2006;177(11):7913-7922.

136. Rolli V, Gallwitz M, Wossning T, et al. Amplification of B cell antigen receptor signaling by a Syk/ITAM positive feedback loop. Mol Cell. 2002;10(5):1057-1069.

137. Okada T, Maeda A, Iwamatsu A, Gotoh K, Kurosaki T. BCAP: the tyrosine kinase substrate that connects $\mathrm{B}$ cell receptor to phosphoinositide 3-kinase activation. Immunity. 2000;13(6):817-827.

138. Inabe K, Ishiai M, Scharenberg AM, Freshney N, Downward J, Kurosaki T. Vav3 modulates $\mathrm{B}$ cell receptor responses by regulating phosphoinositide 3-kinase activation. $J$ Exp Med. 2002;195(2):189-200.

139. Ramadani F, Bolland DJ, Garcon F, et al. The PI3K isoforms p110alpha and p110delta are essential for pre-B cell receptor signaling and B cell development. Sci Signal. 2010;3(134):ra60.

140. Saito K, Scharenberg AM, Kinet JP. Interaction between the Btk PH domain and phosphatidylinositol-3,4,5-trisphosphate directly regulates Btk. $J$ Biol Chem. 2001;276(19):16201-16206.

141. Craxton A, Jiang A, Kurosaki T, Clark EA. Syk and Bruton's tyrosine kinase are required for $\mathrm{B}$ cell antigen receptor-mediated activation of the kinase Akt. $J$ Biol Chem. 1999;274(43):30644-30650.

142. Amin RH, Schlissel MS. Foxo1 directly regulates the transcription of recombinationactivating genes during B cell development. Nature immunology. 2008;9(6):613-622.

143. Dengler HS, Baracho GV, Omori SA, et al. Distinct functions for the transcription factor Foxo1 at various stages of B cell differentiation. Nat Immunol. 2008;9(12):1388-1398.

144. Tijchon E, Havinga J, van Leeuwen FN, Scheijen B. B-lineage transcription factors and cooperating gene lesions required for leukemia development. Leukemia. 2013;27(3):541552.

145. zur Hausen A, Rennspiess D, Winnepenninckx V, Speel E-J, Kurz AK. Early B-Cell Differentiation in Merkel Cell Carcinomas: Clues to Cellular Ancestry. Cancer Research. 2013;73(16):4982-4987.

146. Murakami I, Takata K, Matsushita M, et al. Immunoglobulin expressions are only associated with MCPyV-positive Merkel cell carcinomas but not with MCPyV-negative ones: 
comparison of prognosis. The American journal of surgical pathology. 2014;38(12):16271635.

147. Bhatia K, Goedert JJ, Modali R, Preiss L, Ayers LW. Merkel cell carcinoma subgroups by Merkel cell polyomavirus DNA relative abundance and oncogene expression. International Journal of Cancer. 2010;126(9):2240-2246.

148. Buresh CJ, Oliai BR, Miller RT. Reactivity With TdT in Merkel Cell CarcinomaA Potential Diagnostic Pitfall. American Journal of Clinical Pathology. 2008;129(6):894-898.

149. Sidiropoulos M, Hanna W, Raphael SJ, Ghorab Z. Expression of TdT in Merkel Cell Carcinoma and Small Cell Lung Carcinoma. American Journal of Clinical Pathology. 2011;135(6):831-838.

150. Kolhe R, Reid MD, Lee JR, Cohen C, Ramalingam P. Immunohistochemical expression of PAX5 and TdT by Merkel cell carcinoma and pulmonary small cell carcinoma: a potential diagnostic pitfall but useful discriminatory marker. International Journal of Clinical and Experimental Pathology. 2013;6(2):142-147.

151. Dong HY, Liu W, Cohen P, Mahle CE, Zhang W. B-cell specific activation protein encoded by the PAX-5 gene is commonly expressed in merkel cell carcinoma and small cell carcinomas. The American Journal of Surgical Pathology 2005;29(5):687-692.

152. Mhawech-Fauceglia P, Saxena R, Zhang S, et al. Pax-5 immunoexpression in various types of benign and malignant tumours: a high-throughput tissue microarray analysis. Journal of Clinical Pathology. 2007;60(6):709-714.

153. Visvader JE. Cells of origin in cancer. Nature. 2011;469(7330):314-322.

154. team TACSmaec. Early History of Cancer. American Cancer Society. 2014, June 12.

155. Organization WH. Cancer. World Heath Organization. 2018, September 12.

156. Pilleron S, Sarfati D, Janssen-Heijnen M, et al. Global cancer incidence in older adults, 2012 and 2035: A population-based study. International Journal of Cancer. 2019;144(1):49-58.

157. Feun LG, Savaraj N, Legha SS, Silva EG, Benjamin RS, Burgess MA. Chemotherapy for metastatic Merkel cell carcinoma. Review of the M.D. Anderson Hospital's experience. Cancer. 1988;62(4):683-685.

158. Chan IS, Bhatia S, Kaufman HL, Lipson EJ. Immunotherapy for Merkel cell carcinoma: a turning point in patient care. Journal for ImmunoTherapy of Cancer. 2018;6(1):23.

159. Nowakowski GS, Feldman T, Rimsza LM, Westin JR, Witzig TE, Zinzani PL. Integrating precision medicine through evaluation of cell of origin in treatment planning for diffuse large B-cell lymphoma. Blood Cancer J. 2019;9(6):48-48.

160. Rycaj K, Tang DG. Cell-of-Origin of Cancer versus Cancer Stem Cells: Assays and Interpretations. Cancer research. 2015;75(19):4003-4011.

161. Aponte PM, Caicedo A. Stemness in Cancer: Stem Cells, Cancer Stem Cells, and Their Microenvironment. Stem Cells Int. 2017;2017:5619472.

162. Wierzbinska JA, Toth R, Ishaque N, et al. Methylome-based cell-of-origin modeling (MethylCOOM) identifies aberrant expression of immune regulatory molecules in CLL. Genome Med. 2020;12(1):29.

163. Barker N, Ridgway RA, van Es JH, et al. Crypt stem cells as the cells-of-origin of intestinal cancer. Nature. 2009;457(7229):608-611.

164. Westphalen CB, Asfaha S, Hayakawa $Y$, et al. Long-lived intestinal tuft cells serve as colon cancer-initiating cells. J Clin Invest. 2014;124(3):1283-1295.

165. Bormann F, Rodríguez-Paredes M, Lasitschka F, et al. Cell-of-Origin DNA Methylation Signatures Are Maintained during Colorectal Carcinogenesis. Cell Reports. 2018;23(11):3407-3418. 


Nowadays it is generally accepted that the Merkel cells do not constitute the cellular origin of MCC. However, due to its trilinear differentiation the cellular origin of MCC remains obscure. The most publications had stem cells, not differentiated cells, respectively, as common cell function for their cellular origin. However, there was no evidence.

\section{Contribution to the publication (Chapter 2):}

Emil Chteinberg (EC) isolated DNA, RNA, organized the sequencing, contributed to the design of the study, data interpretations and discussion and wrote the manuscript. Sequencing was performed by GenomeScan, Leiden, NL. Ernst-Jan Speel, Martin Zenke and Anna Kordelia Kurz were involved in the interpretation of the sequencing data and/or critically corrected the manuscript. Joost van den Oord (JvdO) collected the MCC frozen tissues and performed the frozen sections. JvdO, Véronique Winnepenninckx and Axel zur Hausen $(\mathrm{AzH})$ reviewed the histopathology of the MCC tissues. Julia Vogt, Julia Kolarova and Felix Bormann performed the DNAmAge and PluriTest analyses. AzH and Reiner Siebert designed the study and were critically involved in data interpretation and discussion and manuscript writing. $\mathrm{AzH}$ is the principal investigator. 



\section{CHAPTER 2 \\ THE CURIOUS CASE OF MERKEL CELL CARCINOMA: EPIGENETIC YOUTH AND LACKOF PLURIPOTENCY}

EMIL CHTEINBERG, JULIA VOGT, JULIA KOLAROVA, FELIX BORMANN, JOOST VAN DEN OORD, ERNST-JAN SPEEL, VÉRONIQUE WINNEPENNINCKX, ANNA KORDELIA KURZ, MARTIN ZENKE, REINER SIEBERT, AXEL ZUR HAUSEN

-PUBLISHED-

EPIGENETICS. 2020 MAY 30;1-6. 



\section{ABSTRACT}

Merkel cell carcinoma (MCC) is a very rare, but highly aggressive skin cancer which occurs mainly in elderly patients. MCC cells show an expression pattern of three cell lineages: epithelial, neuroendocrine and B-cell progenitor. This trilinear expression pattern indicates stemness activity in MCC. The etiopathogenesis of MCC is either linked to the Merkel cell polyomavirus (MCPyV) or in a smaller proportion $(20 \%)$ to high levels of UV-induced somatic mutations. Both, viral presence as well as accumulation of mutations have been shown to be associated with accelerated DNA methylation Age (DNAmAge) compared to chronological age. The MCC DNAmAge was significantly lower compared to the chronological age, which was irrespective of viral presence or mutational burden. This finding strongly indicates a gain or existing stemness activity of MCC cells which might explain the MCC trilinear expression pattern. 
Merkel cell carcinoma (MCC) is a highly aggressive non-melanoma skin cancer of mainly elderly and immunosuppressed patients. The survival of patients with MCC in advanced clinical stages is only $50 \%$ after nine months ${ }^{1}$. The etiopathogenesis of the majority of MCC is closely linked to the recently discovered Merkel cell polyomavirus (MCPyV) ${ }^{1}$. The remaining approximately $20 \%$ MCPyV-negative MCCs are associated with a very high burden of UVinduced somatic mutations ${ }^{2}$. Interestingly, infection of blood cells with EpsteinBarr virus (EBV), cytomelagovirus (CMV) as well as Human Immunodeficiency Virus (HIV) and expression of the E6/E7 human papillomavirus (HPV) 16/18 proteins in cervical squamous cell carcinoma have been associated with accelerated DNA methylation Age (DNAmAge) as compared to the patients chronological age ${ }^{3-5}$. In addition, Horvath described an inverse relationship between somatic mutations and DNAmAge acceleration ${ }^{3}$. In contrast, a low DNAmAge is found in stem cells and induction of pluripotency is associated with "juvenescence" of cells.

Remarkably, MCC reveal a trilinear differentiation characterized by concurrent neuroendocrine, epithelial and pre/pro B-cell lymphocytic gene expression obscuring its -currently unknown and controversially- debated cellular origin ${ }^{6,7}$. The trilinear differentiation of MCC is suggestive for a certain "stemness" of the cell of origin. Considering these characteristics of MCC and in order to shed further light into their pathogenesis, we here investigated both the DNAmAge and the pluripotency gene expression profile of MCPyV-positive and negative MCCs. We isolated DNA and RNA of 14 fresh-frozen MCC tissues (originating from 12 patients) and four MCC cell lines (MKL-1, MKL-2, WaGa and MCC13) using the AlIPrep DNA/RNA Mini Kit (Qiagen). DNA and RNA were further processed by the custom service provided GenomeScan B.V., Leiden, the Netherlands. First, the DNA concentration was assessed using the Qubit assay from Invitrogen, Carlsbad, California, U.S.A. The quality was assessed by performing gelelectrophoresis. All samples passed the quality control from GenomeScan B.V. Subsequently 500ng of each sample DNA were bisulfite converted using the EZ DNA Methylation Gold Kit (Zymo Research, Irvine, California, U.S.A). A bisulfite quality control on the samples consisting of a qPCR reaction and melting curve analysis was performed by GenomeScan B.V. Again, all samples passed the GenomeScan B.V. quality control. Afterwards, $4 \mu \mathrm{L}$ of each sample were directly 
utilized for the methylation analysis. For the microarray-based DNA methylation analyses, the bisulfite-converted DNA was applied to the Infinium MethylationEPIC BeadChip targeting over 850,000 methylation sites per sample (850K) according to the manufacturer's instructions (Illumina, Inc., San Diego, California, U.S.A performed by GenomeScan B.V. Two different types of Infinium assays are incorporated on the array: one included unmethylated and methylated beads for each locus, the other included one bead per locus which recognize specific unmethylated and methylated DNA. The GenomeScan protocol for sample preparation, hybridization and washing of the $850 \mathrm{~K}$ array was performed without deviations of the Illumina protocol ("Infinium II Methylation Assay Manual Protocol"). Subsequently, the $850 \mathrm{~K}$ arrays were scanned using the Illumina iScan and all samples passed the MethylAid data quality assessment by using the corresponding $\mathrm{R}$ script (version R-3.6.2). Raw hybridization signals were processed using the GenomeStudio software (v2011.1; methylation module 1.9.0; Illumina Inc., USA) applying the default settings and internal controls for normalization. Loci with a detection $p$-value $>0.01$ in all hybridizations (863057/865918) and hybridizations showing a loci call rate above $98 \%$ were $(18 / 18)$ used for further analysis. All hybridizations met the defined quality criteria and entered the next step in the analysis. MCCs were subjected for the DNAmAge calculation as described by Horvath ${ }^{3}$. We extracted from our quality-controlled list of $850 \mathrm{~K}$ loci $(n=863057)$ the 30084 loci necessary for the DNAmAge calculation given by Horwath in the datMiniAnnotation file. Next we uploaded the DNA methylation values of these loci in https://dnamage.genetics.ucla.edu/home (February 2020) and used the normalization option recommended on the home page. Of note, Horvath used Infinium Methylation450 BeadChip targeting over 450,000 methylation sites per sample (450K) for the DNAmAge calculation ${ }^{3}$.We are aware that by using $850 \mathrm{~K}$ generated data an underestimation of -3.96 DNAmAge years compared to $450 \mathrm{~K}$ data and a correlation to the chronological age was observed ${ }^{4}$. For the assessment of the MCC DNAmAge correlation with the chronological age following statistical analyses were performed: the Pearson's correlation coefficient and the two-tailed p-value for the assessment of the scatter plot (Figure $1 \mathrm{~A}$ ) and the paired t-test for the assessment of the boxplots (Figure 1B) were calculated using Graphpad Prism 8.3.1. 
For the PluriTest approach ${ }^{8}$, the RNA of all samples was sequenced by GenomeScan B.V. Briefly, the RNA quality of all samples was assessed using the Fragment Analyzer (Agilent, Santa Clara, California, U.S.A.). All samples passed the quality control. The tissue sample preparation was performed according to the protocol "NEBNext Ultra Directional RNA Library Prep Kit for Illumina" (NEB, Hitchin, Great Britain). The NEBNext Ultra II Directional RNA Library Prep Kit for Illumina was used to process the cell line samples. From the total tissue RNA rRNA was depleted using the rRNA depletion kit (NEB, Hitchin, Great Britain). The cell line mRNA was isolated from total RNA using oligo-dT magnetic beads. Afterwards from all RNAs cDNA synthesis was performed, which was used for ligation with the sequencing adapters and PCR amplification of the resulting product. The quality and yield of all samples matched the company's expectation. The tissue cDNAs were sequenced using the next generation sequencing (NGS) platform Illumina NextSeq 500 (read length of 1 *75bp gained in an average output of 1.2 giga base pairs reads per sample) according to the manufacturer's protocols Illumina Inc., San Diego, California, U.S.A). The cell line cDNAs were sequenced by using the NGS platform Novaseq 6000 (read length of 2 * 150bp gained in an average output of 17 giga base pairs reads per sample) (Illumina Inc., San Diego, California, U.S.A). After alignment to GRCh37.87 (hg19) using the STAR aligner ( $v$. 2.4.5b), the bam-files were subjected to the program featureCounts ( $v$ 1.6.3) to assign the reads to the necessary regions for the PluriTest approach ${ }^{8}$. These regions were chosen to match the positions of probes on expression arrays which were defined in the original PluriTest publication ${ }^{8}$. The raw read counts were then used to address pluripotency by adopting the $\mathrm{R}$ script published by Müller et al. $2011^{8}$ (https://github.com/jhsiao999/pluritest). This script was run using the outdated $R$ version 2.15.1, because it was not runnable with newer $\mathrm{R}$ versions. For the PluriTest approach, five randomly chosen publicly available RNAseq-datasets from induced pluripotent stem cells (iPSC) (GSE107654) were used as positive controls. The raw data fastq-files were downloaded and processed using the same protocol.

The mean DNAmAge for the tested 14 MCC tissues was $33.0 \pm 15.0$ years with a Pearson's correlation coefficient of 0.05 . Thus, the DNAmAge was significantly younger and did not match with the patients chronological age (mean $70.0 \pm 13.0$ years, $p<0.0001$ ) (Fig 1A, B, Table 1). This significant lower DNAmAge was 
observed irrespective of the presence of MCPyV. MCPyV at least in the context of MCC is, thus, not associated with DNAmAge acceleration as it has been described for other viral infections including HPV-associated cancers ${ }^{5}$. This negative DNAmAge is in the range of what has been reported in uterine endometroid cancer with -30 years, colorectal cancer tissue with -20 years and head and neck cancers with approximal -17 years ${ }^{9}$. Comparing two different MCC metastases (ID L-MCC8 and L-MCC16, Table 1) which were resected within one year from patient number 5 revealed no substantial difference of the DNAmAge. Of interest, we observed a 43-year DNAmAge increase between the primary tumor (ID L-MCC7) and its metastasis (ID L-MCC10) of one patient (number 4) which were both resected within one year (Table 1). 
Table 1: Summary of the clinicopathological data of the MCC patients and tissues including DNAmAge

\begin{tabular}{|c|c|c|c|c|c|c|c|c|}
\hline No. & ID & Gender & $\begin{array}{l}\text { Primary or } \\
\text { metastasis }\end{array}$ & Localization & MCPyV & $\begin{array}{c}\text { Chronological } \\
\text { Age }\end{array}$ & DNAmAge & $\begin{array}{c}\text { DNAmAge- } \\
\text { Chronological Age }\end{array}$ \\
\hline 1 & L-MCC2 & $\mathrm{M}$ & met. & para-aortic lymph node & + & 70 & 30.0 & -40.0 \\
\hline 2 & L-MCC4 & M & prim. & face & + & 63 & 23.0 & -40.0 \\
\hline 3 & L-MCC5 & $\mathrm{F}$ & prim. & lower leg & + & 55 & 62.0 & 7.0 \\
\hline \multirow{2}{*}{4} & L-MCC7 & \multirow{2}{*}{$F$} & prim. & face & + & 50 & 7.0 & -43.0 \\
\hline & L-MCC10 & & met. & subcutis & $(+)$ & 51 & 50.0 & -1.0 \\
\hline \multirow{2}{*}{5} & L-MCC8 & \multirow{2}{*}{ M } & met. & upper leg & + & 74 & 15.0 & -59.0 \\
\hline & L-MCC16 & & met. & inguinal lymph node & + & 75 & 14.0 & -61.0 \\
\hline 6 & L-MCC11 & $\mathrm{F}$ & met. & gluteal area & + & 60 & 39.0 & -21.0 \\
\hline 7 & L-MCC12 & $M$ & met. & skin & - & 84 & 32.0 & -52.0 \\
\hline 8 & L-MCC13 & M & prim. & face & + & 87 & 44.0 & -43.0 \\
\hline 9 & L-MCC14 & $M$ & prim. & upper arm & - & 91 & 25.0 & -66.0 \\
\hline 10 & L-MCC15 & M & met. & upper arm & + & 79 & 34.0 & -45.0 \\
\hline 11 & L-MCC17 & $\mathrm{F}$ & prim. & skin & + & 82 & 54.0 & -28.0 \\
\hline 12 & L-MCC18 & $\mathrm{F}$ & met. & axillary lymph node & + & 65 & 39.0 & -26.0 \\
\hline
\end{tabular}

Abbreviations used: No. = number of patient; ID = internal identity; L-MCC= Merkel cell carcinoma from the Leuven cohort; $\mathrm{M}=$ male; F = female; prim = primary; met. = metastasis; $\mathrm{MCPyV}=$ Merkel cell polyomavirus, - = negative; $(+)=$ weak positive $;+$ = positive; grey marked MCC has an accelerated DNAmAge 
Only one of the analyzed MCCs (ID L-MCC5) and two of the analyzed MCC cell lines (MKL-1 and MKL-2) revealed an accelerated DNAmAge compared to the chronological age (Figure $1 \mathrm{C}$ and Table 1).

A

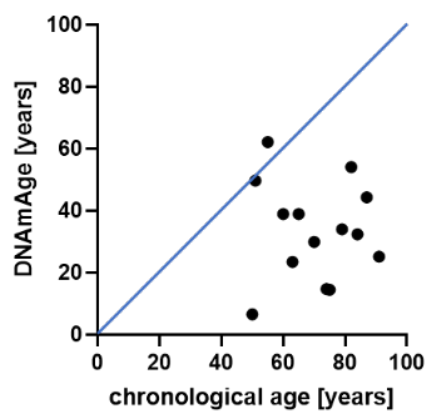

B

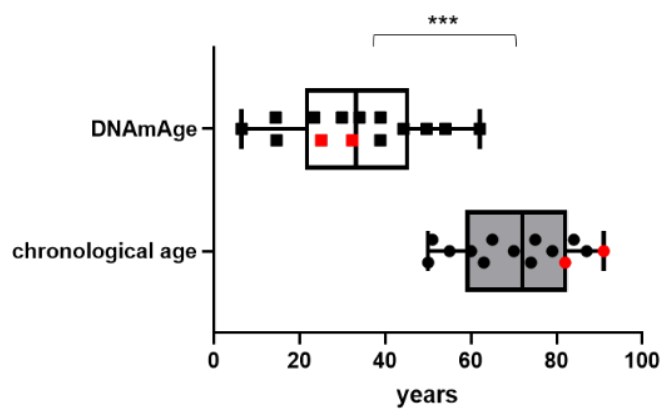

C

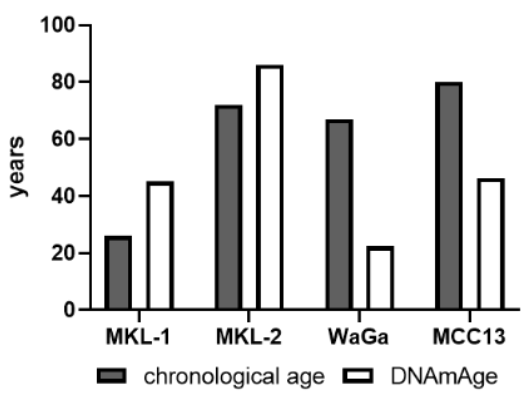

Figure 1 Epigenetic age of MCC cells is significantly younger compared to the chronological age of MCC patients

In A, a scatter plot of 14 Merkel cell carcinoma (MCC) illustrates that there is no significant correlation between chronological age and DNAmAge (Pearson's correlation coefficient of 0.05) The solid blue line corresponds to DNAmAge = chronological age. In B, boxplots illustrate that the MCC DNA methylation age (DNAmAge) is significantly ${ }^{* * *}$ : $p$-value $<0.0001$ ) younger compared to the chronological age. The DNAmAge is irrespective of the presence of the Merkel cell polyomavirus (MCPyV) (MCPyV-negative MCCs marked red). In $\mathbf{C}$, the chronological age and the DNAmAge of the MCC cell line MKL-1, MKL-2, WaGa and MCC13 were plotted. The MCC cell lines WaGa and MCC13 are epigenetically "younger" compared to their chronological age.

The observed approximation of 50-year DNAmAge to 51-year chronological age of patient number 4 within one year might be due to the increase of DNAmAge during disease progression. This has previously been reported for hematopoietic stem cells revealing a DNAmAge deceleration after transplantation and a DNAmAge acceleration compared to the original donor's chronological age after several months ${ }^{10}$. Interestingly, in contrast to the MCC cell lines WaGa as well as MCC13 the DNAmAge of the MCC cell lines MKL-1 and MKL-2 was accelerated. 
Horvath described that the DNAmAge correlates with the passage number ${ }^{3}$. Considering this and that the MCPyV-positive cell lines MKL-1, MKL-2 as well as WaGa were established earlier than $1987^{11}, 2002^{12}$ as well as $2010^{13}$, respectively, one might argue that the DNAmAge acceleration of the cell lines MKL-1 and MKL-2 could be explained by cell culture effects. In contrast, MCC13 was established earlier than $1995^{14}$ and a lower DNAmAge could be calculated. Considering that MKL-1, MKL-2 and the primary MCC tumor L-MCC5 illustrated an acceleration of the DNAmAge it might be that these MCCs possibly belong to a distinct minority subgroup of MCC with accelerated DNAmAge compared to the chronological age. Further studies using larger MCC cohorts are needed to determine in as much MCC consists of different subgroups dividing in accelerated or low DNAmAge.

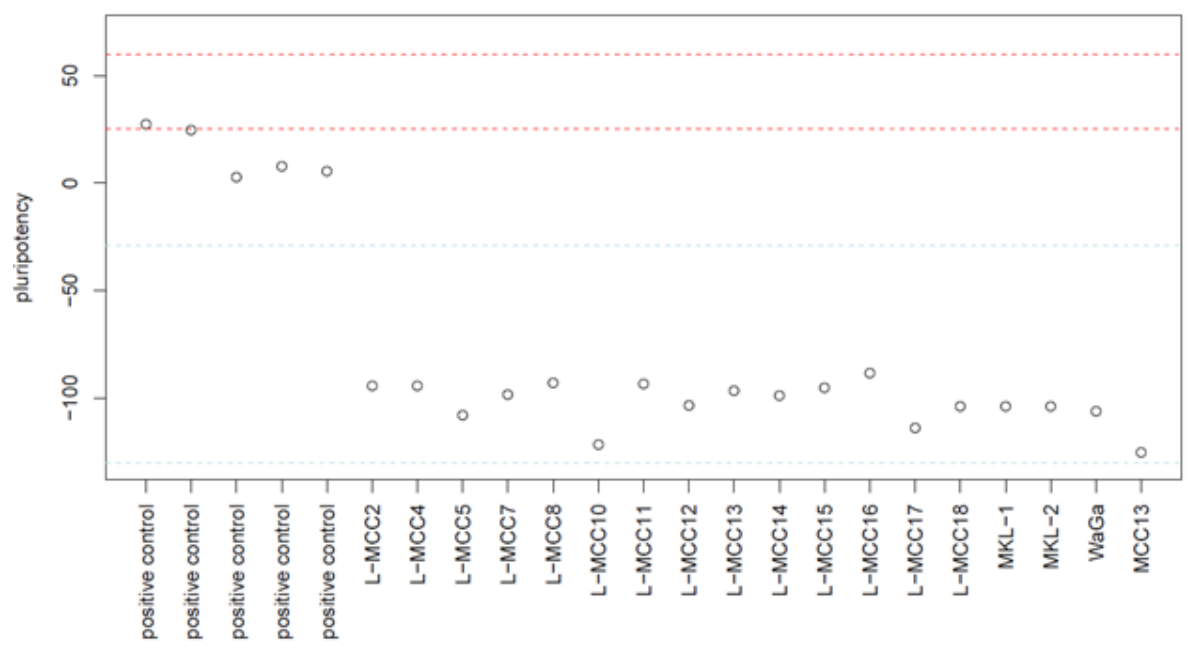

Figure 2 MCCs are not pluripotent

The pluripotency score on the $y$-axis illustrates in as much the samples on the $x$-axis are pluripotent according to the PluriTest. The red lines mark the region of pluripotency, in which only the positive controls (induced pluripotent stem cells (iPSCs)) taken from GSE107654 are closely located. Thus, the MCC tissues and cell lines are not pluripotent. 
The highly significant low DNAmAge in combination with the typical trilinear differentiation of MCC gene expression, might possibly indicate a pluripotency program to be active in these cells. Thus, we assessed the pluripotency status of the MCC cells and cell lines using RNAseq in combination with PluriTest analyses. Using this approach, the MCC tumor cells and the cell lines did consistently not map at, or close to the pluripotency region (Figure 2). Thus, MCC cells and cell lines are not pluripotent according to PluriTest.

Therefore, we conclude that the majority of MCCs are characterized by epigenetic youth but lack of pluripotency. The understanding of these epigenetic findings in MCC might contribute to the identification of the yet elusive cellular origin of MCC. 


\section{2 | THE CURIOUS CASE OF MERKEL CELL CARCINOMA}

\section{REFERENCES}

1. Schadendorf D, Lebbé C, zur Hausen A, et al. Merkel cell carcinoma: Epidemiology, prognosis, therapy and unmet medical needs. European Journal of Cancer. 2017;71:53-69. Harms PW, Harms KL, Moore PS, et al. The biology and treatment of Merkel cell carcinoma: current understanding and research priorities. Nature Reviews Clinical Oncology. 2018;15(12):763-776.

3. Horvath S. DNA methylation age of human tissues and cell types. Genome Biol. 2013;14(10):R115-R115.

4. Dhingra R, Nwanaji-Enwerem JC, Samet M, Ward-Caviness CK. DNA Methylation AgeEnvironmental Influences, Health Impacts, and Its Role in Environmental Epidemiology. Curr Environ Health Rep. 2018;5(3):317-327.

5. Lu X, Zhou Y, Meng J, et al. Epigenetic age acceleration of cervical squamous cell carcinoma converged to human papillomavirus $16 / 18$ expression, immunoactivation, and favourable prognosis. Clinical Epigenetics. 2020;12(1):23.

6. Sauer CM, Haugg AM, Chteinberg E, et al. Reviewing the current evidence supporting early B-cells as the cellular origin of Merkel cell carcinoma. Critical Reviews in Oncology/Hematology. 2017;116:99-105.

7. Kervarrec T, Samimi M, Guyétant S, et al. Histogenesis of Merkel Cell Carcinoma: A Comprehensive Review. Front Oncol. 2019;9:451-451.

8. Müller F-J, Schuldt BM, Williams R, et al. A bioinformatic assay for pluripotency in human cells. Nature methods. 2011;8(4):315-317.

9. Horvath S. Erratum to: DNA methylation age of human tissues and cell types. Genome Biol. 2015;16(1):96.

10. Stölzel F, Brosch M, Horvath S, et al. Dynamics of epigenetic age following hematopoietic stem cell transplantation. Haematologica. 2017;102(8):e321-e323.

11. Rosen ST, Gould VE, Salwen HR, et al. Establishment and characterization of a neuroendocrine skin carcinoma cell line. Lab Invest. 1987;56(3):302-312.

12. Van Gele M, Leonard JH, Van Roy N, et al. Combined karyotyping, CGH and M-FISH analysis allows detailed characterization of unidentified chromosomal rearrangements in Merkel cell carcinoma. International journal of cancer. 2002;101(2):137-145.

13. Houben R, Shuda M, Weinkam R, et al. Merkel cell polyomavirus-infected Merkel cell carcinoma cells require expression of viral $\mathrm{T}$ antigens. Journal of virology. 2010;84(14):7064-7072.

14. Leonard JH, Dash P, Holland P, Kearsley JH, Bell JR. Characterisation of four Merkel cell carcinoma adherent cell lines. International journal of cancer. 1995;60(1):100-107. 


MCC is characterised by the expression of the neuroendocrine genes Chromogranin A and Synaptophysin. If MCC is originating from early B-cells it has to be clarified how neuroendocrine genes like Chromogranin A and Synaptophysin could be expressed in the B-cell like MCC. Therefore, the expression of the master neuroendocrine gene regulator was in focus of the following studies. Thus, in the following study we focus on the expression of Achaete-scute complex 1 (ASCL1) which induce neuroendocrine gene expression and the expression of the negative regulator RE1 silencing transcription factor (REST) which represses neuroendocrine gene expression. Since all MCC cells were absent of both ASCL1 and REST, we further analysed the regulation of REST in MCC which could possibly explain the induction of neuroendocrine genes in MCC. 


\section{Contribution to the publication (Chapter 3):}

Emil Chteinberg designed this study together with Prof. zur Hausen, Prof. Martin Zenke and Prof. Ernst-Jan Speel. All experiments were mainly performed and analysed by Emil Chteinberg. Dorit Rennspiess assisted in performing the immunohistochemistry of REST, ASCL1 and NeuroD1 which were analysed by Emil Chteinberg, Axel zur Hausen, Véronique Winnepenninckx and Jonathan Eben. The REST mRNA detection PCR-primer were ordered by Anke Haugg. Emil Chteinberg and Lisa Schiffelers established the REST-PCRs on RNA and DNA level. Emil Chteinberg together with Lukas Beumers established the Chromogranin A, Synaptophysin and miRNA-9 and miRNA-9* qRT-PCR. Emil Chteinberg performed transfection experiments on WaGa cells to express REST. Thereafter, Emil Chteinberg stained the REST-positive cells for Chromogranin A and Synaptophysin expression.

Emil Chteinberg and Christopher M. Sauer performed the 5- aza-2'-dC treatment of MCC cell lines together and established the methylation specific PCRs for the REST CpGs1 and 3 together. Part of the preliminary data of this manuscript was part of Lisa Schiffelers' Bachelor of Science thesis ("Discovering the cellular ancestors of Merkel cell carcinoma") of the Radboud University, Nijmegen, the Netherlands and was also part of Christopher M. Sauers' doctoral thesis (Dr. med.) ("Assessing the neuroendocrine gene expression and regulation of Merkel cell carcinoma") of the RWTH University Aachen, Aachen, Germany. Emil Chteinberg wrote the from the complete data set which was not used for the theses the manuscript. Prof. Axel zur Hausen and Prof. Ernst-Jan Speel revised the written manuscript. After the peer-review process the resulted manuscript was published in Neoplasia. 




\section{CHAPTER 3 \\ NEUROENDOCRINE KEY REGULATOR GENE EXPRESSION IN MERKEL CELL CARCINOMA}

EMIL CHTEINBERG, CHRISTOPHER MARTIN SAUER, DORIT RENNSPIESS, LUKAS BEUMERS, LISA SCHIFFELERS, JONATHAN EBEN, ANKE HAUGG, VÉRONIQUE WINNEPENNINCKX, ANNA KORDELIA KURZ, ERNST-JAN SPEEL, MARTIN ZENKE, AXEL ZUR HAUSEN

-PUBLISHED-

NEOPLASIA. 2018 DEC; 20(12): 1227-1235 



\section{ABSTRACT}

Merkel cell carcinoma (MCC) is a highly aggressive non-melanoma skin cancer of the elderly which is associated with the Merkel cell polyomavirus (MCPyV). MCC reveals a trilinear differentiation characterized by neuroendocrine, epithelial, and pre/pro B-cell lymphocytic gene expression disguising the cellular origin of MCC.

Here we investigated the expression of the neuroendocrine key regulators RE1 silencing transcription factor (REST), neurogenic differentiation 1 (NeuroD1) and the Achaete-scute homolog 1 (ASCL1) in MCC. All MCCs were devoid of REST and were positive for NeuroD1 expression. Only one MCC tissue reveal focal ASCL1 expression. This was confirmed in MCPyV-positive MCC cell lines. Of interest, MCPyV-negative cell lines did express REST. The introduction of REST expression in REST-negative, MCPyV-positive MCC cells downregulated the neuroendocrine gene expression. The lack of the neuroendocrine master regulator ASCL1 in almost all tested MCCs points to an important role of the absence of the negative regulator REST towards the MCC neuroendocrine phenotype. This is underlined by the expression of the REST-regulated microRNAs miR-9/9* in REST-negative MCC cell lines.

These data might provide the basis for the understanding of neuroendocrine gene expression profile which is expected to help to elucidate the cellular origin of MCC. 


\section{INTRODUCTION}

Merkel cell carcinoma (MCC) is a highly malignant non-melanoma skin cancer which predominantly arises in the sun-exposed skin of elderly patients ${ }^{1,2}$. Next to UV exposure and age, MCC are associated with immune deficiencies and the presence of clonally integrated Merkel cell polyomavirus (MCPyV) ${ }^{3,4}$. More than $80 \%$ of MCC are associated with MCPyV and it has been shown that tumour cell proliferation of MCC is dependent on the expression of the oncogenic viral T antigens ${ }^{5-7}$

Although MCC accounts only for a minority of all cutaneous malignancies its incidence has increased worldwide and has tripled in the US and doubled in some European countries ${ }^{8}$.

The 5 -year survival of local MCC is $71 \%$ but only $20 \%$ in the presence of distant metastases ${ }^{2}$. Recent data of clinical trials on the use of immune checkpoint inhibitors in the treatment of patients with MCC stage IIIB/IV are promising ${ }^{9,10}$.

Despite the major progress that has been made during the past years concerning the understanding of the etiopathogenesis and treatment, the cellular origin of MCC remains enigmatic ${ }^{11}$. It has been postulated that MCC either originate from Merkel cells or epidermal/dermal stem cells ${ }^{11,12}$. To date it is generally accepted that the post-mitotic Merkel cells do not constitute the cellular origin of MCC. Based on the frequently reported co-expression of PAX5, TdT and immunoglobulins in MCCs, we have recently formulated the hypothesis that MCC originate from early B-cells, i.e. pre/pro B-cells ${ }^{13,14}$.

The repressor element 1 (RE1) silencing transcription factor (REST) is a master repressor of neuronal gene expression and neuronal programs in non-neuronal lineages ${ }^{15,16}$. REST binds together with CoREST to the RE1-binding site of neuronal genes, which leads to the inhibition of the expression of these genes ${ }^{17}$. In the absence of REST, neuronal genes will be expressed. Among other genes, REST negatively controls the neuronal target genes encoding chromogranin $A$ and synaptophysin ${ }^{18,19}$. Although the absence of REST is insufficient to explain the full extent of chromogranin A expression, synaptophysin gene expression is predominantly regulated by REST ${ }^{19}$. REST has been proven to function as an oncogene in neural cells and as a tumour suppressor in non-neural cells ${ }^{16}$. In neoplastic neural cells, REST expression is switched on and is overexpressed, e.g. in medulloblastoma and in glioblastoma multiforme ${ }^{20,21}$. In contrast, in non- 
neural tumours REST acts as a tumour suppressor, revealing deletions of the REST locus on chromosome 4 in a significant proportion of tumours ${ }^{22}$.

REST expression is negatively reciprocal regulated by the neuronal development regulator microRNA-9 (miR-9) during neural differentiation 23,24. Further, its passenger strand miR-9* is downregulating CoREST: Recently it has been shown that miR-9 is upregulated in MCC ${ }^{25}$. Interestingly, it has been shown that miR-9 is activated by the human papillomavirus (HPV) E6 protein in cervical cancer ${ }^{26}$. In addition, REST has been shown to interact with other human DNA viruses, e.g. Herpes simplex virus and adenovirus ${ }^{27-29}$.

The basic helix-loop-helix (BHLH) Achaete-scute homolog 1 (ASCL1) transcription factor is known as another master regulator of neuroendocrine differentiation and is detected in most neuroendocrine tumours as small cell lung cancer (SCLC) ${ }^{30}$. In addition, the transcription factor neurogenic differentiation 1 (NeuroD1) was considered as an alternative regulator of neuroendocrine differentiation.

In the present study, we assessed the expression of REST, NeuroD1 and ASCL1 in MCC and MCC cell lines. Moreover, the possible regulation of REST expression by promoter methylation was assessed with 5-aza-2' deoxycytidine (5-aza-2'-dC) treatment and a methylation specific PCR of the REST promoter CpG islands. In addition, we tested the expression of miR-9/9* in REST-positive and RESTnegative MCC cell lines in relation to MCPyV in order to understand in as much the regulation of neuroendocrine gene expression in MCC is affected by MCPyV. 


\section{MATERIALS AND METHODS}

\section{PATIENT SAMPLES}

28 formalin fixed and paraffin embedded (FFPE) primary and metastatic MCC tissues were obtained from the archives of the Department of Pathology, Maastricht University Medical Center + (table 1). All use of tissue and patient data was in agreement with the Dutch Code of Conduct for Observational Research with Personal Data (2004) and Tissue (2001, http://www.fmwv.nl). MCCs were previously diagnosed by histology and immunohistochemistry for CK20, CD56, synaptophysin and chromogranin $A$ in routine diagnostic and have been reviewed by 2 experienced pathologists ( $\mathrm{WW}, \mathrm{AZH})$.

\section{CELL LINES}

The MCPyV-positive MCC cell lines MKL-1, MKL-2, WaGa, PeTa, BroLi, MS-1 the MCPyV-negative MCC cell lines MCC13, MCC26 and the B-ALL cell line REH were used. All MCC cell lines were kindly provided by Jürgen Becker (University Hospital Essen, Essen, Germany). REH was obtained from the Leibniz Institute DSMZ-German Collection of Microorganisms and Cell Cultures, Germany.

The cell lines were cultured in Gibco® RPMI 1640 medium with $10 \%$ fetal calf serum (FCS) (Gibco®, ThermoFisher SCIENTIFIC, The Netherlands) in an incubator at $37^{\circ} \mathrm{C}$ and $5 \% \mathrm{CO} 2$.

\section{IMMUNOHISTOCHEMISTRY}

The expression of REST, ASCL1 and NeuroD1 was tested by immunohistochemistry (IHC) in 20 primary and 8 metastatic MCCs, in the MCPyVpositive MCC cell lines MKL-1, MKL-2, WaGa and in the MCPyV-negative MCC cell lines MCC13 and MCC26. In addition, the expression of these genes was assessed in the B-cell acute lymphoblastic leukaemia (B-ALL) cell line REH. The following antibodies and dilutions were used in this study: Anti-MCPyV LT-antigen (clone: CM2B4) dilution 1:100, SANTA CRUZ BIOTECHNOLOGY, Germany; anti-REST (clone: CL0381) dilution 1:100, Sigma Aldrich, the Netherlands; antiMASH1/Achaete-scute homologe1 (clone: 24B72D11.1) dilution 1:100, Abcam, UK; NeuroD1 (clone: 3H8) dilution 1:100, Abnova, Germany; anti-Cytokeratin 20 (clone: Ks 20.8) "Ready to use antibody", Dako, the Netherlands. All IHC staining were conducted on a Dako Autostainer 48 Link using the EnVision FLEX 
Visualization Kit K8008 Dako as described previously and according to standard diagnostic routine protocols and manufacturer instructions ${ }^{31}$. The $\mathrm{IHC}$ double staining procedure of REST and Cytokeratin 20 (CK20) was performed manually by using the Dako Kit K8008 for anti-REST and K5005 for the staining of antiCK20. The double staining method was adapted to the standard routine protocol.

\section{REST-GFP TRANSFECTION}

The cell line WaGa was transfected with human cDNA ORF GFP tagged clone NM_005612 from Origene. The expression vector led to a transient expression of REST-GFP. The transfection was performed by using Lipofectamine 3000 (ThermoFisher SCIENTIFIC, The Netherlands) according to the instructions of the manufacturer. The expression level changes of synaptophysin and chromogranin A were assessed by immunofluorescence microscopy by using a standard protocol. The cells were formalin fixed, permeabilized with $0,3 \%$ Triton $X-100$, blocked with $5 \%$ BSA, incubated with the first antibodies against chromogranin $A$ 1:250 (SP11, ThermoFisher SCIENTIFIC, The Netherlands) or antisynaptophysin 1:250 (SP12, ThermoFisher SCIENTIFIC, The Netherlands), stained with the second antibody anti Rabbit Texas Red conjugated (T-2767, ThermoFisher SCIENTIFIC, The Netherlands). The detection of the GFP tagged REST and fluorescence stained cells with the Leica microscope DM 5000 B (Leica, the Netherlands).

\section{MIRNA ISOLATION AND MIRNA QUANTITATIVE RT-PCR}

The miRNA was extracted by using the miRNA isolation kit "NucleoSpin $®$ miRNA" according to the manufacturers' instructions (Macherey Nagel, Germany). The miRNA concentration was measured with the Nanodrop 2000 (ThermoFisher SCIENTIFIC, The Netherlands). The cDNA from the isolated miRNAs was synthesized by using the Universal cDNA Synthesis Kit II from Exiqon, the Netherlands.

The expression of miR-9 and miR-9* was analysed in means of the quantitative RT-PCR by using the specific LNA primers hsa-miR-5p (miR-9) and hsa-miR-3p (miR-9*) (Exiqon, the Netherlands). The miRNA expression level was normalized to the expression of miR-103 using the primer set hsa-miR-103a-3p. The qRT- 
PCR was performed by using the SYBR Green Supermix (Bio-Rad, Switzerland) on the CFX96 PCR Detection System (Bio-Rad, Switzerland) and recorded by the Bio-Rad CFX manager.

REST-, SYNAPTOPHYSIN- AND CHROMOGRANIN A- GENE TRANSCRIPT EXPRESSION

RNA was extracted using the RNA isolation kit "NucleoSpin $\AA$ RNA" according to the manufacturer's instructions (Macherey-Nagel, Germany). The RNA concentration was measured with the Nanodrop 2000 (ThermoFisher SCIENTIFIC, The Netherlands). RNA was converted into cDNA using the "iScript ${ }^{\mathrm{TM}}$ Select cDNA Synthesis Kit" (Bio-Rad, Switzerland). Exon 1 and exon 3 of REST were amplified using the R1 and R3 primers (Table S2). In addition, exon 1 and exon 3 spanning amplification of REST cDNA was performed using the REST forward (fw) primer and REST reverse (rv) primer (Table S2).

A quantitative RT-PCR was performed for the analysis of REST-, synaptophysinand chromogranin A- expression in the cell lines MKL-1, MKL-2, WaGa, MCC13, MCC26 and REH. For this purpose, the qRT-PCR primer sets for REST, chromogranin $A$, synaptophysin were used. The resulting $C_{t}$ values were normalized with the housekeeping genes $\beta$-actin or GAPDH (Table S2). The qRTPCR was performed by using the SYBR Green Supermix (Bio-Rad, Switzerland) on the CFX96 PCR Detection System (Bio-Rad, Switzerland) and recorded by the Bio-Rad CFX manager. All used primers were obtained by Eurofins Genomics, Germany.

\section{DNA-PCR}

DNA isolation was performed using the Nucleospin Tissue DNA Kit (MachereyNagel, Germany) according to manufacturer's instructions. PCR was performed on a Veriti well thermal cycler (Applied Biosystems, the Netherlands) with an annealing temperature of $57^{\circ} \mathrm{C}$ for all combinations of primers and 35 cycles. The PCR products were sequenced using the Big Dye Sequencing Kit (ThermoFisher SCIENTIFIC, The Netherlands) according to manufacturers' instructions. All experiments were repeated at least 3 times. 


\section{TREATMENT OF CELL LINES WITH 5-AZA-2' DEOXYCYTIDINE}

The cell lines MKL-1, MKL-2, MCC13 and MCC26 were treated with $0.5 \mu \mathrm{M}, 1.0$ $\mu \mathrm{M}$ and $2.0 \mu \mathrm{M}$ of 5-aza-2'-dC (Sigma-Aldrich, the Netherlands) which was added every $24 \mathrm{hrs}$. In total, the cells were exposed to the demethylation agent for $96 \mathrm{~h}$. After exposure, the cells were formalin fixed and REST expression was tested by IHC.

\section{METHYLATION SPECIFIC PCR (MSP)}

The genomic DNA of all cell lines was extracted using the "NucleoSpin® Tissue" kit (Macherey-Nagel, Germany). The location of the CpG islands was previously described by Kreisler et al. ${ }^{32}$ and was reproduced using the CpG island searcher 32,33 .

The gDNA was bisulphite converted using the EpiTect Bisulfite Kit (Qiagen, the Netherlands) according to the manufacturers' instruction. CpG islands were amplified using specific primers for both methylated and unmethylated specific primer (table S2). As positive control, the unmethylated and the methylated Epitect Control DNAs (Qiagen, the Netherlands) were used.

\section{STATISTICS}

The significance of the qRT-PCR data was determined with Graphpad Prism 6 by using the One-Way ANOVA. Data were expressed as the mean \pm standard deviation (SD). $P$-values of $<0.05$ were considered as statistically significant. 


\section{RESULTS}

PROTEIN EXPRESSION OF REST, ASCL1 AND NEUROD1 IN MCC

Of the 28 MCC tissues, 23 (82.1\%) were MCPyV-positive and 5 (17.8\%) MCPyVnegative as tested by IHC. All MCCs (table 1) were completely devoid of REST expression as assessed by IHC (Figure 1A and C). Double staining for CK20- and REST-expression of MCC tissues revealed a specific nuclear expression of REST within the tumor infiltrating lymphocytes but not in the MCC cells expressing CK20 (Figure 1B). All MCCs were negative for ASCL1, except one case which revealed focal expression for ASCL1 (ID8, table 1). All MCCs revealed a specific moderate to strong nuclear expression of NeuroD1 (table 1, Figure 1D).

In addition, REST expression was assessed in MCC cell lines by IHC. MCPyVpositive cell lines (MKL-1, MKL-2, WaGa, PeTa, BroLi, MS-1) were negative for REST expression (Figure2. and supplemental table S1.). In contrast, the MCPyVnegative cell lines (MCC13, MCC26, REH) revealed a specific nuclear REST expression. In compliance with the MCC specimens, all cell lines were negative for ASCL1 expression, but revealed a strong and specific nuclear NeuroD1 expression in all cell lines. All MCPyV-positive cell lines showed a uniform expression pattern for the tested transcription factors. Therefore, for further experiments MKL-1, MKL-2 and WaGa cells were used. 

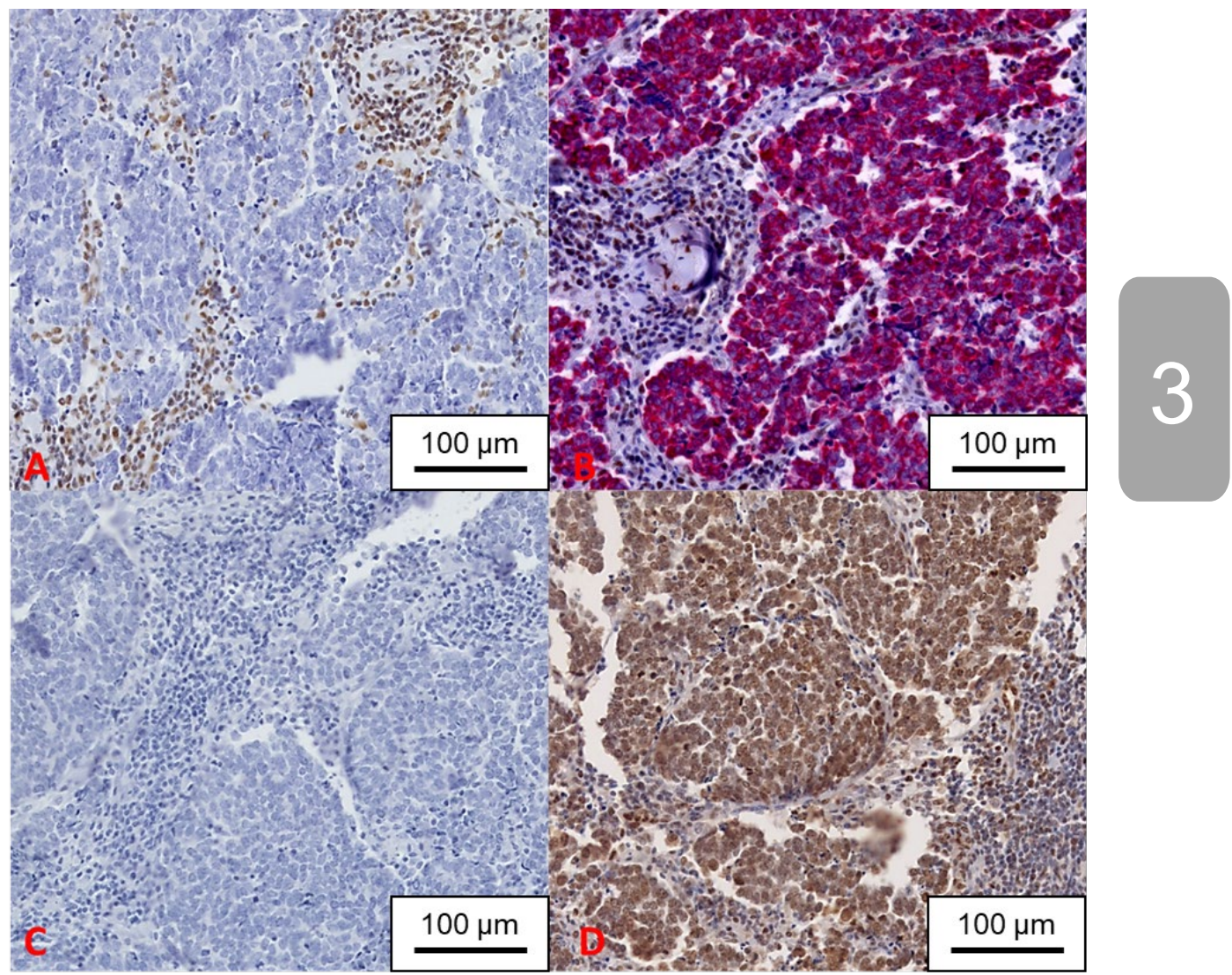

Figure 1: Immunohistochemistry staining of REST, ASCL1 and NeuroD1 in MCC ID 25.

A, IHC reveals no expression of REST expression in the MCC tissue. In $\mathbf{B}$, double staining of CK20 (red) and REST (brown) confirms that the REST positive cells are not located in the MCC tissue. ID25 is negative for ASCL1 and positive for NeuroD1 as shown in C and D. The microphotographs were taken at 20x magnification. 
Table 1: Summary of the clinico-pathological data of the MCC patients and MCC tissues including the results of the immunohistochemical assessment of REST, ASCL1 and NeuroD1.

\begin{tabular}{|c|c|c|c|c|c|c|c|c|c|}
\hline ID & gender & age & location & Dx & Histo & MCPyV & REST & Ascl1 & NeuroD1 \\
\hline \multicolumn{10}{|c|}{ Primary MCCs } \\
\hline 1 & $\mathrm{~m}$ & 63 & head & MCC & int. & pos. & - & - & ++ heter. \\
\hline 2 & $\mathrm{~m}$ & 92 & ear & $\mathrm{MCC}$ & s.c. & neg. & - & - & +++ \\
\hline 3 & $f$ & 85 & buttocks & MCC & s.c. & pos. & - & - & +++ \\
\hline 4 & $\mathrm{~m}$ & 69 & lip & $\mathrm{MCC}$ & int. & pos. & - & - & ++ \\
\hline 5 & $f$ & 93 & upper eye lid & MCC & int. & pos. & - & - & + \\
\hline 6 & $f$ & 60 & tongue & $\mathrm{MCC}$ & int./s.c & pos. & - & - & ++ heter. \\
\hline 7 & $\mathrm{~m}$ & 74 & upper leg & MCC & int. & pos. & - & - & +++ \\
\hline 8 & $\mathrm{~m}$ & 93 & head & MCC & int. & neg. & - & ++ foc. & +++ \\
\hline 9 & $f$ & 76 & buccal & MCC & int. & pos. & - & - & ++ \\
\hline 10 & $f$ & 91 & arm & MCC & int. & pos. & - & n.a. & n.a. \\
\hline 11 & $f$ & 83 & upper eye lid & $\mathrm{MCC}$ & int. & pos. & - & - & +++ \\
\hline 12 & $f$ & 76 & head & $\mathrm{MCC}$ & int. & pos. & - & n.a. & n.a. \\
\hline 13 & $\mathrm{~m}$ & 77 & neck & $\mathrm{MCC}$ & int. & neg. & - & - & +++ \\
\hline 14 & $\mathrm{~m}$ & 79 & head & $\mathrm{MCC}$ & int. & pos. & - & - & ++ \\
\hline 15 & $f$ & 71 & buccal & $\mathrm{MCC}$ & int. & pos. & - & - & ++ \\
\hline 16 & $\mathrm{~m}$ & 68 & buttocks & $\mathrm{MCC}$ & int. & pos. & - & - & +++ \\
\hline
\end{tabular}




\begin{tabular}{|c|c|c|c|c|c|c|c|c|c|}
\hline 17 & $f$ & 58 & buccal & MCC & int./s.c & pos. & - & - & +++ \\
\hline 18 & $\mathrm{~m}$ & 75 & upper leg & MCC & int & pos. & - & - & +++ \\
\hline 19 & $f$ & 65 & arm & MCC & int. & pos. & - & - & ++ \\
\hline 20 & $\mathrm{~m}$ & 63 & buccal & MCC & int. & neg. & - & - & ++ \\
\hline \multicolumn{10}{|c|}{ Metastatic MCC s } \\
\hline 21 & $\mathrm{~m}$ & 71 & pancreas & MCC met. & int. & pos. & - & - & ++ \\
\hline 22 & $f$ & 75 & LN neck & MCC met. & int. & pos. & - & - & ++ \\
\hline 23 & $f$ & 66 & skin & MCC met. & int. & pos. & - & - & $(+)$ \\
\hline 24 & $\mathrm{~m}$ & 74 & groin & MCC met. & int. & pos. & - & - & +++heter \\
\hline 25 & $f$ & 67 & upper arm & MCC met. & int. & pos. & - & - & +++heter \\
\hline 26 & $\mathrm{~m}$ & 65 & LN neck & MCC met. & int. & neg. & - & - & ++heter. \\
\hline 27 & $f$ & 43 & LN groin & MCC met. & int. & pos. & - & - & ++ \\
\hline 28 & $\mathrm{~m}$ & 69 & LN iliaca & MCC met. & int./s.c. & pos. & - & ++heter. & ++ \\
\hline
\end{tabular}

Abbreviation used: ID = identity, $\mathrm{M}=$ male, $\mathrm{F}=$ female, $\mathrm{Dx}=$ diagnosis, $\mathrm{MCC}=$ Merkel cell carcinoma; histo. = histology; int. = intermediate, $\mathbf{s}$. $\mathbf{c} .=$ small cell, foc. $=$ focal, n.a. $=$ not applicable, pos. $=$ positive, neg. $=$ negative, $-=$ no expression, $+=$ weak expression, $++=$ moderate expression, $+++=$ strong expression. 


\section{REST TRANSCRIPT GENE EXPRESSION IN MCC CELL LINES}

The presence of REST transcripts was assessed in MKL-1, MKL-2, WaGa, MCC13, MCC26 and REH cells (Figure 3). No transcript expression of the first (R1) and third (R3) exons and marginal, almost invisible presence of the RNAspecific REST transcript was observed in MKL-1, MKL-2 and WaGa. In contrast, the MCPyV-negative cell lines MCC13, MCC26 and REH revealed an evident and distinctive REST transcript expression. QRT-PCR for REST revealed that the expression of REST transcripts was under the signal threshold in MCPyV-positive MCC cells and thus negative. In contrast, MCPyV-negative cells revealed a high expression of REST transcripts (Figure $3 \mathrm{~A}$ and Figure $3 \mathrm{C}$ ).

The sequencing of the CDNA amplification products for MCC13, MCC26 and REH showed the expression of the identical REST isoform (variant 1) in these three cell lines. The cDNA REST amplification product of MKL-2 (Figure 3A; supplemental Figure S1) showed a faint PCR product, which was confirmed as REST by sequencing, carrying an insertion of $67-b p$. This insertion had previously been reported in SCLC and is supposed to result in a truncated REST ${ }^{34,35}$. 


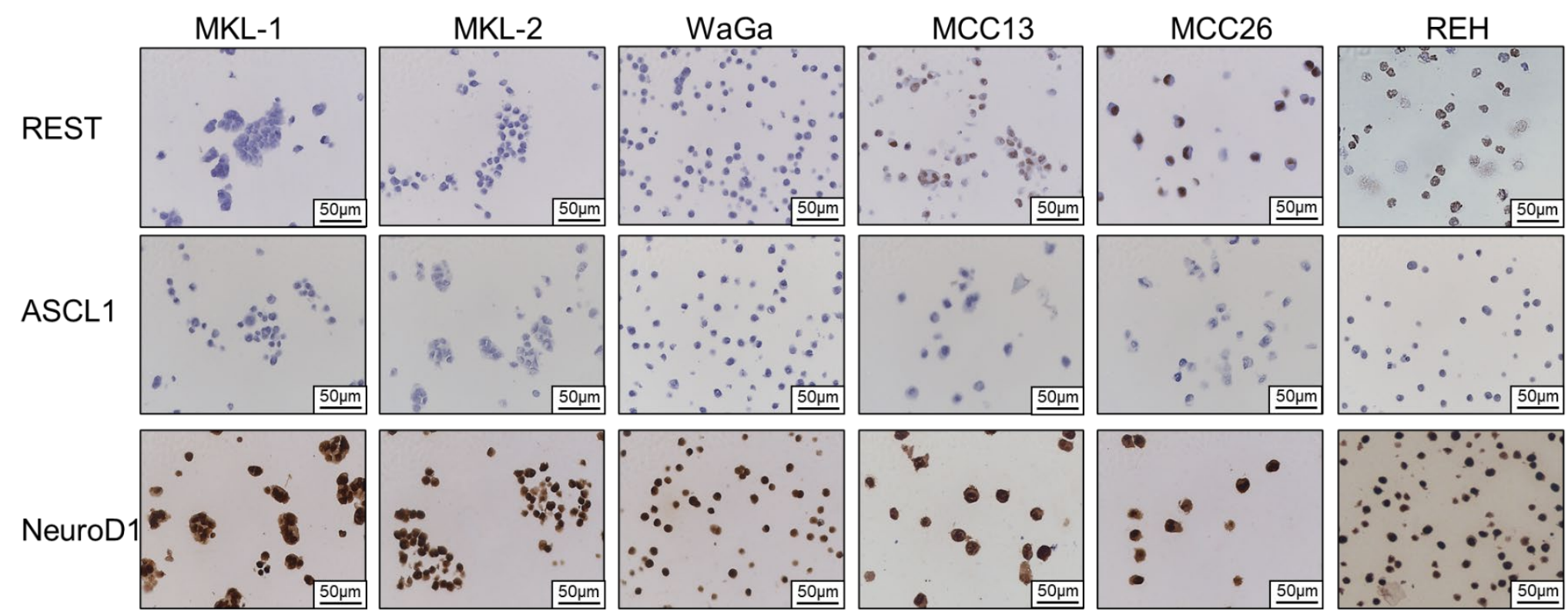

Figure 2: IHC staining of the MCC cell lines MKL-1, MKL-2, WaGa, MCC13, MCC26 and the B-ALL cell line REH for REST, ASCL1 and NeuroD1. Specific nuclear REST expression (brown) is found in the MCPyV-negative cell lines but not in MCPyV-positive cell lines MKL-1, WaGa and MKL-2. All cell lines tested were repeatedly negative for ASCL1 and positive for NeuroD1 by IHC. The scale bar indicate the magnification of the microphotographs. 
cDNA

A

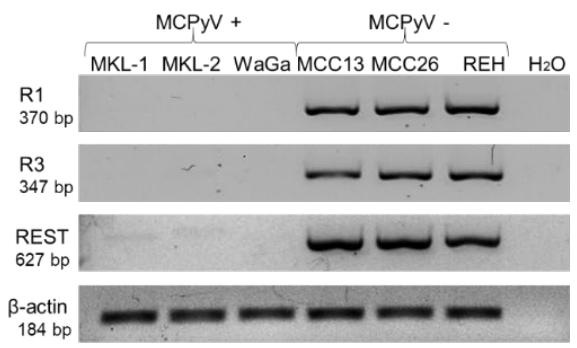

gDNA

B

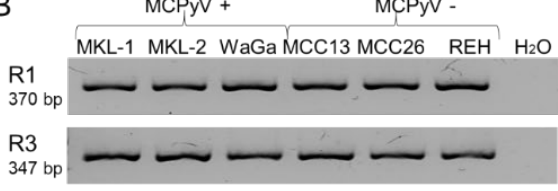

C

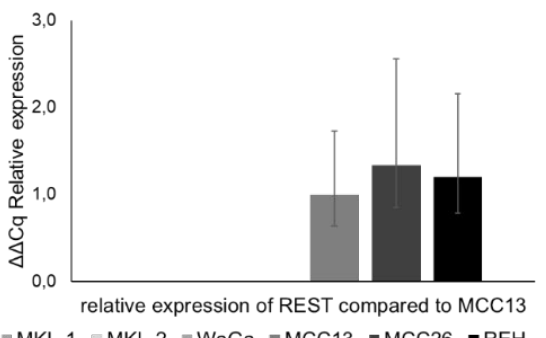

D

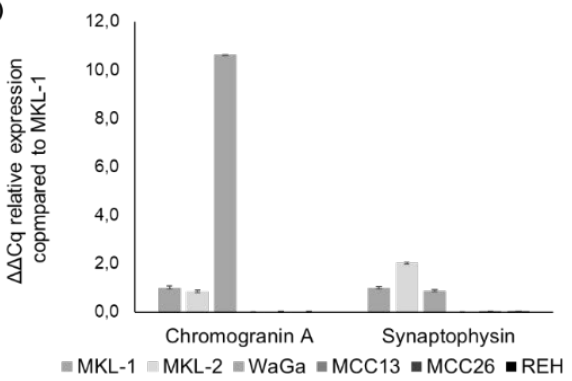

E

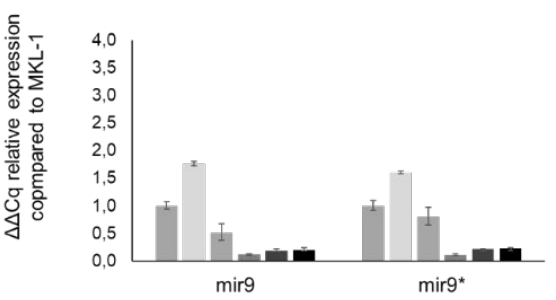

$=\mathrm{MKL}-1=\mathrm{MKL}-2=\mathrm{WaGa} \approx \mathrm{MCC} 13 \approx \mathrm{MCC} 26=\mathrm{REH}$

Figure 3: Analysis of REST, synaptophysin, chromogranin A and miR-9/9* expression.

No REST transcripts were detected in MCPyV-positive MCC cell lines MKL-1, WaGa and MKL-2. Exon 1 (R1), exon 3 (R3) and intron-exon spanning amplification of exon 1 and exon3 (REST) MKL-1, MKL-2 and WaGa were not detectable using CDNA (A) but by using genomic DNA (B) level. The MCPyV-negative cell lines were positive for REST cDNA. The expression of REST, chromogranin A, synaptophysin and miR-9/9* were analysed by means of a RT-qPCR. The cq values were normalized to MKL-1 and the $s d$ of $n=2$ is shown. Only for the REST expression the cq values were normalized to MCC13.

The REST RT-qPCR confirmed this result and shows a comparable REST transcript level in MCC13, MCC26 and REH (C). For chromogranin A and synaptophysin is the pattern vice versa. Whereas WaGa showed a 10 -fold higher chromogranin A expression compared to the other MCPyV positive cell lines (D). In E, the REST positive cell lines MCC13, MCC26 and REH showed an 84 to $76 \%$ respectively lower expression of miR-9 and miR-9* compared to the MCPyV-positive cell lines MKL-1, MKL-2 and WaGa. With a p-value of $<0.5$ the MCPyV positive cell lines had a lower of higher expression of all assessed genes by qRT-PCR. 
CHROMOGRANIN A, SYNAPTOPHYSIN AND MIR-9/MIR-9* EXPRESSION IN MCC

The detected patterns of chromogranin A and synaptophysin expression levels in MCPyV-positive cell lines revealed an inverse correlation with REST expression (Figure 3D). Of interest, a 10-fold higher transcript expression level of chromogranin A was observed in WaGa cells compared to MKL-1 and MKL-2. Interestingly, the WaGa cells revealed an approximately 3-fold higher expression level of the MCPyV T antigens compared to MKL-1 and MKL-2 (Figure 3D and supplemental Figure 2). MiR-9 expression in MCC cell lines was assessed in REST-negative, MCPyV-positive MCC cell lines MKL-1, MKL-2 and WaGa, and REST-positive, MCPyV-negative MCC cell lines MCC13 and MCC26 by means of qRT-PCR. The expression of miR-9 and miR-9* was normalized to MKL-1 (Figure 3E).

The REST-negative, MCPyV-positive, cell lines showed a high miR-9/miR-9* expression compared to the REST-positive, MCPyV-negative, MCC cell lines and the B-ALL cell line REH.

\section{EFFECTS OF THE TRANSIENT EXPRESSION OF REST-GFP IN WAGA CELLS ASSESSED BY IF}

In order to determine the functional importance of REST expression in MCPYVpositive MCC cell lines, WaGa cells were transfected with a GFP-tagged REST and its transient expression was detected in the nuclei. The REST-GFP positive WaGa cells were stained for chromogranin A and synaptophysin. A significant decrease of chromogranin $A$ and synaptophysin compared to the not transfected WaGa cells was observed (Figure 4 and Figure S3) in the transfected cells compared to the non-transfected cells. 


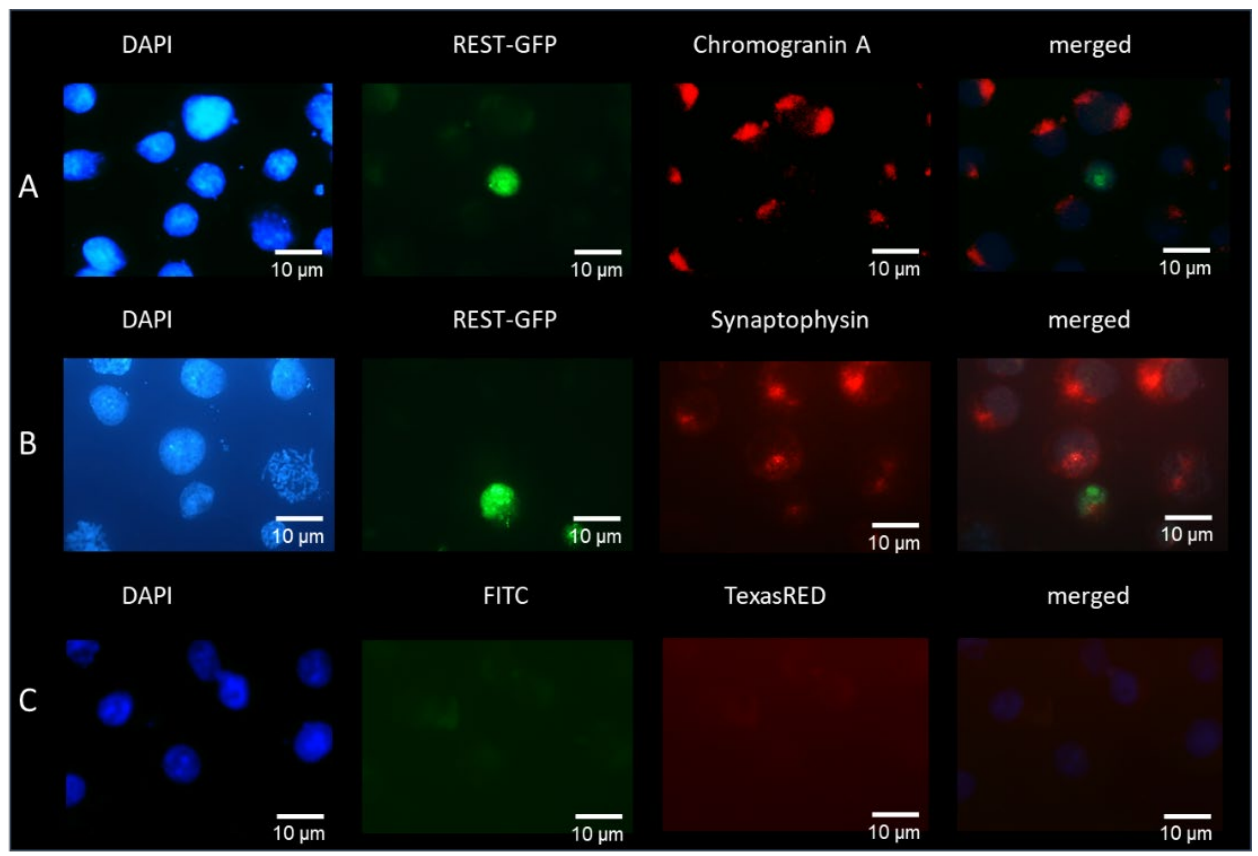

Figure 4: REST-GFP transient expressing WaGa cells with downregulated chromogranin A and synaptophysin expression. WaGa nuclei were shown with DAPI. The transient expressed REST-GFP is detected by green fluorescence. Immunofluorescence staining of chromogranin A (A) and synaptophysin (B) reveal a cytoplasmic detection of both in WaGa cells und red fluorescence. The merged picture shows no detection of chromogranin A and a weak detection of synaptophysin in WaGa cells with REST-GFP. In C the negative control whit no application of the first antibody is shown. The microphotograph scale is indicated. 


\section{METHYLATION OF THE REST PROMOTER IN MCCS}

REST expression had been shown to be regulated by methylation of promoter CpG islands ${ }^{32}$. Since neither REST protein or transcript expression could be detected in the MCPyV-positive cell lines, MKL-1, MKL-2, MCC13, MCC26 and REH were treated with 5-aza-2'-dC (Fig 5A). Of interest, after 0.5 and $1.0 \mu \mathrm{M}$ treatment with 5-aza-2'-dC MCC26 showed exclusively the response of approximate 50 to $60 \%$ respectively decrease of REST expression. However, due to the high standard deviation this failed to reach statistical significance. The expression of REST was not altered in the MCPyV-positive cell lines MKL-1 and MKL-2 by 5-aza2' dC treatment as assessed by IHC and RT-PCR (Figure 5B). The REST expression in the other cell lines was not significantly altered by the 5aza2 dC treatment.

A methylation specific PCR was performed on the CpG islands 1 and 3 (Figure 5D) of the genomic DNA of the above-mentioned cell lines and no methylation was detected on both CpG islands in all tested cell lines. 
A

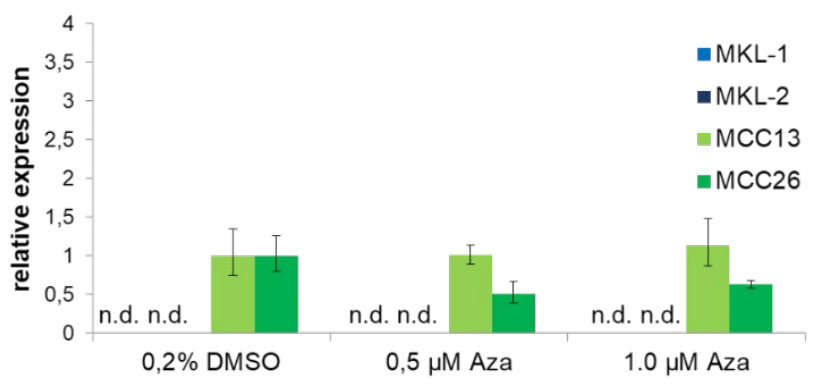

B

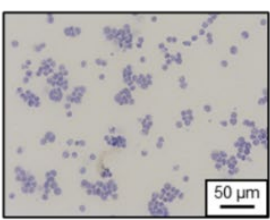

MKL-1 0.2\% DMSO

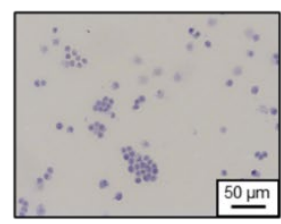

MKL-1 1.0 $\mu$ M Aza

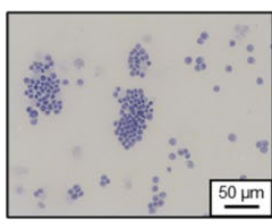

MKL-2 $0.2 \%$ DMSO

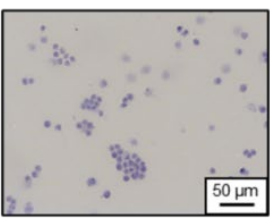

MKL-2 1.0 $\mu \mathrm{M}$ Aza

C

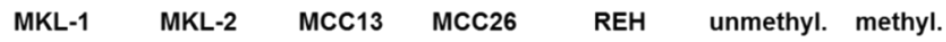

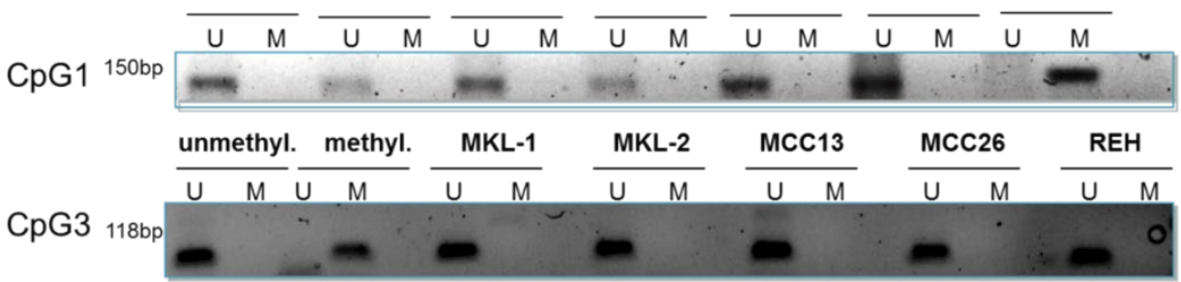

Figure 5: No Methylation of REST CpGs in MCC cell lines. Q-RT-PCR of REST expression after 5 days treatment with $0.5 \mu \mathrm{M}$ and $1 \mu \mathrm{M}$ of 5 -aza-2'-dC of MCC cell lines MKL-1, MKL-2, MCC13 and MCC26 and the BALL cell line REH revealed no increase in expression of REST in MCPyV positive cell lines (A). The p-value of MKL-1/MKL-2 was $<0.01$. For MCC26 the REST expression decreased up to $62 \%$ which is not significant. No REST protein is detectable in MKL-1 and MKL-2 after $2 \mu \mathrm{M}$ treatment (B). In C, the MSP for $\mathrm{CpG} 1$ and 3 showed no methylation in all MCC cell lines and in the B-ALL cell line. The positive controls showed either a methylated or an unmethylated DNA fragment. M: methylated; U: unmethylated 


\section{DISCUSSION}

In the present study we investigated the expression of key regulator genes of neuroendocrine gene expression in MCC. For this purpose a large number of MCC tissues including MCC cell lines was tested for the expression of REST, ASCL1, and NeuroD1.

REST acts as an repressor of neuroendocrine gene expression, whereby loss of REST expression leads to the expression of synaptophysin and chromogranin A. In contrast, ASCL1 and NeuroD1, both proneural basic-helix-loop-helix proteins, have both been identified as activators of neuroendocrine lineage genes expression ${ }^{36}$. In contrast, ASCL1 induces synatophysin expression and NeuroD1 activates CD56 (NCAM1) expression ${ }^{37,38 .}$.

All MCC tissues and cell lines in this study were negative for ASCL1 expression except one MCC which revealed a focal expression of ASCL1 (Table 1). Ralston and colleagues (2008) have previously reported that MCCs were all tested negative for ASCL1 expression by IHC ${ }^{39}$. In contrast, Lewis et al. (2010) found that MCCs arising in the head and neck region were positive for ASCL1 expression ${ }^{40}$. Interestingly, the anti-ASCL antibody in this study and the two previous reports derived from the same antibody clone. Moreover, we show that ASCL1 expression is also absent in all tested MCC cell lines, irrespective of the MCPyV-status (Figure 2).

To the best of our knowledge we report for the first time that NeuroD1 is expressed to $100 \%$ in MCC tissues and cell lines irrespective of the MCPyV-status (Table 1, Figure 2). Interestingly, the acute B-cell lymphoblastic leukaemia cell line REH also reveals a strong expression of NeuroD1, suggesting that NeuroD1 expression alone is not sufficient to induce neuroendocrine differentiation. This is supported by the fact that MCC13, MCC26 and REH were negative for the neuroendocrine genes chromogranin $A$ and synaptophysin.

According to previous data, chromogranin $A$ and synaptophysin gene expression is negatively regulated by REST 18,41 . Therefore, we tested the expression of REST in MCC tissues and MCC cell lines (Table 1, Fig 2.). None of the MCC in our study did reveal any REST expression in the MCC cells irrespective of the MCPyV-status.

The expression of REST-GFP in the MCPyV-positive MCC cell line WaGa and the subsequent REST induced decrease of synaptophysin and chromogranin $A$ 
expression reveals that chromogranin $A$ and synaptophysin are regulated by REST also in MCC cells (Figure 4) ${ }^{18,41}$. Since MCC are devoid of neuroendocrine gene activator ASCL1 expression in combination with the lack of the neuroendocrine gene repressor REST expression strongly indicates that the neuroendocrine gene expression of synaptophysin and chromogranin A in MCC is mediated by the absence of REST. NeuroD1 expression in MCC alone apparently seems to be insufficient to induce the neuroendocrine gene expression of synaptophysin and chromogranin A in the MCPyV-negative MCC (Figure 3C and D). According to previous reports one might speculate that the high NeuroD1 expression in MCC might be responsible for the known expression of NCAM1 (CD56) in MCCs ${ }^{37,42}$.

It is important to note, that the MCPyV-negative variant MCC cell lines MCC13 and MCC26 are currently controversially discussed in as much these cells lines indeed derive from MCC ${ }^{43}$. Further the absence of the neuroendocrine marker chromogranin A and synaptophysin can be explained by the expression of REST in these cells. In the context of the unknown cellular origin of MCC, it would be interesting to get more knowledge about the regulation of REST in MCC.

In this context we also assessed the methylation status of relevant REST promoter CpG islands. It has been shown previously in SCLC cells that REST expression is regulated by the CpG island methylation of the REST promoter. CpG1 and CpG3 islands were stronger methylated in SCLC REST-low expressing cell lines 32 (Figure 5). In our study, we did not observe methylation of CpG1 and CpG3 islands of the REST promoter in MCPyV-positive and -negative MCC cell lines. Moreover, the 5-aza-2'-dC treatment of the REST negative cell lines did not lead to REST expression which confirms the MSPs. Thus, the loss of REST expression in MCC is most likely not due to REST promoter methylation.

Notably, MCPyV-positive WaGa cells revealed an up to 10-fold higher expression of chromogranin A compared to the other MCPyV-positive MCC cell lines which was paralleled by also a 3-fold higher abundance of MCPyV T antigens. This might possibly hint to a direct or indirect activation of MCPyV $\mathrm{T}$ antigens on chromogranin A expression.

REST is not only negatively regulating the gene expression of chromogranin $A$ and synaptophysin but also the expression of miR-9. Indeed, we could show that miR-9 and miR-9* are abundantly present in REST-negative MCPyV-positive 
MCC cell lines. Recently, miR-9 was found to be upregulated in 20 MCC tissues compared to cutaneous lesions of melanoma, squamous cell carcinoma, and basal cell carcinoma ${ }^{25}$. In cervical carcinoma and oropharyngeal squamous cell carcinoma it was shown that miR-9 is activated by HPV 26,44 . It is tempting to speculate that a comparable mechanism might be applicable to MCPyV and miR9 expression in MCC. In the context of the unknown cellular origin of MCC the expression of miR-9 and the absence of REST might be the first step towards understanding the regulation of neuroendocrine gene expression in MCC and might help to identify the cellular ancestry of MCC 13,14 .

\section{CONCLUSION}

MCCs reveal a unique expression pattern of the neuroendocrine key regulator genes REST, ASCL1 and NeuroD1, which is characterized by the lack of REST and ASCL1 expression and the presence of NeuroD1. The absence of REST expression in MCC and in MCPyV-positive MCC cell lines, in combination with REST expression in MCPyV-negative cell lines points to an important role of the MCPyV in the regulation of REST expression in MCC. Our data might provide the basis of MCPyV-related neuroendocrine gene expression in MCC. 


\section{REFERENCES}

1. Calder KB, Smoller BR. New Insights Into Merkel Cell Carcinoma. Adv Anat Pathol. 2010;17 (3):155-161.

2. Albores-Saavedra J, Batich K, Chable-Montero F, Sagy N, Schwartz AM, Henson DE. Merkel cell carcinoma demographics, morphology, and survival based on 3870 cases: a population based study. Journal of Cutaneous Pathology. 2010;37(1):20-27.

3. Hughes MP, Hardee ME, Cornelius LA, Hutchins LF, Becker JC, Gao L. Merkel Cell Carcinoma: Epidemiology, Target, and Therapy. Current Dermatology Reports. 2014;3(1):46-53.

4. $\quad$ Feng $\mathrm{H}$, Shuda M, Chang $\mathrm{Y}$, Moore PS. Clonal Integration of a Polyomavirus in Human Merkel Cell Carcinoma. Science (New York, NY). 2008;319(5866):1096-1100.

5. Kassem A, Schopflin A, Diaz C, et al. Frequent detection of Merkel cell polyomavirus in human Merkel cell carcinomas and identification of a unique deletion in the VP1 gene. Cancer Res. 2008;68(13):5009-5013.

6. Becker JC, Houben R, Ugurel S, Trefzer U, Pföhler C, Schrama D. MC Polyomavirus Is Frequently Present in Merkel Cell Carcinoma of European Patients. Journal of Investigative Dermatology. 2009;129(1):248-250.

7. Houben R, Shuda M, Weinkam R, et al. Merkel cell polyomavirus-infected Merkel cell carcinoma cells require expression of viral $T$ antigens. Journal of virology. 2010;84(14):7064-7072.

8. Schadendorf D, Lebbé C, zur Hausen A, et al. Merkel cell carcinoma: Epidemiology, prognosis, therapy and unmet medical needs. European Journal of Cancer. 2017;71:53-69.

9. Nghiem PT, Bhatia S, Lipson EJ, et al. PD-1 Blockade with Pembrolizumab in Advanced Merkel-Cell Carcinoma. New England Journal of Medicine. 2016;374(26):2542-2552.

10. Kaufman HL, Russell J, Hamid O, et al. Avelumab in patients with chemotherapy-refractory metastatic Merkel cell carcinoma: a multicentre, single-group, open-label, phase 2 trial. The Lancet Oncology. 2016;17(10):1374-1385.

11. Tilling T, Moll I. Which Are the Cells of Origin in Merkel Cell Carcinoma? Journal of Skin Cancer. 2012;2012:6.

12. Jankowski M, Kopinski P, Schwartz R, Czajkowski R. Merkel cell carcinoma: is this a true carcinoma? Experimental Dermatology. 2014;23(11):792-794.

13. zur Hausen A, Rennspiess D, Winnepenninckx V, Speel E-J, Kurz AK. Early B-Cell Differentiation in Merkel Cell Carcinomas: Clues to Cellular Ancestry. Cancer Research. 2013;73(16):4982-4987.

14. Sauer CM, Haugg AM, Chteinberg E, et al. Reviewing the current evidence supporting early B-cells as the cellular origin of Merkel cell carcinoma. Crit Rev Oncol Hematol. 2017;116:99105.

15. JA1 C, J T-R, S K, et al. REST: a mammalian silencer protein that restricts sodium channel gene expression to neurons. Cell. 1995;80(6):949-957.

16. Westbrook TF, Hu G, Ang XL, et al. SCF( $\beta$ TRCP)Controls Oncogenic Transformation and Neural Differentiation Through REST Degradation. Nature. 2008;452(7185):370-374.

17. Ooi L, Wood IC. Chromatin crosstalk in development and disease: lessons from REST. Nat Rev Genet. 2007;8(7):544-554.

18. Lietz $M$, Hohl M, Thiel G. RE-1 silencing transcription factor (REST) regulates human synaptophysin gene transcription through an intronic sequence-specific DNA-binding site. European Journal of Biochemistry. 2003;270(1):2-9.

19. Kashiwagi K, Ishii J, Sakaeda M, et al. Differences of molecular expression mechanisms among neural cell adhesion molecule 1 , synaptophysin, and chromogranin A in lung cancer cells. Pathology International. 2012;62(4):232-245.

20. Conti L, Crisafulli L, Caldera V, et al. REST Controls Self-Renewal and Tumorigenic Competence of Human Glioblastoma Cells. PLoS ONE. 2012;7(6):e38486.

21. Fuller GN, Su X, Price RE, et al. Many human medulloblastoma tumors overexpress repressor element-1 silencing transcription (REST)/neuron-restrictive silencer factor, which can be functionally countered by REST-VP16. Molecular Cancer Therapeutics. 2005;4(3):343-349.

22. Westbrook TF, Martin ES, Schlabach MR, et al. A Genetic Screen for Candidate Tumor Suppressors Identifies REST. Cell. 2005;121(6):837-848.

23. Coolen M, Katz S, Bally-Cuif L. miR-9: a versatile regulator of neurogenesis. Frontiers in Cellular Neuroscience. 2013;7:220.

24. Packer AN, Xing Y, Harper SQ, Jones L, Davidson BL. The bi-functional microRNA miR9/miR-9* regulates REST and CoREST and is down-regulated in Huntington's Disease. The 
Journal of neuroscience : the official journal of the Society for Neuroscience. 2008;28(53):14341-14346.

25. Ning MS, Kim AS, Prasad N, Levy SE, Zhang H, Andl T. Characterization of the Merkel Cell Carcinoma miRNome. Journal of Skin Cancer. 2014;2014:9.

26. Liu W, Gao G, Hu X, et al. Activation of miR-9 by human papillomavirus in cervical cancer. Oncotarget. 2014;5(22):11620-11630.

27. Gu H, Roizman B. Herpes simplex virus-infected cell protein 0 blocks the silencing of viral DNA by dissociating histone deacetylases from the CoREST-REST complex. Proceedings of the National Academy of Sciences of the United States of America. 2007;104(43):1713417139.

28. Gu H, Liang Y, Mandel G, Roizman B. Components of the REST/CoREST/histone deacetylase repressor complex are disrupted, modified, and translocated in HSV-1-infected cells. Proceedings of the National Academy of Sciences of the United States of America. 2005;102(21):7571-7576.

29. Guan H, Ricciardi RP. Transformation by E1A Oncoprotein Involves Ubiquitin-Mediated Proteolysis of the Neuronal and Tumor Repressor REST in the Nucleus. Journal of Virology. 2012;86(10):5594-5602.

30. Altree-Tacha D, Tyrrell J, Li F. mASH1 is Highly Specific for Neuroendocrine Carcinomas: An Immunohistochemical Evaluation on Normal and Various Neoplastic Tissues. Archives of Pathology \& Laboratory Medicine. 2017;141(2):288-292.

31. Kassem A, Schöpflin A, Diaz C, et al. Frequent Detection of Merkel Cell Polyomavirus in Human Merkel Cell Carcinomas and Identification of a Unique Deletion in the <em>VP1</em> Gene. Cancer Research. 2008;68(13):5009-5013.

32. Kreisler A, Strissel PL, Strick R, Neumann SB, Schumacher U, Becker CM. Regulation of the NRSF/REST gene by methylation and CREB affects the cellular phenotype of small-cell lung cancer. Oncogene. 2010;29(43):5828-5838.

33. Takai D, Jones PA. Comprehensive analysis of $\mathrm{CpG}$ islands in human chromosomes 21 and 22. Proceedings of the National Academy of Sciences of the United States of America. 2002;99(6):3740-3745.

34. Coulson JM, Edgson JL, Woll PJ, Quinn JP. A Splice Variant of the Neuron-restrictive Silencer Factor Repressor Is Expressed in Small Cell Lung Cancer: A Potential Role in Derepression of Neuroendocrine Genes and a Useful Clinical Marker. Cancer Research. 2000;60(7):1840.

35. Chen G-L, Miller GM. Extensive Alternative Splicing of the Repressor Element Silencing Transcription Factor Linked to Cancer. PLoS ONE. 2013;8(4):e62217.

36. Borromeo Mark D, Savage Trisha K, Kollipara Rahul K, et al. ASCL1 and NEUROD1 Reveal Heterogeneity in Pulmonary Neuroendocrine Tumors and Regulate Distinct Genetic Programs. Cell Reports. 2016;16(5):1259-1272.

37. Yazawa T. Recent advances in histogenesis research of lung neuroendocrine cancers: Evidence obtained from functional analyses of primitive neural/neuroendocrine cell-specific transcription factors. Pathology International. 2015;65(6):277-285.

38. Osborne JK, Larsen JE, Shields MD, et al. NeuroD1 regulates survival and migration of neuroendocrine lung carcinomas via signaling molecules TrkB and NCAM. Proceedings of the National Academy of Sciences of the United States of America. 2013;110(16):65246529.

39. Ralston J, Chiriboga L, Nonaka D. MASH1: a useful marker in differentiating pulmonary small cell carcinoma from Merkel cell carcinoma. Mod Pathol. 2008;21(11):1357-1362.

40. Lewis JS, Jr., Duncavage E, Klonowski PW. Oral cavity neuroendocrine carcinoma: a comparison study with cutaneous Merkel cell carcinoma and other mucosal head and neck neuroendocrine carcinomas. Oral Surgery, Oral Medicine, Oral Pathology and Oral Radiology. 2010;110(2):209-217.

41. Wagoner MP, Gunsalus KTW, Schoenike B, Richardson AL, Friedl A, Roopra A. The Transcription Factor REST Is Lost in Aggressive Breast Cancer. PLoS Genetics. 2010;6(6):e1000979.

42. Osborne JK, Larsen JE, Gonzales JX, et al. NeuroD1 regulation of migration accompanies the differential sensitivity of neuroendocrine carcinomas to TrkB inhibition. Oncogenesis. 2013;2:e63.

43. Daily K, Coxon A, Williams JS, et al. Assessment of Cancer Cell Line Representativeness using Microarrays for Merkel Cell Carcinoma. The Journal of investigative dermatology. 2015;135(4):1138-1146.

44. Gao G, Gay HA, Chernock RD, et al. A microRNA expression signature for the prognosis of oropharyngeal squamous cell carcinoma. Cancer. 2013;119(1):72-80. 
3 | NEUROENDOCRINE KEY REGULATOR GENE EXPRESSION

\section{SUPPLEMENTAL MATERIAL}

Table S1: Summary of the IHC analysis for REST, ASCL1 and NeuroD1 in MCC cell lines and the B-ALL cell line REH,

\begin{tabular}{|c|c|c|c|c|c|c|c|}
\hline ID & $\begin{array}{l}\text { cancer } \\
\text { type }\end{array}$ & MCPyV & REST & chromogranin A & synaptophysin & ASCL1 & NeuroD1 \\
\hline \multicolumn{8}{|c|}{ Cell lines } \\
\hline MKL-1 & MCC & pos. & - & +++ & +++ & - & +++ \\
\hline MKL-2 & MCC & pos. & - & +++ & & - & +++ \\
\hline MCC13 & MCC & neg. & +++ & - & - & - & +++ \\
\hline MCC26 & MCC & neg. & +++ & - & - & - & +++ \\
\hline WaGa & MCC & pos. & - & +++ & +++ & - & +++ \\
\hline Рета & MCC & pos. & - & +++ & +++ & - & +++ \\
\hline BroLi & MCC & pos. & - & ++ & +++ & - & +++ \\
\hline MS-1 & MCC & pos. & - & +++ & +++ & - & +++ \\
\hline REH & B-ALL & neg. & +++ & - & - & - & +++ \\
\hline
\end{tabular}

Used abbreviation: pos. = positive, neg. = negative, $-=$ no expression, $+=$ weak expression, $++=$ moderate expression, $+++=$ strong expression . 
Table S2: Used primer for all PCR applications

\begin{tabular}{|c|c|c|c|c|}
\hline Primer & Sequence $5^{\prime} \rightarrow 3^{\prime} \mathrm{fw}$ primer & Sequence $5^{\prime} \rightarrow 3^{\prime}$ 'rv primer & Amplicon bp & $\operatorname{Tm}\left({ }^{\circ} \mathrm{C}\right)$ \\
\hline R1 & GAAGGACTTGAAGAGTCTGCTG & CCTTGGAGAAATCTCCCTCT & 370 & $56.9 / 55.9$ \\
\hline R3 & GCCATGAAGGAAGTGACCTA & GCAATCTTAAAAGGTTGTCTGC & 347 & $56.2 / 56.7$ \\
\hline REST & GGGTGAAATGTCAATTCCGGG & GTCTCTACGAAAATGCGGCG & 627 & $57.6 / 58.3$ \\
\hline REST qPCR & GTCCTTACTCAAGTTCTCAGAAGAC & GAACCTGTCTTGCATGGCGG & 164 & $61.3 / 61.4$ \\
\hline chromogranin A & TCCCTGTGAACAGCCCTATGAATAA & AAAGTGTGTCGGAGATGACCTCAA & 78 & 61 \\
\hline synaptophysin & TGCGCTAGAGCATTCTGGG & GCTTAAAGCCTCGCCCCTTCT & 74 & 61 \\
\hline MCPyV LT & $\begin{array}{l}\text { GAGGATTCAGCTTCGGGAAGGCATAC } \\
\text { G }\end{array}$ & GGGCTCCCCTGGATGCATTGGAG & 140 & 67 \\
\hline MCPyV sT & CAGAGGTCCTGGGTGCATGCTTAAGC & GCAAAAACACTCTCCCCACGTCAGAC & 149 & 67 \\
\hline CpG1 M & ATTGGGTGCGCGGCGTAGC & CCCTACCGTCTCGACTACGACAACCG & 148 & $58 / 60$ \\
\hline CpG1 U & $\begin{array}{l}\text { TGGTGTGGGATTGGGTGTGTGGTGTA } \\
\text { GT }\end{array}$ & ТСАСССТАССАТСТСААСТАСААСААССА & 150 & $61 / 58$ \\
\hline CpG3 M & GGCGAGAGGAAGCGAGAGCGTTC & CACCAACGCCTACCTCGACGACG & 116 & $60 / 60$ \\
\hline CpG3U & $\begin{array}{l}\text { GAGGTGAGAGGAAGTGAGAGTGTTTG } \\
\text { AGT }\end{array}$ & TACCACCAACACCTACCTCAACAACAACA & 118 & $58 / 58$ \\
\hline$\beta$-actin & AGAGCTACGAGCTGCCTGAC & AGCACTGTGTTGGCGTACAG & 184 & $61 / 59$ \\
\hline GAPDH & AGGGCTGCTTTTAACTCTGGT & CCCCACTTGATTTTGGAGGGA & 164 & 58 \\
\hline
\end{tabular}


A

Homo sapiens truncated neuron restrictive silencer factor isoform (REST) mRNA, partial cds GenBank AF228045

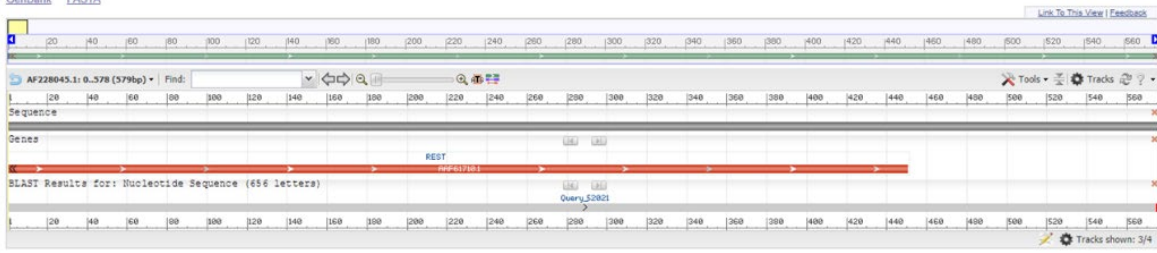

B

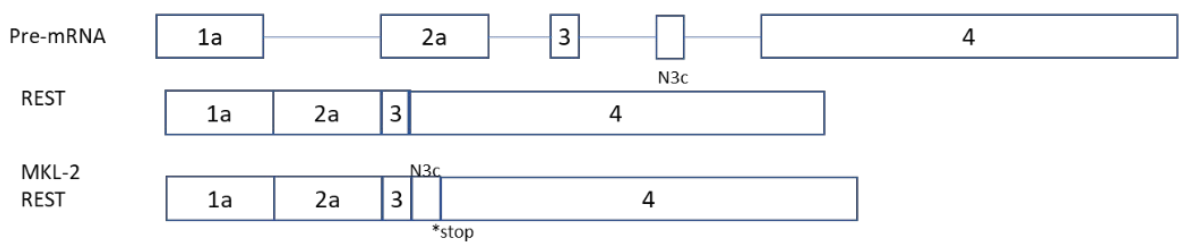

Figure S1: Blast of MKL-2 REST sequence. NCBI blast has revealed the identity of the truncated REST sequence which was detected in SCLC (A). The exons of the nontruncated and truncated splice variant are shown (B).

A

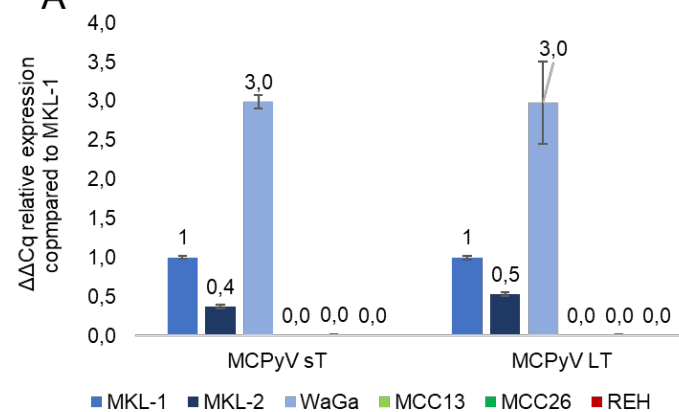

B

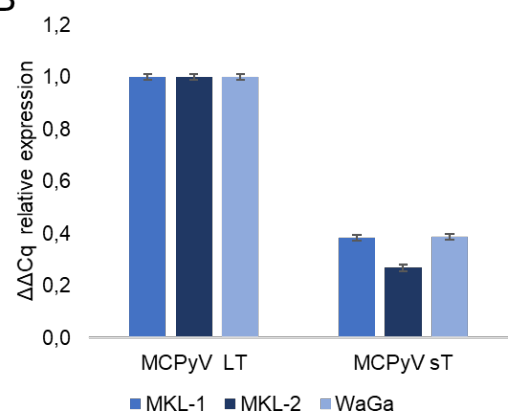

Figure S2: MCPyV expression level in all used cell lines. The expression of MCPyV sT and LT were analysed by means of a qRT-PCR. The cq values were normalized to MKL- 1 and the sd of $n=2$ is shown. The MCPyV-positive MCC cell lines reveal a different expression pattern of MCPyV T antigens whereas the distribution of LT and ST is comparable (A). In addition, the relative concentration of $L T$ to sT were compared in B. ST is up to $60 \%$ less expressed compared to LT 


\section{UNPUPLISHED SUPPLEMENTAL DATA}

A

B

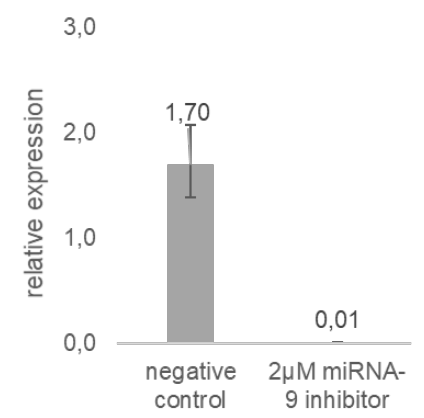

negative control
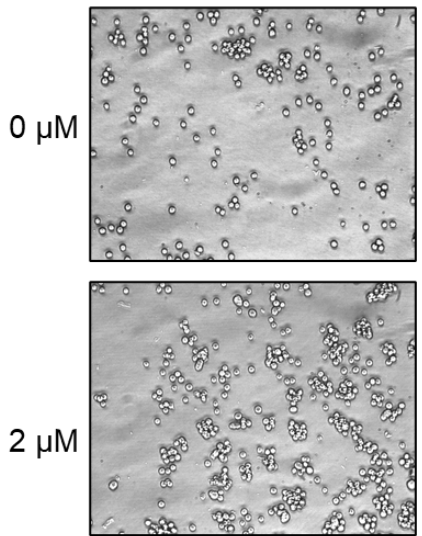

miRNA-9 inhibitor
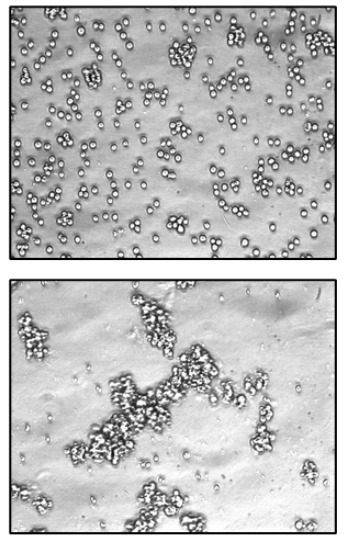

C

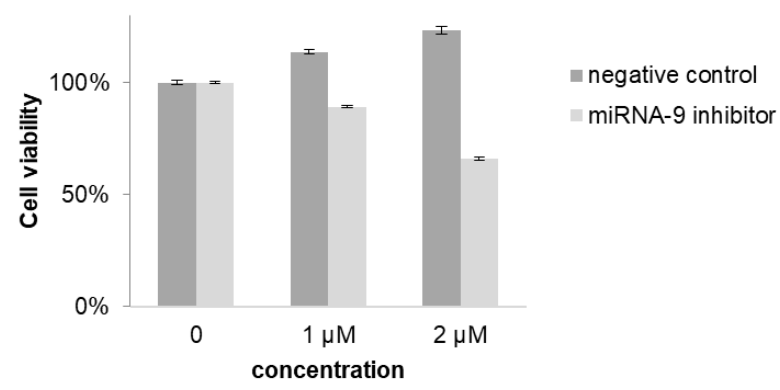

Figure S3: Inhibition of miRNA-9 expression induce morphological changes and reduced cell viability in the Merkel cell carcinoma cell line WaGa

WaGa cells were treated with $1 \mu \mathrm{M}$ and $2 \mu \mathrm{M}$ of the PNAs ${ }^{\mathrm{TM}}$ miRNA inhibitor (Panagene, South Korea) negative control (nonsense RNA-sequence) and PNAs ${ }^{\mathrm{TM}}$ miRNA-9 inhibitor for $96 \mathrm{~h}$. In $\mathbf{A}$ the effective inhibition of the miRNA-9 expression in WaGa cells is shown which was assessed by qRT-PCR. In B the microphotographs were taken after $72 \mathrm{~h}$ incubation for the different concentrations of the miRNA inhibitors is illustrated. In $\mathbf{C}$ the assessment of the effect of the negative control as well as the miRNA9 inhibitor on the cell viability of WaGa cells is shown which was performed using the XTT-assay after 96h incubation time. 

The previous chapters illustrated that MCC cells have a significant decelerated younger DNAmAge compared to the chronological age and that MCC is negative for the neuroendocrine transcription factor REST. Thus, we concluded our data indicate that MCC cells have a stem cell activity and the requirements for the MCC neuroendocrine phenotype. Regarding the elusive cellular origin, we reviewed in chapter 3 the current main cellular origin hypotheses of MCC emphasising the early $B$ cells as putative cellular origin.

\section{Contribution to the manuscript (Chapter 4):}

Emil Chteinberg $(E C)$ contributed to the data compilation and writing of this review. Christopher M. Sauer, Anke Haugg and Axel zur Hausen (AzH) wrote this manuscript. Ernst-Jan Speel, Véronique Winnepenninckx and Jürgen Becker critically discussed and corrected the manuscript including the figures. As principal investigator AzH designed the review together with Anna Kordelia Kurz. EC and Dorit Rennspiess were involved in the design of the figures. The underlying manuscript was part of Christopher M. Sauers' doctoral thesis ("Assessing the neuroendocrine gene expression and regulation of Merkel cell carcinoma") to get the doctoral degree Dr. med. from the RWTH University Aachen, Aachen, Germany. 

CHAPTER 4

\section{REVIEWING THE CURRENT EVIDENCE SUPPORTING EARLY B-CELLS AS THE CELLULAR ORIGIN OF MERKEL CELL CARCINOMA}

CHRISTOPHER MARTIN SAUER*, ANKE HAUGG*, EMIL CHTEINBERG, DORIT RENNSPIESS, VÉRONIQUE WINNEPENNINCKX, ERNST-JAN SPEEL, JÜRGEN BECKER, ANNA KORDELIA KURZ, AXEL ZUR HAUSEN

${ }^{*}$ CONTRIBUTED EQUALLY

-PUBLISHED-

CRITICAL REVIEWS IN ONCOLOLOGY/ HEMATOLOLOGY, 116, 99105, AUG 2017 



\begin{abstract}
Merkel cell carcinoma (MCC) is a highly malignant skin cancer characterized by early metastases and poor survival. Although MCC is a rare malignancy, its incidence is rapidly increasing in the U.S. and Europe. The discovery of the Merkel cell polyomavirus (MCPyV) has enormously impacted our understanding of its etiopathogenesis and biology. MCCs are characterized by trilinear differentiation, comprising the expression of neuroendocrine, epithelial, and B-lymphoid lineage markers. To date, it is generally accepted that the initial assumption of MCC originating from Merkel cells (MCs) is unlikely. This is owed to their post-mitotic character, absence of MCPyV in MCs and discrepant protein expression pattern in comparison to MCC. Evidence from mouse models suggests that epidermal/dermal stem cells might be of cellular origin in MCC. The recently formulated hypothesis of MCC originating from early B-cells is based on morphology, the consistent expression of early B-cell lineage markers and the finding of clonal immunoglobulin chain rearrangement in MCC cells. In this review we elaborate on the cellular ancestry of MCC, the identification of which could pave the way for novel and more effective therapeutic regimens.
\end{abstract}




\section{INTRODUCTION}

Merkel cell carcinoma (MCC) has originally been described as "trabecular carcinoma of the skin"1. MCC mainly occurs in elderly or immunosuppressed patients and is associated with poor clinical outcome ${ }^{2}$. Although the incidence of MCC is low, a steady rise has been observed throughout the last decades ${ }^{3}$. Histologically, MCC reveals distinctive subtypes, which are the intermediate (approx. 90\%), the small cell and the trabecular type of which all reveal cytokeratin 20 (CK20), neural cell adhesion molecule (NCAM/CD56), chromogranin A and synaptophysin expression ${ }^{4}$. Based on this, MCC has been believed to be a neuroendocrine carcinoma deriving from Merkel cells $(M C)^{5}$.

The discovery of the Merkel cell polyomavirus (MCPyV) significantly contributed to the understanding of the etiopathogenesis of $\mathrm{MCC}^{6}$. The clonal integration of the viral genome in MCC, tumour specific oncogenic mutations within the large $T$ antigen (LTAg) of MCPyV, the dependence of MCC cells on the expression of the LTAg and the presence of MCPyV-DNA in approximately $80 \% \mathrm{MCC}_{\text {cases }}{ }^{6}$, led to the classification of MCPyV as a class $2 \mathrm{~A}$ carcinogen by the International Agency on Research of Cancer ${ }^{7}$. Of note, MCPyV-negative MCCs have a different mutational landscape and are mostly caused by sun light exposure. ${ }^{8}$ The current treatment is surgical excision of the primary tumour and the involved lymph nodes in combination with adjuvant radiotherapy ${ }^{9}$. Nevertheless, even aggressive local treatment results in a poor control of the disease, limiting the median survival rate of MCC to 29 months ${ }^{10}$. Over decades, the favoured theory was that MCC originates from MCs ${ }^{1}$. 
Subsequent to the formulation of the epidermal/dermal stem cell hypotheses as possible cells of origin of MCCs the controversy has intensified ${ }^{11}$. Based on the consistent expression of early B-cell antigens in MCCs, the hypothesis that MCCs derive from pre/pro B-cells was formulated ${ }^{12}$. Hereinafter, the current hypotheses on the cellular origin of MCC are comprehensively reviewed. The identification of the cellular ancestors of MCC will contribute to establish more effective treatment regimens.

\section{THE "OUT OF MERKEL CELL” HYPOTHESIS}

Based on clinical characteristics, histological studies and the ultra-structural proof of neuroendocrine granules, MCs were considered to be the source of MCC ${ }^{13}$. This theory was supported by the immunohistochemical finding that MCs and MCCs share the expression of CK20 and CD56 ${ }^{14}$. The typical perinuclear dot-like expression pattern of CK20 in $82 \%$ of MCC is considered almost pathognomonic for MCC diagnosis. In addition, neurofilament expression in $90 \%$ of MCCs has also served as a distinctive marker for MCC ${ }^{15}$.

The arrangement of filaments, such as CK20 and neurofilament, discloses important differences between MCCs and MCs. While the cytoskeleton is arranged diffusely in MCs, it is arranged in plaque-like aggregates in MCC ${ }^{16}$, which is of interest, since it suggests an alternative activation. Noteworthy, many genes commonly expressed in MCCs, including KIT, PAX5, SCF and BCL-2, are absent in MCs, which opposes the "out of Merkel cell hypothesis".

Reasonable concerns have been rising during the past years, doubting the hypothesis that MCC derive from MCs. Of importance, no proliferative activity is detected in MCs as tested either in fetal or adult skin, strongly indicating that MCs are post-mitotic ${ }^{17}$. In addition, transgenic mice models revealed that $\mathrm{MC}$ homeostasis is maintained by differentiating epidermal progenitors and not by proliferating differentiated MCs ${ }^{18}$. Considering that the restoration of the proliferative potential is critical for cells to become cells of origin of cancer, postmitotic MCs are unlikely to give rise to MCC 16,19 . Further evidence challenging MCs as the cell of origin of MCC relies on the localization of MCC: While MCs are located within the basal layer of the epidermis ${ }^{20}$, 
MCCs are generally localized in the dermis or subcutis with spatial distance to the epidermis or to epithelial structures of skin appendages (Fig. 1). Only in about 3$9 \%$ of cases, MCCs reveal contact to the epidermis.

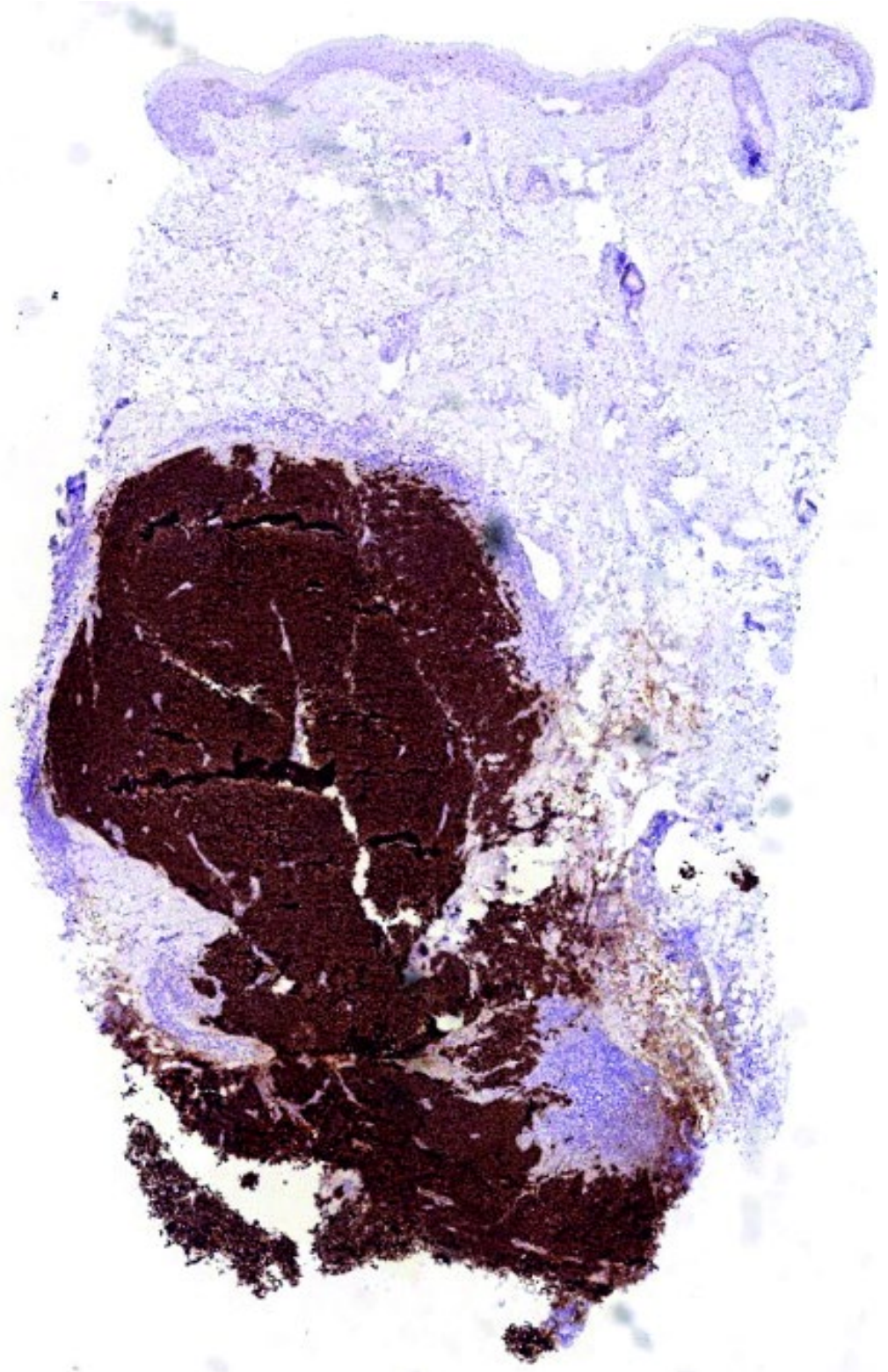

Figure 1: Cytokeratin 20 (CK20) staining of Merkel cell carcinoma (MCC). The MCC cells reveal strong brown staining for CK20 expression. The positive cells are located in the dermis or subcutis of an intermediate type of MCC. The positive stained Merkel cells (MC) are seen in the epidermis. 
Moreover, the cytonuclear morphology of the different subtypes of MCC has to be taken into consideration. The intermediate type of MCCs is morphologically almost indistinguishable from blastic lymphoid malignancies and other small blue round cell tumours ${ }^{21}$. If one MCC subtype was considered to derive from MCs at all, it would be the trabecular type, which in contrast to the intermediate and small cell type of MCC, is a rather well differentiated skin tumour. It appears counterintuitive that fully differentiated cells, including MCs, give rise to three very divergent histomorphological phenotypes.

\section{THE “EPIDERMAL/ DERMAL STEM CELL” HYPOTHESIS}

Lately, research interest shifted to epidermal stem cells as potential cells of origin of MCC. According to this, MCC is considered to be the consequence of a malignant transformation of an epidermal stem cell. Since epidermal stem cells give rise to different lineages, this pathogenic process could explain the divergent histological phenotypes of MCCs.

Testing 13 cases of MCC, Lemasson et al. reported strong cytokeratin 14 (CK14)positivity by IHC. Since CK14 derives from the basal epidermal layer, which also contains epidermal stem cells, the authors reasoned that MCCs may arise from this layer. ${ }^{11}$

The frequent expression of neuronal cell markers such as neurofilament, synaptophysin and neuron-specific enolase (NSE) in MCC, renders the dermal stem cell an intriguing candidate for the cellular origin of MCC ${ }^{22}$. Oncogenic mutations of dermal stem cells, which originate from the embryonic neural crest 23 , could explain the expression of these neuronal cell markers. Furthermore, expression of the transcription factor SOX-2, a neural crest-derived stem cell factor ${ }^{24}$, was detected in all cases of a small series of MCCs $(\mathrm{N}=9)$, with a majority (5/9) even showing a strong nuclear staining. On the contrary, SOX-2 has recently also been found to be expressed in epidermal progenitors of murine tongues ${ }^{25}$, thereby suggesting that SOX-2 expression may be more widespread than previously assumed.

Due to their dermal location and their broad differentiation, a third stem cell population, skin-derived precursors, can be considered to be a possible cell of origin of $\mathrm{MCC}^{23}$. Evidence from mouse models shows that MCPyV T-antigen 
expression results in neoplastic features, such as hyperplasia and increased proliferation ${ }^{26,27}$. In another mice model, Keratin 14-mediated Cre recombinase expression induced expression of MCPyV $\mathrm{T}$ antigens in stratified squamous epithelial cells and Merkel cells of the skin epidermis. Again, features for neoplastic progression could be found, however no malignancy, including MCC, could be induced ${ }^{27,28}$. To this date, MCPyV-DNA could neither be detected in (epi-)dermal stem cells nor skin-derived precursor cells.

\section{THE “DERMAL FIBROBLAST” HYPOTHESIS}

Recently, Liu et al. isolated human foreskin cells and in vitro separately infected the different cells with a MCPyV-GFP pseudovirus and control. Using this experimental approach, the authors identified human dermal fibroblasts - in which productive viral transcription and replication was observed - to be the major target of MCPyV-infection. Using a cell culture model, Liu et al. showed that MCPyVinfection is facilitated by matrix metalloproteinase and by the ß-catenin/WNT pathway. This signalling cascade has previously been shown to be stimulated upon UV light exposure and by aging, which are two major risk factors for the development of MCC ${ }^{29}$. Although MCPyV-DNA is normally not detected in human dermal fibroblasts adjacent to MCPyV-positive MCC by diverse molecular techniques, i.e. DNA-PCR and DNA FISH, these are very interesting findings possibly pointing to the mode of MCPyV-infection of the skin.

\section{THE “PRE/PRO B-CELL” HYPOTHESIS}

The frequent expression of B-lymphoid lineage markers in MCC and its sometimes difficult histological discrimination from lymphoid malignancies 21 contributed to the formulation of the hypothesis that MCC could originate from pre/pro B-cells ${ }^{12}$. According to this, the stage of early B-cell development in which a MCPyV infection occurs, could determine the phenotype and B-cell expression profile of the later MCC. The pre/pro B-cell as the cellular origin of MCC would explain why most MCCs are located within the dermis and subcutis ${ }^{30}$, without revealing contact to the epidermis, where MCs or epidermal stem cells reside (Fig. 1). To this end, the minority of histopathological grossly divergent, MCPyVnegative cases with epidermal dysplasia, such as those recently described by 
Martin et al. ${ }^{31}$, would not be considered to derive from pre/pro B-cells, but represent a distinct subset of MCCs, possible deriving from epidermal or dermal stem cells. In the paragraphs below, an overview of the most decisive steps in early B-cell development is given.

B-cell development starts with pluripotent hematopoietic stem cells (HSC) that differentiate into a pre/pro B-cell (Fig. 2). These are irreversibly committed to the B-cell lineage by expression of early B-cell factor 1 (EBF-1) and E2A, both synergistically cross-regulating the paired-box gene 5 (PAX5) ${ }^{32}$. Notably, their absence results in a failure to develop mature B-lymphocytes ${ }^{33}$.

\begin{tabular}{|c|c|c|c|c|c|c|}
\hline & CLP & Pre-/pro-B cell & Early pro-B cell & Late pro-B cell & Large pre-B cell & Small pre-B cell \\
\hline \multirow{10}{*}{ 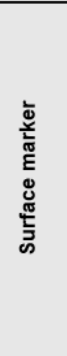 } & KITlow & KIT- & $\mathrm{KIT}^{+}$ & KIT- & KIT- & KIT- \\
\hline & B220- & $\mathrm{B} 220^{+}$ & $\mathrm{B} 220^{+}$ & $\mathrm{B} 220^{+}$ & $\mathrm{B} 220^{+}$ & $\mathrm{B} 220^{+}$ \\
\hline & CD19- & CD19+ & CD19+ & $\mathrm{CD}_{19}{ }^{+}$ & CD19+ & $\mathrm{CD}_{19}{ }^{+}$ \\
\hline & CD43- & $\mathrm{CD}_{43}{ }^{+}$ & $\mathrm{CD}_{43}{ }^{+}$ & $\mathrm{CD}_{43}{ }^{+}$ & CD43- & CD43- \\
\hline & & & CD10+ & CD10+ & & \\
\hline & $\mathrm{CD}_{3} 4^{+}$ & $\mathrm{CD}_{34}{ }^{+}$ & $\mathrm{CD}_{34}{ }^{+}$ & & & \\
\hline & & & $\mathrm{CD}_{38}+$ & CD38+ & $\mathrm{CD}^{2+} 8^{+}$ & $\mathrm{CD}_{3} 8^{+}$ \\
\hline & & & & $\mathrm{CD} 20^{+}$ & $\mathrm{CD} 20^{+}$ & $\mathrm{CD} 20^{+}$ \\
\hline & & & & $\mathrm{CD} 40^{+}$ & $\mathrm{CD} 40^{+}$ & $\mathrm{CD} 40^{+}$ \\
\hline & & & & & $\mu$-chain & $\mu$-chain \\
\hline \multirow{6}{*}{ 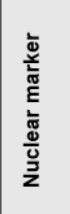 } & & TdT & TdT & $\mathrm{TdT}$ & & $\mathrm{TdT}$ \\
\hline & & RAG-1/-2 & RAG-1/-2 & RAG-1/-2 & & RAG-1/-2 \\
\hline & & PAX -5 & PAX -5 & PAX-5 & PAX-5 & PAX-5 \\
\hline & & EBF-1 & EBF-1 & EBF-1 & EBF-1 & EBF-1 \\
\hline & & E2A & E2A & E2A & E2A & E2A \\
\hline & & & SCF & SCF & & \\
\hline \multirow{4}{*}{ 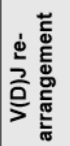 } & $\mathrm{D}_{\mathrm{H}}-\mathrm{J}_{\mathrm{H}}$ & $\mathrm{D}_{\mathrm{H}-\mathrm{J}_{\mathrm{H}}}$ & $\mathrm{D}_{\mathrm{H}-\mathrm{J}_{\mathrm{H}}}$ & $D_{H^{-}} J_{H}$ & $D_{H}-J_{H}$ & $D_{H}-J_{H}$ \\
\hline & & & $\left(D_{H}-D J_{H}\right)$ & $\mathrm{D}_{\mathrm{H}}-\mathrm{DJ} \mathrm{J}_{\mathrm{H}}$ & $\mathrm{D}_{\mathrm{H}}-\mathrm{DJ} \mathrm{H}_{\mathrm{H}}$ & $\mathrm{D}_{\mathrm{H}}-\mathrm{DJ}_{\mathrm{H}}$ \\
\hline & & & & & $V_{L}-J_{L}$ & $V_{L}-J_{L}$ \\
\hline & & & & & $\mathrm{v}_{\mathrm{K}}-\mathrm{J}_{\mathrm{K}} ; \mathrm{v}_{\Lambda}-\mathrm{J}_{\Lambda}$ & $\mathrm{V}_{\mathrm{K}}-\mathrm{J}_{\mathrm{K}} ; \mathrm{V}_{\Lambda}-\mathrm{J}_{\Lambda}$ \\
\hline
\end{tabular}

Figure 2: Overview of the different stages of B-cell development with their respective surface markers ${ }^{34}$, nuclear markers and $V(D) J$ rearrangement. B-cell markers also found in MCCs are highlighted by bold.

Due to the critical role of PAX5, also known as B-cell specific activator protein (BSAP), for B-cell commitment, it is considered to be the guardian of the B-cell lineage ${ }^{35}$. In haematopoiesis, PAX5 expression is B-cell specific and critical for maintaining B-cell function through the whole process of maturation and hereafter 35. On inactivation of PAX5 in vivo, mature B-cells regain the possibility to undergo gene recombination and may even differentiate into macrophages. Interestingly, 
PAX5 expression is commonly deregulated or mutated in B-cell malignancies such as B-cell acute lymphoblastic leukaemia (B-ALL) ${ }^{36}$, B-cell chronic lymphocytic leukaemia (B-CLL), mantle cells lymphoma (MCL), or follicular lymphomas (FLs) ${ }^{37}$. C-KIT, also known as CD117 is another critical factor in early B-cell development. Binding of the C-KIT ligand Stem Cell Factor (SCF) results in the activation of this tyrosine kinase, ultimately promoting survival and proliferation through the RAS/MEK/ERK-signalling pathway ${ }^{38}$.

For a cutaneous malignancy, it is very remarkable that MCCs commonly expresses early B-cell markers. A meta-analysis shows high frequencies with more than $60 \%$ for the TdT and KIT expression and more than $80 \%$ for PAX5 expression in MCC. In three studies, the KIT ligand SCF was detected in $25.0 \%$ of cases. In addition, immunoglobulin expression and rearrangement in MCPyVpositive MCCs has been described. Here, we briefly summarize the previous reports on expression of terminal deoxynucleotidyl transferase (TdT), PAX5, KIT, BCL-2, IgM, IgA and IgG, as well as the Ig lambda and kappa light chain in MCCs (table 1).

Table 1: Summary of different B-lymphocyte markers and their detection frequency in MCC.

\begin{tabular}{|lcccc|}
\hline Marker & positive & Total tested & present & Reference \\
\hline CD56 & 15 & 15 & $100 \%$ & 39 \\
BCL-2 & 15 & 16 & $96 \%$ & 40 \\
PAX5 & 128 & 143 & $89.5 \%$ & $12,41-44$ \\
TdT & 122 & 187 & $65.2 \%$ & $12,41,44-48$ \\
KIT & 204 & 324 & $63 \%$ & $39-41$ \\
SCF & 32 & 128 & $25 \%$ & $49-51$ \\
\hline
\end{tabular}

PAX5 expression is a frequent finding in MCCs. In 89.9\% (24/27) of cases it was recently detected by Kolhe et al. ${ }^{41}$. This was confirmed by Mhawech-Fauceglia et al. $(70.6 \%, 24 / 34)^{43}$. We found PAX5 expression in all $(\mathrm{N}=21)$ tested MCCs ${ }^{12}$, which is in concordance with another recent study $(100 \%, 30 / 30){ }^{44}$. Overall PAX5 is detected in $89.5 \%(128 / 143)$ of MCCs by immunohistochemistry (Table 1$)$. 
TdT expression has been identified as a potential diagnostic pitfall in the discrimination between MCC and lymphoblastic hematological malignancies ${ }^{45,46}$. Sur et al. detected TdT in 8 out of 15 MCCs ${ }^{46}$, while in two other studies a prevalence of $73 \%$ and $78 \%{ }^{41,45}$ was reported. In a larger analysis, $70 \%(28 / 40)$ of the analyzed MCCs were found to be TdT positive ${ }^{47}$. We observed TdT expression in $76.2 \%(16 / 21)$ of MCCs ${ }^{12}$. Interestingly, TdT expression is significantly correlated with the presence of MCPyV ${ }^{48}$. A meta-analysis (table 1) establishes that TdT is expressed in 65\% (122/187) of all MCCs.

Published data on the expression of $\mathrm{Ig}$ in MCC is sparse. Van Gele et al. performed gene-expression profiling of classical (MCPyV-positive) MCC cell lines and variant (MCPyV-negative) MCC cell lines. Hereby, the expression of Membrane-bound and secreted immunoglobulin gamma heavy chain (lgHG3) in the classical MCC cell lines was 100-fold higher as compared to the variant MCC cell lines. Importantly, IgHG3 expression was the single most predictive gene for differentiating classical and variant MCCs ${ }^{52}$. In another transcriptome-wide study of 35 primary MCCs, Paulson found IgJ and Ig-kappa constant mRNA to be significantly up regulated in MCCs with a good prognosis ${ }^{53}$. In addition, we recently demonstrated IgA, IgG and IgM expression by immunohistochemistry in the majority of MCC cases. Of note, two MCPyV-positive cases showed clonal $\lg \mathrm{H}$ and Ig kappa rearrangement ${ }^{12}$. A recent study by Murakami et al. confirms this data: Using $\mathrm{IHC}$, one or more of the tested immunoglobulins $(\lg G, \lg \mathrm{A}, \lg \mathrm{M}$, Igk) was expressed in 70\% of MCPyV-positive MCCs (14/20), while none of the MCPyV-negative MCCs expressed any immunoglobulin $(p=0.0003)$. In addition, the authors identified a MCPyV-positive case with monoclonal IgH recombination. 44.

C-KIT expression is frequently described in MCCs, while it is not expressed in MCs ${ }^{54}$. Overall, the meta-analysis of KIT expression in MCC reveals $63 \%$ (204/324) KIT positive MCCs (table 1). Though critical for early B-cell maturation, C-KIT has also been proven to be important in certain non-haematological malignancies, including melanoma. In non-hematologic malignancies, the C-KIT signalling pathway is exploited through mutations and overexpression of c-kit. Contrarily, C-KIT could not be found to harbour functional mutations nor gene amplifications in MCC 55,56 . 
Data on the expression of the C-KIT ligand SCF in MCC is limited to three studies, in which the detection rates vary considerably (9-94\%). While one group reported co-expression of KIT and SCF in 15.6\% (5/32), another group detected it in $75 \%$ of the cases (12/16). The functional relevance of the ligand receptor interaction was subsequently shown in the MCC cell line MCC-1. Exogenous administration of SCF increased proliferation of MCC-1, while blockage of KIT signalling reduced proliferation 57 . In non-hematologic malignancies, activation of the C-KIT signalling pathway is not achieved by autocrine signalling, but by overexpression and functional mutations in c-kit itself. Although this autocrine loop could possibly be a target for MCC therapy, current clinical experience does not provide a clear picture. While one group could show clinical remission, a phase II trial could not prove imatinib to be efficient ${ }^{58}$.

Recently, knockdown of $b c l-2$ in Merkel cell lines has been shown to result in cell death $^{59}$. Importantly, these finding could be phenocopied by the potent pan-BCL2 inhibitor Navitoclax, which led to the induction of apoptosis in 10 out of 11 cell lines.

\section{CONCLUSION}

Although our knowledge of the underlying etiopathogenesis of MCC has changed tremendously with the recent discovery of MCPyV, the cell of origin of MCC still remains to be defined. Initially, the MC was assumed to be the cellular origin of MCC. However, this view has been discarded based on the data summarized in this review. Alternatively, epidermal stem cells and epidermal precursors have been discussed as possible cellular origin of MCC. We suggest that MCC originates from a pre/pro or pre-B-cell, which is mainly based on descriptive data yielded by IHC and also on molecular data ${ }^{12}$. Descriptive data, in combination with molecular analyses, has been successfully used in the identification of the cellular origin of Non-Hodgkin lymphomas. Indeed, the current WHO classification of malignant lymphomas is largely based on this combination of descriptive and molecular data ${ }^{60}$. However, one should be aware of the fact that a possible transformation-related phenotype switch might impact the interpretation of these findings. 
In contrast to MCs, early B-cells hold the capacity to differentiate into different cell types, which is a necessary and important characteristic of tumorigenesis ${ }^{19}$. The combined synthesis of critical early B-cell markers, including TdT, PAX5, KIT and SCF in a majority of MCCs, strongly suggest B-cells as the cellular origin of MCC. Furthermore, preliminary data from our lab also points to the consistent and strong expression of RAG-1 in 81\% (18/22) of MCCs. Molecular data on the expression of Ig transcripts, also in addition to monoclonal Ig gene rearrangement in some cases, further supports the hypothesis that early B-cell constitute the cellular origin of MCC ${ }^{12,44}$. On the other hand, it needs to be noted that Ig expression, though most prominent in B-cells, can also be found in some non-haematological malignancies ${ }^{61}$. According to the B-cell hypothesis, the respective stage of early B-cell development at which the transforming event takes place will affect the phenotype, as well as the protein expression profile.

Moreover, the pre/pro B-cell as the cellular origin also explains why most MCCs are located within the dermis and subcutis, without revealing contact to the epidermis, where MCs or epidermal stem cells resides (Fig. 1). Yet, it is unknown where the putative cell of origin of MCC is infected and transformed by MCPyV. In the case of pre/pro B-cells, it seems most likely that this infection/transformation occurs in the skin or blood. Previously, it has been shown that pre/pro B-cells enter the blood circulation ${ }^{62,63}$. Very recently, we assessed the presence of pre/pro B-cells in sun damaged skin and were able to demonstrate by TDT and PAX5 IHC double staining the presence of circulating pre/pro B-cells in sun damaged skin (unpublished data). These findings help to understand why MCPyV-negative MCCs do carry a genomic UV damage signature and still reveal the consistent expression of early B-cell markers. In addition, it helps to understand why MCC are sometimes found as collision tumours with BCC or SCC of the skin.

Expression of CK20 in MCC is considered to be the signpost of epithelial origin. However, CK20 expression is variable and can be induced in non-epithelial cells. Indeed, Simian virus 40 (SV40), a closely related polyomavirus, is able to induce expression of cytokeratins in non-epithelial cells ${ }^{64}$. In addition, also non-Hodgkin lymphomas and leukaemia can express cytokeratins ${ }^{65}$. Similarly, the expression of NCAM, also known as CD56, in MCC does not necessarily indicate its 


\section{4 | REVIEWING THE CELLULAR ORIGIN}

neuroendocrine origin, since CD56 is strongly associated with natural killer (NK) cells and the respective lymphomas ${ }^{39}$. Notably, NK cells originate from pre-/ proB-cells.

Furthermore, MCPyV is present in approximately one third of chronic lymphatic leukaemia (CLL) cases, a malignancy that frequently occurs together with MCC 66. Lastly, integration of MCPyV into the host DNA of CLL cells was demonstrated by fluorescence in situ hybridization ${ }^{67}$.

In conclusion, several lines of evidence suggest that MCC originates from pre/proor pre-pro-B-cells. At the same time, there are many unresolved issues and contradictory findings that need to be verified and addressed by functional in vitro studies before any hypothesis can be proven. The very impressive response to Idelalisib (specific inhibitor of PI3K p110ס) treatment of a metastasized MCC as reported by Shiver ${ }^{68}$ emphasizes that the correct identification of the cellular origin of MCC allows to develop novel and more adequate therapeutic regimens for this highly malignant cancer.

In order to proof any of the suggested hypotheses functional in vitro studies, e.g. mouse models, are needed. 
Table 2: Summary of supportive and contradictory arguments for the different hypotheses on the cell of origin of MCC.

\begin{tabular}{|c|c|c|}
\hline $\begin{array}{l}\text { Putative Cell of } \\
\text { Origin }\end{array}$ & Supportive Arguments & Contradictory Arguments \\
\hline Merkel Cell & $\begin{array}{l}\text { 1. Neuroendocrine } \\
\text { granules } \\
\text { 2. CK20 and CD56 } \\
\text { expression } \\
\text { 3. Clinical characteristics }\end{array}$ & $\begin{array}{l}\text { 1. Epidermal location } \\
\text { 2. Postmitotic } \\
\text { 3. Gene-expression } \\
\text { profile }\end{array}$ \\
\hline $\begin{array}{l}\text { (Epi-)dermal stem } \\
\text { cell }\end{array}$ & $\begin{array}{l}\text { 1. Neuronal cell markers } \\
\text { 2. CK14 expression } \\
\text { 3. SOX-2 expression } \\
\text { 4. Mitotic potential }\end{array}$ & $\begin{array}{l}\text { 1. Expression of B-cell } \\
\text { markers }\end{array}$ \\
\hline B-cell & $\begin{array}{l}\text { 1. B-cell specific lineage } \\
\text { factors } \\
\text { 2. Expression of Ig } \\
\text { 3. IgH and IgK } \\
\text { rearrangement } \\
\text { 4. MCC regression with } \\
\text { idelalisib treatment }\end{array}$ & $\begin{array}{l}\text { 1. Neuroendocrine } \\
\text { granules } \\
\text { 2. Location of MCPyV } \\
\text { transduction }\end{array}$ \\
\hline Dermal fibroblasts & $\begin{array}{l}\text { 1. Dermal fibroblasts are } \\
\text { a target of MCPyV } \\
\text { infection }\end{array}$ & $\begin{array}{l}\text { 1. Gene-expression } \\
\text { profile } \\
\text { 2. Neuroendocrine } \\
\text { differentiation } \\
\text { 3. Expression of B-cell } \\
\text { markers }\end{array}$ \\
\hline
\end{tabular}




\section{REFERENCES}

1. Toker C. Trabecular carcinoma of the skin. Archives of dermatology. 1972;105(1):107-110.

2. Mudigonda T, Levender MM, O'Neill JL, West CE, Pearce DJ, Feldman SR. Incidence, risk factors, and preventative management of skin cancers in organ transplant recipients: a review of single- and multicenter retrospective studies from 2006 to 2010. Dermatologic surgery : official publication for American Society for Dermatologic Surgery [et al]. 2013;39(3 Pt 1):345-364.

3. Reichgelt BA, Visser O. Epidemiology and survival of Merkel cell carcinoma in the Netherlands. A population-based study of 808 cases in 1993-2007. European journal of cancer. 2011;47(4):579-585.

4. Becker JC. Merkel cell carcinoma. Annals of oncology : official journal of the European Society for Medical Oncology / ESMO. 2010;21 Suppl 7:vii81-85.

5. Toker C. TRabecular carcinoma of the skin. Archives of Dermatology. 1972;105(1):107-110.

6. Feng $\mathrm{H}$, Shuda $\mathrm{M}$, Chang $\mathrm{Y}$, Moore PS. Clonal integration of a polyomavirus in human Merkel cell carcinoma. Science. 2008;319(5866):1096-1100.

7. Bouvard V, Baan RA, Grosse $\mathrm{Y}$, et al. Carcinogenicity of malaria and of some polyomaviruses. The lancet oncology. 2012;13(4):339-340.

8. Goh G, Walradt T, Markarov V, et al. Mutational landscape of MCPyV-positive and MCPyV-negative Merkel cell carcinomas with implications for immunotherapy. Oncotarget. 2016;7(3):3403-3415.

9. Medina-Franco $\mathrm{H}$, Urist MM, Fiveash J, Heslin MJ, Bland KI, Beenken SW. Multimodality treatment of Merkel cell carcinoma: case series and literature review of 1024 cases. Annals of surgical oncology. 2001;8(3):204-208.

10. Soult MC, Feliberti EC, Silverberg ML, Perry RR. Merkel cell carcinoma: high recurrence rate despite aggressive treatment. The Journal of surgical research. 2012;177(1):75-80.

11. Lemasson G, Coquart N, Lebonvallet N, et al. Presence of putative stem cells in Merkel cell carcinomas. Journal of the European Academy of Dermatology and Venereology : JEADV. 2012;26(6):789-795.

12. Zur Hausen A, Rennspiess D, Winnepenninckx V, Speel EJ, Kurz AK. Early B-cell differentiation in Merkel cell carcinomas: clues to cellular ancestry. Cancer Res. 2013;73(16):4982-4987.

13. Tang CK, Toker C. Trabecular carcinoma of the skin: an ultrastructural study. Cancer. 1978;42(5):2311-2321.

14. Gallego R, Garcia-Caballero T, Fraga M, Beiras A, Forteza J. Neural cell adhesion molecule immunoreactivity in Merkel cells and Merkel cell tumours. Virchows Archiv : an international journal of pathology. 1995;426(3):317-321.

15. Shah IA, Netto D, Schlageter MO, Muth C, Fox I, Manne RK. Neurofilament immunoreactivity in Merkel-cell tumors: a differentiating feature from small-cell carcinoma. Modern pathology : an official journal of the United States and Canadian Academy of Pathology, Inc. 1993;6(1):3-9.

16. Tilling T, Moll I. Which are the cells of origin in merkel cell carcinoma? Journal of skin cancer. 2012;2012:680410.

17. Moll I, Zieger W, Schmelz M. Proliferative Merkel cells were not detected in human skin. Archives of dermatological research. 1996;288(4):184-187.

18. Van Keymeulen A, Mascre G, Youseff KK, et al. Epidermal progenitors give rise to Merkel cells during embryonic development and adult homeostasis. The Journal of cell biology. 2009;187(1):91-100.

19. Visvader JE. Cells of origin in cancer. Nature. 2011;469(7330):314-322.

20. Moll I, Roessler M, Brandner JM, Eispert AC, Houdek P, Moll R. Human Merkel cells--aspects of cell biology, distribution and functions. European journal of cell biology. 2005;84(2-3):259-271. 
21. Walsh NM. Primary neuroendocrine (Merkel cell) carcinoma of the skin: morphologic diversity and implications thereof. Human pathology. 2001;32(7):680-689.

22. Visscher D, Cooper PH, Zarbo RJ, Crissman JD. Cutaneous neuroendocrine (Merkel cell) carcinoma: an immunophenotypic, clinicopathologic, and flow cytometric study. Modern pathology : an official journal of the United States and Canadian Academy of Pathology, Inc. 1989;2(4):331-338.

23. Zabierowski SE, Fukunaga-Kalabis M, Li L, Herlyn M. Dermis-derived stem cells: a source of epidermal melanocytes and melanoma? Pigment cell \& melanoma research. 2011;24(3):422-429.

24. Clewes O, Narytnyk A, Gillinder KR, Loughney AD, Murdoch AP, Sieber-Blum M. Human epidermal neural crest stem cells (hEPI-NCSC)--characterization and directed differentiation into osteocytes and melanocytes. Stem cell reviews. 2011;7(4):799-814.

25. Okubo T, Clark C, Hogan BL. Cell lineage mapping of taste bud cells and keratinocytes in the mouse tongue and soft palate. Stem cells. 2009;27(2):442450.

26. Verhaegen ME, Mangelberger D, Harms PW, et al. Merkel cell polyomavirus small $\mathrm{T}$ antigen is oncogenic in transgenic mice. The Journal of investigative dermatology. 2015;135(5):1415-1424.

27. Shuda M, Guastafierro A, Geng X, et al. Merkel Cell Polyomavirus Small T Antigen Induces Cancer and Embryonic Merkel Cell Proliferation in a Transgenic Mouse Model. PloS one. 2015;10(11):e0142329.

28. Spurgeon ME, Cheng J, Bronson RT, Lambert PF, DeCaprio JA. Tumorigenic activity of merkel cell polyomavirus $T$ antigens expressed in the stratified epithelium of mice. Cancer research. 2015;75(6):1068-1079.

29. Liu W, Yang R, Payne AS, et al. Identifying the Target Cells and Mechanisms of Merkel Cell Polyomavirus Infection. Cell host \& microbe. 2016;19(6):775-787.

30. Calder KB, Smoller BR. New insights into merkel cell carcinoma. Advances in anatomic pathology. 2010;17(3):155-161.

31. Martin B, Poblet E, Rios JJ, et al. Merkel cell carcinoma with divergent differentiation: histopathological and immunohistochemical study of 15 cases with PCR analysis for Merkel cell polyomavirus. Histopathology. 2013;62(5):711-722.

32. Tijchon E, Havinga J, van Leeuwen FN, Scheijen B. B-lineage transcription factors and cooperating gene lesions required for leukemia development. Leukemia. 2013;27(3):541-552.

33. Zhuang Y, Cheng PF, Weintraub H. B-lymphocyte development is regulated by the combined dosage of three basic helix-loop-helix genes, E2A, E2-2, and HEB. Molecular and cellular biology. 1996;16(6):2898-2905.

34. Nagasawa T. Microenvironmental niches in the bone marrow required for B-cell development. Nature reviews Immunology. 2006;6(2):107-116.

35. Cobaleda C, Schebesta A, Delogu A, Busslinger M. Pax5: the guardian of B cell identity and function. Nature immunology. 2007;8(5):463-470.

36. Mullighan CG, Goorha S, Radtke I, et al. Genome-wide analysis of genetic alterations in acute lymphoblastic leukaemia. Nature. 2007;446(7137):758-764.

37. Krenacs L, Himmelmann AW, Quintanilla-Martinez L, et al. Transcription factor Bcell-specific activator protein (BSAP) is differentially expressed in B cells and in subsets of B-cell lymphomas. Blood. 1998;92(4):1308-1316.

38. Edling CE, Hallberg B. c-Kit-A hematopoietic cell essential receptor tyrosine kinase. The International Journal of Biochemistry \& Cell Biology. 2007;39(11):1995-1998.

39. McNiff JM, Cowper SE, Lazova R, Subtil A, Glusac EJ. CD56 staining in Merkel cell carcinoma and natural killer-cell lymphoma: magic bullet, diagnostic pitfall, or both? Journal of cutaneous pathology. 2005;32(8):541-545. 
40. Verhaegen ME, Mangelberger D, Weick JW, et al. Merkel cell carcinoma dependence on bcl-2 family members for survival. The Journal of investigative dermatology. 2014;134(8):2241-2250.

41. Kolhe R, Reid MD, Lee JR, Cohen C, Ramalingam P. Immunohistochemical expression of PAX5 and TdT by Merkel cell carcinoma and pulmonary small cell carcinoma: a potential diagnostic pitfall but useful discriminatory marker. International journal of clinical and experimental pathology. 2013;6(2):142-147.

42. Dong HY, Liu W, Cohen P, Mahle CE, Zhang W. B-cell specific activation protein encoded by the PAX-5 gene is commonly expressed in merkel cell carcinoma and small cell carcinomas. The American journal of surgical pathology. 2005;29(5):687-692.

43. Mhawech-Fauceglia P, Saxena R, Zhang S, et al. Pax-5 immunoexpression in various types of benign and malignant tumours: a high-throughput tissue microarray analysis. Journal of clinical pathology. 2007;60(6):709-714.

44. Murakami I, Takata K, Matsushita M, et al. Immunoglobulin expressions are only associated with MCPyV-positive Merkel cell carcinomas but not with MCPyVnegative ones: comparison of prognosis. The American journal of surgical pathology. 2014;38(12):1627-1635.

45. Buresh CJ, Oliai BR, Miller RT. Reactivity with TdT in Merkel cell carcinoma: a potential diagnostic pitfall. American journal of clinical pathology. 2008;129(6):894-898.

46. Sur M, AlArdati H, Ross C, Alowami S. TdT expression in Merkel cell carcinoma: potential diagnostic pitfall with blastic hematological malignancies and expanded immunohistochemical analysis. Modern pathology : an official journal of the United States and Canadian Academy of Pathology, Inc. 2007;20(11):1113-1120.

47. Sidiropoulos M, Hanna W, Raphael SJ, Ghorab Z. Expression of TdT in Merkel cell carcinoma and small cell lung carcinoma. American journal of clinical pathology. 2011;135(6):831-838.

48. Bhatia K, Goedert JJ, Modali R, Preiss L, Ayers LW. Merkel cell carcinoma subgroups by Merkel cell polyomavirus DNA relative abundance and oncogene expression. International journal of cancer Journal international du cancer. 2010;126(9):2240-2246.

49. Kartha RV, Sundram UN. Silent mutations in KIT and PDGFRA and coexpression of receptors with SCF and PDGFA in Merkel cell carcinoma: implications for tyrosine kinase-based tumorigenesis. Modern pathology : an official journal of the United States and Canadian Academy of Pathology, Inc. 2008;21(2):96-104.

50. Waltari $\mathrm{M}$, Sihto $\mathrm{H}$, Kukko $\mathrm{H}$, et al. Association of Merkel cell polyomavirus infection with tumor p53, KIT, stem cell factor, PDGFR-alpha and survival in Merkel cell carcinoma. International journal of cancer Journal international du cancer. 2011;129(3):619-628.

51. Krasagakis K, Kruger-Krasagakis S, Eberle J, Tsatsakis A, Tosca AD, Stathopoulos EN. Co-expression of KIT receptor and its ligand stem cell factor in Merkel cell carcinoma. Dermatology. 2009;218(1):37-43.

52. Van Gele M, Boyle GM, Cook AL, et al. Gene-expression profiling reveals distinct expression patterns for Classic versus Variant Merkel cell phenotypes and new classifier genes to distinguish Merkel cell from small-cell lung carcinoma. Oncogene. 2004;23(15):2732-2742.

53. Paulson KG, lyer JG, Tegeder AR, et al. Transcriptome-wide studies of merkel cell carcinoma and validation of intratumoral CD8+ lymphocyte invasion as an independent predictor of survival. Journal of clinical oncology : official journal of the American Society of Clinical Oncology. 2011;29(12):1539-1546.

54. Su LD, Fullen DR, Lowe L, Uherova P, Schnitzer B, Valdez R. CD117 (KIT receptor) expression in Merkel cell carcinoma. The American Journal of dermatopathology. 2002;24(4):289-293.

55. Erstad DJ, Jr JC. Mutational analysis of merkel cell carcinoma. Cancers. 2014;6(4):2116-2136. 
56. Swick BL, Srikantha R, Messingham KN. Specific analysis of KIT and PDGFRalpha expression and mutational status in Merkel cell carcinoma. Journal of cutaneous pathology. 2013;40(7):623-630.

57. Krasagakis K, Fragiadaki I, Metaxari M, et al. KIT receptor activation by autocrine and paracrine stem cell factor stimulates growth of merkel cell carcinoma in vitro. Journal of cellular physiology. 2011;226(4):1099-1109.

58. Samlowski WE, Moon J, Tuthill RJ, et al. A phase II trial of imatinib mesylate in merkel cell carcinoma (neuroendocrine carcinoma of the skin): A Southwest Oncology Group study (S0331). American journal of clinical oncology. 2010;33(5):495-499.

59. Verhaegen ME, Mangelberger D, Weick JW, et al. Merkel cell carcinoma dependence on bcl-2 family members for survival. $J$ Invest Dermatol. 2014;134(8):2241-2250.

60. Swerdlow SH CE, Harris NL, et al. WHO Classification of Tumours of Haematopoietic and Lymphoid Tissues. Lyon, France: IARC Press; 2008.

61. Chen Z, Gu J. Immunoglobulin $\mathrm{G}$ expression in carcinomas and cancer cell lines. FASEB journal : official publication of the Federation of American Societies for Experimental Biology. 2007;21(11):2931-2938.

62. Pilarski LM, Mant MJ, Ruether BA. Pre-B cells in peripheral blood of multiple myeloma patients. Blood. 1985;66(2):416-422.

63. Krumbholz M, Meinl I, Kumpfel T, Hohlfeld R, Meinl E. Natalizumab disproportionately increases circulating pre-B and $\mathrm{B}$ cells in multiple sclerosis. Neurology. 2008;71(17):1350-1354.

64. Knapp AC, Franke WW. Spontaneous losses of control of cytokeratin gene expression in transformed, non-epithelial human cells occurring at different levels of regulation. Cell. 1989;59(1):67-79.

65. Adams H, Schmid P, Dirnhofer S, Tzankov A. Cytokeratin expression in hematological neoplasms: a tissue microarray study on 866 lymphoma and leukemia cases. Pathol Res Pract. 2008;204(8):569-573.

66. Barroeta JE, Farkas T. Merkel cell carcinoma and chronic lymphocytic leukemia (collision tumor) of the arm: a diagnosis by fine-needle aspiration biopsy. Diagnostic cytopathology. 2007;35(5):293-295.

67. Haugg AM, Speel EJ, Pantulu ND, et al. Fluorescence in situ hybridization confirms the presence of Merkel cell polyomavirus in chronic lymphocytic leukemia cells. Blood. 2011;117(21):5776-5777.

68. Shiver MB, Mahmoud F, Gao L. Response to Idelalisib in a Patient with Stage IV Merkel-Cell Carcinoma. New England Journal of Medicine. 2015;373(16):15801582. 

After reviewing the hypotheses of the MCC cellular origin the main goal of the following studies (Chapter 5, 6 and 7) is focusing on the MCC early B-cell phenotype. PAX5 is described to be the guardian for the B-cell differentiation. For example, if PAX5 is not expressed in pre-pro B-cells these cells will be differentiate into T-cells. Therefore, the expression pattern of PAX5 in MCC tissue as well as in cell lines is of interest. Further, MCC does not show a complete Bcell phenotype which suggest that PAX5 is not fully functional in MCC. Therefore, the epigenome of the PAX5 binding site was analysed and confirmed by immunohistochemistry (Chapter 5).

The PI3K p110ס subunit which is essential for the pre-B-cell receptor signalling was described to be expressed in MCC. In Chapter 6 the expression of the PI3K p110ס was assessed in a bigger cohort. In addition, the functionality of the PI3K p110ठ subunit was analysed in the MCC cell lines.

BCL-2 which was first described in lymphomas and used as target for the treatment of leukaemia was also shown to be present in $80 \%$ of MCCs. The expression of BCL-2 is addressed in Chapter 7. The expression of BCL-2 was assessed in our cohort. Further the functionality of BCL-2 was analysed by inhibiting the BCL-2 family with Navitoclax. Moreover, the BCL-2 inhibition in combination with the PI3K inhibition were discussed for the treatment of leukaemia and analysed in this study as well. 


\section{Contribution to the manuscript (Chapter 5):}

Emil Chteinberg (EC) designed this study together with Prof. Axel zur Hausen $(A z H)$, Prof. Reiner Siebert (RS), Prof. Martin Zenke (MZ) and Anna Kordelia Kurz (AKZ). Prof. Joost van den Oord, provided the Leuven cohort and the fresh frozen MCC tissues which were subsequently used for $850 \mathrm{~K}$ methylation array analyses and RNA-next generation sequencing (RNA-NGS) which were performed by the company GenomeScan. Felix Bormann (FB) and Han Jin aligned the obtained RNA-NGS data for the downstream analysis. FB generated the PAX5 exon read counts and compared with EC the PAX5 splice variant abundance in different tissues. EC generated the PAX5 sashimi plots and detected the PAX5 splice variants and isoforms. EC performed all PCRs, qRT-PCR Western blot and Immunofluorescence experiments. EC generated the MCPyV-positive REH and MCC13 cell lines and analysed for PAX5 expression. Julia Kolarova (JK) and Julia Vogt analysed the obtained $850 \mathrm{~K}$ array data set and generated the list of differential methylated loci recognized by PAX5. EC performed the subsequent enrichment analysis of the Kulis transcription factors and modules. EC performed the gene ontology analyses. JK and EC generated the phylogenetic trees. Dorit Rennspiess and Kim Severens performed all immunohistochemistry staining used in this study. The IHC staining were all revised by $E C, A z H$, Véronique Winnepenninckx, AKS and Ernst-Jan Speel. Thereafter, EC discussed the resulted data with all Co-authors, especially with $M Z, A K Z, R S$ and $A z H$. EC wrote the manuscript and designed all figures. JK, AzH and RS contributed essentially to the final version by critically revising the written draft of EC. 


CHAPTER 5

DECODING OF PAX5 EXPRESSION AND ITS TRANSCRIPTIONAL NETWORK PROGRAM IN MERKEL CELL CARCINOMA

EMIL CHTEINBERG, JULIA KOLAROVA, JULIA V GT, HA JI/, KIM SEVERENS, DORIT RENNSPIESS, FELIX BON YA N, ERNST-JAN SPEEL, JOOST VAN DEN OORD, JÜRG NDL KL VÉRONIQUE WINNEPENNINCKX, ANNA KORDELIA KURZ, MARTIN ZENKE, REINER SIEBERT, AXEL ZUR HAU CN 


\section{CHAPTER 6 PHOSPHATIDYLINOSITOL 3-KINASE P110ס EXPRESSION IN MERKEL CELL CARCINOMA}

EMIL CHTEINBERG, DORIT RENNSPIESS, RYAN SAMBO, SAMANTHA TAUCHMANN, NICOLE W. J. KELLENERS-SMEETS, VÉRONIQUE WINNEPENNINCKX, ERNST-JAN SPEEL, ANNA KORDELIA KURZ, MARTIN ZENKE, AXEL ZUR HAUSEN

-PUBLISHED-

ONCOTARGET. 2018 JUL 3; 9(51): 29565-29573 



\section{ABSTRACT}

The prognosis of stage III/IV Merkel cell carcinoma (MCC) is very poor. The Phosphatidylinositol 3-kinase $\mathrm{p} 110 \delta$ specific inhibitor idelalisib has recently been reported to induce complete clinical remission in a stage IV MCC patient. Here we assessed the expression of $\mathrm{p} 110 \delta$ in primary MCC and MCC cell lines including its functionality.

Immunofluorescence microscopy revealed a specific cytoplasmic p110ס expression in $71.4 \%$ of the tested MCCs and in all tested MCC cell lines. Compared to the B cell leukaemia cell line REH all MCC cell lines, except MKL-1, revealed a lower response towards the treatment with idelalisib. MKL-1 showed a 10-fold higher IC50 compared to REH which was accompanied by a significant decrease of Akt phosphorylation. However, treating the MCC cells with the specific PI3K p110a subunit inhibitor Alpelisib led to a more effective decrease of the cell viability compared to idelalisib: WaGa cells 30 -fold, PeTa cells 15 -fold and all other MCC cell lines 3-fold.

Although PI3K p110ס is expressed in the majority of MCCs and cell lines its inhibition by idelalisib alone does not suffice to effectively affect MCC cells viability. 


\section{INTRODUCTION}

Merkel cell carcinoma (MCC) is a very aggressive virus associated non-melanoma human skin cancer ${ }^{1-3}$. The Merkel cell polyomavirus (MCPyV) is clonally integrated in more than $80 \%$ of the MCCs ${ }^{4,5}$ and it has been shown that the expression of the oncogenic $\mathrm{T}$-antigens are important drivers for the oncogenesis of MCC ${ }^{6,7}$. Next to MCPyV, UV exposure, age and immune deficiency are contributing to the pathogenesis of $\mathrm{MCC}^{1}{ }^{1}$. In addition, the risk to develop MCC is significantly increased upon solid organ transplantation (23.8-fold) and for HIV patients (11-fold) $)^{8,9}$.

Despite its rarity the incidence of MCC has tripled in the USA and Europe ${ }^{1}$. This and the low 5-year survival rate of $20 \%$ of MCCs with distant metastasis emphasizes the need for an unique treatment ${ }^{10}$. Recently, a complete clinical response induced by the phosphoinositide 3-kinase (PI3K) p110ס selective inhibitor idelalisib in a patient with stage IV - with proven p110ठ transcript expression by quantitative RT-PCR - has been reported by Shiver et al ${ }^{11}$.

The activity of the PI3K-pathway has already been studied in MCC by inhibiting the $p 110 a$ subunit ${ }^{12,13}$. Yet, it remains unclear to which extent the transcript expression of PI3K p110ס leads to a significant specific protein expression in MCC. and to which extent $\mathrm{p} 110 \delta$ contributes to the PI3K pathway activity in MCC. It is expected that elucidating PI3K p110ס activity in MCC might help to identify potential additional therapeutic options for this currently poorly treatable nonmelanoma skin cancer.

Here we assessed the expression of p110ס in 21 MCC tissues and 7 MCC cell lines. The functionality of $\mathrm{p} 110 \delta$ was analysed by idelalisib treatment of MCC cell lines and compared to the $p 110 \alpha$ subunit by treatment with the $p 110 \alpha$ specific inhibitor Alpelisib. 


\section{MATERIALS AND METHODS}

\section{PATIENT SAMPLES}

Twenty-one formalin fixed and paraffin embedded (FFPE) MCC tissues, 18 primary and 3 metastases, were obtained from the archives of the Department of Pathology, Maastricht University Medical Centre+, Maastricht, the Netherlands. All use of tissue and patient data is in agreement with the Dutch Code of Conduct for Observational Research with Personal Data (2004) and Tissue (2001, "http://www.fmwv.nl"). MCC have been defined by histology and immunohistochemistry for CK20, CD56, synaptophysin, chromogranin A and MCPyV (Anti-large T antibody CM2B4, SANTA CRUZ BIOTECHNOLOGY) and have been reviewed by 2 experienced pathologists (VW, $A Z H)$.

\section{CELL LINES}

The MCPyV-positive MCC cell lines MKL-1, MKL-2, WaGa, PeTa; the MCPyVnegative MCC cell lines MCC13, MCC26 and the B-ALL cell line REH were used. All MCC cell lines were kindly provided by Jürgen Becker (University Hospital Essen, Essen, Germany). REH was obtained from the Leibniz Institute DSMZGerman Collection of Microorganisms and Cell Cultures. The multiple myeloma cell line U266 was kindly provided by Department of Transplantation Immunology, Tissue Typing Laboratory from the Maastricht Medical Centre, NL. As described by Ikeda and colleagues U266 is negative for the PI3K p110ס subunit ${ }^{14} \mathrm{~s}$, and thus served as negative control in this study. The cell lines were cultured in Gibco $\circledast$ RPMI 1640 medium (Life-science) with $10 \%$ fetal calf serum (FCS) (Gibco ${ }^{\circledR}$, Thermo Fisher Scientific) in an incubator at $37^{\circ} \mathrm{C}$ and $5 \% \mathrm{CO} 2$.

\section{WESTERN BLOTTING}

The MCPyV-positive cell lines MKL-1, MKL-2, WaGa, PeTa and MCPyV-negative cell lines MCC13, MCC26 and the B-ALL cell line REH were grown in T25 flasks $\left(25 \mathrm{~cm}^{2}\right)$. The cells were harvested, pelleted, washed with cold PBS and resuspended in protein stabilizing buffer which consists of CHAPS Cell Extract Buffer (cell signalling technology) and phosphatase-protein inhibitor cocktail (Thermo Fisher Scientific). The proteins were isolated by freezing and thawing 
cycles by using liquid nitrogen. The protein concentration was determined by using the Pierce ${ }^{T M}$ BCA Protein Assay Kit (Thermo Fisher Scientific) according to the manufacturer's instructions. $35-60 \mu \mathrm{g}$ protein samples were separated by SDS-PAGE in $12 \%(\mathrm{w} / \mathrm{v})$ polyacrylamide gels, transferred to nitrocellulose membranes according to the manufacturer's instructions using Bio-Rad Mini Protean tetra systems. Followed by blocking with 5\% BSA (Sigma), incubated with $\begin{array}{llllll}\text { primary antibodies anti-(PI3K } \mathrm{p} 100 \delta & \mathrm{A}-8 & 1: 300 & \text { (SANTA } & \text { CRUZ }\end{array}$ BIOTECHNOLOGY); PI3K p100a antibody 1:1000 (cell signalling technologies), AKT antibody 1:1000 (cell signalling technologies) and pAKT (Thr308) antibody $1: 1000$ (cell signalling technologies) and monoclonal Anti $\beta$-actin antibody clone AC-15 1:10000 (Sigmal-Aldrich). diluted in blocking buffer and incubated over night at $4^{\circ} \mathrm{C}$, washed and incubated with the secondary antibody Alkaline Phosphatase AffiniPure $F(a b ')_{2}$ Fragment Goat Anti-Mouse/Rabbit IgG + IgM $(\mathrm{H}+\mathrm{L})$ (Jackson ImmunoResearch). The blots were developed by NBT/BCIP (Thermo Fisher Scientific) incubation according to the manufacturer's instructions. The blots were scanned using Canon CanoScan 9000F Mark II.

\section{IMMUNOFLUORESCENCE MICROSCOPY}

The expression of PI3K p110ס was assessed by immunofluorescence microscopy (IFM) in 18 primary and 3 metastatic MCCs, MCPyV-positive MCC cell lines MKL1, MKL-2, WaGa, PeTa and MCPyV-negative MCC cell lines MCC13 and MCC26. Further the expression of PI3K p110ס was analysed in the B cell acute lymphoblastic leukaemia (B-ALL) cell line REH. All samples were formalin fixed and paraffin embedded. The FFPE sections were deparaffinized and rehydrated in xylene and ethanol baths. The antigen retrieval was performed by boiling the slides in $1 \mathrm{mM}$ EDTA pH 8.0. The slides were blocked in 5\% BSA TBST, incubated with the first antibody Anti-PI3K p100ס antibody A-8 (SANTA CRUZ BIOTECHNOLOGY) at $4{ }^{\circ} \mathrm{C}$ over-night, followed by washing and incubation with the secondary antibody Goat anti-Mouse IgG $(\mathrm{H}+\mathrm{L})$ Secondary Antibody, DyLight 488 (Thermo Fischer Scientific). The nuclei of the cells were stained with DAPI mounting medium (VECTASHIELD, VECTOR LABORATORIES) according manufacturer's instructions. The detection of the fluorescence stained cells was performed with the Leica microscope DM 5000 B (Leica). 


\section{TREATMENT OF CELL LINES WITH PI3K INHIBITORS}

The cell lines MKL-1, MKL-2, WaGa, PeTa, MCC13, MCC26 and REH were treated with idelalisib (Selleckchem, Germany) and Alpelisib (Selleckchem, Germany). Both agents were dissolved in DMSO. Following concentrations were used for the treatments: $10 \mathrm{nM}, 100 \mathrm{nM}, 500 \mathrm{nM}, 1 \mu \mathrm{M}, 12.5 \mu \mathrm{M}, 25 \mu \mathrm{M}, 50 \mu \mathrm{M}$ and $100 \mu \mathrm{M}$.

The cells were incubated in a 96 well plate (Greiner Bio-One, Austria) for 120h, in Gibco® RPMI 1640 medium (Life-science) with 10\% fetal calf serum (FCS) (Gibco®, Thermo Fisher Scientific) in an incubator at $37^{\circ} \mathrm{C}$ and $5 \% \mathrm{CO} 2$. The effect of the drug on the cell viability was assessed by the XTT assay (Thermo Fisher Scientific) according to the protocol provided by the manufacturer. The read out of the XTT assay was done with the iMark ${ }^{\text {TM }}$ Microplate Absorbance Reader (BIO-RAD).

To determine the effect of idelalisib on the PI3K pathway the phosphorylation of AKT was assessed by Western blotting. Therefore, the cells were treated with $0.2 \%$ DMSO, $1 \mu \mathrm{M}, 12.5 \mu \mathrm{M}$ and $25 \mu \mathrm{M}$ of idelalisib for $72 \mathrm{~h}$.

\section{STATISTICS}

The half maximal inhibitory concentration $\left(\mathrm{IC}_{50}\right)$ values were determined with Graphpad Prism 6. By using the One-Way ANOVA test the significance of the dose response curves was determined. The western blots were quantified via ImageJ ${ }^{15}$. 
Table 1: Clinicopathological data of MCC patients and corresponding tissues including the results of PI3K p110ס expression as tested by immunofluorescence microscopy (IFM)

\begin{tabular}{|c|c|c|c|c|c|c|c|}
\hline \multicolumn{8}{|c|}{ primary MCCs } \\
\hline ID & gender & age & location & $d x$ & histo. & MCPyV & PI3K p110ס \\
\hline 1 & $\mathrm{~m}$ & 63 & head & MCC & int. & pos. & + \\
\hline 2 & $\mathrm{~m}$ & 92 & ear & MCC & s.c. & neg. & ++ \\
\hline 3 & $f$ & 85 & buttocks & MCC & s.c. & pos. & ++ \\
\hline 4 & $\mathrm{~m}$ & 69 & $\begin{array}{c}\text { lip } \\
\text { upper eve }\end{array}$ & $\mathrm{MCC}$ & int. & pos. & ++ \\
\hline 5 & $f$ & 93 & lid & MCC & int. & pos. & +heterogen. \\
\hline 6 & $f$ & 60 & tongue & MCC & int./s.c. & pos. & - \\
\hline 7 & $\mathrm{~m}$ & 74 & upper leg & MCC & int. & pos. & - \\
\hline 8 & $\mathrm{~m}$ & 93 & head & $\mathrm{MCC}$ & int. & neg. & ++ \\
\hline 9 & $f$ & 76 & $\begin{array}{c}\text { buccal } \\
\text { upper eye }\end{array}$ & MCC & int. & pos. & - \\
\hline 12 & $f$ & 83 & lid & MCC & int. & pos. & ++ \\
\hline 14 & $\mathrm{~m}$ & 74 & upper leg & MCC & int. & pos. & ++ \\
\hline 15 & $\mathrm{~m}$ & 77 & neck & $\mathrm{MCC}$ & int. & neg. & ++ \\
\hline 16 & $f$ & 66 & arm & MCC & int. & pos. & ++ \\
\hline 17 & $\mathrm{~m}$ & 79 & head & MCC & int. & pos. & - \\
\hline 19 & $\mathrm{~m}$ & 68 & buttocks & MCC & int. & pos. & ++ \\
\hline 20 & $f$ & 58 & buccal & MCC & int./s.c. & pos. & ++ \\
\hline 24 & $\mathrm{~m}$ & 74 & upper leg & MCC & int. & pos. & - \\
\hline 30 & $\mathrm{~m}$ & 63 & upper lip & MCC & int. & pos. & ++ \\
\hline \multicolumn{8}{|c|}{ metastases MCC } \\
\hline ID & gender & age & location & $d x$ & histo. & MCPyV & PI3K p110ס \\
\hline 21 & $\mathrm{~m}$ & 71 & pancreas & $\begin{array}{l}\text { MCC } \\
\text { met. } \\
\text { MCC }\end{array}$ & int. & pos. & + \\
\hline 22 & $f$ & 75 & LN neck & $\begin{array}{c}\text { met. } \\
\text { MCC } \\
\text { met. }\end{array}$ & int. & pos. & ++ \\
\hline
\end{tabular}

Abbreviations used: ID = identity; $m=$ male; $f=$ female; $d x=$ diagnosis; $L N=$ lymph node; $\mathrm{MCC}=$ Merkel cell carcinoma; histo. = histological subtype; int. = intermediate; s.c. $=$ small cell; MCPyV = Merkel cell polyomavirus; $\mathrm{IHC}=$ immunohistochemistry; pos. = positive; neg. = negative; heterogen.$=$ heterogeneous; $-=$ no expression; $+=$ weak expression; $++=$ moderate expression; $+++=$ strong expression; met. $=$ metastasis 


\section{RESULTS}

EXPRESSION OF PI3K P110ס IN MCC

The expression of $\mathrm{PI} 3 \mathrm{~K} \mathrm{p} 110 \delta$ was analysed in 18 primary and in three metastatic MCCs by immunofluorescence microscopy (IFM). A specific cytoplasmic staining could be observed in 13 of 18 primary MCC $(72.2 \%)$ and in 2 out of 3 metastatic MCC (66.6\%) (Tab. 1 and Figure 1). All MCPyV negative MCCs (3 out of 18 primary MCC tested) were positive for the $\mathrm{p} 110 \delta$ subunit.

DAPI and PI3K p110

A

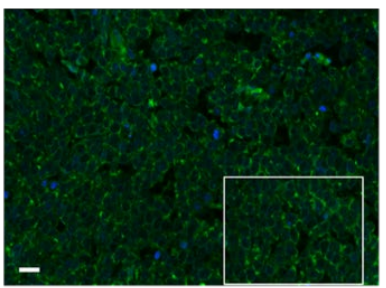

B

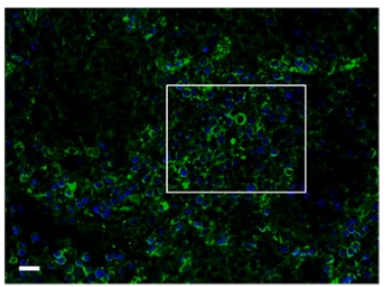

C

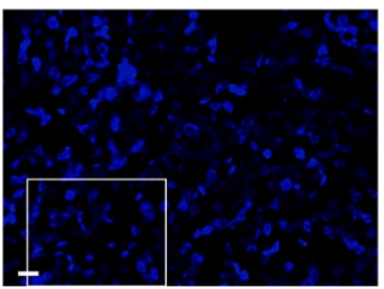

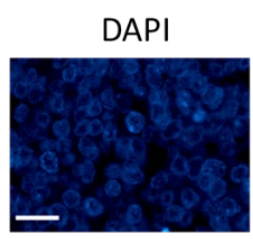

PI3k p1108
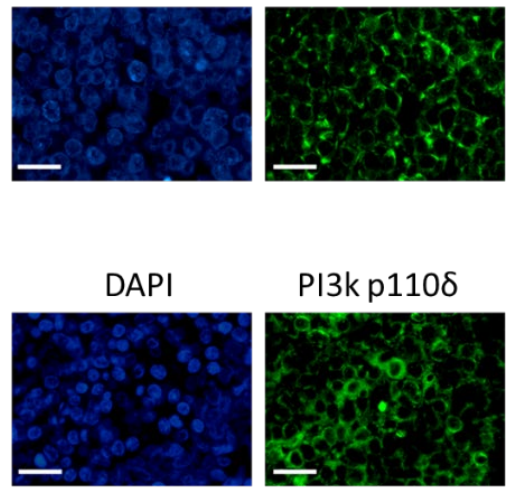

DAPI

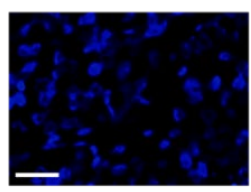

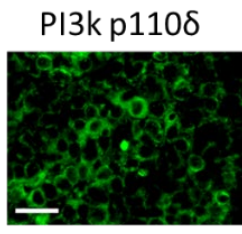

PI3k p1108

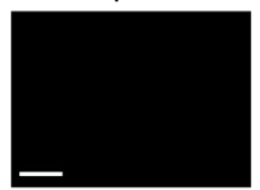

merged

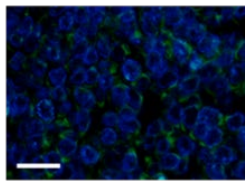

merged

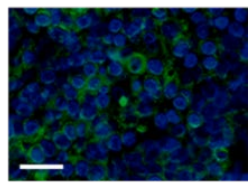

merged

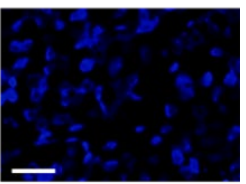

Figure 1: Immunofluorescence staining of PI3K p110ס in MCCs.

The IFM photographs of three MCCs ID14 (A), ID15 (B) and ID7 (C). The wide merged photographs (DAPI staining and PI3K p110ס) were taken at a magnitude of $10 \mathrm{x}$. The squares in the pictures indicate the region which is chosen for an image enlargement which was taken at a magnitude of $63 x$. The enlarged pictures show separately the nucleus by the DAPI staining and the PI3K p110ס staining. The merged pictures show a specific cytoplasmic staining of the p110ס subunit in ID14 (A) and ID15 (B). ID7 (C) is an example of a p110 $\delta$ negative MCC. The scale bares represent a length of $100 \mu \mathrm{m}$. 
A

B

50

I3K p110 a

${ }_{37}-$

$\beta$-actin

(42 kDA)

MKL-1

DAPI

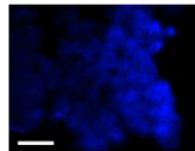

PI3K

p1108

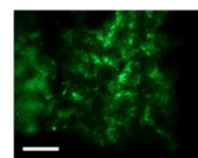

merged

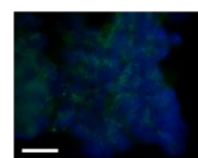

MKL-2
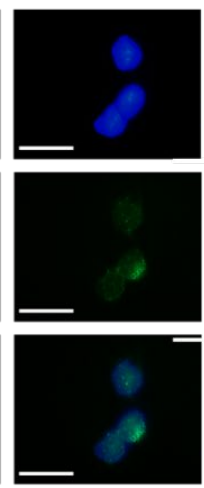

WaGa
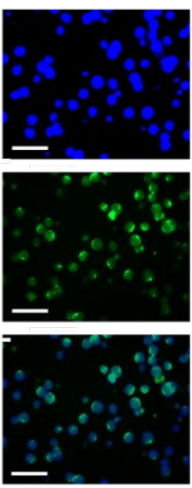

PeTa
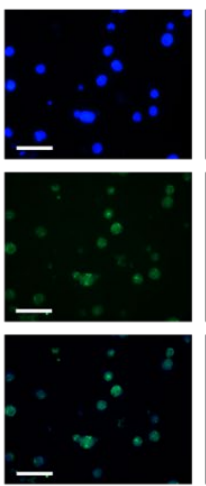

MCC13
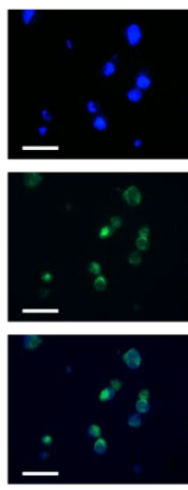

MCC26
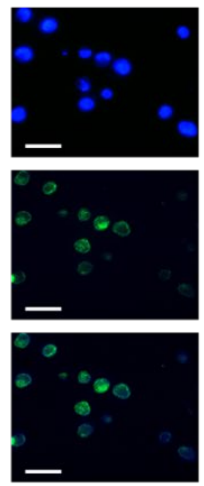

U266
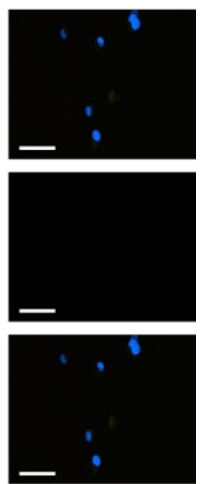

Figure 2: Assessment of PI3K p110ס expression by Western blotting (A) and immunofluorescence microscopy (B).

A. Expression level of PI3K p110ס and PI3K p110a in cell lysates of REH, MKL-1, MKL-2, WaGa, PeTa, MCC13, MCC26, and U266. All cell lines

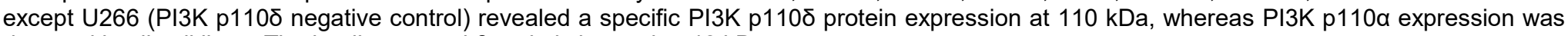
detected in all cell lines. The loading control $\beta$-actin is located at $42 \mathrm{kDa}$.

B. The corresponding IFM photographs for DAPI, PI3K p110ס and merged are shown for these cell lines. The merged photograph identifies PI3K

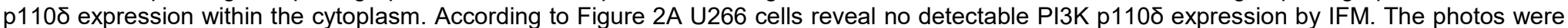
taken with $63 x$ magnification. The scale bars represent a length of $100 \mu \mathrm{m}$. 


\section{EXPRESSION OF PI3K P110ס AND P110a IN MCC CELL LINES}

In addition, the expression of the PI3K p110 a and PI3K p110ס was assessed in the MCC cell lines MKL-1, MKL-2, WaGa, PeTa, MCC13 and MCC26. The B-ALL cell line REH was used as positive control and the human multiple myeloma cell line $\mathrm{U} 266$ as negative control (Figure $2 \mathrm{~A}$ ) ${ }^{14}$. A strong protein band the expected size of PI3K p110ס of $119 \mathrm{kDa}$ could be observed for the cell lysate of REH. Thinner protein bands were also visible in the MCPyV-positive and MCPyVnegative cell line lysates and completely absent in U266 cell lysate. In comparison, all cell line lysates showed a strong protein band at $119 \mathrm{kDa}$ specific for PI3K p110a (Figure $2 \mathrm{~A}$ ). The results for the $\mathrm{p} 110 \delta$ subunit were confirmed by immunofluorescence microscopy (IFM): in all cell lines except U266 a specific cytoplasmic staining could be detected (Figure2 B). Thus, PI3K p110ס is expressed in the majority of primary and metastatic MCCs and in MCC cell lines irrespective of the MCPyV status. 

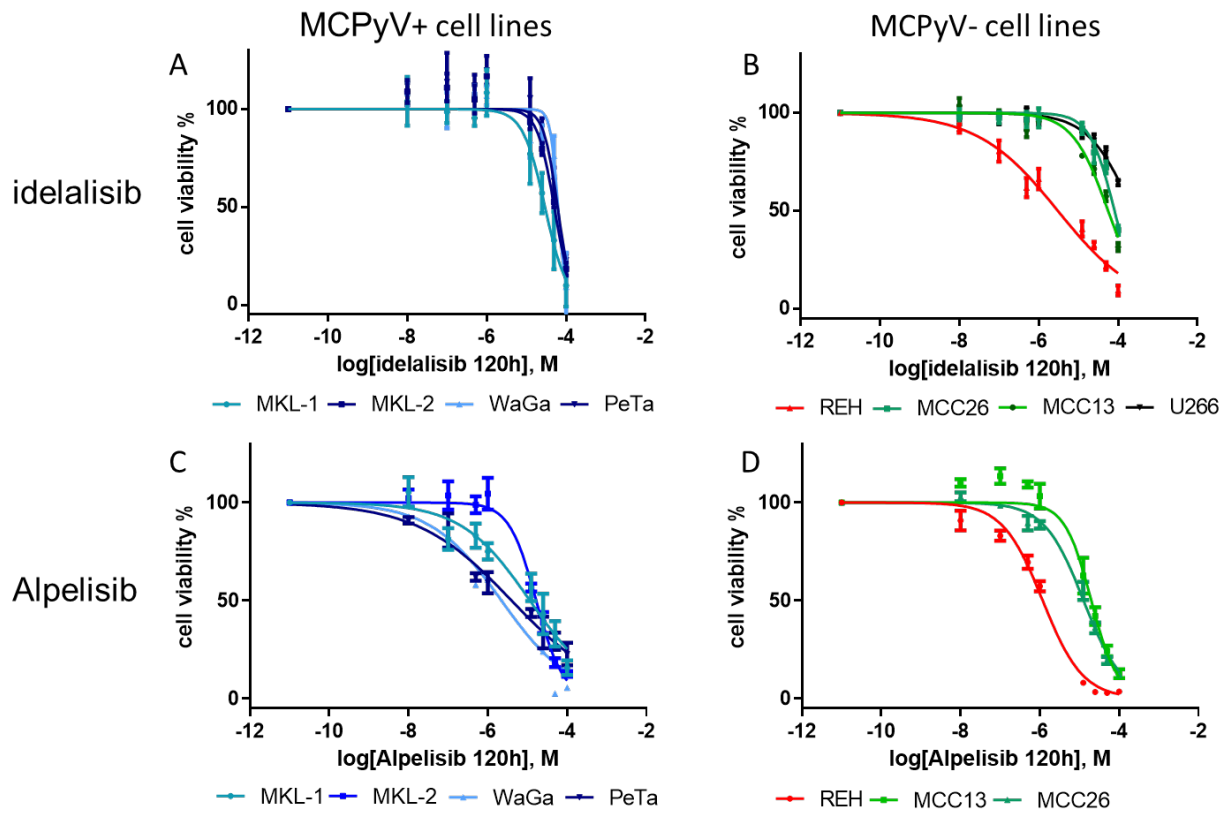

Figure 3: Dose-response curves of the MCPyV-positive MKL-1, MKL-2, WaGa, PeTa (A and C), and MCPyV-negative MCC13, MCC26, REH and U266 $(B$ and $D)$ cell lines after $120 \mathrm{~h}$ treatment with varying molar concentrations [M] of idelalisib and Alpelisib.

The cell viability is inhibited by idelalisib or Alplelisib (BYL719) in all cell lines in a dosedependent manner. $I C_{50}$ were calculated from 3 independent $(n=3)$ experiments with eight replicates each. Bars symbolize the standard deviation of the mean. The overall $p$ values of all dose response curves besides the treatment of U266 are $<0.001$.

\section{TREATMENT WITH PI3K INHIBITORS}

The cell lines were tested for their sensitivity towards the PI3K p110ס specific inhibitor idelalisib. The decrease of the cell viability of almost all treated cell lines was observed after $120 \mathrm{~h}$ incubation. The best response was observed in the BALL cell line REH with an $\mathrm{IC}_{50}$ of $3.1 \mu \mathrm{M}$. The cell lines MKL-2, WaGa, PeTa and MCC13 showed for the idelalisib treatment almost a comparable range of $\mathrm{IC}_{50} 50$ $\mu \mathrm{M}$ to $63 \mu \mathrm{M}$. The MKL-1 cells were 2-fold more sensitive compared to all other MCC cell lines. MCC26 cells showed a 1.4-- to 1.6-fold weaker response compared to all other MCC cell lines. The multiple myeloma cell line U266 showed a decrease of the cell viability at a concentration of $12.5 \mu \mathrm{M}$, an $\mathrm{IC}_{50}$ value could not be determined for this PI3K p110ס-negative cell line. In general, all MCC cell 
lines showed with an overall p-value $<0.001$ a significant dose-dependent sensitivity to idelalisib after $120 \mathrm{~h}$ incubation (Figure 3).

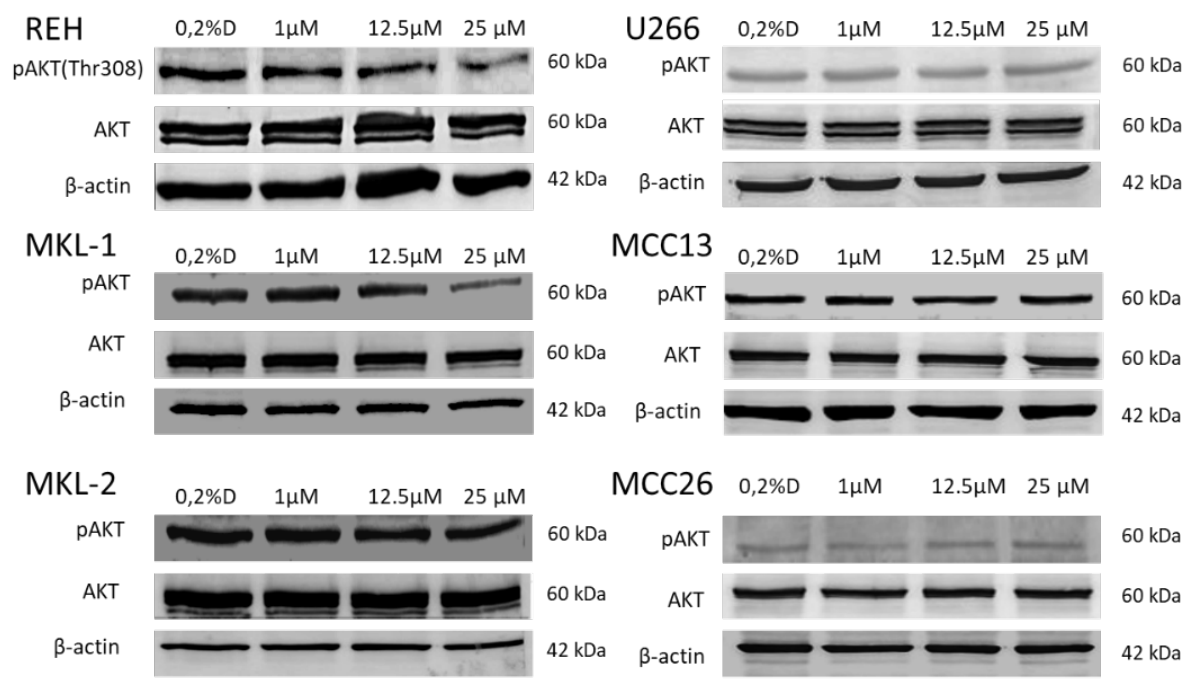

Figure 4: Western blotting of AKT phosphorylation (p-AKT) in idelalisib treated cell lines REH, MKL-1, MKL-2, MCC13, MCC26 and U266.

For p-AKT and AKT a t $60 \mathrm{kDa}$ protein band could be detected in all cell lines. Only in the MCC cell line MKL-1 and the B-ALL cell line REH a decrease of $p-A K T$ protein band density with increasing idelalisib concentrations could be observed. AKT and $\beta$-actin (42 kDa) was used as a loading control. $0.2 \% \mathrm{DMSO}(0.2 \% \mathrm{D})$ without idelalisib were used as a treatment negative controls. 
Table 2: $I_{50}$ values of idelalisib and Alpelisib treatment of MCC, B-ALL and multiple myeloma cell lines

\begin{tabular}{|ccccc|}
\hline cell lines & cancer type & MCPyV & $\begin{array}{c}\mathbf{I C}_{50} \\
\text { Idelalisib } \\
(\boldsymbol{\mu} \mathbf{M})\end{array}$ & $\begin{array}{c}\mathbf{I C}_{50} \\
\text { Alpelisib } \\
(\boldsymbol{\mu} \mathbf{M})\end{array}$ \\
\hline MKL-1 & MCC & pos. & 29.6 & 11.5 \\
MKL-2 & MCC & pos. & 50.7 & 16.6 \\
WaGa & MCC & pos. & 63.1 & 2.2 \\
PeTa & MCC & pos. & 59.2 & 4.2 \\
MCC13 & MCC & neg. & 56.5 & 20.0 \\
MCC26 & MCC & neg. & 81.9 & 12.7 \\
REH & B-ALL & neg. & 3.1 & 1.2 \\
U266 & multiple & neg. & not deter. & n.d. \\
\hline
\end{tabular}

Abbreviations used: $\mathrm{IC}_{50}=$ half maximal inhibitory concentration, $\mathrm{B}-\mathrm{ALL}=\mathrm{B}$-cell acute lymphoblastic leukaemia; pos. = positive; neg. = negative; $n$. deter. = not determinable, $n . d$. $=$ not done.

The effect of idelalisib on the PI3K pathway of the treated cell lines was tested by Western blotting analysing the threonine 308 phosphorylation of protein kinase $B$ (AKT) which is located downstream of PI3K. A significant decrease of AKT phosphorylation was restricted to $\mathrm{REH}$ and $\mathrm{MKL}-1$ with increasing concentrations of idelalisib (Figure 4).

In addition, the MCC cell lines and the B-ALL cell line REH were treated with the specific PI3K p110a inhibitor Alpelisib. In general, all cell lines showed a higher sensitivity towards Alpelisib treatment compared to the idelalisib treatment. Again, REH showed the strongest response compared to all other cell lines. The MCPyVpositive cell lines WaGa and PeTa were more sensitive for Alpelisib compared to MKL-1 and MKL-2 (Figure 3). 


\section{DISCUSSION}

Under physiological conditions the PI3K p110ס subunit plays an important role in the differentiation of early B-cells into mature B-cells ${ }^{16}$. In the present study, we tested the expression and functionality of PI3K p110ס in MCC. Using IFM we found that $71 \%$ of MCC tested, revealed a specific cytoplasmic expression of the p110ס subunit. Prior to the use of IFM we had checked the monoclonal antibody for its specificity using Western blotting All MCC cell lines were PI3K p110ס positive by Western blotting as confirmed by IFM. The B-ALL cell line REH revealed the highest protein PI3K p110ס expression compared to the other cell lines. To the best of our knowledge this is the first proof of PI3K p110ס protein expression in MCC tissues and MCC cell lines. Previously, Shiver et al. have reported PI3K p110ס expression on the transcript level in one MCC sample of a stage IV MCC patient ${ }^{11}$. This patient was treated with combined radiotherapy and idelalisib which is a selective PI3K p110ס inhibitor, that has effectively been used in the treatment of chronic lymphocytic leukemia (CLL), B-ALL and Hodgkin lymphoma $(\mathrm{HL}){ }^{17}$. In our cell culture treatment assay idelalisib significantly affected the cell viability of all MCC cell lines. However, compared to the B-ALL cell line REH this decrease of the cell viability has to be interpreted as weak.

The results of our analysis of the PI3K downstream pathway could possibly provide an explanation for the weak response of the MCC cell lines towards idelalisib treatment. Since AKT becomes phosphorylated upon PI3K activation we analyzed the phosphorylation status of AKT in the MCC cell lines. Of interest, only MKL-1 showed a decrease of phosphorylated AKT with increasing concentrations of idelalisib. Although this effect was 10-fold weaker as compared to the B-ALL cell line REH, MKL-1 was the only MCC cell line which revealed a comparable effect as seen in REH cells implying that PI3K p110ס is functional in MKL-1.

Functional PI3K p110ठ is primarily restricted to leukocytes and has been reported to be critical for the activation, proliferation and survival of B-cells ${ }^{18}$ and the differentiation of pre-pro B-cells in pro B-cells ${ }^{16}$. Thus, together with the recently reported pre-pro/pro- B- cell differentiation of MCC, i.e. TdT and PAX5, immunoglobulin (Ig) expression and Ig rearrangements ${ }^{19,20}$, the functional PI3K p110ס expression in MCC might add another tesserae in the discussion of the cellular origin of MCC. 
The inhibition of the PI3K p110 a by Alpelisib of the same cell lines has revealed a stronger impact on the MCC cell lines. The cell line REH showed again the best response towards the treatment with Alpelisib, followed by WaGa, PeTa, MKL-1, MKL-2, MCC26 and MCC13. Hafner and colleagues had treated the MCC cell lines WaGa, MKL-1, MKL-2 and MCC13 with another PI3K p110 $\alpha$ inhibitor LY$294002^{13}$. They report $I_{50}$ values which are 6-fold, for WaGa, 1.6-fold for MKL1, 1.8-fold for MKL-2 and 1.5-fold for MCC13 lower as compared to the calculated concentrations for Alpelisib. This might indicate that Alpelisib is either more specific for the alpha subunit or is easier penetrating the cells. However, the order of the response to the drugs is still the same, $\mathrm{WaGa}$ cells are most responsive to the treatments followed by MKL-1, MKL-2 and MCC13 ${ }^{13}$.

This strong impact on the MCC cell lines is not observed with idelalisib treatment rendering PI3K p110ס expression and/or function less important for cell viability and for the PI3K pathway function of almost all MCC cell lines tested as shown by the unaltered pAKT concentration. To what extent the findings of our study add to the understanding of the recent case report of Shiver et al. (10) cannot completely be resolved, because the patient described by Shiver et al. did also receive radiotherapy. Iyer and colleagues described single-fraction radiation therapy for MCCs as a convenient alternative for chemotherapy ${ }^{21}$. So it might be that radiotherapy alone or in combination with idelalisib has led to the full remission of MCC ${ }^{11}$.

\section{CONCLUSION}

The tested MCCs and MCC cell lines express PI3K p110ס. However, the MCC cell lines seem to be resistant towards treatment with the specific $p 110 \delta$-inhibitor idelalisib. Our data indicate that idealisib monotherapy will not suffice to treat MCC. In as much MCC patients might benefit of a combination of radiotherapy and idealisib remains to be elucidated by clinical studies. 


\section{REFERENCES}

1. Schadendorf D, Lebbé C, zur Hausen A, et al. Merkel cell carcinoma: Epidemiology, prognosis, therapy and unmet medical needs. European Journal of Cancer. 2017;71(Supplement C):53-69.

2. Becker JC, Stang A, DeCaprio JA, et al. Merkel cell carcinoma. Nature Reviews Disease Primers. 2017;3:17077.

3. Harms PW. Update on Merkel Cell Carcinoma. Clinics in Laboratory Medicine. 2017;37(3):485-501.

4. Hughes MP, Hardee ME, Cornelius LA, Hutchins LF, Becker JC, Gao L. Merkel Cell Carcinoma: Epidemiology, Target, and Therapy. Current Dermatology Reports. 2014;3(1):46-53.

5. Feng $\mathrm{H}$, Shuda $\mathrm{M}$, Chang $\mathrm{Y}$, Moore PS. Clonal Integration of a Polyomavirus in Human Merkel Cell Carcinoma. Science (New York, NY). 2008;319(5866):1096-1100.

6. Verhaegen ME, Mangelberger D, Harms PW, et al. Merkel cell polyomavirus small T antigen is oncogenic in transgenic mice. J Invest Dermatol. 2015;135(5):1415-1424.

7. Kwun HJ, Wendzicki JA, Shuda Y, Moore PS, Chang Y. Merkel cell polyomavirus small T antigen induces genome instability by E3 ubiquitin ligase targeting. Oncogene. 2017.

8. Clarke CA, Robbins HA, Tatalovich Z, et al. Risk of Merkel Cell Carcinoma After Solid Organ Transplantation. Journal of the National Cancer Institute. 2015;107(2).

9. Engels EA, Frisch M, Goedert JJ, Biggar RJ, Miller RW. Merkel cell carcinoma and HIV infection. The Lancet. 2002;359(9305):497-498.

10. Albores-Saavedra J, Batich K, Chable-Montero F, Sagy N, Schwartz AM, Henson DE. Merkel cell carcinoma demographics, morphology, and survival based on 3870 cases: a population based study. Journal of Cutaneous Pathology. 2010;37(1):20-27.

11. Shiver MB, Mahmoud F, Gao L. Response to Idelalisib in a Patient with Stage IV MerkelCell Carcinoma. New England Journal of Medicine. 2015;373(16):1580-1582.

12. Nardi V, Song YC, Santamaria-Barria JA, et al. Activation of PI3K signaling in Merkel cell carcinoma. Clinical cancer research : an official journal of the American Association for Cancer Research. 2012;18(5):1227-1236.

13. Hafner C, Houben R, Baeurle A, et al. Activation of the PI3K/AKT Pathway in Merkel Cell Carcinoma. PLOS ONE. 2012;7(2):e31255.

14. Ikeda $\mathrm{H}$, Hideshima $\mathrm{T}$, Fulciniti $\mathrm{M}$, et al. $\mathrm{PI} 3 \mathrm{~K} / \mathrm{p} 110 \delta$ is a novel therapeutic target in multiple myeloma. Blood. 2010;116(9):1460-1468.

15. Schneider CA, Rasband WS, Eliceiri KW. NIH Image to ImageJ: 25 years of image analysis. Nat Meth. 2012;9(7):671-675.

16. Beer-Hammer S, Zebedin E, von Holleben M, et al. The catalytic PI3K isoforms p110y and p110ס contribute to B cell development and maintenance, transformation, and proliferation. Journal of Leukocyte Biology. 2010;87(6):1083-1095.

17. Akinleye A, Avvaru P, Furqan M, Song Y, Liu D. Phosphatidylinositol 3-kinase (PI3K) inhibitors as cancer therapeutics. Journal of Hematology \& Oncology. 2013;6(1):1-17.

18. Vanhaesebroeck B, Welham MJ, Kotani K, et al. P110delta, a novel phosphoinositide 3kinase in leukocytes. Proceedings of the National Academy of Sciences of the United States of America. 1997;94(9):4330-4335.

19. Zur Hausen A, Rennspiess D, Winnepenninckx V, Speel EJ, Kurz AK. Early B-cell differentiation in Merkel cell carcinomas: clues to cellular ancestry. Cancer Res. 2013;73(16):4982-4987.

20. Murakami I, Takata K, Matsushita M, et al. Immunoglobulin Expressions Are Only Associated With MCPyV-positive Merkel Cell Carcinomas But Not With MCPyV-negative Ones: Comparison of Prognosis. The American Journal of Surgical Pathology. 2014;38(12):1627-1635.

21. Iyer JG, Parvathaneni U, Gooley T, et al. Single-fraction radiation therapy in patients with metastatic Merkel cell carcinoma. Cancer Medicine. 2015;4(8):1161-1170. 


\section{SUPPLEMENTAL FIGURES}
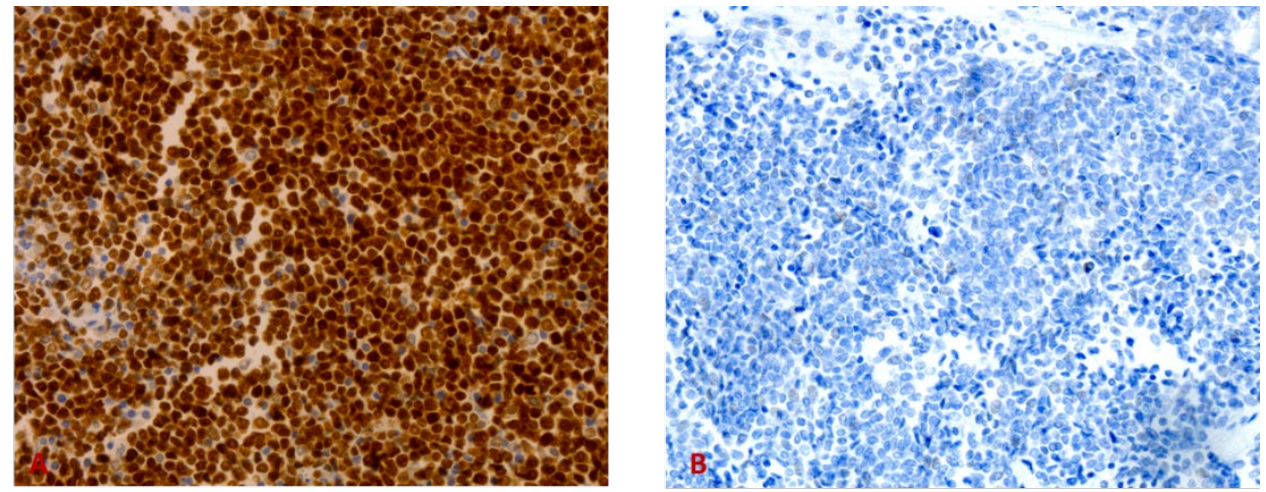

Figure S1 MCPyV IHC of ID3 (A) and ID8 (B)

ID1 MCC cells showing a specific and distinct nuclear expression of the MCPyV LT antige 




\section{Contribution to the manuscript (Chapter 7):}

Emil Chteinberg designed this study together with Prof. Axel zur Hausen, Prof. Martin Zenke, Prof. Ernst-Jan Speel and Anna Kordelia Kurz. All experiments were mainly performed and analysed by Emil Chteinberg. Wouter Gerritsen performed the BCL-2 immunohistochemistry of the MCC tissues as well as cell lines. Emil Chteinberg together with Prof. Axel zur Hausen, Prof. Ernst-Jan Speel and Véronique Winnepenninckx analysed the expression pattern. Emil Chteinberg and Wouter Gerritsen treated the cell lines with Navitoclax and the three different combinations. Emil Chteinberg performed the western blot analysis. Emil Chteinberg treated the cells for the Annexin- $V$ assay. The subsequent FACS analysis was performed by Suzan Wetzels, Emil Chteinberg and Lieve Temmerman. The results were discussed with Prof. Erik Biessen. Thereafter, Emil Chteinberg statically analysed the results of all treatments. Felix Borman provided the R-script to generate the 3D-Cl plots. Emil Chteinberg wrote the resulted manuscript. Prof. Axel zur Hausen and Prof. Ernst-Jan Speel revised the written manuscript. 

CHAPTER 7A

\section{NAVITOCLAX COMBINED WITH ALPELISIB EFFECTIVELY INHIBITS MERKEL CELL CARCINOMA CELL GROWTH IN VITRO}

EMIL CHTEINBERG, SUZAN WETZELS, WOUTER GERRITSEN, LIEVE TEMMERMAN, VÉRONIQUE WINNEPENNINCKX, ERIK BIESSEN, ANNA KORDELIA KURZ, MARTIN ZENKE, ERNST-JAN SPEEL, AXEL ZUR HAUSEN

-ACEPTED FOR PUBLICATION IN THERAPEUTIC ADVANCES IN MEDICAL ONCOLOGY- 



\section{ABSTRACT}

Background: Merkel cell carcinoma (MCC) is a highly malignant skin cancer. Despite major treatment improvements during the last decade, up to $50 \%$ of patients do not respond to therapy or develop recurrent disease. For these patients, alternative treatment options are urgently needed. Here, we assessed the efficacy of the combination of the BCL-2 inhibitor Navitoclax and the PI3K p110a inhibitor Alpelisib in MCC cell lines.

Methods: The expression of BCL-2 was assessed by immunohistochemistry in MCC and MCC cell lines. Treatment with Navitoclax and Alpelisib alone and in combination were performed on four MCC cell lines. The decrease of cell viability during treatment was assessed by XTT assay and visualized for the combinations by 3D combinatorial index $(\mathrm{Cl})$ plotting. The increase of apoptotic cells was determined by cleaved PARP Western blotting and Annexin- $V$ staining.

Results: Ninety-four percent of MCCs and all three MCPyV-positive cell lines showed BCL-2 expression. Navitoclax monotreatment showed to be highly effective when treating $\mathrm{BCL}-2$-positive cell lines ( $\mathrm{IC}_{50}$-values ranging from 96.0 to $323.0 \mathrm{nM}$ ). The combination of Alpelisib and Navitoclax resulted in even stronger synergistic and prolonged inhibitions of MCC cell viability through apoptosis up to four days.

Discussion: Our results show that the antiapoptotic BCL-2 is frequently expressed in MCC and MCC cell lines. Inhibition of BCL-2 by Navitoclax in combination with Alpelisib revealed a strong synergy and prolonged inhibition of MCC cell viability and induction of apoptosis. The combination of Navitoclax and Alpelisib is a novel potential treatment option for MCC patients. 


\section{INTRODUCTION}

Merkel cell carcinoma (MCC) is a rare and aggressive skin cancer of the elderly. Eighty percent of the MCCs are associated with the Merkel cell Polyomavirus (MCPyV) and the remaining tumours with UV-induced mutations ${ }^{1,2}$. For long time they have been treated by chemotherapeutic regimens including the DNA intercalating drug Doxorubicin (an anthracycline) and the anti-mitotic cytostatic Vincristine (vinca alkaloid). These treatments showed ORRs ranging from 20 to $61 \%{ }^{3,4}$ with promising initial responses, but median overall survival rates of approximately 9 to 9.5 months ${ }^{5}$. Chemotherapeutics also induced adverse events e.g. fatigue, vomiting, mucositis, and in 5 to $7 \%$ of patients serious events such as neutropenia and sepsis ${ }^{5}$.

Recently, immune check point inhibitors (CPIs) targeting the programmed cell death protein ligand 1 (PD-L1) or its receptor PD-1 has been introduced in the first line treatment of MCC patients ${ }^{6-9}$. It has been assumed that the MCPyV small and large $\mathrm{T}$-antigen ( $\mathrm{T}-\mathrm{Ag}$ ) oncoproteins as well as the ultraviolet-induced neoantigens in these tumours elicit immune responses, which may induce PD-L1 expression 2,6-8. In more than $50 \%$ of MCC tissues at least 1 to $5 \%$ of the tumour cells were positive for PD-L19-11. The CPI treatment leads to ORRs of $50-70 \%$ in MCC patients. Again, adverse events are frequently reported such as infusion related reaction or fatigue 12,13 . The remaining $30-50 \%$ of MCC patients do not respond to CPIs ${ }^{12}$, and alternative treatments thus are urgently required for this group of patients.

Several promising alternative treatments have recently been reported. For example, it is known that the PI3K pathway is activated in $66-88 \%$ of MCCs ${ }^{14,15}$ and we have recently shown that the PI3K inhibitor Alpelisib (Byl719) is potent in inhibiting MCC cell line growth in vitro ${ }^{16}$. Although no data are available on MCC patients, Alpelisib in combination with Fulvestrant has demonstrated efficacy in the treatment of hormone receptor-positive and human epidermal growth factor receptor-2-negative metastatic breast cancer ${ }^{17}$. Known adverse events of Alpelisib comprise hyperglycaemia, diarrhoea and nausea ${ }^{18,19}$.

The B-cell lymphoma 2 (BCL-2) inhibitor Navitoclax is an additional promising treatment. BCL-2 expression has been detected in approximately $80 \%$ of MCC, irrespective of MCPyV-presence ${ }^{20}$. Verhaegen and colleagues reported that a MCC mice xenograft expressing BCL-2 showed a growth arrest after daily 
treatment with this compound for 18 days ${ }^{21}$. Also, $10 \mathrm{BCL}-2$ positive university of Michigan (UM)-MCC cell lines, including MCPyV-positive and negative, showed sensitivity for this inhibitor ${ }^{21}$. Although, no data are available for MCC patients, Navitoclax treatment in chronic lymphocytic leukaemia (CLL) patients in a phase I trial showed an ORR of $35 \%{ }^{22}$. Adverse events included dosage-dependent thrombocytopenia ${ }^{23}$. Combined with Rituximab an improved ORR of $55 \%$ was observed in CLL patients in phase 2 studies, and this treatment was well tolerated 24,25 . Thus, combination treatments with Navitoclax may increase outcome without compromising adverse events.

Several studies have shown effective dual inhibition of BCL-2 and PI3K p110 a and $\delta$ pathways and induction of apoptosis in different tumour cells in vitro i.e. human myeloid leukaemia (HML), glioblastoma as well as small cell lung cancer (SCLC) ${ }^{26-28}$. A combined inhibition of BCL-2 and of the active PI3K pathway in MCC thus may also improve the treatment outcome of MCC. In this study, we first analysed the expression of BCL-2 in 47 MCCs, 5 MCC cell lines and one B-cell acute lymphoblastic (B-ALL) cell line. Subsequently, the efficacy of the Navitoclax monotreatment and combinations with the PI3K inhibitor Alpelisib were investigated. 


\section{MATERIALS AND METHODS}

\section{PATIENT SAMPLES}

The MCC tissues were obtained from the Laboratory of Translational Cell and Tissue Research, University of Leuven, Belgium, $(n=16)$ and the Department of Pathology, Maastricht University Medical Centre+ (MUMC+), the Netherlands, ( $n=$ 37) (Table 1). These tissues are part of the "Study on the cellular origin of Merkel cell carcinoma - towards innovative treatment", which is validated by the Clinical Trial Center of the University Hospital Leuven under the reference number 67603 and Local MUMC+, MPTC protocol number: 2013-11. The use of all patient material and patient data was in agreement with the Dutch Code of Conduct for Observational Research with Personal Data (2011) and Tissue (2011,https://www.federa.org/sites/default/files/digital version first part code o f conduct in uk 2011 12092012.pdf). MCCs were previously diagnosed by histology and immunohistochemistry (CK20, CD56, synaptophysin and chromogranin $A$ ) in routine diagnostic setting and have been reviewed by three experienced pathologists (JVO, VW, AZH).

\section{CELL LINES}

The MCPyV-positive MCC cell lines MKL-1, MKL-2, WaGa, PeTa; the MCPyVnegative MCC cell line MCC13 and the B-ALL cell line REH were used. All MCC cell lines were kindly provided by Jürgen Becker (University Hospital Essen, Essen, Germany). REH was obtained from the Leibniz Institute DSMZ-German Collection of Microorganisms and Cell Cultures. The cell lines were cultured in Gibco® RPMI 1640 medium (Life-science) with 10\% fetal calf serum (FCS) (Gibco®, Thermo Fisher Scientific) in an incubator at $37^{\circ} \mathrm{C}$ and $5 \% \mathrm{CO} 2$. 


\section{IMMUNOHISTOCHEMISTRY}

All procedures of immunohistochemistry $(\mathrm{IHC})$ were performed on FFPE tissues and FFPE cell lines. The expression of BCL-2 was tested by immunohistochemistry in the Leuven cohort $(n=16)$ and the MUMC+ cohort $(n=37)$. In total 37 primary and 16 metastatic MCCs were assessed in this study. In addition, BCL-2 expression was tested in the MCPyV-positive MCC cell lines MKL-1, MKL-2, in the MCPyV-negative MCC cell line MCC13 and in the B-cell acute lymphoblastic leukemia (B-ALL) cell line REH. The following antibodies and dilutions were used in this study: anti-Flex BCL-2 Oncoprotein MxH clone 124 (Dako, the netherlands) ready to use; Anti-BCL-XL clone OTI2D1 1:300 (LsBio, USA) and anti-BCL-W polyclonal antibody 1:300 (LsBio, USA). The IHC detection was conducted on a Dako Autostainer 48 Link using the EnVision FLEX Visualization Kit K8008 Dako as described previously and according to standard diagnostic routine protocols and manufacturer's instructions ${ }^{32}$.

qRT-PCR

RNA was extracted using the RNA isolation kit "NucleoSpin RNA" according to the manufacturer's instructions (Macherey-Nagel, Germany). The RNA concentration was measured with the Nanodrop 2000 (ThermoFisher SCIENTIFIC, The Netherlands). RNA was converted into CDNA using the "iScript ${ }^{\mathrm{TM}}$ Select cDNA Synthesis Kit" (Bio-Rad, the Netherlands). A quantitative RT-PCR was performed for the analysis of BCL-2 expression in the cell lines MKL1, MKL-2, WaGa, PeTa, MCC13, and REH using the forward primer 5'CTGCACCTGACGCCCTTCACC-3' and the reverse primer 5'CACATGACCCCACCGAACTCAAAGA-3'33.

The resulting $C_{t}$ values were normalized using the housekeeping gene GAPDH which was amplified using following primers forward 5'AGGGCTGCTTTTAACTCTGGT-3' and reverse 5' CCCCACTTGATTTTGGAGGGA-3: The qRT-PCR was performed by using the SYBR Green Supermix (Bio-Rad, the Netherlands) on the CFX96 PCR Detection System (Bio-Rad, the Netherlands) and recorded by the Bio-Rad CFX manager. All used primers were obtained from Eurofins Genomics, Germany. 


\section{WESTERN BLOTTING}

The MCPyV-positive cell lines MKL-1, MKL-2, WaGa, PeTa and MCPyV-negative cell line MCC13 and the B-ALL cell line REH were grown in T25 flasks $\left(25 \mathrm{~cm}^{2}\right)$. The cells were harvested, pelleted, washed with cold PBS and lysed in RIPA lysisbuffer (Cell Signaling Technology, the Netherlands) containing phosphataseprotein inhibitor cocktail (Thermo Fisher Scientific, the Netherlands). The protein concentration was determined by using the Pierce ${ }^{\mathrm{TM}}$ BCA Protein Assay Kit (Thermo Fisher Scientific, the Netherlands) according to the manufacturer's instructions. $25 \mu \mathrm{g}$ protein samples were separated by SDS-PAGE in $8 \%(\mathrm{w} / \mathrm{v})$ polyacrylamide gels, transferred to nitrocellulose membranes according to the manufacturer's instructions using Bio-Rad Mini Protean tetra systems (Bio-Rad Laboratories, the Netherlands). Followed by blocking with 5\% BSA (SigmaAldrich, the Netherlands), incubated with primary antibodies anti-BCL-2 clone 124 (Dako, the Netherlands) 1:500, anti- full length and cleaved PARP clone 46D11 (Cell Signaling Technology, the Netherlands) 1:1000, anti-a-tubulin clone 23610501 (Thermo Fisher Scientific, the Netherlands) 1:5000, and monoclonal anti$\beta$-actin antibody clone AC-15 1:10000 (Sigmal-Aldrich, the Netherlands) diluted in blocking buffer and incubated over night at $4^{\circ} \mathrm{C}$, washed and incubated with the secondary antibody Alkaline Phosphatase AffiniPure F(ab')2 Fragment Goat AntiMouse/Rabbit IgG + IgM (H+L) (Jackson ImmunoResearch, USA). The blots were developed by NBT/BCIP (Thermo Fisher Scientific, the Netherlands) incubation according to the manufacturer's instructions. The blots were scanned using Canon CanoScan 9000F Mark II. The quantification of the protein bands was performed using Image $J^{34}$. The protein of interest signals were normalized to the corresponding loading control.

\section{TREATMENT OF CELL LINES}

The cell lines MKL-1, MKL-2, WaGa, MCC13 and REH were treated with Navitoclax (MedChemExpress, Sweden), ALPELISIB (MedChemExpress, Sweden), Vincristine (Sigma-Aldrich, the Netherlands) and Doxorubicin (SigmaAldrich, the Netherlands). All compounds were dissolved in DMSO. Following concentrations were used for the treatment with Navitoclax: $10 \mathrm{nM}, 25 \mathrm{nM}, 50 \mathrm{nM}$, 75nM, 100nM, 125nM, 150nM, 200nM, 250nM, 300nM, 350nM, 400nM, 450nM and $500 \mathrm{nM}$. The concentrations for Alpelisib 10nM, 100nM, 250nM, 500nM, $1 \mu \mathrm{M}$ 
$12.5 \mu \mathrm{M}, 25 \mu \mathrm{M}$ and $50 \mu \mathrm{M}$. Following concentrations were used of Vincristine $0.05 \mathrm{nM}, 0.1 \mathrm{nM}, 0.5 \mathrm{nM}, 1.0 \mathrm{nM}, 5.0 \mathrm{nM}$ and 10nM. For the Doxorubicin 0.5nM, $1 \mathrm{nM}, 5 \mathrm{nM}, 10 \mathrm{nM}, 25 \mathrm{nM}, 50 \mathrm{nM}, 100 \mathrm{nM}$ and 500nM. The cells were incubated in a 96 well plate (Greiner Bio-One, Austria) for $72 \mathrm{~h}$ with different concentrations of Navitoclax, Doxorubicin and Vincristine as well as for $120 \mathrm{~h}$ with different concentrations of Alpelisib in Gibco ${ }^{\circledR}$ RPMI 1640 medium (Life-science, the Netherlands) with $10 \%$ fetal calf serum (FCS) (Gibco®, Thermo Fisher Scientific, the Netherlands) in an incubator at $37^{\circ} \mathrm{C}$ and $5 \% \mathrm{CO} 2$. The effect of the drugs on the cell viability was assessed by the XTT assay (Thermo Fisher Scientific, the Netherlands) according to the protocol provided by the manufacturer. The read out of the XTT assay was done with the iMark ${ }^{\text {TM }}$ Microplate Absorbance Reader (Bio-Rad Laboratories, the Netherlands). For the combination experiments of Vincristine, Doxorubicin and Alpelisib with Navitoclax the single effect of all compound concentrations on the cell viability was measured and compared with the combinations. The apoptotic effect of the compounds on the cells was assessed by Western blot detection of cleaved PARP. Cleaved PARP was detected after $24 \mathrm{~h}$ treatment with some concentrations of all compounds with and without combinations.

\section{ANNEXIN-V AND PI APOPTOSIS ASSAY}

For the apoptosis assay the REH and WaGa cells were cultured in T75 flasks (Corning, The Netherlands) in RPMI 10\% FCS at a cell concentration of $2 * 10^{5}$ cells $/ \mathrm{mL}$. The cells were treated with Vincristine or Alpelisib alone and in combination with Navitoclax for $96 \mathrm{~h}$. At the incubation start and after each $24 \mathrm{~h}$ the cell number was measured using the TC20 Automated Cell Counter (Bio-Rad Laboratories, the Netherlands). In addition, at every time point a $1 \mathrm{~mL}$ sample was taken and stained with Annexin-V-FITC as well as with phosphatidylinositol (PI) (Sigma-Aldrich, the Netherlands). The Annexin-V-FITC was kindly provided by C. Reutelingsperger, Department of Biochemistry, Cardiovascular Research Institute Maastricht and used as described by Vermes et al. 35

Half of the stained cells was used for fluorescence-activated cell sorting (FACS). For the right gating $\mathrm{REH}$ and $\mathrm{WaGa}$ cells were treated with $1 \mu \mathrm{M}$ Staurosporin. For right gating of the cells unstained cells or stained cells only with Annexin-V-FITC or PI were used. For the Annexin-V positive cells the FITC gate and for PI the PE- 
Cy7 gate were used. Thus, the necrotic cells were detected with the PE-Cy7 gate. The early apoptotic cells were detected with the FITC gate and the late apoptotic cells were the cells which are detected by both gates.

The other part of the cells was used to make a cytospin of all Annexin- $V$ as well as PI stained cells with the Cyto-Tek Centrifuge (SAKURA, the Netherlands). The nuclei of the cells were stained with DAPI mounting medium (VECTASHIELDVECTOR LABORATORIES, USA) according manufacturer's instructions. The detection of the fluorescence stained cells was performed with the Leica microscope DM 5000 B (Leica, the Netherlands).

\section{STATISTICS}

The half maximal inhibitory concentration $\left(\mathrm{IC}_{50}\right)$ values were determined with Graphpad Prism 8. By using the One-Way ANOVA test the significance of the dose response curves was determined P-values $<0.5$ are considered as significant. Further, the combinatory index $(\mathrm{Cl})$ for the different combinations are determined to state if the combinatory effect for a range of combinations is synergistic, additive or antagonistic. First, the HillSlope $(\mathrm{H})$ and the $\mathrm{IC}_{50}$ values were used to calculate $\mathrm{IC}_{\mathrm{n}}$ in the range from $\mathrm{IC}_{10}$ to $\mathrm{IC}_{90}$

$$
I C_{n}=\left(\frac{n}{100-n}\right)^{\frac{1}{H}} * I C_{50}
$$

From the different $\mathrm{IC}_{\mathrm{n}} \mathrm{s}$ the $\mathrm{Cls}$ for the different combinations are calculated. For every calculate IC one Navitoclax concentration stays constant and the concentration of the second compound varies. For the calculation of the Cls the corresponding IC of Navitoclax $\left(\mathrm{IC}_{\mathrm{nC} 1}\right)$ and of the second compound $\left(\mathrm{IC}_{\mathrm{nC} 2}\right)$ are used.

$$
C I=\frac{\operatorname{conc}_{C 1}}{I C_{C 1}}+\frac{\operatorname{conc}_{C 2}}{I C_{C 2}}
$$

The different calculated $\mathrm{Cls}$ for the different combinations (conc $\mathrm{c}_{1}$ and concc2 $_{2}$ ) are used to generate a $3 \mathrm{D}$ isobologram plot. The $3 \mathrm{D}$ isobologram generation was performed using the R package "scatterplot3d"36,37. Red marked region illustrates a synergistic effect $(\mathrm{Cl}<1)$ of both compounds, whereas white and blue represent an additive $(\mathrm{Cl}=1)$ and antagonistic $(\mathrm{Cl}>1)$ effect, respectively. 


\section{RESULTS}

CYTOPLASMIC EXPRESSION OF BCL-2 IN MCC

BCL-2 expression was assessed in 47 FFPE MCC tissues and 5 MCC cell lines by immunohistochemistry, and semi quantitatively scored from negative (-) to very strong positive (+++) as illustrated in Figure 1 (A to E). In total, $98 \%$ (46 out of 47 ) of MCCs as well as all the MCPyV-positive cell lines (MKL-1, MKL-2, WaGa and $\mathrm{PeTa}$ ) revealed a specific cytoplasmic expression of BCL-2. The intensity of expression varied between the MCC tissues: $34 \%$ (16 out 47) very strong, $36 \%$ (17 out of 47 ) strong, 23\% (11 out of 47 ) moderate and $4 \%$ (2 out of 47 ) weak (Table 1). The MCPyV-negative cell line MCC13 was negative for BCL-2 (Figure $1 \mathrm{~F}$ ). The BCL-2 expression in cell lines was confirmed on RNA-level by quantitative RT-PCR and on protein-level by Western blot (Figure $1 \mathrm{G}$ and $\mathrm{H}$ ).

\section{BCL-2 INHIBITION INDUCES APOPTOSIS IN MCC CELLS}

The MCC cell lines WaGa, MKL-1, MKL-2 and MCC13 as well as the B-ALL cell line REH were treated with different concentrations (range $1 \mathrm{nM}$ to $1 \mu \mathrm{M}$ ) of the specific BCL-2 inhibitor Navitoclax (Figure 11). With increasing concentrations, the cell viability decreased. For all cell lines except for BCL-2 negative MCC13 (due to poor response) dose-response curves and $\mathrm{I}_{50}$ values could be generated. MKL-1, WaGa and REH demonstrated similar high sensitivity towards Navitoclax treatment ( $\mathrm{IC}_{50}$ around 100nM). Surprisingly, MKL-2 was less sensitive $\left(\mathrm{IC}_{50}=323.3 \mathrm{nM}\right)$, whereas this cell line showed a high $\mathrm{BCL}-2$ expression.

Subsequently, we assessed if BCL-2 inhibition promotes apoptosis, as assessed by the detection of cleaved PARP protein by apoptosis activated caspases. Indeed, all cell lines except MCC13 (Figure $1 \mathrm{~L}$ and M) showed increase of different levels of cleaved PARP with increasing Navitoclax concentration. 
7A | EFFECTIVE INHIBITION OF CELL GROWTH IN VITRO

Table 1: Summary of clinicopathological data of patients with Merkel cell carcinoma (MCC) as well as immunohistochemistry for MCPyV and BCL-2 expression

\begin{tabular}{|c|c|c|c|c|c|}
\hline \multicolumn{4}{|c|}{ Merkel cell carcinoma clinicopathological data } & \multicolumn{2}{|c|}{ Immunohistochemistry } \\
\hline ID & Gender & $\begin{array}{l}\text { primary or } \\
\text { metastasis }\end{array}$ & $\begin{array}{l}\text { Tumour } \\
\text { localization }\end{array}$ & MCPyV & BCL-2 \\
\hline L-MCC2 & M & met. & $\begin{array}{l}\text { para-aortic lymph } \\
\text { node }\end{array}$ & + & ++ \\
\hline L-MCC5 & M & prim. & lower leg & + & ++ \\
\hline L-MCC6 & $\mathrm{F}$ & met. & inguinal lymph node & + & + \\
\hline L-MCC7 & M & prim. & face & + & +++ \\
\hline L-MCC8 & M & met. & upper leg & + & ++ \\
\hline L-MCC10 & $\mathrm{F}$ & met. & subcutis & $(+)$ & ++ \\
\hline L-MCC12 & $\mathrm{F}$ & met. & skin & - & +++ \\
\hline L-MCC13 & $\mathrm{F}$ & prim. & face & + & $(+)$ \\
\hline L-MCC14 & $\mathrm{F}$ & prim. & upper arm & - & +++ \\
\hline L-MCC15 & $M$ & met. & upper arm & + & + \\
\hline L-MCC16 & $M$ & met. & inguinal lymph node & + & $(+)$ \\
\hline L-MCC17 & $\mathrm{F}$ & prim. & skin & + & +++ \\
\hline L-MCC18 & M & met. & axillary lymph node & + & +++ \\
\hline M-MCC2 (14) & M & prim. & outer ear & - & ++ \\
\hline M-MCC3 (13) & $\mathrm{F}$ & prim. & cheek & +++ & ++ \\
\hline M-MCC4 (1) & M & prim. & suboccipital & + & ++ \\
\hline M-MCC11 (21) & M & met. & pancreas & +++ & ++ \\
\hline M-MCC14 (3) & $\mathrm{F}$ & prim. & upper eye & +++ & +++ \\
\hline M-MCC15 (18) & $\mathrm{F}$ & prim. & tongue & + & ++ \\
\hline M-MCC20 (4) & $\mathrm{F}$ & prim. & cheek & +++ & + \\
\hline M-MCC24 (7) & $\mathrm{F}$ & prim. & knee & +++ & $(+)$ \\
\hline M-MCC25 (10) & $\mathrm{F}$ & prim. & dorsal upper arm & +++ & +++ \\
\hline M-MCC26 (8) & $\mathrm{F}$ & prim. & upper eye lid & +++ & - \\
\hline M-MCC27 (16) & $\mathrm{F}$ & prim. & glabella & ++ & +++ \\
\hline M-MCC40 (20) & M & prim. & upper leg & +++ & +++ \\
\hline M-MCC46 & M & prim. & infra-auricular & - & ++ \\
\hline
\end{tabular}




\begin{tabular}{|c|c|c|c|c|c|}
\hline M-MCC47 & $\mathrm{F}$ & prim. & Lower arm & +++ & ++ \\
\hline M-MCC50 & $M$ & prim. & cheek & + & - \\
\hline M-MCC52 & $\mathrm{F}$ & prim. & cheek & +++ & ++ \\
\hline M-MCC54 & $\mathrm{M}$ & prim. & gluteus area & +++ & ++ \\
\hline M-MCC56 & $\mathrm{F}$ & prim. & cheek & +++ & ++ \\
\hline M-MCC57 & $M$ & prim. & upper leg & +++ & - \\
\hline M-MCC58 & $\mathrm{M}$ & met. & lymph node & - & + \\
\hline M-MCC59 & $\mathrm{F}$ & prim. & upper arm & +++ & + \\
\hline M-MCC60 & $\mathrm{F}$ & met. & lymph node & +++ & +++ \\
\hline M-MCC61 & $\mathrm{M}$ & met. & lymph node & ++ & ++ \\
\hline M-MCC62 & $\mathrm{M}$ & prim. & cheek & - & ++ \\
\hline M-MCC64 & $M$ & prim. & upper lip & & ++ \\
\hline M-MCC65 & $\mathrm{F}$ & met. & lymph node & +++ & +++ \\
\hline M-MCC66 & $M$ & prim. & skin & ++ & + \\
\hline M-MCC67 & $\mathrm{F}$ & prim. & skin & - & + \\
\hline M-MCC69 & $M$ & prim. & skin & - & +++ \\
\hline M-MCC70 & $\mathrm{M}$ & met. & cheek & +++ & +++ \\
\hline M-MCC71 & $\mathrm{F}$ & prim. & upper leg & + & $(+)$ \\
\hline M-MCC72 & $\mathrm{F}$ & prim. & cheek & + & + \\
\hline M-MCC74 & $M$ & prim. & gluteus area & - & $(+)$ \\
\hline M-MCC78 & $\mathrm{F}$ & prim. & cheek & - & +++ \\
\hline & & & & & $\begin{array}{l}44 / 47 \\
94.0 \% \\
\end{array}$ \\
\hline
\end{tabular}

Abbreviation used: ID = identity; L-MCC = Merkel cell carcinoma from the Leuven cohort; M-MCC = M Merkel cell carcinoma from the Maastricht cohort $=$ male; $\mathrm{F}=$ female ; prim. $=$ primary; met. = metastasis; $-=$ no expression, $(+)=$ weak expression; $+=$ moderate expression; $++=$ strong expression, $+++=$ very strong expression; in grey marked patient data and ID numbers in brackets are the numbers also reported in zur Hausen et al. 2013 

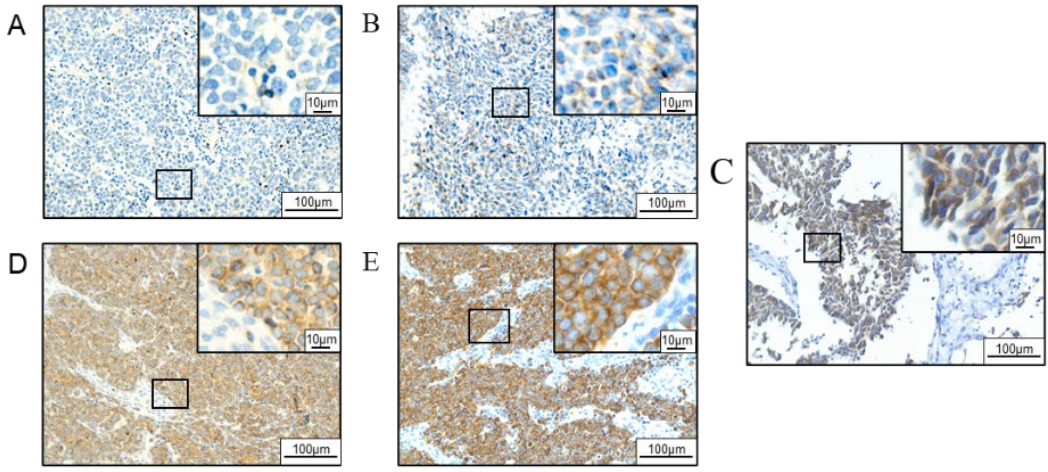

$\mathrm{F}$

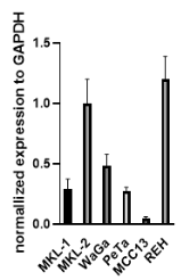

G

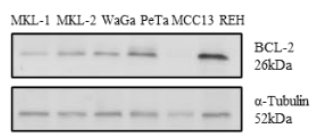

$\mathrm{H}$

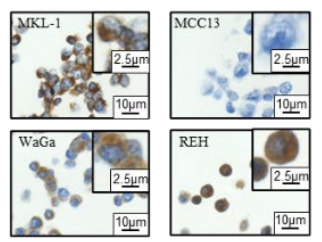

I

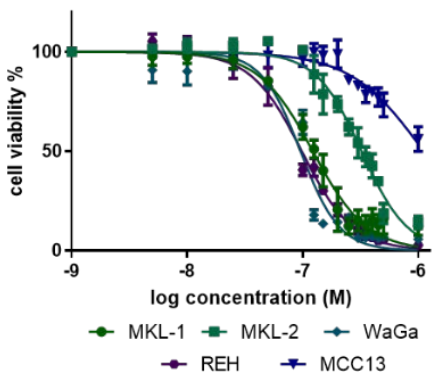

$\mathrm{J}$

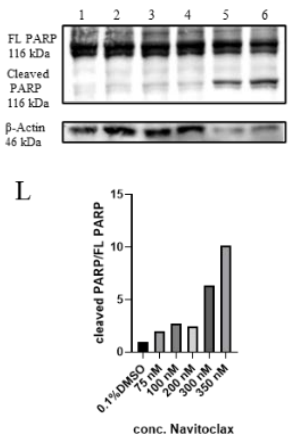

$\mathrm{K}$

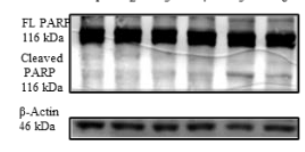

M

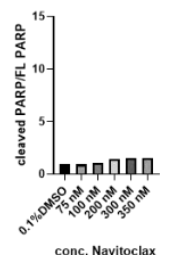

Figure 1: Presence of BCL-2 in MCC tissue as well as in cell lines and successful BCL-2 inhibition of MCC cell lines induces apoptosis

Exemplarily negative (A), weak (B), moderate (C), strong (D), very strong (E) cytoplasmatic expression of BCL-2 in the MCC tissues M-MCC50, M-MCC21, M-MCC20, M-MCC4 and M-MCC14, respectively, are shown by immunohistochemistry staining. The expression of BCL-2 in MCPyV-positive cell lines MKL-1, MKL-2, WaGa and PeTa is confirmed on RNAlevel by q-RT-PCR $(\mathbf{F})$ and on protein-level by Western Blot $(\mathbf{G})$. Exemplarily the moderate BCL-2 expression is shown in the MCC MKL-1 and WaGa cells assessed by IHC $(\mathbf{H})$. The treatment of the MCC cell lines with the specific BCL-2 inhibitor Navitoclax gained in doseresponse curves for all assessed cell lines except MCC13 (I). The cell viability was assessed by the XTT-viability assay. Exemplarily, the apoptotic effect of Navitoclax is assessed for MKL-2 $(\mathbf{J})$ and MCC13 $(\mathbf{K})$ by the detection of cleaved PARP. normalized to. The normalization against $\beta$-Actin and full length (FL) PARP of these Westerns blots is shown in L for MKL-2 and in M for MCC13. The tissue microphotographs were taken at 20x magnification, the squares in the right corner of the images were a 40x magnification of the tissue cells. The cell line microphotographs were taken at $40 x$ magnification. 
Subsequently, we assessed if BCL-2 inhibition promotes apoptosis, as assessed by the detection of cleaved PARP protein by apoptosis activated caspases. Indeed, all cell lines except MCC13 (Figure 1L and M) showed increase of different levels of cleaved PARP with increasing Navitoclax concentration.

\section{EFFECT OF THE PI3K P110A INHIBITOR ALPELISIB WITH NAVITOCLAX ON CELL GROWTH AND APOPTOSIS}

Since we recently reported that the PI3K p110a inhibitor Alpelisib is a potent inhibitor of MCC cell growth in vitro, we investigated the efficacy of the combination of Alpelisib with Navitoclax in the $4 \mathrm{MCC}$ cell lines and REH. Treatment with Alpelisib alone (AN0) resulted in $\mathrm{IC}_{50}$-values ranging from $2.2 \mu \mathrm{M}$ in $\mathrm{REH}$ to $32.2 \mu \mathrm{M}$ in MCC13 (Figure $2 \mathrm{~A}, \mathrm{~B}, \mathrm{C}$, Figure S2 A, B and Table 2). Subsequently the cell lines were treated with increasing concentrations of Navitoclax added to the eight Alpelisib concentrations used to produce the ANO dose-response curve, i. e. WaGa, MKL-1 and REH (more sensitive to Navitoclax) were treated with Navitoclax concentrations ranging from 25 to 100nM (AN25 to AN100), and MKL-2 and MCC13 (less sensitive to Navitoclax) with concentration ranging from 200 to 400nM (AN200 to AN400) (Figure 2 and Figure S2).

In comparison to Alpelisib alone the combination treatment resulted in stronger inhibitions of cell growth, but differed in sensitivity when comparing WaGa, MKL1, MKL-2 and REH. The sensitivity of WaGa and MKL-1 increased 100-fold, of $\mathrm{REH}$ and MKL-2 10-fold. This is also reflected in the $\mathrm{IC}_{50}$-values of these treatments which decreased with increasing Navitoclax concentrations (Figure 2D, E, F and Figure S2B). MCC13 did not show any increase in cell growth inhibition which was in line with the lack of response to Navitoclax (Figure S2).

Interestingly, WaGa cells showed only at the two higher Navitoclax concentrations (75nM and $100 \mathrm{nM})$ a higher sensitivity for the combined treatment than for Alpelisib alone (Figure 2A). This observation indicates that some combinations of Navitoclax and Alpelisib complement each other and other combinations counter act each other. Such effects can also be visualized using 3D isobologram plotting according to the Chou-Talalay method ${ }^{29}$ (Figure $2 \mathrm{G}, \mathrm{H}, \mathrm{I}$ ). With this method one can visualize if combinations of inhibitors at certain concentrations are synergistic, additive or antagonistic. This can be represented by the combination index $(\mathrm{Cl})$ : $\mathrm{Cl}<1$, synergistic; $\mathrm{Cl}=1$, additive; $\mathrm{Cl}>1$, antagonistic. In WaGa cells synergy was 
observed when the Navitoclax concentration was $\geq 60 \mathrm{nM}$ and the Alpelisib concentration was $\leq 10 \mu \mathrm{M}$ (Figure 2G; red coloured area). At other combinations the inhibitory effect on the cell viability was additive or even antagonistic (Figure 2G; white and blue coloured area, respectively). In contrast, in MKL-1 cells the combined treatment showed a large range of possible concentrations with which synergy could be obtained (Figure $2 \mathrm{H}$ ).

In MKL-2 cells synergy again was seen at smaller range of concentrations i.e. 200nM of Navitoclax combined with Alpelisib concentrations between $1 \mu \mathrm{M}$ and $12.5 \mu \mathrm{M}$ (Figure 2C and I). In REH cells maximal synergy of the combined treatment could be observed compared to the other cell lines (Figure 2). It is clear from the dose-response curves and the 3D plots that synergy especially is obtained at concentrations where inhibition is at its maximum (Figure 2).

Table 2: Summary of the BCL-2 immunostaining results in the 4 MCC cell lines and $\mathrm{REH}$, as well as the calculated $\mathrm{IC}_{50}$-values when treated with Navitoclax

\begin{tabular}{|llllll|}
\hline & \multicolumn{3}{c}{ IHC } & \multicolumn{2}{c|}{ IC $_{50}$ treatment } \\
\hline Cell lines & $\begin{array}{l}\text { Derived } \\
\text { from }\end{array}$ & MCPyV & BCL-2 & Navitoclax & Alpelisib \\
WaGa & MCC & + & + & $95.6 \mathrm{nM}$ & $5.1 \mu \mathrm{M}$ \\
MKL-1 & MCC & + & + & $122.0 \mathrm{nM}$ & $18.2 \mu \mathrm{M}$ \\
MKL-2 & MCC & + & + & $323.3 \mathrm{nM}$ & $18.4 \mu \mathrm{M}$ \\
MCC13 & MCC & - & - & n.d. & $32.2 \mu \mathrm{M}$ \\
REH & B-ALL & - & + & $98.0 \mathrm{nM}$ & $2.2 \mu \mathrm{M}$ \\
\hline
\end{tabular}

Abbreviation used: IHC = immunohistochemistry; $\mathrm{MCC}=$ Merkel cell carcinoma; $\mathrm{B}-\mathrm{ALL}=$ B-cell acute lymphoblastic leukaemia; MCPyV- = no expression; + = expression; $I_{50}=$ the half maximal inhibitory concentration; n.d. = could not be determined based on the dose response curve 


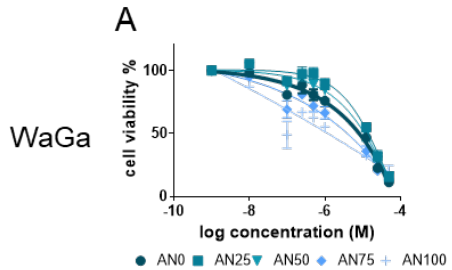

B

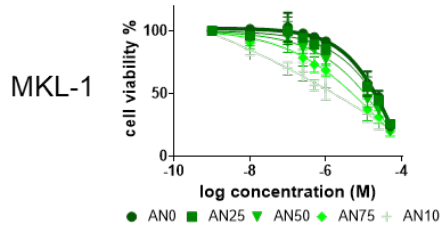

C

MKL-2
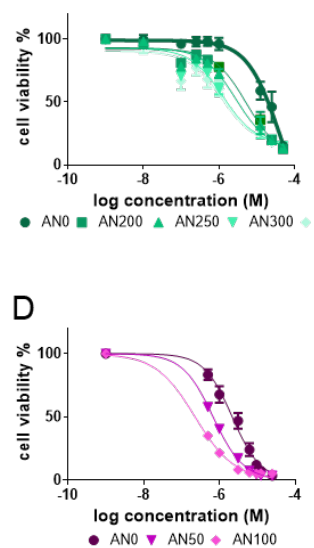

$\mathrm{E}$

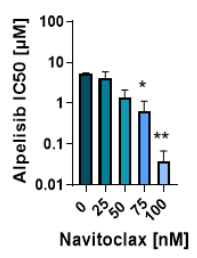

I

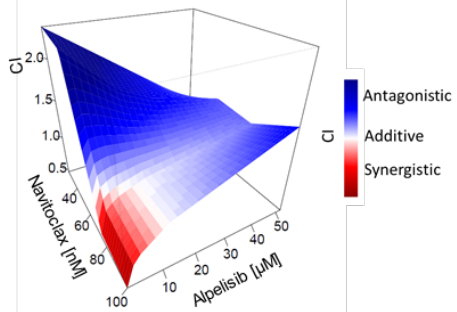

F

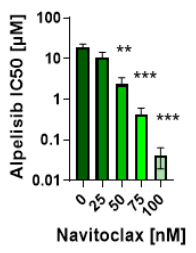

$J$

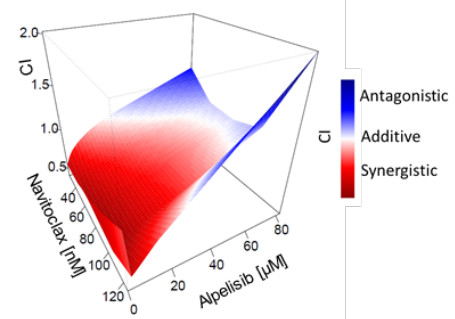

$\mathrm{K}$
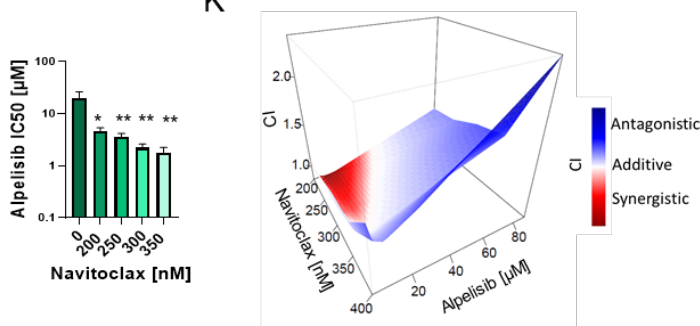

$\mathrm{H}$

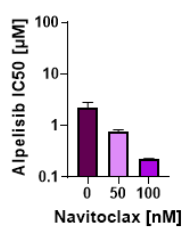

Figure 2: Significant synergistic combinatorial effect of Alpelisib and Navitoclax on the MCC cell line cell viability

The dose response curves for Alpelisib without Navitoclax for the MCPyV-positive MCC cell lines (MKL-1 (A), MKL-2 (B), WaGa (C) and REH (D)) are illustrated by the AN0 curves. The increasing concentrations (nM) of Navitoclax are illustrated by the numbers AN25, BN50, AN75, AN100 etc. The calculated $\mathrm{IC}_{50}$ of Alpelisib alone and in combination with different Navitoclax concentrations ( $\mathrm{nM}$ ) are shown for the corresponding cell line (E to $\mathbf{H})$. The 3D combinatory index $(\mathrm{Cl})$-plots visualize the combined concentrations of Navitoclax and Alpelisib which are synergistic (red), additive (white) or antagonistic (blue) (I to L). The red circle in the dose response curves illustrates the determined synergistic range. The standard errors are illustrated by the standard error of the mean (SEM). $\left({ }^{*}=p<0.05\right) ;\left({ }^{* *}=\right.$ $p<0.01) ;(* * *=p<0.001)$ 
Because we have earlier seen that Navitoclax can induce apoptosis, we investigated if the combined Alpelisib-Navitoclax treatment within $24 \mathrm{~h}$ resulted in higher levels of cleaved PARP assessed by Western blotting (Figure 3). For WaGa, MKL-1 and REH an increase of cleaved PARP could be detected at the highest concentrations used. Treatment of $\mathrm{WaGa}$ cells showed that particularly Navitoclax promotes apoptosis that only can be increased in combination with the highest Alpelisib concentration (synergistic effect) (Figure 3). In contrast, in REH cells the combination of Navitoclax with the highest Alpelisib concentration resulted in increased cleaved PARP (synergistic effect). In MKL-2 cells an increase of cleaved PARP was observed with increasing Alpelisib concentrations but was more optimal at the $300 \mathrm{nM}$ than the $350 \mathrm{nM}$ Navitoclax concentration (Figure $3 \mathrm{D}$ ). This is in agreement with the observation that the first concentration is in the synergistic and the second is in the additive range (Figure $2 \mathrm{I}$ ). No apoptosis induction was detected in MCC13 cells (Figure $3 \mathrm{E}$ ). 

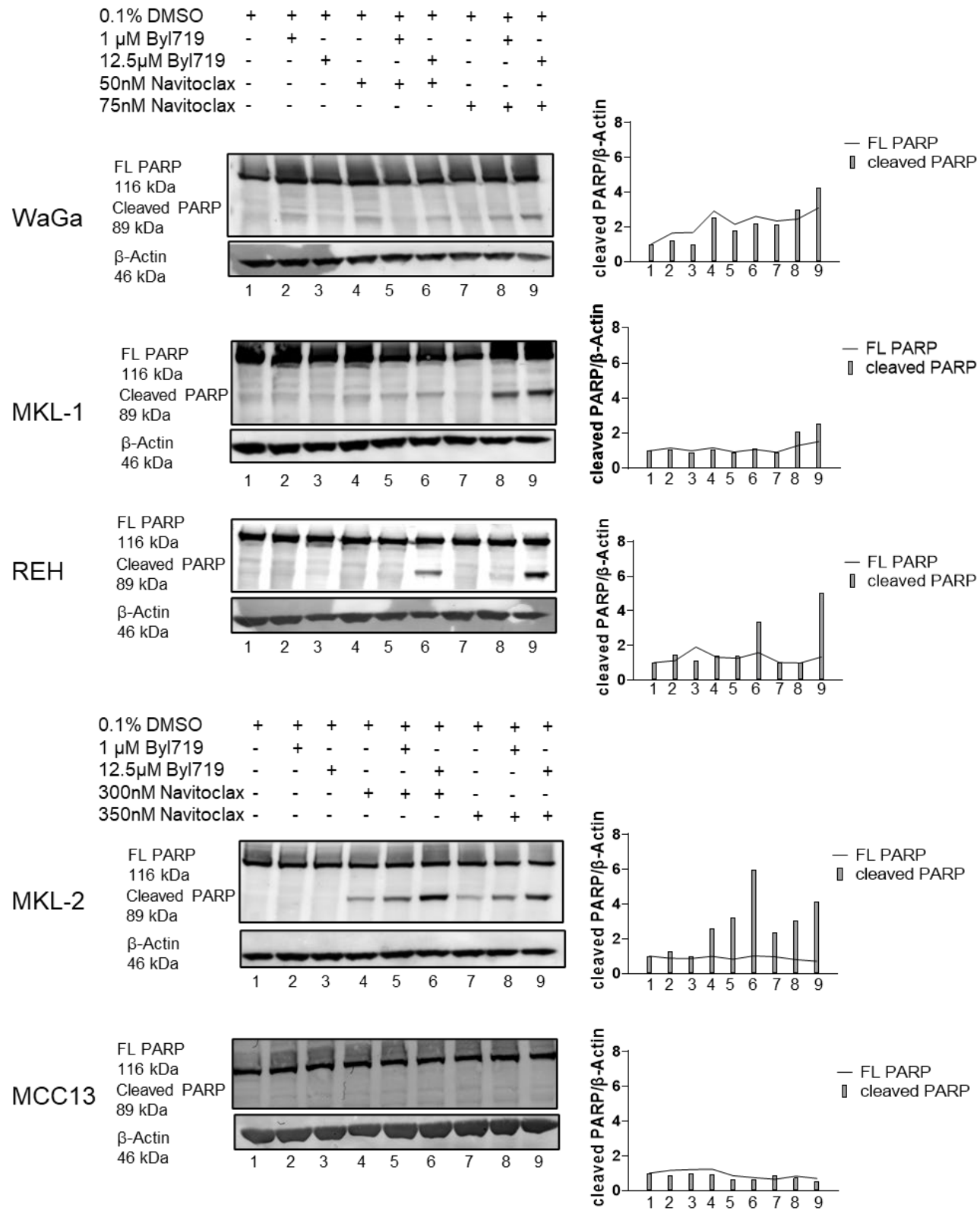

Figure 3: Combinatorial apoptotic effect of Alpelisib and Navitoclax on the MCC cell lines

Different concentrations of Navitoclax and Alpelisib alone and in combination are used to treat the MCC cell lines MKL-1, MKL-2, WaGa and MCC13 as well as the B-ALL cell REH. The MCC cell lines and REH except MCC13 reveal a stronger cleaved band abundance compared to Navitoclax and Alpelisib without combination as seen by westernblot and quantification using Image J. 
In order to assess the long-term effect of the combined treatment on apoptosis induction, we incubated WaGa and REH cells with 100nM Navitoclax and 12.5 $\mu \mathrm{M}$ Alpelisib alone and in combination for five days and analysed apoptosis using the Annexin-V propidium iodide (PI) FACS-assay. MKL-1 and MKL-2 cells were omitted in this experiment because of their different growth pattern (cell clumps) which is a limitation for this assay. FACS analyses separated WaGa as well as REH cells into live ( $\mathrm{PI}$, Annexin-V negative), necrotic ( $\mathrm{Pl}$-single positive), early apoptotic (Annexin-V-single positive) and late apoptotic ( $\mathrm{PI}$ as well as Annexin-V positive) cells (Figure S4). The increase or decrease of these cell populations was recorded for five days. In WaGa cells the level of necrotic cells was low and did not increase during treatment (Figure 4), whereas the number of Annexin-V positive apoptotic cells increased significantly (Figure 4). As previously seen for cleaved PARP Navitoclax alone but in particularly in combination with Alpelisib strongly induced apoptosis (14.2 and 44.6\%, respectively) already within 24 hours of treatment. While after 24 hours the percentage of apoptotic cells decreased for Navitoclax and slightly increased for Alpelisib, it remained significantly higher for the Alpelisib-Navitoclax treated cells. Remarkably, the combined treatment resulted in a strong increase of late apoptotic cells and a more slowly increase of early apoptotic cells. In comparison to Navitoclax or Alpelisib alone these data suggest that in WaGa cells Navitoclax boosts apoptosis within the first 24 hours which is slowly continued of the synergistic effect of Alpelisib in the next three incubation days. In REH cells a similar effect on apoptosis induction was observed but to a lesser extent (Figure 4). Thus, compared to the single treatments the apoptotic effect of the Alpelisib-Navitoclax combination persisted and resulted in higher apoptotic cell numbers in both cell lines. 

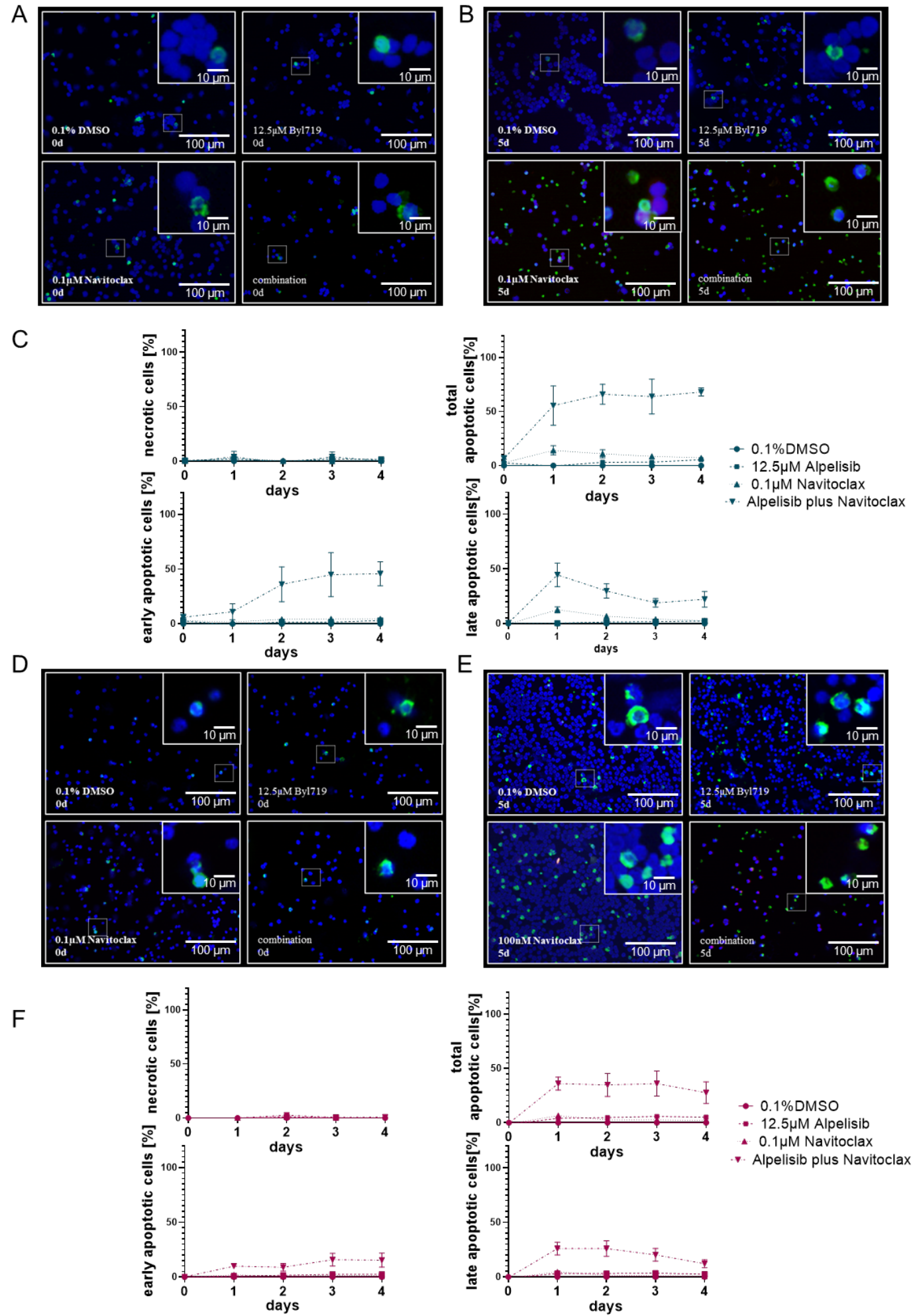
Figure 4: Combined Alpelisib-Navitoclax treatment induces increased apoptosis in WaGa and REH cells. Only the Alpelisib-Navitoclax combination inhibit cell growth.

WaGa and REH cells were treated with Alpelisib in combination with and without Navitoclax for 5 days. After each day, the early apoptotic cells were detected by Annexin- $V$ (GFP/green). The late apoptotic cells were detected with nuclear PI staining (red) and membranous Annexin- $V$ (green). A part of the treated cells was stained additionally with DAPI and visualized using fluorescence microscopy. Exemplarily, the cell staining of day 0 and day 4 were shown for, the $0.1 \%$ DMSO control Alpelisib, Navitoclax and combinations of Alpelisib with Navitoclax (A, B for WaGa and D, E for REH). Further, the necrotic cells (PI positive), all apoptotic cells (early and late), the early apoptotic cells (Annexin-Vpositive) and late apoptotic cells (PI- and Annexin-V-positive) which were determined by FACS screening were shown. For the PI detection the PE-Cy7 and for the Annexin-V the FITC gates were used ( $\mathbf{C}$ for $\mathrm{WaGa}$ and $\mathbf{F}$ for $\mathrm{REH}$ ). 


\section{DISCUSSION}

The aim of this study was to investigate the efficacy of a combination treatment of the BCL-2 inhibitor Navitoclax and the PI3K inhibitor Alpelisib on cell growth inhibition and apoptosis induction in MCCs. Our results demonstrate that almost all MCCs express the anti-apoptotic BCL-2 protein and MCC cell lines are sensitive for Navitoclax. The combination of Navitoclax with Alpelisib further decreased cell line viability through induction of apoptosis. At concentrations at which both inhibitors acted synergistically, the apoptosis induction continued for up to 4 days.

A prerequisite for effective treatment with Navitoclax is the expression of the antiapoptotic BCL-2 protein in tumour cells. For this purpose, we investigated the expression of these proteins in 47 MCCs and five MCC cell lines. $98 \%$ of MCCs and all five cell lines were positive for BCL-2, which is in agreement with an overall occurrence of approximal $80 \%$ (325 of 403) BCL-2 positivity in MCC tissues based on the current literature ${ }^{20,30-36}$. High expression BCL-2 expression has been also reported for epithelial cancers and melanomas, and was thought to induce resistance towards chemotherapy or immunotherapy ${ }^{37,38}$. It is tempting to speculate that such a mechanism also is responsible for the resistance in MCCs treated by these therapies $3,4,12,13$.

Navitoclax treatment showed to be highly effective when treating MCC cell lines MKL-1, MKL-2 and WaGa (IC 50 -values ranging from 96.0 to $323.0 \mathrm{nM}$ ), which express high levels of BCL-2. In contrast, the BCL-2 negative MCC13 cell line, showed a lower sensitivity to Navitoclax. In general, it is accepted that the inhibition of BCL-2 might increase the induction of apoptosis in tumour cells ${ }^{39}$. Indeed, we observed that the single Navitoclax treatment reduced the cell viability through apoptosis induction in the cell lines and this effect was lowest in the MCC13 cell line. Our data are in agreement with a previous study, showing that Navitoclax was a potent inhibitor of viability in other MCC cell lines ${ }^{21}$. It might be that BCL-2 expression can serve as predictive biomarker for BCL-2 inhibitor treatments.

Although Navitoclax treatment of patients with several forms of leukaemia have resulted in strong apoptosis induction in tumour cells, $17 \%$ of patients also suffered from severe adverse events such as grade 4 thrombocytopenia ${ }^{24,40}$. The risk for Navitoclax-induced thrombocytopenia is dosage dependent, and could be 
decreased by using lower Navitoclax concentrations, for example when applied in combination with other compounds in leukaemia patients 22,24,25,41,42. In the current study, we have investigated the combination of Navitoclax with the FDA-approved PI3K inhibitor Alpelisib, which has been previously described as a potent cell viability inhibitor of MCC cell lines ${ }^{16,17}$. This treatment combination further improved the inhibiting effect on the cell viability of the MCC cell lines WaGa, MKL1 and MKL-2 cells through strong apoptosis induction. This also demonstrates that the concentrations of both compounds could be reduced to achieve the same effects of single Navitoclax application. Our data further add to the knowledge on effective double inhibition of BCL-2 and PI3K pathways in other tumours in vitro i.e. human myeloid leukaemia (HML), glioblastoma as well as small cell lung cancer (SCLC) $26-28,43,44$. In this light, also the B-ALL cell line REH tested in the current study proved to be sensitive for the combination of Navitoclax and Alpelisib.

In addition to the potent inhibitory effect of the combined treatment in MCC and $\mathrm{REH}$ cell lines, we also examined if the induction of apoptosis continues during longer incubations. For this purpose, the WaGa and REH cells were treated for 4 days, resulting in a rapid increase of apoptosis within $24 \mathrm{~h}$ and stabilisation of the percentage of apoptotic cells for up to 4 days. In comparison with incubations of Navitoclax alone, this inhibitor appears to be responsible for the rapid increase of apoptotic cells within the first day (regular apoptotic events due to for example stress in addition to the effect of the treatment), after which the combination with Alpelisib extends this effect over a longer time period. This can be measured by a high percentage of late apoptotic cells (both PI and Annexin-V positive) already after one day that decreases afterwards, whereas the percentage of early apoptotic cells (only Annexin-V positive) indicating apoptosis induction still increases and maximizes at day three. Because treatments containing Navitoclax have so far always been given in daily regimens in cell lines studies and clinical trials ${ }^{40,44-46}$, our data indicate that regimens of the here tested combination with Alpelisib might be effective over a longer time-frame and should be further investigated for clinical use.

A limitation of this study is the fact that we used a limited number of MCC cell lines to investigate the Navitoclax-Alpelisib treatment. It will be interesting to assess the treatment effect in MCC xenograft mice model for example the model reported by 
Verhaegen et al ${ }^{21}$. Our results obtained in the BCL-2 negative MCC13 cell line suggest that if BCL-2 is not expressed the combination treatment of Navitoclax and Alpelisib is not significantly effective. An additional consideration may concern the efficacy of one dose of the combined treatment to inhibit the MCC cell lines for up to 4 days, taking into account that the half-life in humans of both Navitoclax and Alpelisib have been reported to be $17 \mathrm{~h}$ and $7.6 \mathrm{~h}$, respectively ${ }^{18,24}$. Although, this information is not indicative for the time these compounds are active within tumour cells, further studies are needed to investigate this subject. A technical limitation concerned the fact that the Annexin- $V$ assay was not compatible with the spheroid growth of MKL-1 and MKL-2, but an impression of apoptosis could be established using the cleaved PARP Western blot assay.

In conclusion, our results reveal that Navitoclax and Alpelisib show strong synergy in the inhibition of cell viability and induction of apoptosis in MCPyV-positive cell lines. The treatment response showed to last for up to 4 days with application of one dose. The combination of Navitoclax with Alpelisib should therefore further be explored and could be a potential new treatment for MCC patients. 


\section{REFERENCES}

1 Schadendorf D, Lebbé C, zur Hausen A et al. Merkel cell carcinoma: Epidemiology, prognosis, therapy and unmet medical needs. European Journal of Cancer 2017; 71: 53-69. Harms PW, Harms KL, Moore PS et al. The biology and treatment of Merkel cell carcinoma: current understanding and research priorities. Nature Reviews Clinical Oncology 2018; 15 : 763-76.

Del Marmol V, Lebbé C. New perspectives in Merkel cell carcinoma. Current opinion in oncology 2019; 31: 72-83.

Becker JC, Lorenz E, Ugurel S et al. Evaluation of real-world treatment outcomes in patients with distant metastatic Merkel cell carcinoma following second-line chemotherapy in Europe. Oncotarget 2017; 8: 79731-41.

lyer JG, Blom A, Doumani R et al. Response rates and durability of chemotherapy among 62 patients with metastatic Merkel cell carcinoma. Cancer Med 2016; 5: 2294-301.

Becker JC, Stang A, DeCaprio JA et al. Merkel cell carcinoma. Nat Rev Dis Primers 2017; 3: 17077-.

Lyngaa R, Pedersen NW, Schrama D et al. T-cell responses to oncogenic merkel cell polyomavirus proteins distinguish patients with merkel cell carcinoma from healthy donors. Clin Cancer Res 2014; 20: 1768-78.

Harms PW, Vats P, Verhaegen ME et al. The Distinctive Mutational Spectra of Polyomavirus-Negative Merkel Cell Carcinoma. Cancer research 2015; 75: 3720-7. Afanasiev OK, Yelistratova L, Miller N et al. Merkel Polyomavirus-Specific T Cells Fluctuate with Merkel Cell Carcinoma Burden and Express Therapeutically Targetable PD-1 and Tim3 Exhaustion Markers. Clinical Cancer Research 2013; 19: 5351-60. Richter I, Dvorak T. Expression and prognostic significance of programmed death-ligand 1 (PD-L1) in Merkel cell carcinoma. J buon 2019; 24: 2155-60. Lipson EJ, Vincent JG, Loyo $M$ et al. PD-L1 expression in the Merkel cell carcinoma microenvironment: association with inflammation, Merkel cell polyomavirus and overall survival. Cancer Immunol Res 2013; 1: 54-63. in oncology 2020; 32: 114-21.

Joseph J, Zobniw C, Davis J et al. Avelumab: A Review of Its Application in Metastatic Merkel Cell Carcinoma. Ann Pharmacother 2018; 52: 928-35.

Nardi V, Song Y, Santamaria-Barria JA et al. Activation of PI3K signaling in Merkel cell carcinoma. Clin Cancer Res 2012; 18: 1227-36.

Hafner C, Houben R, Baeurle A et al. Activation of the PI3K/AKT Pathway in Merkel Cell Carcinoma. PLOS ONE 2012; 7: e31255.

Chteinberg E, Rennspiess D, Sambo R et al. Phosphatidylinositol 3-kinase p110ठ expression in Merkel cell carcinoma. Oncotarget 2018; 9. André F, Ciruelos EM, Rubovszky G et al. Alpelisib (ALP) + fulvestrant (FUL) for advanced breast cancer (ABC): Results of the phase III SOLAR-1 trial. Annals of Oncology 2018; 29: viii709.

Juric D, Rodon J, Tabernero J et al. Phosphatidylinositol 3-Kinase a-Selective Inhibition With Alpelisib (BYL719) in PIK3CA-Altered Solid Tumors: Results From the First-in-Human Study. J Clin Oncol 2018; 36: 1291-9. Markham A. Alpelisib: First Global Approval. Drugs 2019; 79: 1249-53. cell carcinoma regardless of the presence of Merkel cell polyomavirus. Virchows Arch 2012; 461: 553-9.

Verhaegen ME, Mangelberger D, Weick JW et al. Merkel cell carcinoma dependence on bcl-2 family members for survival. J Invest Dermatol 2014; 134: 2241-50.

Roberts AW, Seymour JF, Brown JR et al. Substantial susceptibility of chronic lymphocytic leukemia to BCL2 inhibition: results of a phase I study of navitoclax in patients with relapsed or refractory disease. J Clin Oncol 2012; 30: 488-96.

Kaefer A, Yang J, Noertersheuser $\mathrm{P}$ et al. Mechanism-based pharmacokinetic/pharmacodynamic meta-analysis of navitoclax (ABT-263) induced thrombocytopenia. Cancer Chemother Pharmacol 2014; 74: 593-602.

Wilson WH, O'Connor OA, Czuczman MS et al. Navitoclax, a targeted high-affinity inhibitor of BCL-2, in lymphoid malignancies: a phase 1 dose-escalation study of safety, pharmacokinetics, pharmacodynamics, and antitumour activity. Lancet Oncol 2010; 11: 1149-59. 
Kipps TJ, Eradat $\mathrm{H}$, Grosicki $\mathrm{S}$ et al. A phase 2 study of the $\mathrm{BH} 3$ mimetic BCL2 inhibitor navitoclax (ABT-263) with or without rituximab, in previously untreated B-cell chronic lymphocytic leukemia. Leuk Lymphoma 2015; 56: 2826-33.

Rahmani M, Aust MM, Attkisson E et al. Dual inhibition of Bcl-2 and Bcl-xL strikingly enhances PI3K inhibition-induced apoptosis in human myeloid leukemia cells through a GSK3- and Bim-dependent mechanism. Cancer research 2013; 73: 1340-51.

Pareja F, Macleod D, Shu C et al. PI3K and Bcl-2 inhibition primes glioblastoma cells to apoptosis through downregulation of Mcl-1 and Phospho-BAD. Mol Cancer Res 2014; 12 : 987-1001.

Potter DS, Galvin M, Brown S et al. Inhibition of PI3K/BMX Cell Survival Pathway Sensitizes to BH3 Mimetics in SCLC. Mol Cancer Ther 2016; 15: 1248-60.

Chou TC. Drug combination studies and their synergy quantification using the Chou-Talalay method. Cancer Res 2010; 70: 440-6.

Plettenberg A, Pammer J, Tschachler E. Merkel cells and Merkel cell carcinoma express the BCL-2 proto-oncogene. Exp Dermatol 1996; 5: 102-7.

Kennedy MM, Blessing K, King G et al. Expression of bcl-2 and p53 in Merkel cell carcinoma. An immunohistochemical study. The American Journal of dermatopathology 1996; 18: 2737.

Feinmesser M, Halpern M, Fenig E et al. Expression of the apoptosis-related oncogenes bcl-2, bax, and p53 in Merkel cell carcinoma: Can they predict treatment response and clinical outcome? Human Pathology 1999; 30: 1367-72.

Sur M, AlArdati H, Ross C et al. TdT expression in Merkel cell carcinoma: potential diagnostic pitfall with blastic hematological malignancies and expanded immunohistochemical analysis. Modern Pathology 2007; 20: 1113-20.

Knapp CF, Sayegh Z, Schell MJ et al. Expression of CXCR4, E-cadherin, Bcl-2, and survivin in Merkel cell carcinoma: an immunohistochemical study using a tissue microarray. The American Journal of dermatopathology 2012; 34: 592-6.

Lai JH, Fleming KE, Ly TY et al. Pure versus combined Merkel cell carcinomas: immunohistochemical evaluation of cellular proteins (p53, Bcl-2, and c-kit) reveals significant overexpression of p53 in combined tumors. Human pathology 2015; 46: 1290-6. Azmahani A, Nakamura $\mathrm{Y}$, Ishida $\mathrm{H}$ et al. Estrogen receptor $\beta$ in Merkel cell carcinoma: its possible roles in pathogenesis. Human pathology 2016; 56: 128-33.

Gul O, Basaga $\mathrm{H}$, Kutuk O. Apoptotic blocks and chemotherapy resistance: strategies to identify Bcl-2 protein signatures. Brief Funct Genomic Proteomic 2008; 7: 27-34.

Lee EF, Harris TJ, Tran S et al. BCL-XL and MCL-1 are the key BCL-2 family proteins in melanoma cell survival. Cell Death \& Disease 2019; 10: 342.

García-Aranda M, Pérez-Ruiz E, Redondo M. Bcl-2 Inhibition to Overcome Resistance to Chemo- and Immunotherapy. Int J Mol Sci 2018; 19.

Roberts AW, Advani RH, Kahl BS et al. Phase 1 study of the safety, pharmacokinetics, and antitumour activity of the BCL2 inhibitor navitoclax in combination with rituximab in patients with relapsed or refractory CD20+ lymphoid malignancies. British journal of haematology 2015; 170: 669-78.

1 Senkevitch E, Durum S. The promise of Janus kinase inhibitors in the treatment of hematological malignancies. Cytokine 2017; 98: 33-41.

Gandhi L, Camidge DR, Oliveira MRd et al. Phase I Study of Navitoclax (ABT-263), a Novel Bcl-2 Family Inhibitor, in Patients With Small-Cell Lung Cancer and Other Solid Tumors. Journal of Clinical Oncology 2011; 29: 909-16.

Rahmani M, Nkwocha J, Hawkins E et al. Cotargeting BCL-2 and PI3K Induces BAXDependent Mitochondrial Apoptosis in AML Cells. Cancer research 2018; 78: 3075-86. Stratikopoulos EE, Kiess N, Szabolcs M et al. Mouse ER+/PIK3CA(H1047R) breast cancers caused by exogenous estrogen are heterogeneously dependent on estrogen and undergo BIM-dependent apoptosis with BH3 and PI3K agents. Oncogene 2019; 38: 47-59.

Badarni M, Prasad M, Balaban N et al. Repression of AXL expression by AP-1/JNK blockage overcomes resistance to PI3Ka therapy. JCl Insight 2019; 4.

6 Rudin CM, Hann CL, Garon EB et al. Phase II study of single-agent navitoclax (ABT-263) and biomarker correlates in patients with relapsed small cell lung cancer. Clin Cancer Res 2012; 18: 3163-9.

47 Zur Hausen A, Rennspiess D, Winnepenninckx $V$ et al. Early B-cell differentiation in Merkel cell carcinomas: clues to cellular ancestry. Cancer Res 2013; 73: 4982-7.

48 Ge Y, Dombkowski AA, LaFiura KM et al. Differential gene expression, GATA1 target genes, and the chemotherapy sensitivity of Down syndrome megakaryocytic leukemia. Blood 2006; 107: $1570-81$. 
49 Schneider CA, Rasband WS, Eliceiri KW. NIH Image to ImageJ: 25 years of image analysis. Nature Methods 2012; 9: 671-5.

50 Vermes I, Haanen C, Steffens-Nakken $\mathrm{H}$ et al. A novel assay for apoptosis Flow cytometric detection of phosphatidylserine expression on early apoptotic cells using fluorescein labelled Annexin V. Journal of Immunological Methods 1995; 184: 39-51.

51 U. L, M. M. Scatterplot3d - an R Package for Visualizing Multivariate Data. Journal of Statistical Software 2003; 8: 1-20.

52 Team RC. A language and environment for statistical computing. R Foundation for Statistical Computing, Vienna, Austria 2013. 


\section{SUPPLEMENTAL FIGURES}

A

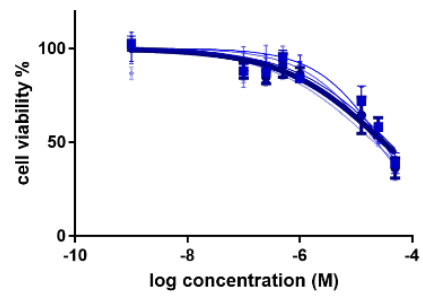

- ANO - AN25 - AN50 - AN75 - AN100

\section{$\mathrm{MCC} 13 \quad \mathrm{~B}$}

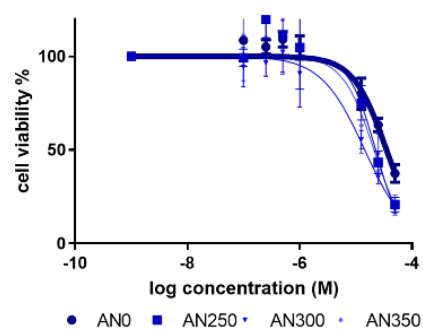

$\mathrm{C}$

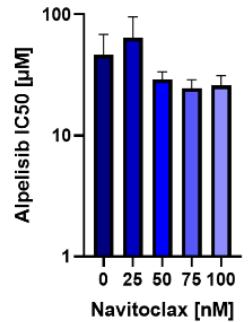

D

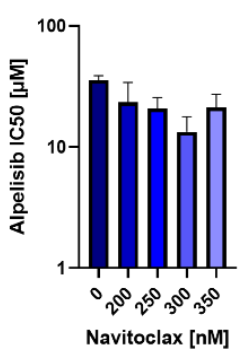

Figure S1: No significant synergistic combinatorial effect of Alpelisib and Navitoclax on MCC13

The dose response curves for Alpelisib without Navitoclax for the treated cell lines are illustrated by the ANO curves. The increasing concentrations (nM) of Navitoclax are illustrated by the numbers AN25, AN50, AN75, AN100 etc. (A). The calculated IC 50 of Alpelisib alone and in combination with different Navitoclax concentrations (nM) are shown in $\mathbf{B}$. 


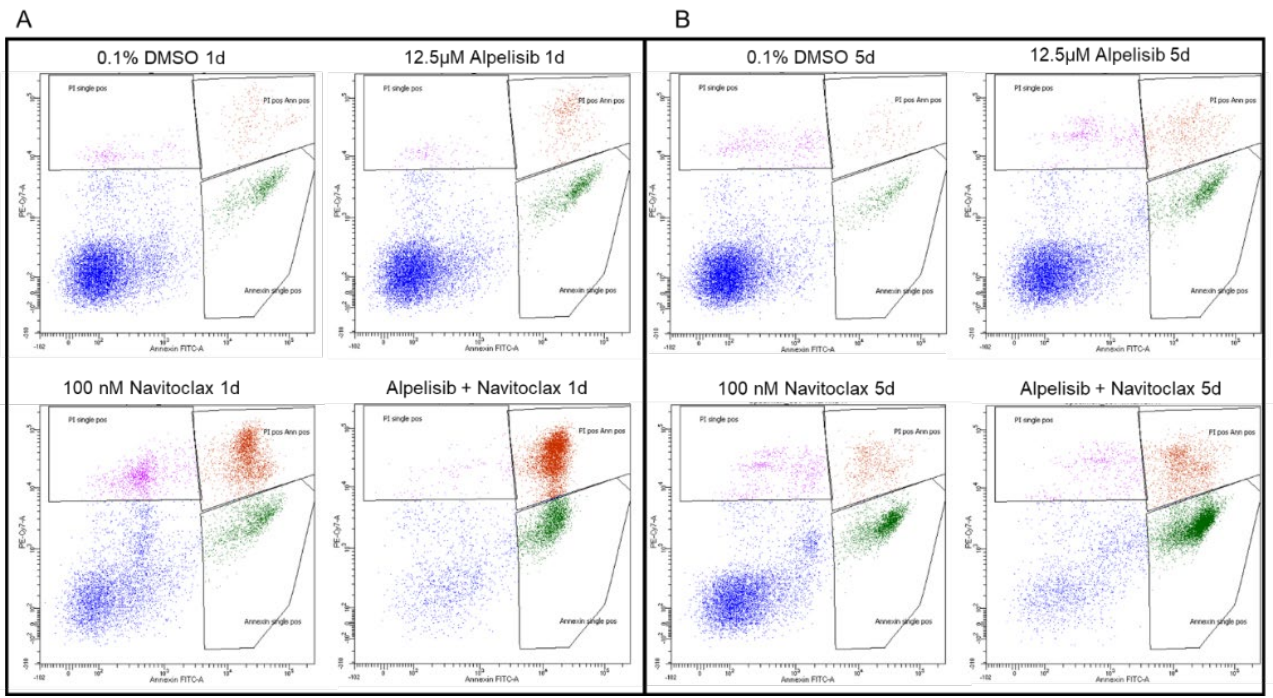

Figure S2: Overview of distribution of vital, necrotic, early and late apoptotic WaGa cells sorted by FACS

WaGa cells treated with $0.1 \%$ DMSO, $100 \mathrm{nM}$ Navitoclax, $12.5 \mu \mathrm{M}$ Alpelisib and in combination after 1 day $(\mathbf{A})$ and 5 days $(\mathbf{B})$ of treatment were sorted with FACS. The necrotic cells are sorted by PI positivity (PI singl. pos) by using the gate PE-Cy7. The early apoptotic cells are positive for Annexin-V (Annexin single pos.) and visualized with the FITC gate. Cells which were positive for both PI and Annexin-V (PI pos. Ann pos.) were defined as late apoptotic cells. 


CHAPTER 7B

NAVITOCLAX COMBINED WITH CHEMOTHERAPEUTICS IS LESS EFFECTIVE IN MERKEL CELL CARCINOMA CELL GROWTH INHIBITION INLVITRO

EMIL CHTEINBERG, SUZAN WETZELS, WOUTEP GERPITS LIEVE TEMMERMAN, VÉRONIQUE WINNEPENNINCK _RIKABIESSEN, ANNA KORDELIA KURZ, MARTIN ZENKE, ZUR HAUSEN

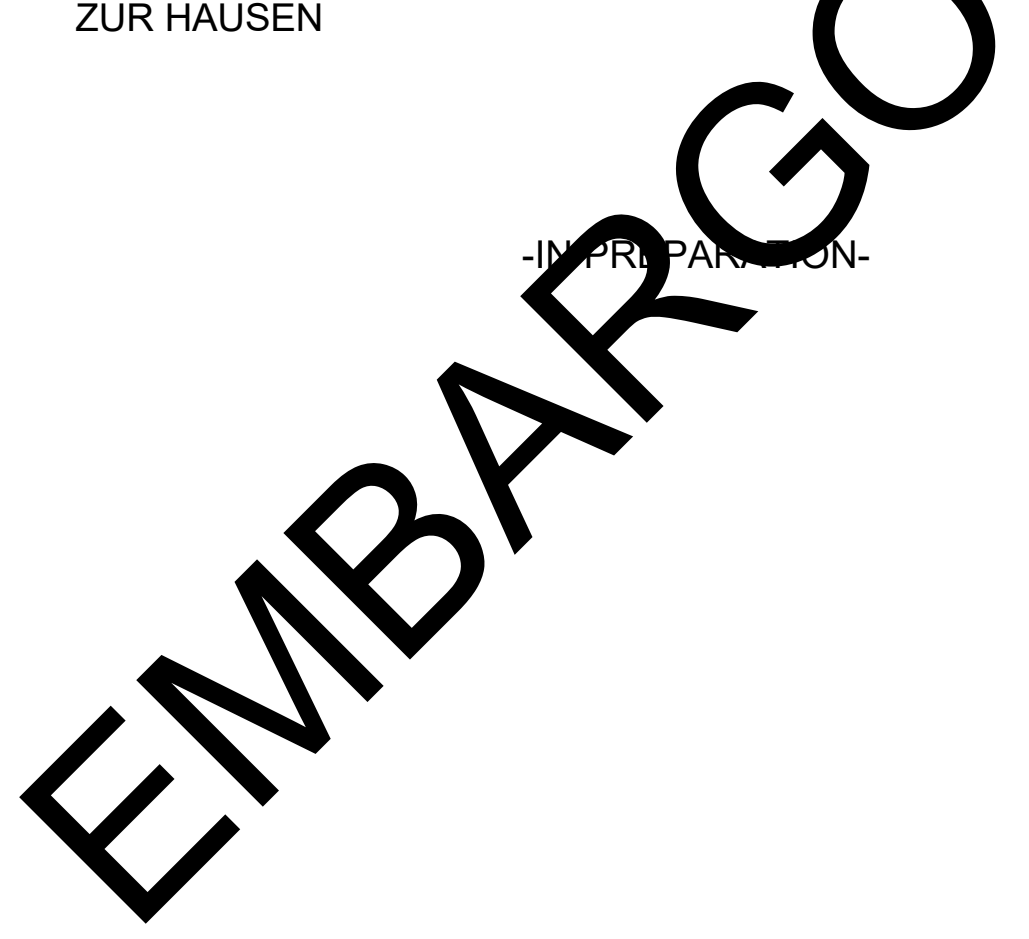
PEEL, AXEL 
CHAPTER 8

GENERAL DISCUSSION

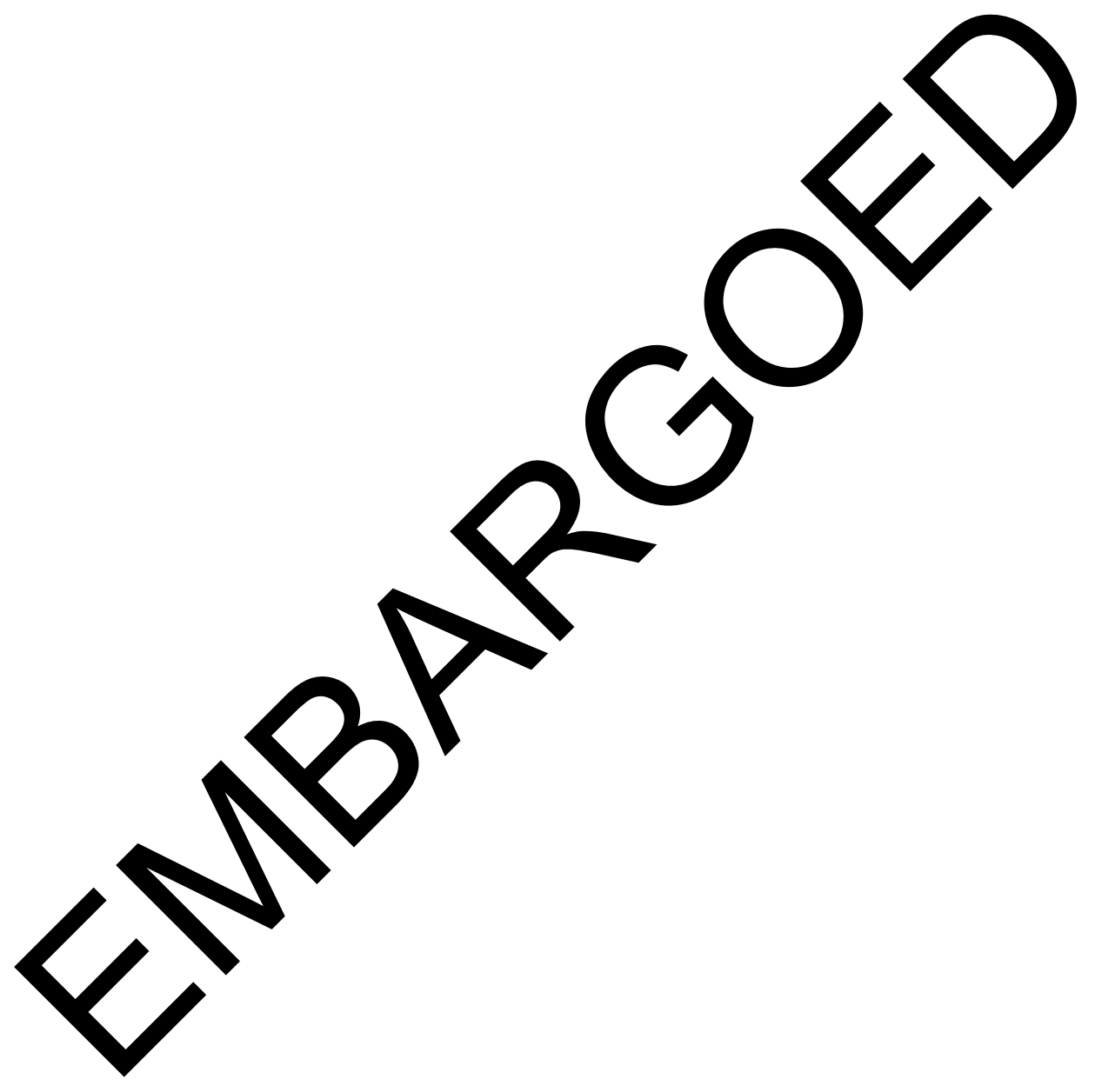


ADDENDUM 



\section{SUMMARY}

ZUSAMMENFASSUNG

SAMENVATTING 



\section{SUMMARY}

Merkel cell carcinoma (MCC) is a rare but highly malignant non-melanoma skin cancer which mainly affects elderly and immunosuppressed people. Despite its rareness the incidence of $\mathrm{MCC}$ has tripled during the last decade in the Western countries. Merkel cell polyomavirus (MCPyV) - initially detected in 2008 and shown to be clonally integrated into the MCC genome - is a novel human tumour virus causing approx. $80 \%$ of MCC. The etiopathogenesis of the remaining MCCs is linked to UV-damage. Based on the detection in the early 1980ies that MCC share some features with Merkel cells, e.g. the expression of neuroendocrine genes and cytokeratins, the term Merkel cell carcinoma was introduced. Since Merkel cells (MCs) which are located at the epidermal/dermal junction, are terminally differentiated, post-mitotic, and non-proliferative cells it is nowadays generally accepted that MCs are not the cellular origin of MCC.

MCC is characterized by a typical trilinear expression pattern of epithelial (cytokeratins), neuroendocrine (chromogranin A and synaptophysin) and early Bcell (Paired box 5 (PAX5) and terminal desoxynucleotidyl transferase (TdT)) genes. A trilinear expression pattern is possibly suggestive for a certain degree of stemness or possibly indicating pluripotency of MCC cells. Thus, we investigated in Chapter 2 the DNA methylation Age (DNAmAge) of 13 MCCs using the Horvath's clock and the pluripotency of MCCs. The MCC DNAmAge was significantly lower compared to the chronological age, which was irrespective of the presence of MCPyV or the UV-associated mutational burden. Although, we found that MCCs are not pluripotent, the finding of a significantly decreased DNAmAge strongly indicates an existing or gained stemness activity of MCC cells. Based on this, the cell of origin of MCC might be closer to a stem cell and thus possibly explaining the trilinear expression pattern of MCC.

In Chapter 3 we aimed to understand the regulation of the neuroendocrine gene expression in MCC. The expression of chromogranin A and synaptophysin in nonneuronal cells is negatively regulated by the RE1 silencing transcription factor (REST). The expression of the neuroendocrine key regulators REST, neurogenic differentiation 1 (NeuroD1) and the Achaete-scute homolog 1 (ASCL1) were tested in MCC and MCC cell lines. Of interest, all MCCs were devoid of REST expression. All MCCs expressed NeuroD1, and all MCCs - except one - did not 
express ASCL1. This was confirmed in MCPyV-positive MCC cell lines. The introduction of REST expression in REST-negative, MCPyV-positive MCC cells downregulated the neuroendocrine gene expression. The absence of ASCL1 expression in almost all tested MCCs indirectly emphasizes an important role for REST for the neuroendocrine gene expression in MCC. This is underlined by the expression of the REST-regulated microRNAs miR-9/9* in REST-negative MCC cell lines.

In Chapter 4 we addressed the early B cell gene expression in MCC by comprehensively reviewing the current evidence supporting early B-cells as the possible cellular origin of MCC. The consistent and concomitant expression of the early B-cell lineage markers PAX5 and TdT and the finding of clonal immunoglobulin chain rearrangement in some MCCs triggered this hypothesis.

PAX5 is a pivotal regulator of B-cell commitment in early B-cells (pre-pro-/pro/pre-B-cells). In Chapter 5 we were interested to compare the PAX5 expression pattern and the methylation of CpG loci located in PAX5 binding sites in MCC cells with benign B-cells. Therefore, we identified diverse PAX5 isoforms expressed in MCC using RNA next generation sequencing of which the canonical as known as the B-cell specific activation protein PAX5 isoform could be verified to be expressed in MCC. In addition, out of 63844 PAX5 binding sites, 771 were excessively hypermethylated in MCC as analysed by $850 \mathrm{~K}$ methylation array. These binding sites are recognized by other pivotal B-cell lineage transcription factors. Moreover, the PAX5-binding sites corresponding to T-cell lineage genes - not expressed in MCC - are not differentially methylated. Although, a part of the B-cell receptor signalling pathway regulated by PAX5 was identified in MCC, PAX5 fails to launch the commitment to a complete B-lineage-specific gene expression program in MCC cells.

In Chapter 6 we investigated the expression and the functionality of the BCR signalling member phosphatidylinositol 3-kinase (PI3K) p110ס in MCC by immunofluorescence microscopy and inhibition with the PI3K p110ס specific inhibitor idelalisib. The majority, i.e. $71.4 \%$ of the tested MCCs and in all tested MCC cell lines were positive for PI3K p110ס expression. Despite its expression in the MCC cell lines the inhibition of the $p 110 \delta$ subunit did not result in a significant inhibition of the cell viability and revealed only in one cell line a slight decrease of 
the phosphorylation of the protein kinase B (AKT). According to these results, PI3K $\mathrm{p} 110 \delta$ is expressed in MCC, but most likely not functional in MCC. In Chapter 6 we also illustrated that the inhibition of the PI3K p110a subunit resulted in a remarkably higher decrease of $\mathrm{MCC}$ cell line cell viability. Based on our hypothesis on the cellular origin of MCC we aimed to assess in Chapter 7 the efficacy of the combined inhibition of the B-cell lymphoma 2 (BCL-2) family and the inhibition of the PI3K p110a subunit, which is successfully used for diverse haematological diseases. First, the immunohistochemistry analysis confirmed that MCCs do express BCL-2 to a high extent. The combination of the BCL-2 family member inhibitor Navitoclax (ABT-263) and the PI3K p110a inhibitor Alpelisib (Byl-719) resulted in significant improved sensitivity on the decrease of cell viability. This could be explained by the prolonged synergistic apoptotic effect on the MCPyV-positive MCC cell lines.

In Chapter $\mathbf{8}$ the experimental findings of Chapter $\mathbf{2}$ to Chapter $\mathbf{7}$ regarding the MCC cellular origin and the possible molecular treatment applications were discussed. MCC stemness and the early B-cell circuit gene expression support that MCCs are originating from early B-cells. Considering the absence of the BCR and the associated membranous proteins like CD79a and CD79b MCC is comparable with the classical Hodgkin Lymphoma. Further, we could illustrate that the gain in knowledge about MCC tumorigenesis will possibly enable novel promising treatment options as e.g. the effective combined inhibition of PI3K p110a and BCL-2. 


\section{ZUSAMMENFASSUNG}

Das Merkelzellkarzinom (MKZ) ist ein hoch maligner Hautkrebs, der hauptsächlich bei älteren und immunsupprimierten Menschen diagnostiziert wird. Obwohl das MKZ selten ist, hat sich die Inzidenz vom MKZ in den westlichen Ländern in den letzten Jahrzehnten verdreifacht. 2008 wurde das Merkelzell Polyomavirus (MCPyV) erstmals klonal integriert in etwa $80 \%$ der MKZ-Geweben nachgewiesen. In den darauffolgenden Jahren wurde die Karzinogenese dieser Virus-positiven MKZs mit den kleinen und großen MCPyV Tumor Antigen in Verbindung gebracht. Im Gegensatz dazu sind die Virus-negativen MKZs durch UV-induzierte Mutationen charakterisiert. Trotz dieser neuen Erkenntnisse ist der zelluläre Ursprung umstritten. Dieser wurde auf der Grundlage der Detektion von der Expression von neuroendokrinen Genen und Zytokeratinen in den 1980ern Jahren den Merkel Zellen zugeschrieben. Allerdings sind Merkel Zellen ausdifferenzierte, post-mitotische, und nicht teilungsaktive Zellen, die im Gegensatz zum MKZ im Übergang von der Dermis zur Epidermis lokalisiert sind. Aus diesem Grund ist es weitgehend akzeptiert, dass die Merkel Zellen nicht mehr als zellulären Ursprung vom MKZ in Betracht kommen.

Das MKZ hat ein typisches trilineares Expressionsmuster von epithelialen (Zytokeratine), neuroendokrinen (Chromogranin A und Synapthophysin) und frühen B-Zell Genen (paired box 5 (PAX5) und terminale Desoxynukleotidyltransferase (TdT)). Dieses trilineare Expressionsmuster könnte auf Stammzelleigenschaften und Pluripotenz der möglichen MKZ Ursprungszellen hinweisen. Aus diesem Grund wurde in Kapitel 2 das DNAMethylierungsalter (DNAmAge) von 13 MKZs unter Verwendung der „HorvathClock" und die Pluripotenz von den MKZs anhand von RNA Sequenzierungsdaten der MKZs untersucht. Das MKZ-DNAmAge war im Vergleich zum chronologischen Alter der Patienten, unabhängig vom MCPyV oder der UVassoziierten Mutationen, signifikant niedriger. Obwohl die MKZs sich als nicht pluripotent herausstellten, weist das signifikant verringerte DNAmAge auf eine vorhandene oder gewonnene Stammzellaktivität der MKZ-Zellen hin. Daraus lässt sich Schlussfolgern, dass die Ursprungszellen eine gewisse Nähe zu Stammzellen aufweisen müssen, die das trilineare Expressionsmuster vom MKZ erklären könnten. 
In Kapitel 3 stand die Regulation der neuroendokrinen Genexpression als Teil des trilinearen Expressionsmusters im MKZ im Fokus. Die neuroendokrine Genexpression in MKZ ist unteranderem charakterisiert durch die Expression von Chromogranin A und Synaptophysin, die in nicht-neuronalen Zellen durch den RE-1-silencing-Transkriptionsfaktor (REST) reprimiert wird. Somit wurden in diesem Kapitel die Expression der wichtigen neuroendokrinen Regulatoren wie REST, das neurogenen Differenzierung 1 (NeuroD1) und das Achaete-ScuteHomologen 1 (ASCL1) im MKZ untersucht. Alle MKZ Gewebe waren negativ für REST und bis auf einen MKZ auch negativ für ASCL-1. Dem entgegengesetzt waren alle MKZs positiv für NeuroD1. Die MCPyV-positiven MKZ Zelllinien waren alle ASCL1 und REST negativ und positiv für NeuroD1. Nach der Induktion von REST in einer dieser Zellinien, konnte beobachtet werden, dass sich die Expression von Chromogranin A und Synaptophysin reduziert hatte. Diese Reduktion und das Fehlen des neuroendokrin-positiven Regulators ASCL1 in fast allen getesteten MKZs impliziert, dass die Abwesenheit von REST für die neuroendokrine Genexpression in $\mathrm{MKZ}$ wichtig ist. Darüber hinaus wird diese Rolle noch durch die Expression der REST-regulierten microRNA mir-9/9* in REST-negativen MKZ-Zelllinien hervorgehoben.

In Kapitel 4 wurden anhand einer Literaturstudie die frühe B-Zell Genexpression, welches zum trilinearen Expressionsmuster des MKZs zugehörig ist, zusammengetragen. Dabei wurden die aktuellen Beweise für die B-ZellGenexpression und die daraus folgende Theorie, dass frühe B-Zellen den zellulären Ursprung des MKZs darstellen, zusammengetragen und abgewogen. Durch die konsistente und gleichzeitige Expression der frühen B-Zell Gene PAX5 und TdT, der Feststellung der Umlagerung der Immunoglobulin Gensegmente in einigen MKZs bestärken diese Hypothese.

PAX5 ist ein wichtiger Regulator der B-Zell Entwicklung von prä-pro / pro / prä-BZellen. In Kapitel $\mathbf{5}$ wurde das Expressionsmuster von PAX5 und die Methylierung der CpGs, die in PAX5 Bindungsstellen lokalisiert sind, in MKZ Zellen mit benignen B-Zellen verglichen. Dabei wurden verschiedene PAX5 Isoformen in MKZ mittels RNA Next Generation Sequenzierung identifiziert, von denen die primäre kanonische PAX5 Isoform, besser bekannt als spezifischer BZell Aktivierungsprotein, in den MKZs bestätigt werden konnte. Zusätzlich wurden 


\section{ADDENDUM | ZUSAMMENFASSUNG}

anhand von 850K-Methylierungsarray bestimmten Analysen, von insgesamt 63844 PAX5-Bindungsstellen in MKZ, 771 als übermäßig hypermethyliert identifiziert. Diese Bindungsstellen werden von anderen Transkriptionsfaktoren, die neben PAX5 für die B-Zell Entwicklung wichtig sind, erkannt. Darüber hinaus sind die PAX5-Bindungsstellen, die den Genen der T-Zell Differenzierung entsprechen, nicht differentiell methyliert und werden nicht exprimiert. Obwohl ein Teil des durch PAX5 regulierten B-Zell-Rezeptor (BZR) Signalwegs in MCC identifiziert wurde, kann PAX5 einen vollständige B-Zell-spezifischen Genexpressionsprogramm in MCC-Zellen nicht induzieren.

In Kapitel 6 wurde die Expression und Funktionalität des BZR Signalwegmitglieds Phosphatidylinositol-3-Kinase (PI3K) p110ס in MKZ durch Immunfluoreszenzmikroskopie und Inhibition der Funktion mit dem PI3K p110סspezifischen Inhibitor Idelalisib untersucht. Die Mehrheit, nämlich 71,4\% der getesteten MKZs und alle getesteten MKZ-Zelllinien, waren positiv für die PI3K p110ס. Trotz seiner Expression in den MKZ-Zelllinien führte die Inhibition der p110ס-Untereinheit nicht zu einer signifikanten Beeinträchtigung der MKZ Zellvitalität und zeigte nur in einer Zellinie eine leichte Abnahme der Phosphorylierung der Proteinkinase B (AKT). Demnach wird PI3K p110ס in MCC exprimiert, ist jedoch höchstwahrscheinlich in MKZ nicht funktionsfähig.

In Kapitel 6 haben wir auch gezeigt, dass die Hemmung der PI3K p110aUntereinheit zu einer bemerkenswerten hohen Abnahme der Vitalität der MKZZelllinienzellen führte. Basierend auf unserer Hypothese zum zellulären Ursprung von MKZ, wurde in Kapitel 7 die Wirksamkeit der kombinierten Inhibition des BZell-Lymphom-2 (BCL-2) und die Hemmung der PI3K-p110a-Untereinheit untersuchen, die erfolgreich bei der Behandlung verschiedene hämatologische Erkrankungen in klinischen Studien eingesetzt wurde. Zuerst wurde mittels immunhistochemischer Analyse die Expression von BCL-2 bestätigt. Darauf wurden, die Zellen mit der Kombination des BCL-2-Familienmitglied-Inhibitors Navitoclax und des PI3K p110a-Inhibitors Alpelisib behandelt. Dies führte aufgrund des synergistischen apoptotischen Effekte auf die MCPyV-positiven MKZ-Zelllinien zu einer signifikant verbesserten Empfindlichkeit. Darüber hinaus wurde das Zellwachstum nach einer initialen Behandlung für vier Tage anhaltend inhibiert. 
In Kapitel 8 wurden die experimentellen Ergebnisse von Kapitel 2 bis Kapitel 7 bezüglich des zellulären Ursprungs von MKZ und der möglichen molekularen Behandlungsanwendungen diskutiert. Die MKZ Stammzellähnlichkeit und die frühe B-Zell Genexpression unterstützen die Hypothese, dass das MKZs aus frühen B-Zellen abstammen könnte. In Anbetracht des Fehlens des BZRs und der damit verbundenen Membranproteine wie CD79a und CD79b ist das MKZ mit dem klassischen Hodgkin-Lymphom vergleichbar. Ferner konnten wir veranschaulichen, dass der Zugewinn an Wissen über die MKZ-Karzinogenese neue vielversprechende Behandlungsoptionen, wie z. B. die wirksame kombinierte Inhibition von PI3K p110a und BCL-2, ermöglichen könnten. 


\section{SAMENVATTING}

Het Merkelcelcarcinoom (MCC) is een zeer kwaadaardige vorm van huidkanker die voornamelijk voorkomt bij ouderen en mensen met een verzwakt immuunsysteem. Hoewel dit een zeer zeldzame vorm van huidkanker is, is de incidentie van het MCC in westerse landen het afgelopen decennium verdrievoudigd. Ongeveer $80 \%$ van de MCC gevallen wordt veroorzaakt door het Merkelcelpolyomavirus (MCPyV). De overige MCC's worden gekenmerkt door mutaties veroorzaakt door langdurige blootstelling aan UV-straling. In 1980 werd beschreven dat MCC-cellen gelijkenis vertoonden met Merkelcellen (MC's) namelijk de expressie van neuro-endocriene genen en cytokeratine - en werd de term "Merkelcelcarcinoom" geïntroduceerd. Aangezien MC's terminaal gedifferentieerde, post-mitotische en niet-delende cellen zijn die zich bevinden in de dermo-epidermale junctie, worden MC's niet langer beschouwd als de cellulaire oorsprong van het MCC.

Het MCC wordt gekenmerkt door een trilineair expressiepatroon van epitheliale (cytokeratine), neuro-endocriene (chromogranine A en synapthophysin) en vroege B-cel (paired box 5 (PAX5) en terminale deoxynucleotide transferase $(\mathrm{TdT})$ ) genen. Dit trilineaire expressiepatroon kan wijzen op stamceleigenschappen en pluripotentie van de mogelijke MCC-oorsprongscellen. Om deze reden werd in Hoofdstuk 2 de DNA-methylatie leeftijd (DNAmAge) van 13 MCC's onderzocht met behulp van de "Horvath-klok" en werd de pluripotentie van de MCC's geanalyseerd. De MCC-DNAmAge bleek significant lager in vergelijking met de chronologische leeftijd van de patiënten, ongeacht de aanwezigheid van het MCPyV of de met UV-geassocieerde mutaties. Hoewel onze resultaten erop wijzen dat MCC's niet-pluripotent zijn, duidt deze significant verminderde DNAmAge op een bestaande of behaalde stamcelactiviteit van de MCC-cellen. Hieruit kunnen we concluderen dat de MCC-oorsprongscellen sterke overeenkomsten hebben met stamcellen, wat het trilineaire expressiepatroon van het MCC zou kunnen verklaren.

In Hoofdstuk 3 wordt dieper ingegaan op de regulatie van de neuro-endocriene genexpressie als onderdeel van het trilineaire expressiepatroon in MCC. De neuro-endocriene genexpressie in MCC wordt gekenmerkt door de expressie van chromogranin A en synaptophysin. De expressie van deze genen wordt in niet- 
neuronale cellen onderdrukt door RE-1 silencing transcriptiefactor (REST). In dit hoofdstuk wordt de expressie van belangrijke neuro-endocriene regulatoren zoals REST, neurogene differentiatie 1 (NeuroD1) en Achaete-Scute homoloog 1 (ASCL1) in MCC en MCC-cellijnen onderzocht. Hier laten we zien dat alle MCC's negatief waren voor REST expressie en - met uitzondering van één enkele MCC - ook negatief waren voor ASCL1 expressie. Daarentegen waren alle MCC's positief voor NeuroD1 expressie. Deze bevindingen werden verder bevestigd in MCPyV-positieve MCC-cellijnen. De introductie van REST expressie in RESTnegatieve, MCPyV-positieve MCC-cellijnen resulteerde in een afgenomen endocriene genexpressie. De afwezigheid van de neuro-endocriene regulator ASCL1 in bijna alle geteste MCC's impliceert dat REST een belangrijke rol speelt in de regulatie van de neuro-endocriene genexpressie in MCC. Deze rol wordt verder bevestigd door de expressie van de REST-gereguleerde microRNA mir$9 / 9$ * in REST-negatieve MCC-cellijnen.

Hoofdstuk 4 is een literatuurstudie naar de vroege B-cel genexpressie in MCC, waarin we al het huidige wetenschappelijke bewijs over vroege B-cellen hun mogelijke rol als MCC-oorsprongscellen bespreken. Bovenstaande hypothese werd getriggerd door de consistente en gelijktijdige expressie van de vroege $B$ cel markers PAX5 en TdT en de herschikking van de immunoglobulinensegmenten in sommige MCC's. PAX5 is een cruciale regulator in de ontwikkeling van vroege B-cellen (pre-pro-/pro-/pre-B-cellen).

In Hoofdstuk 5 vergelijken we het PAX5-expressiepatroon en de CpGmethylering op PAX5-bindingsplaatsen tussen MCC-cellen en benigne B-cellen. Daartoe hebben we verschillende PAX5-isovormen die tot expressie komen in MCC geïdentificeerd met behulp van RNA Next Generation Sequencing, en hebben we de aanwezigheid van de PAX5-isovorm, beter bekend als het specifieke B-celactivatie-eiwit, kunnen bevestigen in MCC. Daarnaast werden 771 van de 63,844 PAX5-bindingsplaatsen in MCC geïdentificeerd als overmatig gehypermethyleerd op basis van de resultaten van de $850 \mathrm{~K}$-methyleringsassay. Deze bindingsplaatsen worden herkend door andere belangrijke transcriptiefactoren die, naast PAX5, cruciaal zijn voor de ontwikkeling van Bcellen. Bovendien waren de PAX5-bindingsplaatsen die overeenkomen met de genen voor T-celdifferentiatie niet differentieel gemethyleerd en werden ze niet tot 


\section{ADDENDUM | SAMENVATTING}

expressie gebracht. Hoewel een deel van de PAX5-gereguleerde B-celreceptor (BCR) -signaleringsroute werd geïdentificeerd in MCC, is PAX5 niet in staat om een volledig B-cel specifiek genexpressieprogramma te induceren in MCC-cellen. In Hoofdstuk 6 werd de expressie en functionaliteit van het BCR-signaleringseiwit phosphatidylinositol-3-kinase (PI3K) p110ס in MCC onderzocht met behulp van immunofluorescentiemicroscopie en de PI3K p110ס-specifieke remmer Idelalisib. De meerderheid, namelijk 71,4\% van de MCC's en alle geteste MCC-cellijnen, testten positief voor PI3K p110ס. Echter leidde inhibitie van de p110ס-subunit niet tot een significante verslechtering van de cel vitaliteit en werd maar in één enkele cellijn een lichte afname van de fosforylering van proteïnekinase B (AKT) gevonden. Hieruit kunnen we concluderen dat PI3K p110ס aanwezig is, maar hoogstwaarschijnlijk niet functioneel is in MCC. Echter hebben we in er ook aangetoond dat inhibitie van de PI3K p110a-subunit resulteerde in een opmerkelijk hogere afname van de cel vitaliteit van de MCC-cellijnen.

Gebaseerd op onze hypothese over de cellulaire oorsprong van MCC, laat Hoofdstuk 7 de werkzaamheid van een gecombineerde inhibitie van de Bcellymfoom-2 (BCL-2) familie en de PI3K-p110a-subunit zien. De gecombineerde inhibitie van deze eiwitten is succesvol bevonden in verschillende klinische onderzoeken naar hematologische ziekten. De expressie van BCL-2 door MCC's werd eerst bevestigd met behulp van een immunohistochemische analyse. Vervolgens werden de MCC-cellen behandeld met een combinatie van de BCL-2 remmer Navitoclax (ABT-263) en de PI3K p110a-remmer Alpelisib (Byl-719). Vanwege hun synergetische apoptotisch effecten op de MCPyV-positieve MCCcellijnen resulteerde dit in een significant verbeterde gevoeligheid voor Alpelisib. Bovendien werd de celgroei gedurende vier dagen na de initiële behandeling geremd. 
In Hoofdstuk 8 worden de experimentele resultaten van Hoofdstuk 2 tot en met Hoofdstuk 7 over de cellulaire oorsprong van MCC en de mogelijke toepassingen voor moleculaire behandeling besproken. De overeenkomsten tussen MCC's en stamcellen, in combinatie met de vroege B-cel genexpressie, ondersteunen de hypothese dat de MCC's afkomstig kunnen zijn van vroege B-cellen. Gezien het ontbreken van de BCR en de bijbehorende membraaneiwitten zoals CD79a en CD79b, is het MCC vergelijkbaar met het klassieke Hodgkin-lymfoom. Bovendien hebben we kunnen aantonen dat de toename aan kennis over MCC-carinogenese nieuwe en veelbelovende behandelingsopties biedt, zoals de effectieve gecombineerde inhibitie van PI3K p110a en BCL-2. 



\section{VALORIZATION}



Valorization is the estimation in as much the published scientific work can be utilized in the practice and depends on the category of performed research. Whereas data from clinical research, e.g. clinical trials, or translational research might impact clinical practice earlier, it is well know that research data gained from basic research might take longer before they will be transferred or implemented in the clinical practice. Here, I will point out how the main results of this thesis are very likely to improve the diagnosis and clinical management of Merkel cell carcinoma (MCC) in the near future.

Depending on the localization, the rare and aggressive skin cancer MCC is mostly detected at late stage III and IV3. At stage III MCC is metastasized to local lymph nodes. At stage IV it is either metastasized to distant lymph nodes or solid organs e.g. lung3. In the latter it might possibly difficult to distinguish MCCs from small cell lung cancer (SCLC). In chapter 3 , we described the complete absence of RE1 silencing transcription factor REST as well as the achaete-scute family BHLH transcription factor 1 (ASCL1) in MCC. Contrariwise, ASCL1 was shown to be expressed in $70 \%$ of SCLCs4. Moreover, the hematopoietic program and the presence of splice variants of the paired box protein PAX5 in MCC which we showed is unique for MCC (chapter 5) might be also used in as marker to distinguish SCLC from MCC.

The main focus of this thesis was to get more insight into the cellular origin of MCC. Irrespective of the cellular origin of MCC, it is expected that the results of this research will contribute to the understanding of its pathogenesis, ultimately possibly leading to novel treatment options. Based on the results presented in this dissertation we now know that the cellular origin should have stem cell activity, is very likely to be of hematopoietic origin and is characterized by a significant, however partially defective hematopoietic PAX5 transcription program. Thus, the pre-pro B-cell is currently the most appropriate candidate for the cellular origin.

The gained knowledge about the cellular origin can now be applied to the treatment of MCC. Because of its rareness clinical trials on MCC treatment of more than 100 people cohorts are rare. Therefore, the most clinical trials for the treatment of MCC are starting from phase 2 or phase 3 where MCC patients are included in a general cohort among others with solid tumors like cutaneous squamous cell carcinoma. A successful example of a nowadays approved 
compound for the treatment of MCC is Avelumab which was assessed in clinical trial phase 2 in 200 MCC patients which showed an overall response rate of 50 to $70 \%$ 5-7. In chapter 7 we used our gained knowledge about the early B-cell phenotype of MCC and treated the cells with the promising combination of the BCL-2 family member inhibitor Navitoclax and the PI3K p110 Alpelisib. The compounds induced only in combination a stagnation in cell viability. Both compounds are in individual clinical trials phase $27-9$. Therefore, the costs for the first phase of the clinical trial of about $475,000 €$ in the Netherlands can be skipped11. The costs of about $11,379 €$ per patient in clinical trial 2 has still to be considered.12 Clinical trial phase II takes several months with a group of at least 100 people. For MCC to get that many cases are difficult, therefore international cooperation like it was performed with Avelumab are necessary to realize a significant evaluation of the synergism of these compounds in the clinic. Therefore, a clinical trial phase 2 to evaluate the efficacy of Navitoclax/Alpelisib might be conducted within several months and might be approved by the FDA.

After successful treatment, the patients have to be evaluated for recurrence of the cancer by follow-up care. The easiest way is to use biological fluids like blood. The younger DNA methylation age (DNAmAge) of blood cells compared to the chronological age have a significant correlation2. In chapter 2 we characterized that MCCs have a significantly younger DNA methylation age (DNAmAge) compared to the chronological age of the MCC patients. Therefore, it might be possible to establish an assay to determine the DNAmAge of DNA located in the blood. For this screening method only $10 \mathrm{ng}$ of purified DNA is enough for enrichment using the capture enrichment Illumina technology and hybridized with the $353 \mathrm{CpG}$ sites of the Horvath's clock. If the DNAmAge is significant younger, it is most likely that the patient has aberrant cells and the patient has to be screened for recurrence of the cancer.

The knowledge about the synergism of the Navitoclax/Alpelisib combination can be therefore transferred into clinical practice. The combination would not be tested on MCC if we had not observed the hematopoietic pre-pro B-cell origin of MCC. Moreover, the DNAmAge determination blood screening method might be also utilized in the clinic for the follow-up control of MCC. Therefore, this dissertation 
has gained important data which potentially will be successfully translated into a pre-clinical setting and transferred further into the clinical practice.

\section{REFERENCES}

1. Schiffman JD, Fisher PG and Gibbs P. Early Detection of Cancer: Past, Present, and Future. American Society of Clinical Oncology Educational Book 2015: 57-65. DOI: 10.14694/EdBook_AM.2015.35.57.

2. Horvath $\bar{S}$. DNA methylation age of human tissues and cell types. Genome Biol 2013; 14: R115-R115. DOI: 10.1186/gb-2013-14-10-r115.

3. Schadendorf D, Lebbé C, zur Hausen A, et al. Merkel cell carcinoma: Epidemiology, prognosis, therapy and unmet medical needs. European Journal of Cancer 2017; 71: 53-69.

4. Kudoh S, Tenjin $\mathrm{Y}$, Kameyama $\mathrm{H}$, et al. Significance of achaete-scute complex homologue 1 (ASCL1) in pulmonary neuroendocrine carcinomas; RNA sequence analyses using small cell lung cancer cells and Ascl1-induced pulmonary neuroendocrine carcinoma cells. Histochem Cell Biol 2020; 153: 443-456. DOI: 10.1007/s00418-020-01863-z.

5. Samimi M, Kervarrec $T$ and Touze A. Immunobiology of Merkel cell carcinoma. Current opinion in oncology 2020; 32: 114-121. DOI: 10.1097/CCO.0000000000000608.

6. Joseph J, Zobniw C, Davis J, et al. Avelumab: A Review of Its Application in Metastatic Merkel Cell Carcinoma. Ann Pharmacother 2018; 52: 928-935. 2018/04/04. DOI: $10.1177 / 1060028018768809$.

7. Chin K, Chand VK and Nuyten DSA. Avelumab: clinical trial innovation and collaboration to advance anti-PD-L1 immunotherapy. Annals of Oncology 2017; 28: 1658-

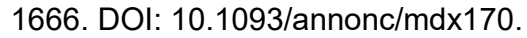

8. André F, Ciruelos EM, Rubovszky G, et al. Alpelisib (ALP) + fulvestrant (FUL) for advanced breast cancer (ABC): Results of the phase III SOLAR-1 trial. Annals of Oncology 2018; 29: viii709. DOI: 10.1093/annonc/mdy424.010.

9. Wilson WH, O'Connor OA, Czuczman MS, et al. Navitoclax, a targeted highaffinity inhibitor of BCL-2, in lymphoid malignancies: a phase 1 dose-escalation study of safety, pharmacokinetics, pharmacodynamics, and antitumour activity. Lancet Oncol 2010; 11: 1149-1159. 2010/11/18. DOI: 10.1016/S1470-2045(10)70261-8.

10. Kipps TJ, Eradat $\mathrm{H}$, Grosicki S, et al. A phase 2 study of the BH3 mimetic BCL2 inhibitor navitoclax (ABT-263) with or without rituximab, in previously untreated B-cell chronic lymphocytic leukemia. Leuk Lymphoma 2015; 56: 2826-2833. 2015/05/12. DOI: 10.3109/10428194.2015.1030638.

11. van Asselt T, Ramaekers B, Corro Ramos I, et al. Research Costs Investigated: A Study Into the Budgets of Dutch Publicly Funded Drug-Related Research. Pharmacoeconomics 2018; 36: 105-113. 2017/09/22. DOI: 10.1007/s40273-017-0572-7.

12. Pascarella G, Capasso A, Nardone A, et al. Costs of clinical trials with anticancer biological agents in an Oncologic Italian Cancer Center using the activity-based costing methodology. Plos one 2019; 14: e0210330-e0210330. DOI: 10.1371/journal.pone.0210330. 

LIST OF ABBREVIATIONS 



\section{LIST OF ABBREVIATIONS}

4E-BP1

5-aza-2'-dC

ASCL1

ATOH1

B-ALL

BCAP

BCL-2

BCR

bHLH

BTK

CD56

CD79a

$\mathrm{CD} 79 \mathrm{~b}$

$\mathrm{Cl}$

CK

CKIT

CLPs

CpG

CPIs

CSC

DAPI

DNAmAge

DSB

E2A

EBF1

FACS

FCS

FFPE

FITC

FOXO1

GCF
Eukaryotic translation initiation factor $4 \mathrm{E}$-binding protein 1

5-Aza-2'-deoxycytidine

Achaete-scute family $\mathrm{BHLH}$ transcription factor 1

Atonal homolog 1

B-cell acute lymphoblastic leukemia

Phospohoinositide-3-kinase adaptor protein 1

B-cell lymphoma 2

B-cell receptor

Basic helix-loop-helix

Bruton tyrosine kinase

Neural cell adhesion molecule

B-cell antigen receptor complex-associated protein alpha chain

B-cell antigen receptor complex-associated protein beta chain combinatory index

Cytokeratin

tyrosine-protein kinase KIT

common lymphoid progenitor

Cytosine and Guanin residues

check point inhibitors

Cancer stem cells

4',6-diamidino-2-phenylindole

DANN methylation age

Double stranded break

Transcription factor 3

Early B-cell factor 1

Fluorescence activated cell sorter

Fetal calf serum

Formalin fixed paraffin embedded

Fluorescein isothiocyanate

Forkhead box $\mathrm{O} 1$

Germinal center founders 
GFP

$\mathrm{GO}$

HE

$\mathrm{HL}$

HSC

IC

IF

$\lg$

$\mathrm{IHC}$

IKZF1

IRF

ITAM

LMPP

LT

$\mathrm{MC}$

MCC

MCPyV

MiR

MSP

mTOR

NEhM

NEUROD1

NF

NGS

NHEJ

NSE

OCT2

PARP

PAX5

PBS

PD-L1

PE-Cy7

PluriTEST
Green fluorescence protein

Gene ontology

Hematoxylin and eosin

Hodgkin lymphoma

Hematopoietic stem cell

inhibitory concentration

Immunofluorescence

Immunoglobulin

Immunohistochemistry

Ikaros family zinc finger protein 1

Interferon regulatory factor

Integrin subunit alpha M

Lymphoid-primed multipotent progenitors

MCPyV large tumor antigen

Merkel cells

Merkel cell carcinoma

Merkel cell Polyomavirus

microRNA

Methylation specific PCR

Mechanistic target of rapamycin kinase

not excessively hypermethylated

Neuronal differentiation 1

Neurofilament

Next generation sequencing

Non-homologous end joining

Enolase 2

POU Class 2 Homeobox 2

Poly (ADP-ribose) polymerase 1

Paired box gene 5

Phosphate buffered saline

programmed death-ligand 1

Phycoerythrin coupled to a cyanine dye (Cy7)

Pluripotency Test 
PP2A Protein phosphatase 2

Pu.1

qRT-PCR

RAG

RB1

REST

SCLC

sT

TdT

UV

VP

XTT
Spi-1 Proto-Oncogene

quantitative reverse transcriptase polymerase chain reaction Recombination Activating

Retinoblastoma protein

$\mathrm{RE}-1$ silencing transcription factor

Small cell lung cancer

MCPyV small tumor antigen

Terminal deoxynucleotidyl transferase

Ultraviolet

Viral protein

2,3-Bis-(2-Methoxy-4-Nitro-5-Sulfophenyl)-2H-

Tetrazolium-5-Carboxanilid 

CURRICULUM VITAE 



\section{CURRICULUM VITAE}

\section{PERSONAL DETAILS}

Name

Emil Chteinberg

Date of birth:

May 1, 1990

Place of birth

Tashkent, Uzbekistan

Nationality:

German

Language:

German (Native), Russian (2 ${ }^{\text {nd }}$ native language), English (good), Dutch (good)

\section{FELLOWSHIPS/ ACHIEVEMENTS}

November 2015- October Fellowship provided by the RWTH Aachen 2018

University,

Aachen,

Germany:

„Graduiertenförderung nach Richtlinien zur

Förderung des wissenschaftlichen

Nachwuchses (RFwN)“

2014

Dean's List of the RWTH Aachen University, Aachen, Germany (selected as one of the top $5 \%$ student of the scientific year 2014)

October 2013 - September Studentship provided by the Hans Hermann 2014

Voss Foundation from the "Bildungsfond NRW", Germany 


\section{WORK EXPERIENCE}

Since August 2020

PostDoc at the human genetics Department at the University Medical Center Ulm, Germany

November 2015 - July Joint-PhD at the Department of Pathology, 2020 Maastricht University Medical Centre+, Maastricht, the Netherlands

Augustus 2015 - October Department of Pathology, Viral Oncogenesis 2015 Research, Maastricht University Medical Centre+, Maastricht, the Netherlands

February 2013 - December Fraunhofer Institute for Molecular Biology and 2013 Applied Ecology (IME), Plant Pathogen Resistance, Aachen, Germany

\section{UNIVERSITY EDUCATION}

November 2015 - July Joint-PhD thesis at the RWTH Aachen 2020

University, Aachen, Germany and the Maastricht University Medical Centre+, Maastricht, the Netherlands: "Molecular assessment of the cellular origin of Merkel cell carcinoma"

April 2013 - May 2015

Master of Science (M.Sc. RWTH), Molecular and Applied Biotechnology at RWTH Aachen University, Aachen, Germany September 2009 - February Bachelor of Science (B.Sc.), 2013

Biotechnology with practical semester at FH Aachen University of Applied Sciences, Jülich, Germany

\section{INTERNSHIPS}

July 2014 - March 2015 Department of Pathology, Viral Oncogenesis Research, Maastricht University Medical Centre+, Maastricht, the Netherlands 
March 2014 - June Department of Pathology, Viral Oncogenesis 2014

Research, Maastricht University Medical

Centre+, Maastricht, the Netherlands

March 2012 - January Fraunhofer Institute for Molecular Biology and 2013

Applied Ecology (IME), Plant Pathogen

Resistance, Aachen, Germany

July 2009 - September Institute for Microbiology (Bio IV), RWTH 2009

Aachen University, Aachen, Germany

\section{PRESENTATIONS AT SCIENTIFIC CONFERENCES}

\section{POSTERS:}

E. Chteinberg, A. Haugg, A. zur Hausen;

"Effects of B-cell acute lymphoblastic leukaemia (B-ALL) chemotherapeutics on Merkel cell carcinoma (MCC) cell lines";

School for Oncology and Developmental Biology (GROW) Science Day 2014;

Maastricht University Medical Centre+, Maastricht, the Netherlands, 2014 Nov 12

E. Chteinberg, C. Sauer, D. Rennspiess, L. Schiffelers, J. Eben, A. Haugg, V. Winnepenninckx, A. K. Kurz, E.-J. Speel, M. Zenke, A. zur Hausen;

"Neuroendocrine regulator expression in Merkel cell carcinoma";

$19^{\text {th }}$ International AEK Cancer Congress;

Heidelberg, Germany, 2017 Mar 1 - 3.

E. Chteinberg, C. Sauer, L. Schiffelers, J. Eben, D. Rennspiess, C. B. Buck, V. Winnepenninckx, A. K. Kurz, E.-J. Speel, M. Zenke, A. zur Hausen;

$1 . \quad$ "No REST in Merkel cell carcinoma";

AACR Annual Meeting 2017;

Washington DC, USA 2017 Apr 1 - 5;

Cancer Research. 2017 Jul; 77(13 Supplement):3532-3532.

E. Chteinberg, D. Rennspiess, S. Tauchmann, V. Winnepenninckx; E.-J. Speel, A.

K. Kurz; M. Zenke, A. zur Hausen;

"PI3K p110ס expression in Merkel cell carcinoma cell lines";

$13^{\text {th }}$ Congress of the European Association of Dermato-Oncology (EADO) 2017;

Athens, Greece, 2017 May 3 - 6;

Journal of the European Academy of Dermatology and Venereology. 2017 Jun; 31, S3, FC1.3 P155.

E. Chteinberg, C. Sauer, D. Rennspiess, V. Winnepenninckx, A. K. Kurz, E.-J. Speel, M. Zenke, A. zur Hausen;

"Expression of Neuroendocrine Key Regulators in Merkel cell carcinoma"; $107^{\text {th }}$ Annual Meeting of the United-States-and-Canadian-Academy-of-Pathology USCAP; 
Vancouver, Canada, 2018 Mar 17 - 23;

Modern pathology. 2018 Mar; 31: 192-215.

E. Chteinberg, D. Rennspiess, V. Winnepenninckx, E.-J. Speel, A. K. Kurz, M. Zenke, A. zur Hausen;

"Is PI3K p110 delta Expressed and Functional in Merkel Cell Carcinoma?";

$107^{\text {th }}$ Annual Meeting of the United-States-and-Canadian-Academy-of-Pathology

USCAP;

Vancouver, Canada, 2018 Mar 17 - 23;

Modern pathology. 2018 Mar; 31: 192-215.

E. Chteinberg, The Netherlands W. Gerritsen, E. Speel, V. Winnepenninckx, J. van den Oord, A. K. Kurz, M. Zenke, A. zur Hausen;

PAX5 expression in Merkel cell carcinoma

103. Jahrestagung der Deutschen Gesellschaft für Pathologie;

Frankfurt am Main, Germany 2019, June $13-15$

E. Chteinberg, The Netherlands W. Gerritsen, E. Speel, V. Winnepenninckx, J. van den Oord, A. K. Kurz, M. Zenke, A. zur Hausen;

PAX5 is constitutively expressed in Merkel cell carcinoma and Merkel cell carcinoma cell lines and reveals a broad range of B-cell characteristic PAX5 splice variants;

$31^{\text {st }}$ European Congress of Pathology

Nice, France 2019, September 7 - 11

E. Chteinberg, The Netherlands W. Gerritsen, E. Speel, V. Winnepenninckx, J. van den Oord, A. K. Kurz, M. Zenke, A. zur Hausen;

B-lymphoid PAX5 isoform expression pattern in Merkel cell carcinoma;

$1^{\text {st }}$ international symposium on Merkel cell carcinoma

Tampa, USA 2019 October 21-22

\section{PRESENTATIONS}

E. Chteinberg, A. Haugg, A. zur Hausen;

"Effects of B-cell acute lymphoblastic leukaemia (B-ALL) chemotherapeutics on Merkel cell carcinoma (MCC) cell lines";

School for Oncology and Developmental Biology (GROW) Science Day 2014;

Maastricht University Medical Centre+, Maastricht, the Netherlands, 2014 Nov 12.

E. Chteinberg, C. Sauer, D. Rennspiess, V. Winnepenninckx, A. K. Kurz, E.-J. Speel, M. Zenke, A. zur Hausen;

"No REST in Merkel cell carcinoma";

$8^{\text {th }}$ international congress on HPV \& polyomavirus in skin cancer;

Maastricht, the Netherlands, 2016 Nov 16 - 18.

E. Chteinberg, C. Sauer, L. Schiffelers, J. Eben, J. D. Rennspiess, V.

Winnepenninckx, E.-J. Speel, A. K. Kurz, M. Zenke, A. zur Hausen;

"Merkel cell carcinomas are RESTless";

$13^{\text {th }}$ Congress of the European Association of Dermato-Oncology (EADO) 2017;

Athens, Greece, 2017 May 3 - 6;

Journal of the European Academy of Dermatology and Venereology. 2017 Jun; 31; S3, FC1.3. 
E. Chteinberg, D. Rennspiess, S. Tauchmann, V. Winnepenninckx, A. K. Kurz, E.-J. Speel, M. Zenke, A. zur Hausen;

"PI3K p110ठ in Merkelzellkarzinom-Zelllinien";

101. Jahrestagung der Deutschen Gesellschaft für Pathologie;

Erlangen, Germany, 2017 Jun 22 - 24.

E. Chteinberg, C. Sauer, L. Schiffelers, J. Eben, D. Rennspiess, V. Winnepenninckx, A. K. Kurz, E.-J. Speel, M. Zenke, A. zur Hausen;

"Die Expression des neuroendokrinen Regulators REST im Merkelzellkarzinom";

101. Jahrestagung der Deutschen Gesellschaft für Pathologie;

Erlangen, Germany, 2017 Jun 22 - 24.

E. Chteinberg, D. Rennspiess, A. M. Haugg, V. Winnepenninckx, E.-J. Speel, A. K. Kurz, M. Zenke, A. zur Hausen;

"Early B Cell Gene Expression Pattern in Merkel Cell Carcinoma";

$11^{\text {th }}$ Joint Meeting of the British Division of the International Academy of Pathology

and the Pathological Society of Great Britain \& Ireland;

Maastricht, Netherlands, 2018 Jun 19 - 22;

The journal of pathology, 2018 Sep; 246 (S1): S19-S19.

E. Chteinberg, W. Gerritsen, E. Speel, V. Winnepenninckx, A. K. Kurz, M. Zenke, A. zur Hausen;

Effective treatment of Merkel cell carcinoma cell lines by the combined inhibition of $\mathrm{BCL}-2$ and PI3Ka;

$31^{\text {st }}$ European Congress of Pathology

Nice, France, September $7-112019$

OTHER CONFERENCES ATTENDED

DNA Tumour Virus 2017 (DNATV) University of Birmingham, UK, 2017 Jul 17 - 22 


\section{ADDENDUM | CURCICULUM VITAE}

\section{PUBLICATIONS}

C. M. Sauer*, A. M. Haugg*, E. Chteinberg, D. Rennspiess, V. Winnepenninckx, E.-J. Speel, J. C. Becker, A. K. Kurz, A. zur Hausen;

"Reviewing the current evidence supporting early B-cells as the cellular origin of Merkel cell carcinoma";

Crit Rev Oncol Hematol. 2017 Aug; 116:99-105;

( ${ }^{*}$ contributed equally).

C. M. Sauer, E. Chteinberg, D. Rennspiess, A. K. Kurz, A. zur Hausen;

"Merkelzellkarzinom: kutane Manifestation einer hochmalignen Prä-/pro-B-ZellNeoplasie?";

Hautarzt. 2017 Mar; 68(3):204-210.

E. Chteinberg, D. Rennspiess, R. Sambo, S. Tauchmann, N. W.J. Kelleners-Smeets, V. Winnepenninckx, E.-J. Speel, A. K. Kurz, M. Zenke, A. zur Hausen;

"Phosphatidylinositol 3-kinase p110ठ expression in Merkel cell carcinoma";

Oncotarget. 2018 Jul; 3, 9(51):29565-29573.

E. Chteinberg, C. Sauer, D. Rennspiess, L. Beumers, L. Schiffelers, J. Eben, A. Haugg, V. Winnepenninckx, A. K. Kurz, E.-J. Speel, M. Zenke, A. zur Hausen;

"Neuroendocrine key regulator gene expression in Merkel cell carcinoma";

Neoplasia, 2018 Dec; 20(12):1227-1235.

E. Chteinberg, F. Klufah, M. Mannheims, D. Rennspiess, M. A. Abdul-Hamid, M. Losen, M. Keijzers, M. H. De Baets, A. K. Kurz, A. zur Hausen;

"Prevalence of Merkel cell Polyomavirus in human epithelial thymoma tumors";

Thorac Cancer. 2019 Mar;10(3):445-451.

E. Chteinberg, J. Vogt, J.van den Oord, V. Winnepenninckx, M. Zenke, A. Kurz, R. Siebert, A. zur Hausen;

"The curious case of Merkel cell carcinoma: Epigenetic youth and lack of pluripotency"; Epigenetics. 2020 May 30;1-6

F. Klufah, G. Mobaraki, E. Chteinberg, R. A Alharbi, V. Winnepenninckx, E-JSpeel, D. Rennspiess, S.W O. Damink, U. P Neumann, A. K. Kurz, I. Samarska, A. zur Hausen; High Prevalence of Human Polyomavirus 7 in Cholangiocarcinomas and Adjacent Peritumoral Hepatocytes: Preliminary Findings

Microorganisms. $2020 \mathrm{Jul}$ 27;8(8):1125

E. Chteinberg, S. Wetzels, W. Gerritsen, L. Temmerman, V. Winnepenninckx, E. Biessen, A. Kurz, E. Speel, M. Zenke, A. zur Hausen;

"Navitoclax combined with Alpelisib effectively inhibits Merkel cell carcinoma cell growth in vitro"

Accepted for publication in Therapeutic Advances in Medical Oncplogy

E. Chteinberg, J. Kolarova, J. Vogt, H. Jin, K. Severens, D. Rennspiess, F. Bormann, E.-J. Speel, J. van den Oord, C. Schneider, S. Stilgenbauer, J. Becker, V.

Winnepenninckx, E. Biessen, M. Zenke, A. K. Kurz, R. Siebert, A.zur Hausen;

Decoding of PAX5 expression and its transcriptional network program in Merkel cell carcinoma"

Submitted 


ACKNOWLEDGMENT

DANKWOORD

DANKSAGUNG 



\section{ACKNOWLEDGEMENTS / DANKWOORD / DANKSAGUNG}

It was a pleasure to work both in Maastricht and in Aachen, to get in touch with colleagues and friends without whom none of the work in this dissertation would have been possible. Thank you very much for your support and help. In following I would like to thank everyone personal.

Professor Dr. Axel zur Hausen, M.D., Ph.D., lieber Axel, ich danke Dir, dass ich schon mehr als 6 Jahre auf der Abteilung Pathologie des Maastrichters Krankenhaus arbeiten durfte. In dieser Zeit sind wir noch nicht reich, aber berüchtigt geworden. Es hat mir sehr viel Spaß bereitet an dem zur Hausen BZell Karzinom zu arbeiten. Auch wenn es zum Duzen länger gedauert hat, als bei anderen, bin ich Dir sehr dankbar für die Freiheiten, die ich hatte, um meine Kenntnisse und mich persönlich weiter zu entwickeln. Auch danke ich Dir, dass ich auf diversen internationalen Kongressen sein durfte, wodurch ich die wissenschaftliche und kulturelle Welt zum ersten Mal aus einem anderen Blickwinkel kennen gelernt habe. Aber vor allem danke ich Dir für die konstruktive Kritik, die Geduld und die genommene Zeit, wodurch ich sehr viel von Dir lernen durfte. Ich danke Dir auch für das sorgfältige Korrekturlesen, auch wenn Dich die Microsoft Absatzzeichen immer irritiert haben. Wir haben einiges in dieser kurzen Zeit miteinander erreicht. Ich freue mich auf unsere zukünftigen gemeinsamen Projekte.

Professor Dr. rer. nat. Martin Zenke, lieber Herr Zenke, ohne Ihr damaliges Einverständnis die Betreuung dieser Dissertation hätte ich nie diese Dissertation anfangen können. Ich danke Ihnen sehr dafür, dass Sie die Betreuung auf sich genommen haben und für die Unterstützung bei den Anträgen der Graduierendenförderung der RWTH Aachen. Ich danke Ihnen sehr für alle Ihre Anregungen, Verbesserungsvorschläge und Unterstützung, ganz besonders in den letzten Monaten der Anfertigung der Dissertation.

Professor Dr. Ernst-Jan Speel, Ph.D., beste Ernst-Jan, de discussies over de projecten vond ik altijd nuttig, daardoor kon ik heel veel van jouw expertise leren. Ik vond de vrijdag middag borrel op jouw kantoor altijd leuk en gezellig. Maar vooral de Zoom/Skype meetings aan het begin van de corona lockdown zal ik mij 


\section{ADDENDUM | ACKNOWLEDGEMENT}

altijd herinneren. Jij hebt mij laten zien hoe sommige formuleringen beter zijn en dat het goed is om over sommige zinnen langer dan een minuut na te denken.

Beste Dr. Véronique Winnepenninckx, beste co-promotor, ook jou wil ik hartelijk bedanken voor je ondersteuning, interesse en dat jij altijd daar was voor problemen. Ik heb heel veel van jouw expertise geleerd.

Professor Joost van den Oord, beste Joost, wij hebben ons de eerste keer op de EADO 2017 in Athene ontmoet. Ik had over de neuro-endocrine eigenschappen en de cellulaire oorsprong van het Merkel-cel carcinoom presenteert en u hebt mij daarna een moeilijke vraag gesteld over de Merkel cellen en waarom die niet de oorsprong kunnen zijn. Maar toch heeft $u$ ons de fresh-frozen weefsels van uw cohort gegeven. Die zijn een heel belangrijk deel van dit thesis geworden. Hartelijk dank daarvoor!

Professor Dr. med. Reiner Siebert, lieber Reiner, zwei Kapitel dieser Dissertation verdanke ich Dir und Deinem Team. Ohne Deine Unterstützung und Deinen Vorschlägen würde dieser Arbeit was fehlen. Darüber hinaus, danke ich Dir, dass ich zwei Wochen in Deinem Labor verbringen durfte. Durch die Diskussionen konnte ich mein Wissen über Methylomics und deren Verwendung vertiefen. Ich freue mich sehr, dass es funktioniert hat und dass ich in deinem Labor an Methylomics von Lymphomen arbeiten darf. Hierbei dank ich Julia V. für die die super Zusammenarbeit und für das Grundsteinlegen für die DNAmAge Publikation. Julia K. auch dir danke ich für die super Zusammenarbeit, für das Korrekturlesen der DNAmAge Publikation und vor allem für die Analysen des PAX5 Manuskripts. Wir mussten sehr oft die Analysen wiederholen, aber es hat sich doch gelohnt. Ich danke auch der gesamten Ulmer Humangenetik für die großartige Aufnahme, während ich bei euch zu Besuch war. Ganz besonders danke ich: Naveed, Ingo und Laura W.

Professor Dr. Jürgen Becker, lieber Jürgen vielen Dank für die Kooperation, für das kritische Durchlesen des PAX5 Papers und die lebendigen Diskussionen über den zellulären Ursprung des Merkel Zellkarzinoms. Dabei würde ich dir, Jan, auch 
gerne für die lebendigen Diskussionen danken. Ich bin sehr gespannt was Ihr aus unseren MCCs Methylomics Daten noch rausholt.

Professor Dr. Erik Biesen, beste Erik, hartelijk dank voor de discussies en ondersteuning van de PAX5 en BCL-2 manuscripten. En nog dankjewel voor de algemene interesse in mijn onderzoek. Ik zou ook graag de volgenden mensen bedanken van de EVP-groep: Beste Judith, dankjewel voor de meetings met jou waardoor ik geleerd heb dat ik kritischer moest kijken naar mijn onderzoek. Ik wens je veel succes met je groep. Beste Lieve en Suzan, dankjewel voor de discussies en de ondersteuning bij de FACS en Annexin-V assays. Ik wens jullie nog veel succes en Suzan veel succes met je kleine familie ;-). Beste Marjo en Pieter hartelijk dank voor jullie interesse in mijn onderzoek, het was leuk om met jullie samen te werken. Han and Chang, I learned a lot about bioinformatics from you. Thank you, a lot, for your support, especially thank you Han for analysing the effect of the MCPyV T-antigens on the B-ALL cell line. Jan und Adele, war schön mit euch zusammen zu arbeiten, ich wünsche euch viel Erfolg mit eurem PhD. Renée, meestal waren wij als laatste op de afdeling. Ik hoop dat je niet meer tot zo laat hoeft te werken en wens je veel succes met je PhD. Anke we zijn bijna tegelijk aan onze $\mathrm{PhD}$ begonnen en het was leuk met je. Ik wens jou veel succes met het afronden van de thesis. Danielle, Kim v. K. and Margaux, I wish you success with your future. Elke und Thomas, euch beide habe ich während meines Forschungspraktikums kennengelernt und habe von euch eine Menge gelernt. Besonders hat es mir Spaß bereitet mit dir Elke an den Geldanträgen zu schreiben.

Professor Manon van Engeland, beste Manon hartelijk dank voor je interesse in mijn onderzoek en voor het idee van de methylomic analyses. Ook wil ik graag Veerle en Kim danken voor de discussies en de leuke momenten in de meetings. Nathalie ik hoop dat ik je kon overtuigen dat niet alle Duitsers raar zijn, was gezellig met je, vooral de momenten dat we elkaar altijd op de gang tegenkwamen. Tim, Muriel en Joop dankjewel voor jullie interesse in mijn onderzoek en voor de discussies. Glenn wij zijn ongeveer tegelijk met onze stage begonnen en ik had wel een beetje meer tijd nodig om alles af te ronden. Bedankt voor de interesse en de discussies. Veel succes met je nieuwe baan. Maartje, 
Kim L. en Simone dankjewel voor de interesse, discussies en leuke momenten op de afdeling. Ik wens jullie veel succes met jullie PhD's. Selena jij bent echt een inspiratie, met een gezin ben je met veel succes afgestudeerd en ik weet zeker dat je met veel succes zal promoveren. Dankjewel voor de leuke momenten en de discussies. Zheng it was a pleasure talking to you and it was a long way for you to complete your PhD thesis like it was for me. You were always interested how my research was going and we also had funny moments like the one when you were scared that I was losing my proteins on the ELISA plate. I wish you the best! Musa, I wish you success with your PhD thesis and in your future life in the Netherlands.

Now I would like to thank the people without the research work would not have been possible: the technicians. Jaleesa en Nikkie in de afgelopen jaren zijn jullie een grote hulp voor alle mogelijke vragen geweest. Kim W. dankjewel voor je ondersteuning en leren wat de beste manier is om MSP-primer te designen. Gregorio bedankt voor de gezellige koffie momenten en in het speciaal de keer dat we Duitse liedjes zaten te luisteren toen Heike binnenkwam was erg grappig. Edith dankjewel voor de sterilisatie van de Pasteurpipetten en de PBS flessen. Peter jouw boekje van Duitse en Nederlandse spreekwoorden zal ik nooit vergeten, ook was het gezellig om met jou in het lab te werken. Jet en Jaques dankjewel voor de korte gezellige tijd.

Jack C. dankjewel voor de ondersteuning met de Ventana scanner. Maarten dankjewel voor de leuke gesprekken over Duitsland en voetbal, het was altijd gezellig. Guido en Benoit dankjewel voor de ondersteuning bij de werkzaamheden in jullie laboratoria. Peter dankjewel voor het opzoeken van patiëntengegevens. Cecile, Stefan, Carla en Erik dankjewel voor de immunohisto-kleuringen. Andrea dankjewel voor de ondersteuning met de FISH. Sabine bedankt voor de leuke gespreken op de gang, die ik zal missen. Ik wens je veel succes met je wijn en met je gitaarlessen. Ook aan de medewerkers van het patiëntenzorgsecretariaat Peggy B., Peggy G, Yolande, Mirella en Denise dankjewel voor de aanname van alle pakketjes en voor de hulp om pakketjes weg te sturen. Amir, it was a pleasure to talk to you about different things. Unfortunately, we could not talk in Hebrew with each other. You know, I have still 
the scar from your research. I hope that it was worth it :-D. I am sure that everything will turn out well. I wish you all the best and thanks for the funny moments. Iryna большое спасибо за обсуждение и поддержку! Lisa H. Und Jan B. vielen Dank für die Unterstützung und Diskussionen. Es war lustig mit euch beiden.

Verder zou ik graag de medewerkers van het staf secretariaat- het service punt voor de hele afdeling- dank zeggen voor de ondersteuning. Lysette, als hoofd van de secretariaten ben je heel druk, maar ondanks de drukte had je meestal toch tijd voor mijn vragen en problemen. Maar daarvoor moest ik jouw olifant laten verdwijnen. Als voorbeeld hebt je mij geholpen met de aanmelding van de PhD thesis en het Joint-PhD contract afteronden. Het was leuk met je en dankjewel voor jouw hulp. Audrey, Ingrid en Tonneke dankjewel voor jullie ondersteuning. Danielle helaas ben je het laatste jaar van mijn promotie niet meer op de afdeling geweest. Jij en Lysette hebt mij met het Joint-PhD contract geholpen. Jij was altijd hulpvaardig voor alle problemen qua promotie, afspraken etc. Monique in de stafsecretariaat lach je alle medewerkers toe die binnenkomen. Helaas kunnen we niet langer samen werken. Dankjewel voor jouw ondersteuning en hulp. De grappigste momenten hadden we met het bestellen van onderzoeksmateriaal. Ik weet zeker dat het allemaal goed komt.

Now the time has come to thank the people who I worked the most time together or with whom I spent the most time in the same office. Zuerst, danke ich dir Anke H., für die Annahme zum Forschungspraktikum und für die gute Betreuung, sowie die Ratschläge. Ich wünsche dir viel Erfolg bei deinem neuen Arbeitsgeber. Sreedhar, you were an inspiration. I learned a lot from you. I wish you all the best. Robin, we zijn tegelijk met onze banen begonnen en hadden met Dorit een leuke kamer. Het was wel jammer dat jij naar de diagnostiek bent gegaan. Dorit, du warst die erste Ansprechpartnerin, wenn was schief ging oder wenn Immunos gemacht werden mussten. Ich verdanke dir das Thymom paper und dass du mir gezeigt hast, dass Publikationen sehr wichtig sind. Vielen Dank für alles! Wouter, jij was er op een tijdpunt waar ik heel veel ideeën had en jij probeerde mij daarmee te hulpen. Gelukkig is het met het BCL-2 manuscript en de kleuringen voor het PAX5 manuscript gelukt. Ook toen je niet meer op de afdeling werkte bleven we 


\section{ADDENDUM | ACKNOWLEDGEMENT}

elkaar zien, onze koffie momenten waren altijd gezellig. Ik wens je succes met de dier cursus en met je verdere onderzoek. Ondanks dat jij, Kim S, in het laatste jaar van mijn PhD bent gekomen, heb je mij nog met veel kleuringen kunnen ondersteunen. Het was leuk met je samen te werken en over alles te praten. Links van mij hoor ik jou nog steeds praten :-D. Ik wens je nog veel succes en ik ben er zeker van dat je een winst voor onze groep bent. Faisal, it was a pleasure to work with you. I know it was not always easy and we had some struggles, but I am happy that we got through it. I wish you all the best and I hope that we will work together on some virus projects. Chris, ich danke dir für die gute Zusammenarbeit am Review und dem REST Manuskript. Beim letzteren hast du mich trotz meines Urlaubs daran erinnert, dass ich in Maastricht gebraucht wurde. Obwohl ich dich damals von der Distanz betreut hatte, ist zum Glück was Gutes dabei rausgekommen. Ghalib it was a pleasure working with you. I will miss the funny moments, especially when you were singing in the office. Thank you for the Cokes and for the support. Dan and Shuai, it was a pleasure to work with you. Thank you very much for the Chinese meals, for the evenings which we spent together at the department and for the funny moments. I wish you all good luck with your dissertations. Sebnem, you were for a short period of time at our department and you taught me that you are never too old to fulfil your dreams. I wish you the best and a lot of success to fulfil your dreams. Mara, ik weet niet in welke taal ik kan me bij jou bedanken, weil du manchmal mixing the languages im gleichen Satz. I think I will stick to English. Most of the time when I saw your bag and jacket in our office I knew, Mara was here and is in the lab. I wish you a lot success with AKO. Laura M. hartelijk dank voor de leuke verhalen, jij kunt echt goede vertellen. Het was leuk met je op dezelfde kamer, helaas wilde je naar de leukere mensen toe. Imke het was heel gezellig met je, ik zal de discussies met jou over de treatments en Westerns missen. Ik wens jullie twee veel succes met jullie PhD's. Frans, twee jaar op dezelfde kamer was gezellig, vooral de avonden bij de Gouverneur zal ik mij altijd herinneren. Ik wens je veel succes met je boekje. Felix, du warst wirklich oft der Retter in der Not. Ich danke dir für alle Auswertungen der RNASequenzierungsdaten und der Hilfe bei den 3D plots. Ich wünsche dir weiterhin viel Erfolg mit deiner kleinen Firma. 
Next, I would like to thank all the students who I supervised and thus, participated in this dissertation. Sam, Lisa S. and Danielle you guys were the first students whom I supervised during my PhD. I was always strict with you guys, but I was happy to see how you evolved during your internships. I thank you for your great work and that you assisted me in generating the data for this thesis. Lukas, wie du siehst war ich zu jedem sehr streng. Ich danke dir für die sehr motivierte und engagierte Zusammenarbeit. Ein Moment gehört zu meinen Highlights, nämlich der Moment, als du Nathalie auf Deutsch zum Geburtstag gratuliert hast. Ryan, I hope that your Spanish daily soaps are ready and that you can now concentrate in the lab. It was fun to work with you and that you assisted in generating the Westerns for the PI3K publication. Mick, het was gezellig met je en ook heb je een belangrijke bijdrage aan de Thymoma publicatie geleverd. Dankjewel daarvoor! Cliff, jou kon ik echt rustig alleen laten werken, zonder mij af te vragen waar je bent en of je problemen hebt. Dankjewel, voor het sequentie werk, wat het begin van het hele PAX5 manuscript was. Anouk, dankjewel voor de hulp. Ik hoop dat de nieuwe studie beter voor je is. Amanda and Martina, you were the last students of whom I had the pleasure to be the daily supervisor. You both did a great job during the Corona time and brought me the idea to use a part of your results in the discussion section. Thank you all, a lot, for your help. I am sure that we will use your results for future research. I wish you all the best!

Nu zou ik graag mijn paranimfen dankzeggen: Kelly en Josien. Het was erg leuk met jullie, onze awkward momenten zijn echt hilarisch geweest. Onze koffie pauzes, die altijd door Axel onderbroken werden, waren een leuke afleiding van het lab. Als nu terugdenk aan toen we elkaar voor de eerste keer zagen hebben op het lab, dacht ik dat jullie assistenten van Gregorio waren :D. Eerst bij de PathSoc had ik met Josien meer gesproken en ik schaamde me wel een beetje toen zij gezegd had dat jullie PhD studenten zijn. Toen wist ik niet dat wij drie een goede vriendschap zouden opbouwen. Van harte dank ik jullie voor de ondersteuning en voor de gesprekken. Ik wens jullie veel succes met jullie PhD en we zien en spreken elkaar zeker nog ;-). En een grote dank voor het doorlezen en korregeren van deze dankwoord en van de Nederlandse samenvating. 


\section{ADDENDUM | ACKNOWLEDGEMENT}

Wie nu goed opgelet had, denkt dat ik een analist ben vergeten. Maar dat is niet zo. Mat in hoeveel talen wilde je met mij praten :D. In het begin was het Engels met Duits. Ondanks dat jouw Duits erg goed is, wilde ik ook Nederlands met je praten. Maar dit lukte niet altijd, nog steeds begin je Engels of Duits tegen me te praten :D. Jij ben wel de analist die een echte allrounder is, jij kan goed met databases omgaan en met heel veel moleculaire technieken ben je ook bekend. Daarom was het altijd leuk om daarover te discussiëren met jou, als ik je uiteindelijk in een van de labs kon vinden. Als ik je niet kon vinden, wist ik dat ik moest vergeten dat ik op zoek was naar jou, en dan zat je plotseling uit het niks op je zitplaats. Dankjewel voor de discussies en je ondersteuning!

Ich danke dem Gesundheitszentrum/ Fitnesszentrum K3 für die sportliche Betreuung und Stärkung meines Körpers und Geistes. Diese hat es mir ermöglicht immer Höchstleistung auf der Arbeit zu bringen. Vor allem danke ich folgenden Trainern: Janine, Jakob, Alex, Kevin und Arne.

Lieber Martin Z., auch Dir will ich extra danken. Vor mehr als 11 Jahren, stand ein gerade fertiger Abiturient vor deinem Büro und hatte Dich, über Herrn Prof. Kreuzaler, darum gebeten, ihm ein Vorpraktikum, welches er für das Studium an der FH Aachen brauchte, zu ermöglichen. Ich bin dir bis heute sehr dankbar, dass ich bei Dir mein Praktikum absolvieren durfte, auch wenn mein Giftangriff mit der Winogradsky-Säule nicht hätte sein müssen. Ich bin Dir nicht nur sehr dankbar für den guten Start in meine wissenschaftliche Laufbahn, sondern auch für die Freundschaft, die sich daraus entwickelt hat. Eins war und ist mir klar, ohne Dich wäre ich nicht so weit und ich wäre definitiv nicht in Maastricht. Somit ist diese Arbeit auch Dein Verdienst! Vielen Dank!

Liebe Freunde, es ist endlich soweit, ich bin frei und kann mehr Zeit mit euch verbringen :-). Ihr alle habt mich auf eure Weise unterstützt und deswegen möchte ich euch auch im Einzelnen danken. Da ich schon Martin gedankt habe, fange ich mit der restlichen Doppelkopfrunde an. Mathias W. du musstest unbedingt immer demjenigen vorhalten, wenn er was falsch aufgespielt hat! War zwar manchmal nervig, aber so habe ich doch was gelernt. Kevin R. deine Kochkünste sind unvergessen und deine Drang zu gewinnen noch mehr. Wir haben uns über die 
Fachschaft kennengelernt und sind noch weiter in Kontakt geblieben, was ich bis heute nicht bereue, bin auch froh, dass du mir meine schlechten Erdkundekenntnisse bezüglich des Pots verziehen hast :-D. Rene H., eigentlich kann ich bis heute nicht verstehen, wieso du immer bei den Hemden und Polos den Kragen hochziehen musst. Obwohl das die erste Sache war, die du anstelle eines Hallos bei mir gemacht hast und mir sehr viele Shots mal ausgegeben hast, schätze ich unsere Freundschaft sehr. Ich danke dir und auch Anna für die schönen und witzigen Momente bzw. Ablenkungen von dem stressigen Laboralltag.

Den wenigen Jülicher Kommilitonen, zu denen ich noch Kontakt habe, möchte ich mich auch bedanken, für die schöne Zeit während des Studiums und für die drauffolgende Freundschaft und Unterstützung während allen Lebenslagen. Speziell will ich euch, Patrick B. und Julia S., ganz herzlich danken. Gerade erinnere ich mich wie wir uns das erste Mal alle unterhalten getroffen hatten. Wenn ich mich recht erinnere hat Julia Sachen behauptet, die alle nicht stimmten, :-D. Ne Witz beiseite, ich bin echt froh euch als Freunde zu haben.

Patrick S. wir hatten Höhen und Tiefen, bin aber froh, dass wir weiterhin gute Freunde sind. Anscheinend haben wir auch den gleichen Hunger-Rhythmus, wenn wir mit zwei unterschiedlichen Autos fahren und an der gleichen Raststätte uns treffen. Vielen Dank für deine Unterstützung und Freundschaft. Falk und Catrin, endlich habe ich es auch geschafft. Ich bin euch auch sehr dankbar für eure Freundschaft und Unterstützung während des Studiums und während der Promotion. Die besten Momente hatten wir beim Einkaufen mit dem einen Einkaufswagen und beim Platzieren von Stickern :D. Ich freue mich schon auf die nächsten spannenden Momente.

Géza und Anke, euch kenne ich gefühlt mein halbes Leben, Moment, das ist mein halbes Leben. Soooo lange habe ich euch ertragen müssen? :-D. Spaß bei Seite, ich bin sehr froh, dass ihr noch immer an meiner Seite seid und wir einander haben. Obwohl ich Aachen verlasse, bin ich mir sicher, dass unsere Freundschaft niemals reißen wird. Ich bin euch sehr dankbar für Ablenkungen, für die motivierenden Worte und fürs Zuhören und fürs Verständnis. 


\section{ADDENDUM | ACKNOWLEDGEMENT}

Liebe Familie, liebe Mama, vielen Dank für alles, du hast mich aufgebaut, als ich nicht mehr weiterwusste, du hast versucht meine Arbeit zu verstehen und hast mir die Kraft gegeben immer weiter zu machen. Vielen Dank für tatkräftige Unterstützung, und dass du an mich geglaubt hast. Ohne das alles wäre ich nicht da, wo ich heute bin. Liebe Großeltern, liebe Oma, ohne dich wäre ich heute nicht hier: du hast damals darauf bestanden, dass ich aufs Gymnasium gehe, und nicht auf die Realschule. Du hast mich sogar dazu gezwungen zum Herrn Prof. Kreuzaler zu gehen, um inn zu fragen, ob er mir bei der Suche, um einen Vorpraktikumsplatz helfen könnte. Nur so habe ich Martin Z. kennen gelernt und wie ich schon Martin Z. gesagt habe, dass ich ohne inn nicht in Maastricht wäre, wäre ich es auch nicht ohne dich.

Vielen Dank dafür und für vieles mehr! Большое спасибо! Люблю вас!

Again, thank you all! If I missed someone, it was not on purpose. In the department of Pathology al lot of nice people are working. If I mentioned all, it would take me months to write the acknowledgments. Thus, a big thanks goes to all former and current members of the department of Pathology from the MUMC+.

Emil 


\section{EIDESSTATTLICHE ERKLÄRUNG}

\section{Emil Chteinberg}

erklärt hiermit, dass diese Dissertation und die darin dargelegten Inhalte die eigenen sind und selbstständig, als Ergebnis der eigenen originären Forschung, generiert wurden.

Hiermit erkläre ich an Eides statt

1. Diese Arbeit wurde vollständig oder größtenteils in der Phase als Doktorand dieser Fakultät und Universität angefertigt;

2. Sofern irgendein Bestandteil dieser Dissertation zuvor für einen akademischen Abschluss oder eine andere Qualifikation an dieser oder einer anderen Institution verwendet wurde, wurde dies klar angezeigt;

3. Wenn immer andere eigene- oder Veröffentlichungen Dritter herangezogen wurden, wurden diese klar benannt;

4. Wenn aus anderen eigenen- oder Veröffentlichungen Dritter zitiert wurde, wurde stets die Quelle hierfür angegeben. Diese Dissertation ist vollständig meine eigene Arbeit, mit der Ausnahme solcher Zitate;

5. Alle wesentlichen Quellen von Unterstützung wurden benannt;

6. Wenn immer ein Teil dieser Dissertation auf der Zusammenarbeit mit anderen basiert, wurde von mir klar gekennzeichnet, was von anderen und was von mir selbst erarbeitet wurde;

7. Teile dieser Arbeit wurden zuvor veröffentlicht, und zwar in:

a. Critical Reviews in Oncology/Hematology, 2017 August; 116:99-105

b. Oncotarget, 2018 Juli; 9(51):29565-29573

c. Neoplasia, 2018 Dezember; 20(12):1227-1235

d. Epigenetics, 2020 Mai 30:1-6

20.07.2020 
